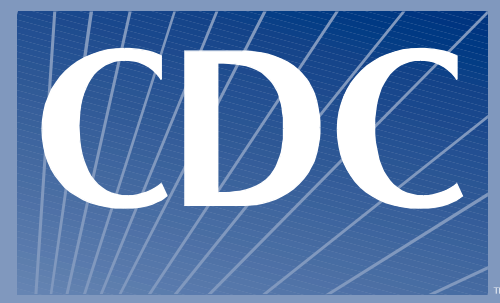

CENTERS FOR DISEASE CONTROL AND PREVENTION

\title{
NIOSH HAZARD REVIEW
}

\section{CARBONLESS COPY PAPER}
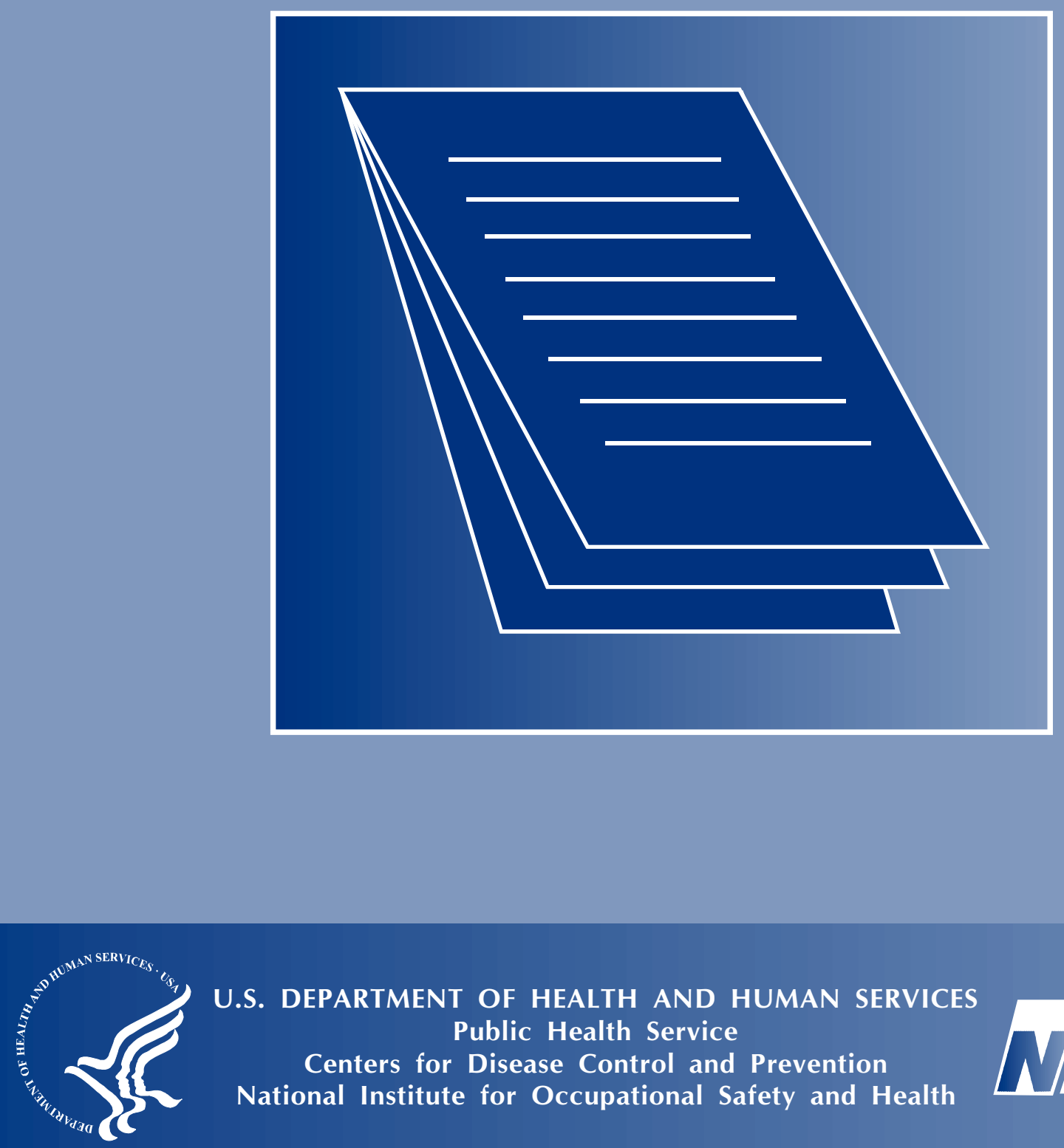

U.S. DEPARTMENT OF HEALTH AND HUMAN SERVICES

Public Health Service

Centers for Disease Control and Prevention

National Institute for Occupational Safety and Health 


\section{NIOSH HAZARD REVIEW}

\section{Carbonless Copy Paper}

U.S. Department of Health and Human Services

Public Health Service - Centers for Disease Control and Prevention

National Institute for Occupational Safety and Health

December 2000 


\title{
Ordering Information
}

To receive documents or other information about occupational safety and health topics, contact the National Institute for Occupational Safety and Health (NIOSH) at

\author{
NIOSH—Publications Dissemination \\ 4676 Columbia Parkway \\ Cincinnati, OH 45226-1998
}

Telephone: 1-800-35-NIOSH (1-800-356-4674)

Fax: $1-513-533-8573$

E-mail: pubstaft@cdc.gov

or visit the NIOSH Web site at www.cdc.gov/niosh

This document is in the public domain and may be freely copied or reprinted.

Disclaimer: Mention of any company or product does not constitute endorsement by NIOSH.

DHHS (NIOSH) Publication No. 2001-107 


\section{Foreword}

Tn response to its mandate to provide a safe and healthful workplace for working women and men, the National Institute for Occupational Safety and Health (NIOSH) critically evaluates the scientific data on potentially hazardous occupational exposures or work conditions and recommends measures for minimizing the risk from the hazard. Millions of workers routinely handle carbonless copy paper (CCP) forms each day. Reports of possible health effects from at least 12 countries have been published in the scientific literature. This document presents a review of the health effects of CCP. When investigating the relationship between occupational exposures and adverse health effects, NIOSH generally prefers to use the published literature; but some unpublished sources were used in this review because the published literature was limited. Also considered as part of this review were more than 14,000 pages of material submitted to NIOSH in response to Federal Register notices requesting information about CCP. Such a comprehensive review should help address issues of CCP exposure in the U.S. workforce.

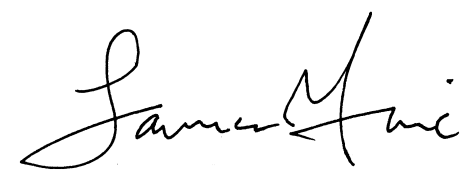

Lawrence J. Fine, M.D., Dr.P.H. Acting Director, National Institute for Occupational Safety and Health Centers for Disease Control and Prevention 


\section{Executive Summary}

$\mathrm{I}$ n 1987, the Occupational Safety and Health Administration (OSHA) requested that the National Institute for Occupational Safety and Health (NIOSH) investigate the validity of reported adverse health effects in workers occupationally exposed to chemicals contained in or released from carbonless copy paper (CCP). Because of limited published information, NIOSH issued a Federal Register notice soliciting information about possible adverse health effects from CCP exposure [52 Fed. Reg. 22534 (1987)]. On the basis of information available at that time, no strong conclusion could be reached concerning a consistent link between CCP and major health effects. Between 1987 and 1997, additional reports involving health problems potentially related to CCP were identified. Therefore, in 1997 NIOSH issued a second Federal Register notice soliciting new information [62 Fed. Reg. 8023 (1997)]. This report contains a review of the published literature on CCP and the submissions to the NIOSH docket from the two Federal Register notices.

CCP was introduced in 1954 by the National Cash Register Company as no-carbon-required (NCR) paper - an alternative to separate sheets of carbon paper [Sandberg 1955; Green 1955; Miller and Phillips 1972; Calnan 1979; Buring and Hennekens 1991]. A given CCP can vary greatly as to its constituents, weight and types of paper coatings, paper color, dye colors and combinations of dyes used on coatings, solvents and solvent mixtures (including

${ }^{*}$ Federal Register. See Fed. Reg. in references. variations from different suppliers), physical form of the paper (rolls versus sheets), and final form of the product (i.e., bound with adhesives). Thus the product known as $\mathrm{CCP}$ is not a single product but includes thousands of different and often unique products [Mead Corporation 1997]. This fact needs to be considered when interpreting the findings from the scientific literature.

About 10 years after the introduction of CCP, medical complaints began to be reported by office workers [North Carolina Medical Journal 1982; Magnusson 1974; Göthe et al. 1981; Buring and Hennekens 1991]. Since 1965, various health effects associated with exposure to CCP have been reported in the literature appearing from Denmark, Finland, England, Sweden, Germany, the Netherlands, France, Italy, Belgium, Japan, Norway, and the United States.

NIOSH has reviewed the published and unpublished literature on CCP. The following paragraphs summarize the findings from this review regarding the primary health effects associated with CCP exposure.

\section{Irritation of the Skin, Eyes, and Upper Respiratory Tract}

The most common findings from the human studies are symptoms consistent with irritation of the skin, eyes, and upper respiratory system following exposure to some types of CCP. These symptoms have also been described in numerous case reports and case series of persons exposed to $\mathrm{CCP}$, and associations between these symptoms and 
CCP exposure have been observed in several cross-sectional epidemiologic studies. A positive exposure-response relationship between these symptoms and CCP exposure has also been observed in those studies that examined this relationship.

The cross-sectional epidemiologic studies have several major methodologic limitations that make them difficult to interpret. One major potential source of bias in these studies is overreporting of symptoms by workers who are already aware of a potential association between CCP exposure and irritative symptoms. This form of bias is often referred to as "recall bias" and is well recognized to be a potentially important factor in epidemiologic studies in which symptoms or exposures are identified by questionnaires administered to the study subjects. Selection bias is also a major concern-particularly in studies with a low participation rate, where subjects with symptoms may have been more likely to return the questionnaires. These studies may also have been biased toward observing no effects by (1) analyzing a mix of workers with high and low potential for CCP exposures and (2) including only active workers and thus excluding workers who may have left the workforce as a result of adverse health effects related to $\mathrm{CCP}$ exposure.

The strongest evidence for an association between symptoms and CCP exposure comes from the studies of indoor air quality. These studies report a positive (and in several cases statistically significant) association between CCP exposure and symptoms of skin, eye, and upper respiratory tract irritation. Of the studies reviewed in this document, the indoor air quality studies are the least susceptible to recall bias because they were not conducted in workplaces where specific concerns about CCP or other indoor pollutants were heightened by previous complaints. None of these indoor air studies were designed primarily to address the CCP question, hence investigator bias is also less likely.

Other information supports the plausibility of the findings from the experimental studies in humans. The plausibility of signs and symptoms of irritation associated with CCP exposure is supported by the presence of several known irritants and allergens (e.g., formaldehyde, kerosene, phthalates, acrylates, glutaraldehyde, amines, and isocyanates) in some types of CCP and by similar effects in experimental studies of animals. For example, in seven studies of CCP and formaldehyde, nearly all exposure measurements exceeded the NIOSH REL (but not the OSHA PEL) for formaldehyde [Norbäck 1983b; Gockel et al. 1981; Hazelton Laboratories 1985; Apol and Thoburn 1986; Chovil et al. 1986; Omland et al. 1993; Zimmer and Hadwen 1993]. Finally, laboratory experiments in humans support the plausibility of the associations between irritative symptoms and exposure to CCP. Signs consistent with irritation of the skin and/or the upper respiratory tract have been noted in a few of the experimental laboratory studies in humans. However, most of these studies failed to demonstrate any effects or showed extremely mild reactions to $\mathrm{CCP}$ exposure. Inconsistencies in the findings of these studies might easily be explained by differences in study design and particularly by differences in the types of CCP tested.

\section{Allergic Contact Dermatitis}

Several authors have reported cases of allergic contact dermatitis that appear to have been associated with CCP or its components [Marks 1981; Kannerva et al. 1990a,b, 1993; Shehade 1987]. Development of sensitization to CCP or its components was also reported in a few persons in several industry-sponsored repeated insult patch test (RIPT) studies (Report 77-512-70 and Supplemental Report 79-512b-70, Report 77-896-71, and Report 
79-0085-73, all from Hill Top Research, Inc.; and Project SH-72-4, dated April 18, 1972, performed by the Shelanski Holding Company, Conshohocken, Pennsylvania, for Monsanto Co., St. Louis, Missouri). In 8 of 217 test materials, study investigators indicated that skin sensitization occurred in some human subjects. However, these studies were mostly judged to be negative for irritation by the investigators. Thus in a small proportion of the population, CCP or its components appear capable of inducing cell-mediated (type IV) immune response and allergic contact dermatitis, particularly under the intensive exposures associated with RIPT protocols. Cases of allergic contact dermatitis were reported only in RIPT studies from the 1970s that were submitted to the 1987 NIOSH docket; no cases were reported in the studies submitted to the 1997 docket. This fact indicates that the CCP component(s) responsible for the allergic contact dermatitis observed in the early studies may have been removed from current formulations of CCP.

\section{Systemic Reactions}

Three patients with systemic reactions clinically suggestive of mast cell and/or basophil degranulation after cutaneous challenge with CCP or its components have been reported in two published case reports [Marks et al. 1984; LaMarte 1988]. These reports suggest that some CCPs or their components can induce reactions clinically compatible with those caused by mast cell and/or basophil mediator release. Immunologic sensitization was not adequately evaluated in these studies, and thus it is unclear whether an immunologic mechanism underlies these reactions. However, no additional reports were located in the peer-reviewed literature over the last 12 years. Thus, even if the reported reactions were referable to CCP exposure, systemic reactions of this type appear to be exceedingly rare. Furthermore, the relevance of these reports to current CCP exposures is uncertain.

\section{Conclusions}

On the basis of a NIOSH review of the scientific literature and information submitted in response to its 1987 and 1997 Federal Register notices, NIOSH concludes the following:

- The weight of the evidence supports the conclusion that exposure to certain types of CCP or its components has, under some conditions, resulted in symptoms of irritation of the skin and of the mucosal membranes of the eyes and upper respiratory tract.

This conclusion is based primarily on interpretation of the evidence from the epidemiologic studies. Although the magnitude of the effects observed in these studies was only weak to moderate, these studies were reasonably consistent in reporting an association and evidence of an exposure-response relationship between CCP exposure and irritative symptoms of the eyes, skin, and upper respiratory tract. The plausibility of the epidemiologic evidence is supported by the presence of known irritants in some types of CCP, toxicologic studies that demonstrate mild irritation in laboratory animals exposed to CCP, and the evidence for respiratory and skin irritation in some of the experimental laboratory studies in humans. Some of the epidemiologic studies may have been biased, particularly by overreporting from study subjects who were already concerned about the potential effects of CCP exposure (i.e., recall bias). However, it is unlikely that recall bias could explain the associations observed between CCP exposure and irritative symptoms of the eyes, skin, and upper respiratory tract in the indoor air quality studies, since these studies were not conducted in an atmosphere of concern regarding the health effects of $\mathrm{CCP}$. 
- Exposure to CCP or its components may rarely cause allergic contact dermatitis.

This conclusion is based on published case reports of allergic contact sensitization and results reported in several industry-sponsored RIPT studies. Cases of allergic contact dermatitis were reported only in RIPT studies from the 1970s that were submitted to the $1987 \mathrm{NIOSH}$ docket; no cases were reported in the studies submitted to the 1997 docket. This fact may indicate that the CCP component responsible for the allergic contact dermatitis observed in the early studies was removed from the more recent formulations of CCP.

- Systemic reactions have occurred in a few persons exposed to CCP.

This conclusion is based on the finding that three such cases have been reported in the peer-reviewed medical literature. No cases have been reported in the last 7 years, and thus there is no evidence that current exposures to CCP present a risk for this health outcome.

- Data are insufficient to evaluate claims of other adverse health effects (such as neurologic effects and reports of multiple chemical sensitivity $[\mathrm{MCS}])$ that have been suggested in some of the clinical reports submitted to the NIOSH docket.

In conclusion, although the weight of the evidence indicates that exposure to $\mathrm{CCP}$ in the past has resulted in adverse health effects, it is uncertain whether current formulations of CCP represent a significant risk to exposed workers. Only a few cases of systemic reactions and allergic contact dermatitis have been reported in the United States or in Europe, which suggests that the risk of these serious outcomes is extremely low given the large number of people who have been exposed to CCP over a period of many years. Recently conducted experimental studies in humans (RIPT studies) suggest that the potential for skin irritation from exposure to current formulations of CCP is nonexistent, or at most slight. However, it is unclear how well these experimental studies simulate the exposures and potential responses of CCP users - particularly heavy users. Data from industry reporting systems suggest no widespread problem and in fact indicate a decrease in health-related complaints in recent years despite an increase in CCP production. However, these passive reporting systems are unlikely to capture all or even most cases of CCP-related health effects, and changes in publicity about CCP may have caused fluctuations in the reporting of cases. Since the 1980s, no epidemiologic studies have been conducted to determine irritative symptoms among U.S. workers exposed to CCP [Mendell et al. 1991]. A positive epidemiologic study was conducted in Finland in 1991 [Jaakkola and Jaakkola 1999]. However, the relevance of these findings for U.S. workers may be limited because of differences between the CCP products used in Europe and the United States. Thus information is lacking about the prevalence of irritation of the eyes, skin, and upper respiratory tract among workers currently handling CCP in the United States.

\section{Recommendations}

NIOSH recognizes that it may occasionally be necessary to limit CCP exposure in certain workers through administrative controls (such as job rotation). But in most cases, implementing normal precautions and recommendations for maintaining acceptable indoor air quality should be adequate to reduce or eliminate symptoms. Good industrial hygiene and work practices are likely to prevent symptoms from potent irritants (such as formaldehyde) that 
may be emitted from CCP. These include adequate ventilation, humidity, and temperature controls; proper housekeeping; minimal hand-to-mouth and hand-to-eye contact; and periodic cleansing of hands.

In addition, NIOSH recommends the following:

- CCP manufacturers and their suppliers are encouraged to follow best practices, such as the Product Stewardship Code of Management Practices [American Chemistry Council 2000]; they should also consider enhancing their product guidance to reflect that published studies indicate that irritative symptoms appear to increase with increasing exposure to CCP.
- CCP manufacturers and their suppliers should also consider how human test procedures (e.g., RIPT) can be modified by the use of standardized protocols that include proper controls (e.g., bond paper), tests that mimic high-use situations, and meaningful criteria for scoring and interpreting these tests to assess safety from skin contact (e.g., ASTM D 6355-98) [ASTM 1999]. Current best practices in the field of product testing may not be sensitive enough to identify mild skin irritants.

- As part of ongoing surveillance, CCP manufacturers and their suppliers may want to evaluate the frequency and severity of irritation in workers using CCP. 


\section{Contents}

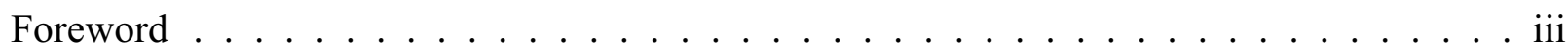

Executive Summary . . . . . . . . . . . . . . . . . . . . . iv

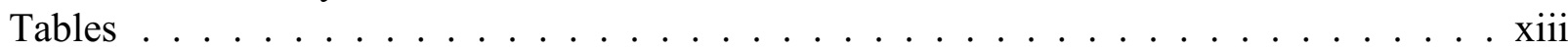

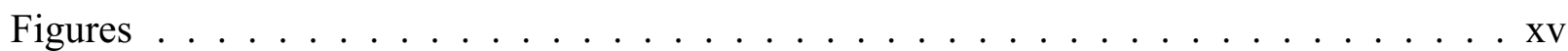

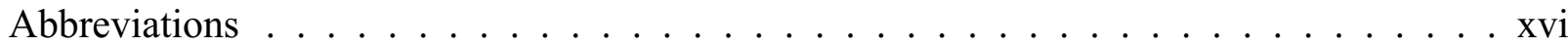

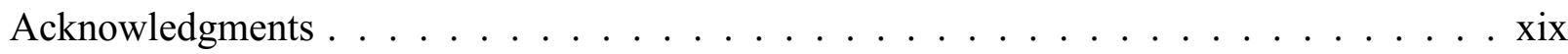

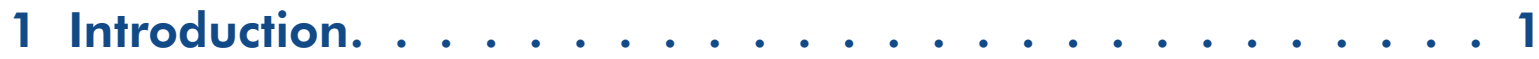

1.1 Background . . . . . . . . . . . . . . . . . . 1

1.2 Development and production of CCP . . . . . . . . . . . . . 1

1.3 Reported health effects . . . . . . . . . . . . . . . . . . . . . . 2

1.4 Information sources and types. . . . . . . . . . . . . . . . . 4

2 The Technology of CCP ............. 5

2.1 How CCP works. . . . . . . . . . . . . . . . . . . 5

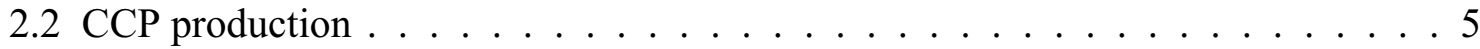

2.3 Microcapsule production . . . . . . . . . . . . . . .6 6

2.4 CCP production process. . . . . . . . . . . . . . . . . . 7

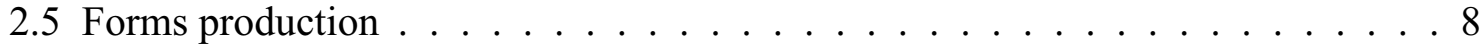

2.6 Other forms and variations of CCP technology . . . . . . . . . . . . 8

2.7 Desensitizing inks . . . . . . . . . . . . . . . . . . . . 9

2.8 Summary of chemical components of CCP . . . . . . . . . . . . .99

2.9 Brand names or trademarks for CCP . . . . . . . . . . . . . . . . 12

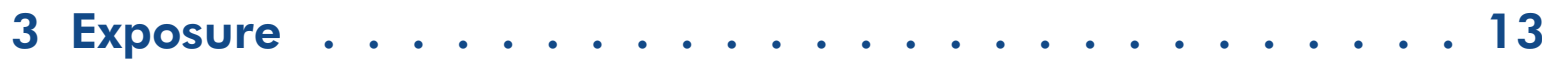

3.1 Introduction . . . . . . . . . . . . . . . . . . . 13

3.2 Exposure data . . . . . . . . . . . . . . . . . . . 13

3.2.1 Published studies . . . . . . . . . . . . . . . . . . 13

Jujo Paper Company, Ltd. 1979 . . . . . . . . . . . . . . . . . . 13

Mølhave and Grunnet 1981 . . . . . . . . . . . . . . . . . . 13

Göthe et al. 1981 and Norbäck et al. 1983b . . . . . . . . . . . . . . . 16

Gockel et al. 1981 . . . . . . . . . . . . . . . . . . . . . 16

Chrostek and Moshell 1982 . . . . . . . . . . . . . . . . . . . . 16

Norbäck et al. 1983b . . . . . . . . . . . . . . . . . . . . 16

Norbäck and Göthe 1983. . . . . . . . . . . . . . . . . . . . . 17 
Olsen and Mørck 1985 . . . . . . . . . . . . . . . . . . . . . . . . . . 19

Apol and Thoburn 1986, Chovil et al. 1986, and

Burton and Malkin 1993 . . . . . . . . . . . . . . . . . . . . . . . 19

Omland et al. 1993 . . . . . . . . . . . . . . . . . . . . . . . 19

Zimmer and Hadwen 1993. . . . . . . . . . . . . . . . . . . . . . . . 19

Thompson $1996 \ldots \ldots$. . . . . . . . . . . . . . 20

3.2.2 NIOSH docket submissions . . . . . . . . . . . . . . . . . . . 21

3.2.2.1 Winfield $1983 \ldots \ldots \ldots$. . . . . . . . . . . . 21

3.2.2.2 Hazelton Laboratories $1985 \ldots \ldots$. . . . . . . . . . . . 21

Product test methods. . . . . . . . . . . . . . 21

Product testing . . . . . . . . . . . . . 22

Office activities . . . . . . . . . . . . . . 24

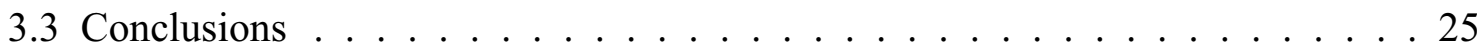

4 Health Effects . . . . . . . . . . . . 28

4.1 Introduction . . . . . . . . . . . . . . . . . . . . . . 28

4.2 Human studies . . . . . . . . . . . . . . . . . . . . . . . . . . . . . . . . . . 29

4.2.1 Published case reports and case series . . . . . . . . . . . . . . . . . 29

Magnusson $1974 \ldots \ldots \ldots \ldots$

Hannuksela 1975 . . . . . . . . . . . . . . . . . . . . . . . 30

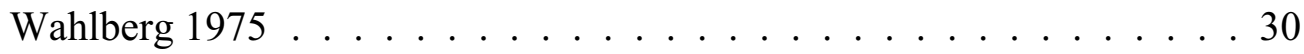

Hirvonen et al. 1976. . . . . . . . . . . . . . . . . . . . 30

Maggio et al. $1978 \ldots \ldots$. . . . . . . . . . . . . . . 36

Andanson et al. $1979 \ldots \ldots \ldots \ldots$. . . . . . . . . . . . . . . . . .

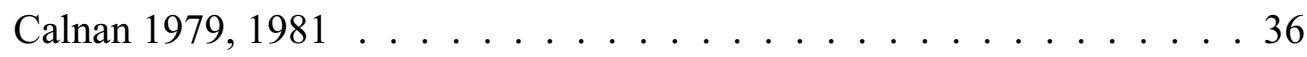

Cronin $1980 \ldots \ldots$. . . . . . . . . . . . . . . 37

Dodds and Butler $1981 \ldots \ldots$. . . . . . . . . . . . . . . 37

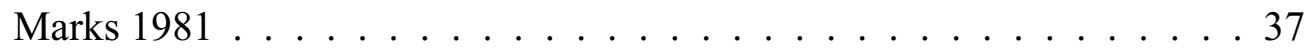

Menné et al. $1981 \ldots \ldots$. . . . . . . . . . . . . . . . . . 37

Chrostek and Moshell 1982 . . . . . . . . . . . . . . . . . 38

Levy and Hanoa 1982 . . . . . . . . . . . . . . . . . . . . . . . 38

Roure et al. $1982 \ldots \ldots$. . . . . . . . . . . . . . . . 39

Certin and Zissu 1983 . . . . . . . . . . . . . . . . . . . . . . . . . . 39

Norbäck et al. 1983a,b,c;1988 . . . . . . . . . . . . . . . . . . 39

Jeansson et al. 1983, 1984 . . . . . . . . . . . . . . . . . . . . . . 40

Marks et al. 1984; Trautlein et al. 1984 . . . . . . . . . . . . . . . . . 40

Messite and Baker 1984; Messite and Fannick 1980 . . . . . . . . . . . 40

Menné and Hjorth 1985 . . . . . . . . . . . . . . . . . . . . . . . . 41

Olsen and Mørck 1985 . . . . . . . . . . . . . . . . . . . . . . . . . . 41

Apol and Thoburn 1986. . . . . . . . . . . . . . . . . . 41

Bennett and Chrostek 1986 . . . . . . . . . . . . . . . . . . . 42

Chovil et al. $1986 \ldots \ldots \ldots$. . . . . . . . . . . . . 442 
Shehade et al. 1987 . . . . . . . . . . . . . . . . . . . 42

LaMarte et al. 1988 . . . . . . . . . . . . . . . . . 43

Hammel $1990 \ldots \ldots$. . . . . . . . . . . . . . . . 43

Kanerva et al. 1990a,b;1993 . . . . . . . . . . . . . . . . . 44

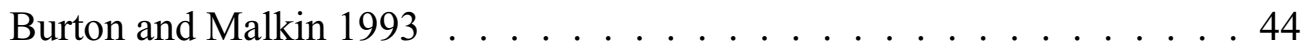

Sim and Echt $1993 \ldots \ldots . \ldots . \ldots . \ldots 45$

Zimmer and Hadwen 1993 . . . . . . . . . . . . . . . . . 45

Ziem and McTamney $1997 \ldots$. . . . . . . . . . . . . . . 445

Smith et al. $1999 \ldots \ldots$. . . . . . . . . . . . . . . . 46

4.2.2 NIOSH docket submissions . . . . . . . . . . . . . . . . . 46

4.2.2.1 Unpublished case reports and case series submitted by individuals ..................... 46

4.2.2.2 Inquires about health effects submitted by CCP manufacturers . . 47

Appleton Papers, Inc., 1987 . . . . . . . . . . . . . . . . 47

Moore Business Forms, Inc., 1987 . . . . . . . . . . . . . . 47

CCP Manufacturers 1998 . . . . . . . . . . . . . . . 47

4.2.3 Cross-sectional studies . . . . . . . . . . . . . . . . . . 48

4.2.3.1 Cross-sectional studies of indoor air contaminants . . . . . . . . 57

Skov et al. 1987, 1989 . . . . . . . . . . . . . . . 57

Zweers et al. $1992 \ldots \ldots \ldots \ldots$. . . . . . . . . . . . . . . . . . . . . 58

Mendell 1991 and Fiske et al. 1993 . . . . . . . . . . . 58

Omland et al. 1993 . . . . . . . . . . . . . . 58

Jakkkola and Jaakkola 1999 . . . . . . . . . . . . . . . . . . . . . . 68

4.2.3.2 Cross-sectional studies of CCP exposures . . . . . . . . . . 61

Fristedt and Pettersson 1980 . . . . . . . . . . . . . 61

Andersson et al. $1980 \ldots \ldots$. . . . . . . . . . 6 . . . . . . . . . . 63

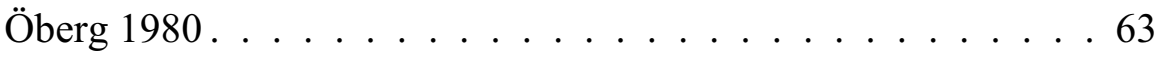

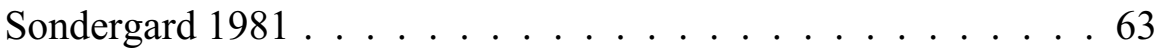

Menné et al. 1981 . . . . . . . . . . . . . . . . . . 63

Göthe et al. 1981 and Norbäck et al. 1983b . . . . . . . . . . . . 64

Kolmodin-Hedman et al. 1981 . . . . . . . . . . . . . . 66

Kleinman and Horstman 1982 . . . . . . . . . . . . . 66

Pryor et al. $1983 \ldots \ldots$. . . . . . . . . . . . . 67

Olsen and Mørck 1985 . . . . . . . . . . . . . . . . . 67

Omland et al. 1993 . . . . . . . . . . . . . . . . . . . . . . . . . . . . . . .

Apol and Thoburn 1986 . . . . . . . . . . . . 71

4.2.4 Laboratory studies in humans . . . . . . . . . . . . . . 71

4.2.4.1 Peer-reviewed literature studies . . . . . . . . . . . . 71

Nilzen 1975. . . . . . . . . . . . . . . . . . . . 71

Jeansson et al. 1983, $1984 \ldots \ldots$. . . . . . . . . . . 74

Morgan and Camp 1986 . . . . . . . . . . . . . 75 
4.2.4.2 NIOSH docket submissions . . . . . . . . . . . . . . . 75

RIPT studies . . . . . . . . . . . . . . . . . . . . 75

Tests under simulated conditions of use . . . . . . . . . . . 998

4.2.4.3 Summary . . . . . . . . . . . . . . . . . . . 999

4.3 Animal Studies. . . . . . . . . . . . . . . . . . . . . . . . . . . . 99

4.3.1 Published studies . . . . . . . . . . . . . . . . . . . . . . . . 999

Hasegawa et al. 1982a. . . . . . . . . . . . . . . . . . 999

Hasegawa et al. 1982b . . . . . . . . . . . . . . . . 999

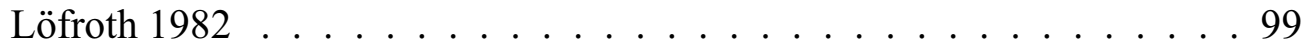

Certin and Zissu $1983 \ldots \ldots \ldots$

Cameron et al. $1986 \ldots \ldots \ldots \ldots 10 \ldots \ldots$

Wolkoff et al. $1988 \ldots \ldots$. . . . . . . . . . . . . . 101

Anderson 1992. . . . . . . . . . . . . . . . . . . 101

4.3.2 NIOSH docket submissions . . . . . . . . . . . . . . . . 102

4.3 .3 Summary . . . . . . . . . . . . . . . . . . 105

5 Summary and Conclusions. . . . . . . . . 107

5.1 Irritation of the skin, eyes, and upper respiratory tract $\ldots \ldots \ldots \ldots$

5.1 .1 Strength of the association . . . . . . . . . . . . . . . 110

5.1 .2 Consistency . . . . . . . . . . . . . . . . . . 110

5.1 .3 Specificity . . . . . . . . . . . . . . . . . . . 110

5.1 .4 Relationship in time (temporality) . . . . . . . . . . . . . 111

5.1 .5 Biological gradient . . . . . . . . . . . . . . . . . 111

5.1 .6 Biological plausibility . . . . . . . . . . . . . . . . 111

5.1 .7 Coherence . . . . . . . . . . . . . . . . . . . . 112

5.1 .8 Experimental evidence. . . . . . . . . . . . . . . . . . . . . 112

5.1 .9 Reasoning by analogy . . . . . . . . . . . . . . . . . . 113

5.1 .10 Summary . . . . . . . . . . . . . . . . . . . . 113

5.2 Allergic contact dermatitis . . . . . . . . . . . . . . . . 113

5.3 Systemic reactions . . . . . . . . . . . . . . . . . . . 114

5.4 Conclusions . . . . . . . . . . . . . . . . . . . . 114

6 Recommendations ............... 117

6.1 Historical recommendations in the scientific literature . . . . . . . . . . . 117

$6.2 \mathrm{NIOSH}$ recommendations . . . . . . . . . . . . . . . . . . . . . 118

References. . . . . . . . . . . . . . . . . . . . . 120

Other publications examined $\ldots \ldots \ldots \ldots \ldots$ 


\section{Tables}

2-1 CF coating slurry formulation $\ldots \ldots \ldots \ldots \ldots \ldots$

3-1 Exposures from CCP handling $\ldots \ldots \ldots \ldots \ldots \ldots \ldots \ldots \ldots \ldots$

3-2 Solvent emissions from CCP with intact microcapsules and 1\% crushed microcapsules $\left(\mathrm{mg} / \mathrm{m}^{2}\right.$ per hour $) \ldots \ldots \ldots \ldots \ldots$

3-3 Airborne concentrations of total dust and solvents produced with standardized paper handling in the laboratory $\left(\mathrm{mg} / \mathrm{m}^{3}\right) \ldots \ldots \ldots \ldots$

3-4 GC/MS analysis of CCP samples, SurSol 290 solvent, and area air samples (ppb) $\cdots 20$

3-5 Formaldehyde concentration after repeated turning of $\mathrm{CCP}$ sheets in a test

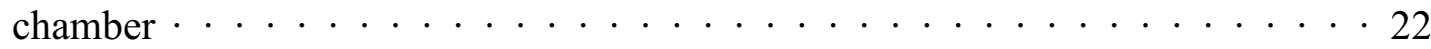

3-6 Formaldehyde concentrations in the test chamber at various points after turning (total of 60 sheets for each condition) $\ldots \ldots \ldots \ldots \ldots \ldots$

3-7 Formaldehyde concentrations in the test chamber during a 90-min period $\cdots \cdots 23$

3-8 Formaldehyde concentrations in a test chamber containing eight CCP products $\cdots 24$

3-9 Effect of ventilation on formaldehyde concentrations in test chambers

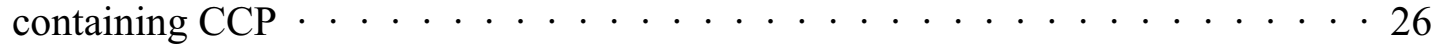

3-10 Summary of formaldehyde concentrations reported in CCP studies $\cdots \ldots 26$

4-1 Published case reports, case series, and health hazard evaluations involving exposure to CCP or CCP components . . . . . . . . . . . . . 31

4-2 Summary of health-related inquiries from customers to Appleton Papers, Inc., May 1976 to December $1986 \ldots \ldots \ldots$. . . . . . . . . 47

4-3 Summary of cross-sectional studies that used questionnaires to assess the health effects of indoor air contaminants in general or CCP specifically $\cdots . . .49$

4-4 Job or workspace factors associated with the prevalence of work-related symptoms after adjustment for other personal, psychological, job, workspace, 
and building factors in northern California office workers,

June-September 1990 . . . . . . . . . . . . . . . . . . . . 59

4-5 Types and locations of skin and mucous membrane symptoms in a Swedish

questionnaire study $\ldots \ldots \ldots 62$

4-6 Dose-response relationship of CCP handling frequency with symptoms reported by

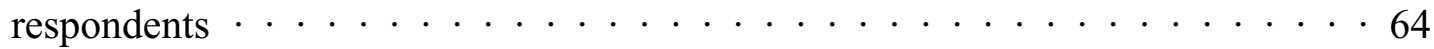

4-7 Frequency of respiratory tract symptoms by type of paper and exposure level $\cdots \quad \cdot 65$

4-8 Positive findings from physician interviews of 53 respondents to a health

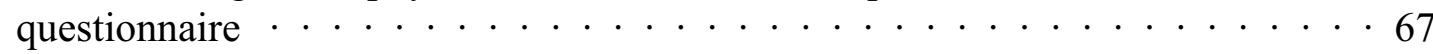

4-9 Dose-response relationship between CCP handling and mucous membrane and skin symptoms in two form-printing shops . . . . . . . . . . 68

4-10 Incidence of symptoms in exposed workers and their matched comparison workers during two exposure periods . . . . . . . . . . . . . . . 69

4-11 Experimental laboratory investigations of allergic and irritative reactions in humans exposed to CCP . . . . . . . . . . . . . . . . . .

4-12 Analysis of repeated insult patch test (RIPT) studies submitted by industry clients in response to 1987 and 1997 Federal Register notices on CCP and its

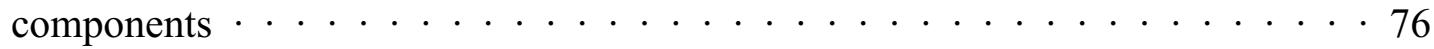

4-13 Frequency of occurrence and animal irritation category for chemicals identified in 12 French CCPs . . . . . . . . . . . . . . . . . . . . 100

5-1 Summary of studies that examined exposure-response relationships between CCP handling and irritative symptoms of the skin, eyes, or upper respiratory tract . . . . . . . . . . . . . . . . . . 108

5-2 Elevated ORs for CCP exposure and irritation of the skin, eyes, nose, or respiratory system reported in the indoor air cross-sectional studies 


\section{Figures}

2-1 Three-part carbonless copy paper system $\ldots \ldots \ldots \ldots$

4-1 Production of CCP and number of inquiries per year for all U.S. manufacturers from 1987 to $1996 \ldots \ldots \ldots \ldots \ldots \ldots \ldots \ldots \ldots \ldots \ldots \ldots \ldots \ldots \ldots$

4-2 Prevalence of pruritus among CCP handlers by sheets of CCP handled during the

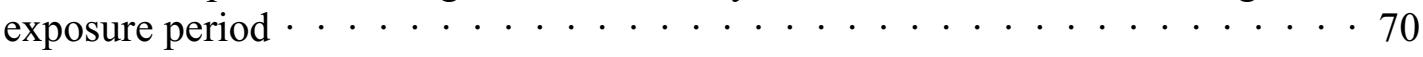




\section{Abbreviations}

\begin{tabular}{|c|c|}
\hline ASHRAE & $\begin{array}{l}\text { American Society of Heating, Refrigerating, and Air-Conditioning } \\
\text { Engineers }\end{array}$ \\
\hline BLASB & benzoyl leuco acronal sky blue \\
\hline BLMB & benzoyl leuco methylene blue \\
\hline${ }^{\circ} \mathrm{C}$ & degrees centrigrade \\
\hline $\mathrm{CB}$ & coated back \\
\hline $\mathrm{CCP}$ & carbonless copy paper \\
\hline $\mathrm{CF}$ & coated front \\
\hline CFB & coated front and back \\
\hline CFR & Code of Federal Regulations \\
\hline $\mathrm{CI}$ & confidence interval \\
\hline $\mathrm{cm}$ & centimeter \\
\hline CPSC & Consumer Product Safety Commission \\
\hline CVL & crystal violet lactone \\
\hline D-ink & desensitizing ink \\
\hline DETA & diethylenetriamine \\
\hline DPM & diphenylmethane \\
\hline EDTA & ethylenediaminetetraacetic acid \\
\hline Fed. Reg. & Federal Register \\
\hline $\mathrm{ft}$ & foot (feet) \\
\hline $\mathrm{ft}^{2}$ & square foot (feet) \\
\hline $\mathrm{g}$ & $\operatorname{gram}(\mathrm{s})$ \\
\hline GC & gas chromatography \\
\hline GC/MS & gas chromatography/mass spectrometry \\
\hline HMDI & hexamethylene diisocyanate \\
\hline $\mathrm{hr}$ & hour(s) \\
\hline
\end{tabular}




\begin{tabular}{|c|c|}
\hline in. & inch(es) \\
\hline $\mathrm{kg}$ & kilogram(s) \\
\hline KMC-A & Kureha Microcapsule Oil (diisopropylnaphthalenes) \\
\hline $\mathrm{L}$ & liter(s) \\
\hline LAB & linear alkyl benzene \\
\hline $\mathrm{lb}$ & pound(s) \\
\hline $\mathrm{LC}_{50}$ & lethal concentration for $50 \%$ of the test animals \\
\hline $\mathrm{LD}_{50}$ & lethal dose for $50 \%$ of the test animals \\
\hline $\mathrm{m}$ & meter(s) \\
\hline $\mathrm{MCS}$ & multiple chemical sensitivity \\
\hline $\mathrm{mg}$ & milligram(s) \\
\hline $\min$ & minute(s) \\
\hline MIPB & monoisopropyl biphenyl \\
\hline MRI & magnetic resonance imaging \\
\hline MSDS & material safety data sheet \\
\hline N-BLMB & N-benzoylleucomethylene blue \\
\hline NA & not applicable \\
\hline NCR & no carbon required \\
\hline $\mathrm{NIOSH}$ & National Institute for Occupational Safety and Health \\
\hline $\mathrm{nm}$ & nanometer(s) \\
\hline NR & not reported \\
\hline OR & odds ratio \\
\hline OSHA & Occupational Safety and Health Administration \\
\hline$P$ & probability \\
\hline PCBs & polychlorinated biphenyls \\
\hline PEL & permissible exposure limit \\
\hline PG & prostaglandin \\
\hline $\mathrm{ppb}$ & parts per billion \\
\hline ppm & parts per million \\
\hline REL & recommended exposure limit \\
\hline
\end{tabular}




$\begin{array}{ll}\text { RIPT } & \text { repeated insult patch test } \\ \text { RUDS } & \text { reactive upper airways dysfunction syndrome } \\ \text { SAS } & \text { 1-phenyl-1-xylyl-ethanes } \\ \text { SBS } & \text { sick building syndrome } \\ \text { SC } & \text { self-contained } \\ \text { SCP } & \text { self-copying paper } \\ \text { sec } & \text { second(s) } \\ \text { SKTF } & \text { Swedish Association of Municipal Technology } \\ \text { SPECT } & \text { single position emission computed tomography } \\ \text { TLC } & \text { thin-layer chromatography } \\ \text { TWA } & \text { time-weighted average } \\ \text { UV } & \text { ultraviolet } \\ \text { U.S. } & \text { United States } \\ \text { VDT } & \text { video display terminal } \\ \mu \text { g } & \text { microgram } \\ \mu \mathrm{m} & \text { micrometer } \\ \% & \text { percent }\end{array}$




\section{Acknowledgments}

$\mathrm{T}$ his document was developed by the staff of the National Institute for Occupational Safety and Health (NIOSH). Paul A. Schulte, Ph.D., Director, Education and Information Division, had overall responsibility for the document. Major NIOSH contributors were Richard W. Niemeier, Ph.D. (project team leader), toxicologist; Barry R. Belinky, chemist; Lawrence F. Mazzuckelli, toxicologist; Mark A. Toraason, Ph.D., toxicologist; Kenneth Weber, Ph.D., toxicologist; David Weissman, M.D., clinical immunologist; Leslie T. Stayner, Ph.D., epidemiologist; and Robert Park, epidemiologist. NIOSH reviewers included Marilyn A. Fingerhut, Ph.D.; Gary Kent Hatfield, Ph.D.; Kay Kreiss, M.D.; Boris D. Lushniak, M.D.; Bonita D. Malit, M.D., M.P.H.; Leela Murthy, Ph.D.; Andrea Okun, Dr.P.H.; Lynne Pinkerton, M.D., M.P.H.; Kyle Steenland, Ph.D.; Marie Haring Sweeney, Ph.D.; and Mitch Singal, M.D., M.P.H.

Editorial review and camera copy production were provided by Vanessa Becks, Susan Feldmann, Anne C. Hamilton, Susan Kaelin, and Jane Weber. Erica Davis, Karen Dragon, Rose Hagedorn, and Kris Wasmund provided word processing.

We thank the following external peer reviewers for their contributions:

R.J. McCunney, M.D., M.P.H., American College of Occupational and Environmental Medicine (ACOEM), Arlington Heights, Illinois

W.J. Waddell, M.D., Professor and Chairman, Emeritus, Department of Pharmacology and Toxicology, School of Medicine, University of Louisville, Louisville, Kentucky

M.B. Kent, Acting Director, Health Standards, U.S. Department of Labor, Occupational Safety and Health Administration, Washington, D.C.

L.E. Saltzman, Director, Division of Health Studies, Consumer Product Safety Commission

Mark R. Cullen, M.D., Director, Occupational and Environmental Medicine Program, Yale School of Medicine, New Haven, Connecticut

D.S. Rigel, M.D., President, American Academy of Dermatology, Schaumburg, Illinois

C.J. Schmidt, Assistant Director, Analytical Toxicology Core Laboratory, University of Florida, Gainesville, Florida

G.M. Marsh, Ph.D., Professor of Biostatistics, Graduate School of Public Health, University of Pittsburgh, Pittsburgh, Pennsylvania 
J.S. Morawetz, Director, ICWUC Center for Worker Health and Safety Education, Cincinnati, Ohio

P. Skov, M.D., Clinic of Occupational Medicine, University of Copenhagen, Denmark

J. T. McClintock, Ph.D., Chief, Science Support Branch, Risk Assessment Division, U.S. Environmental Protection Agency - including reviews by the following:

D. Bruce Henschel, Indoor Environmental Management Branch Matt Gillen, C.I.H., Office of Pollution Prevention and Toxics

Terry O'Bryan, Office of Pollution Prevention and Toxics John Scalera, Office of Pollution Prevention and Toxics Ronald Ward, Ph.D., Science Support Branch, Risk Assessment Division J. Beaubier, Ph.D., Science Support Branch, Risk Assessment Division Gregory J. Macek, C.E.B.

The Sapphire Group, Bethesda, Maryland - representing the CCP industry and including reviews from the following:

Robert G. Tardiff, Ph.D., ATS, President of The Sapphire Group Carol Gevecker Graves, Ph.D., Senior Scientist, The Sapphire Group

Rudolph J. Jaeger, Ph.D., DABT, DABFM, Professor of Environmental Medicine, New York University School of Medicine; Principal Scientist at Environmental Medicine, Inc.; CEO of CH Technologies, Inc.

Noel R. Rose, M.D., Ph.D., Professor of Medicine, and Professor and Chairman, Department of Immunology and Infectious Diseases, Johns Hopkins University School of Medicine, Baltimore, Maryland

Andrew Saxon, M.D., Professor of Medicine, Department of Medicine, Chief, Division of Clinical Immunology/Allergy, Associate in Molecular Biology Institute, University of California, Los Angeles, California

Richard B. Schlesinger, Ph.D., Professor, Director of Graduate Studies Program in Environmental Health, Systemic Toxicology Program and Laboratory for Pulmonary Biology and Toxicology, Institute of Environmental Medicine, Department of Environmental Medicine, New York University School of Medicine Genevieve Matanoski, M.D., The Johns Hopkins University Professional Consultants in Occupational Health, Inc., Bethesda, Maryland 


\section{Introduction}

\subsection{Background}

Tn 1987, the Occupational Safety and Health Administration (OSHA) requested the National Institute for Occupational Safety and Health (NIOSH) to investigate the validity of reported adverse health effects in workers occupationally exposed to chemicals contained in or released from carbonless copy paper (CCP). OSHA also requested that NIOSH publish its findings if health effects were confirmed. The OSHA request was based on one worker's concern that skin, respiratory problems, and possible brain damage were due to consistent exposure to CCP [52 Fed. Reg. 22534 (1987)]. In addition, 10 to 12 of the initial complainant's coworkers who were also exposed to CCP were reported to have suffered adverse health effects.

Thus in 1987, NIOSH issued a Federal Register notice soliciting information about possible adverse health effects from CCP exposure [52 Fed. Reg. 22534 (1987)]. On the basis of information available at that time, no strong conclusion could be reached concerning a consistent link between CCP and major health effects. Between 1987 and 1997, a number of additional incidents were identified as involving health problems potentially related to CCP. Therefore, in 1997 NIOSH issued a second Federal Register notice soliciting new information [62 Fed. Reg. 8023 (1997)].

\footnotetext{
${ }^{*}$ Federal Register. See Fed. Reg. in references.
}

This report contains a review of the published literature on CCP and the submissions from the two Federal Register notices. NIOSH prefers to use the published literature when investigating the relationship between an occupational exposure and adverse health effects, but some unpublished sources were used in this case because the published literature was limited. The unpublished information was found to be of variable quality, validity, and utility.

\subsection{Development and Production of CCP}

CCP was introduced in 1954 by the National Cash Register Company as no-carbon-required (NCR) paper - an alternative to separate sheets of carbon paper [Sandberg 1955; Green 1955; Miller and Phillips 1972; Calnan 1979; Buring and Hennekens 1991]. NCR was a patented name, but many of the patents have expired, and several companies have licenses in other countries.

The mechanism of CCP involves coating the under surface of the top sheet of CCP with an emulsion of a colorless dye in a solvent (see Chapter 2). The emulsion is held in microscopic capsules (microcapsules) that are ruptured by firm pressure from a writing instrument. The released dye reacts with a reagent on the surface of the paper and changes the dye to a colored product (generally violet, blue, or black). CCP may also be referred to as one of the following:

- Pressure-sensitive paper 
- Reaction-copy paper

- Color-reaction paper

- Self-copying paper

CCP comprises an extremely complex grouping of products. A given CCP can vary greatly as to its constituents, weight and types of paper coatings, paper color, dye colors and combination of dyes used on coatings, solvents and solvent mixtures (including variations from different suppliers), physical form (rolls versus sheets), and final form of the product (i.e, bound with adhesives). To improve quality and performance, the "recipes" used in the manufacture of CCP change frequently. No single product can be identified as a typical formulation of CCP since each product may have its own distinct constituents and different manufacturing processes. Thus the product known as CCP is not a single product but includes thousands of different and often unique products [Mead Corporation 1997 (a NIOSH docket submission)].

Production of CCP grew on an enormous scale after its introduction in 1954. By the 1960s, U.S. sales were about 16,000 tons, and production had started in Europe. In 1962, a Japanese company signed a license agreement with the National Cash Register Company, and by 1970, worldwide production rose to 100,000 tons. In 1991, about 1.8 million tons of CCP (the equivalent of nearly 200 billion 8.5- $\times$ 11-in. sheets) [Fetters 1997 (a NIOSH docket submission)] were produced and used [Buring and Hennekens 1991; Murray 1991]. Consumption is divided into three principal regions: North America—800,000 tons, Japan and the Far East-300,000 tons, and Europe-600,000 tons [Murray 1991]. The Association of European Manufacturers of Carbonless Papers [AEMCP 1985] indicated that in 1985 there were more than 50 manufacturers of CCP throughout the world.
By 1979, four companies in Great Britain, four in Japan, five in other European countries, and five major companies in the United States were manufacturing this paper [Calnan 1979]. Currently, 12 plants (5 manufacturers) in the United States [Fetters 1997 (a NIOSH docket submission)] and more than 50 plants around the world [AEMCP 1985] manufacture CCP. U.S. production averaged nearly 1 million tons during the period 1987-1996 [Graves and Tardiff 1999]. Annual global sales exceed $\$ 5$ billion [Finch 1990].

The production industry employs more than 10,000 workers [Fetters 1997 (a NIOSH docket submission)]. Although the total number of workers potentially exposed to CCP in workplaces other than manufacturing (such as offices, laboratories, other businesses, schools, banking, etc.) is unknown [Pedersen 1998], it is likely to be in the millions. Also unknown is the extent to which the general public is potentially exposed to CCP during business transactions, receipt checking, etc.

\subsection{Reported Health Effects}

About 10 years after the introduction of CCP, medical complaints began to be reported by exposed office workers [North Carolina Medical Journal 1982; Magnusson 1974; Göthe et al. 1981; Buring and Hennekens 1991]. In 1975, OSHA requested information from physicians about any unusual frequency of eye, mucous membrane, or skin irritation associated with CCP similar to the information being reported at that time in Sweden [North Carolina Medical Journal 1982].

Since 1965, various health effects associated with exposure to CCP have been reported in the literature appearing from Denmark, Finland, England, Sweden, Germany, the Netherlands, France, Italy, Belgium, Japan, Norway, and the United States. The National Swedish Board of Occupational Safety and Health 
[1976] gathered information about the components of CCP and came to the following conclusions:

- None of the substances present in CCP at that time had known irritant or allergenic effects.

- The problems of skin and mucous membrane irritation are most common in the winter when the humidity is low.

- None of the substances gave rise to large amounts of dust.

- None of the substances would lead one to expect vapors to be generated at room temperatures.

- The odor reported by some may originate from the solvents in the adhesives or the inks.

Despite these negative conclusions, the Swedish Board noted that further attention to the question was warranted, "since problems with the skin and mucous membranes are still being reported by persons working with carbonless paper." Thus they also issued advice and instructions related to the handling of CCP $[\mathrm{Na}-$ tional Swedish Board of Occupational Safety and Health 1976].

In February 1980, the Swedish Trade Union called for a ban on CCP [Göthe et al. 1981], which was claimed to be the cause of numerous conditions including the following [Göthe et al. 1981; Kanerva et al. 1993]:

$\begin{array}{ll}\text { Itching } & \text { Headache } \\ \text { Redness of the skin } & \text { Joint pain } \\ \text { Breathing difficulty } & \text { Rapid heart beat } \\ \begin{array}{l}\text { Hoarseness and } \\ \text { airway obstruction }\end{array} & \begin{array}{l}\text { Burning of the nose, } \\ \text { eyes, mouth, and chest }\end{array}\end{array}$

$\begin{array}{lc}\begin{array}{c}\text { Chest tightness and } \\ \text { pain }\end{array} & \begin{array}{c}\text { Unpleasant smell } \\ \text { and taste }\end{array} \\ \text { Asthma } & \text { Contact urticaria } \\ \text { Fatigue } & \begin{array}{c}\text { Allergic contact } \\ \text { dermatitis }\end{array} \\ \text { Nausea } & \begin{array}{c}\text { Irritant contact } \\ \text { dermatitis }\end{array}\end{array}$

Government and public concerns have waxed and waned in response to various reports in the literature as well as anecdotal information. The Danish, French, Swedish, and German governments have offered recommendations for reducing exposure to CCP (summarized in Chapter 6) that rely on simple work practices, personal hygiene, substitution, administrative controls, and increased ventilation as preventive measures. The Danish, French, and German governments have also recognized alleged health effects from CCP exposure as compensable according to the seriousness of the worker's reaction [Norbäck et al. 1983b].

At the first symposium on CCP (which was held in Stockholm and attended by producers, labor, government, and representatives from nine nations), Göthe et al. [1981] commented that strong forces had been mobilized in Sweden 2 years before the meeting to ban CCP or find a substitute for it. They noted that support for such resolutions has "often been anxiousness enhanced by unverified rumors or alarming mass-media reports about dramatic and serious diseases caused by work with carbonless copy papers." On the basis of their field investigations, Göthe et al. [1981] indicated that handling large amounts of CCP might induce dose-related but benign and nonallergic irritative symptoms, particularly in the mucous membranes of the nose and mouth. These authors did not consider these symptoms to be specific for CCP: they could also be elicited by handling large amounts of ordinary paper. But it appeared that a higher percentage of CCP workers might develop these symptoms than workers exposed to ordinary paper. These 
investigators did not consider the phenomenon to indicate any large health risk, but they noted that CCP seems to be somewhat more irritating than ordinary paper in equivalent amounts.

In Canada, Harris [1983] reported that the symptoms directly associated with use of CCP (and shown to decrease outside of work or at other tasks) develop primarily in office workers who use CCP and less in those who make it. He stated that the symptoms (1) appear to be quickly reversible when exposure ceases, (2) are rarely caused by allergic reactions, and (3) vary greatly from office to office (which may depend on combinations of factors including the brand of CCP, the intensity of use, and office conditions such as ventilation and humidity). He further stated that no individual chemicals such as formaldehyde, oils, or paper dust had been identified as causing the related symptoms and that measurements in the office air were generally too low to account for the symptoms. Harris [1983] concluded that the reported health problems were due to the mixture of chemicals used in CCP and to mechanical irritation by the clay coatings on the paper.

To provide a comparison with the information available on CCP, Brissette and Paquette [1987] summarized the known information about the prevalence of health problems associated with carbon paper in Quebec, Canada. They reported that 34 of 390 cases of industrial dermatitis reported in 1929 and 5 of 5,000 cases reported between 1932 and 1936 were related to carbon paper, but the observations were not based on patch testing. They further reported that at the Finsen Institute in Copenhagen, cutaneous toxicity to carbon paper was evaluated in 40,000 people. Only four cases of allergic contact dermatitis were recorded, and the agents responsible were triorthocresyl phosphate, oleic alcohol, nigrosine, and violet methyl. None of these agents are reported to be used in CCP.

On February 13, 1986, the National Swedish Board of Occupational Safety and Health decreed that the CCP Announcement No. 1976:2 [National Swedish Board of Occupational Safety and Health 1976] (which recommended actions to be taken when CCP-exposed workers showed symptoms of irritation) was no longer valid: "The problems which were previously considered to be caused by carbonless paper are now regarded as being of an extremely complex nature and have been linked directly to the paper only in a small number of cases (see Arbete Och Hälsa [Work and Health] 1983:2, Report on Problems Caused by Carbonless Paper).

\subsection{Information Sources and Types}

This NIOSH report is based on published and unpublished information. The published information includes case studies and case series, cross-sectional epidemiological studies, patent literature, and some reports of human and animal experimental studies. The unpublished materials were submitted to the NIOSH Docket in response to the Federal Register notices in 1987 and 1997 [52 Fed. Reg. 22534 (1987) and 62 Fed. Reg. 8023 (1997)]. These unpublished materials generally include human repeat insult patch test (RIPT) studies, animal exposure studies, and medical records of workers who indicated that they had exposure to $\mathrm{CCP}$. 


\section{The Technology of CCP}

\subsection{How CCP Works}

\begin{abstract}
A three-part business form (Figure 2-1) il- lustrates the concept of how CCP works. The first sheet in this three-part example is a coated-back (CB) sheet, the second is a coated-front and -back (CFB) sheet, and the third is a coated-front (CF) sheet. The bottom surfaces of the top and the second sheet are coated with a layer of microcapsules that have a diameter of 3 to $6 \mu \mathrm{m}$. The coating includes inert spacer particles ("stilts," such as floc, uncooked arrowroot, and/or wheat starch particles) that are larger than the microcapsules and are added to protect the microcapsules from premature rupture. The microcapsules (filled with a colorless solution of $2 \%$ to $6 \%$ dye dissolved in a high-boiling-point-organic solvent) rupture under pressures encountered in normal handwriting or impact printing. For example, in a three-part form, the released dye solution is transferred from the bottom surfaces of the first and second sheets to the top surfaces of the second and third sheets, respectively, where it reacts with the clay or resin coating to form an image. The capsules and reactive coating can be coated onto the same paper surface. In this case, the product is called self-contained CCP.
\end{abstract}

\subsection{CCP Production}

The principles of the CCP production process are similar throughout the industry, but many components are variable and complex. During CCP production, an acid-sensitive dye precursor such as crystal violet lactone (CVL) or $\mathrm{N}$-benzoylleucomethylene blue (N-BLMB) is microencapsulated with a high-boiling-point solvent or oil within a cross-linked gelatin or in synthetic mononuclear microcapsules, including polyamides, polyesters, or polyurethanes. From the origination of NCR paper until 1970, the main solvent for the dyes was polychlorinated biphenyls (PCBs [Arochlor]). Examples of solvents that have replaced PCBs are hydrogenated terphenyls, diarylethanes, alkylnaphthalenes, cyclohexane, and dibutylphthalate (more detailed information about solvent composition, technical requirements, and admixtures is given later in this section). These materials are often diluted with odorless kerosene [Calnan 1979].

CCP production consumes thousands of tons of microcapsules annually. During CCP manufacturing, microcapsules are coated onto the back of the top sheet (referred to as a CB sheet) at a density of several million per $\mathrm{cm}^{2}$ with a binder or suitable adhesive [Certin and Zissu 1983]. Since paper is the usual support, the binders or adhesives are principally paper-coating agents such as the following [Murray 1991; Mathiaparanam 1992]:

- Gum arabic

- Hydroxymethyl cellulose

- Casein

- Methyl cellulose

- Dextrin

- Starch or starch derivatives (wheat or corn) or polymer lattices (e.g., butadiene/styrene copolymers or acrylic homopolymers or copolymers) 
- Vinyl acetate and water soluble polymers such as carboxymethyl cellulose

- Polyvinylacetate

- Gelatin

- Polyacrylates

- Polystyrene

- Polyvinyl alcohol

The paper employed comprises not only normal paper made from cellulose fibers, but also paper in which cellulose fibers are replaced (partially or completely) by synthetic polymers [Bedekovic and Fletcher 1986]. (Please refer to Section 2.8 for a listing of brand names and trademarks of CCP.)

The sheet intended to receive the image, the CF sheet, is treated on the front with a clay or resin that is alkaline on the surface but acidic inside, or with an alternative reactive coating [Calnan 1979]. In Europe, the color developer system is typically based on clays, whereas phenolic resins are most commonly used in the United States and Japan [Murray 1991]. The coating is spread in a mixture, dried, and adhered with a styrene-butadiene-latex or one of the binders listed above. When the top sheet is mechanically impacted, the dye capsules rupture and the dye solution is transferred to the receiving sheet, where the acid developer activates the dye as a result of a change in $\mathrm{pH}$ or oxidation.

\subsection{Microcapsule Production}

Three processes can be used to microencapsulize the dyes for the size requirements of CCP: complex coacervation, interfacial polymerization, or in situ polymerization [Kroschwitz and Howe-Grant 1979, 1995; Sliwka 1975]. The complex coacervation process produces a shell material of gelatin and gum arabic (treated with glutaraldehyde); the chemical class is a protein-polysaccharide complex. Interfacial polymerization produces a shell of polyurea or polyamide and is chemically classed as a cross-linked polymer. The in situ process results in a shell material of aminoplasts and is also considered to be in the cross-linked polymer chemical class. Microcapsules have a wide range of geometries and structures. These range from a continuous core shell that surrounds the core material to a multinuclear capsule in which a number of cells of core material are distributed uniformly throughout the matrix of shell material and a continuous core capsule with two different shells. Examples of other synthetic resins used for the microencapsulation process are

$$
\begin{aligned}
& \text { CB (coated-back) sheet } \\
& \text { CFB (coated-front and -back) sheet } \\
& \text { CF (coated-front) sheet }
\end{aligned}
$$$$
\text { /////////////////////// } \longleftarrow \text { Base paper }
$$

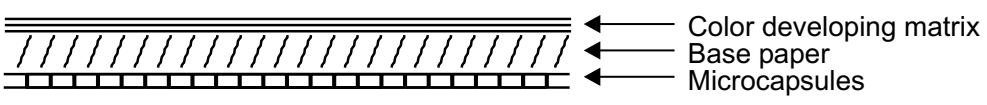

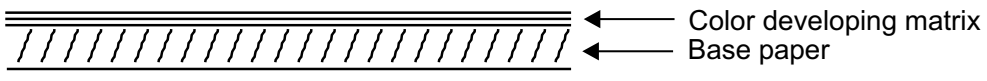

Figure 2-1. Three-part carbonless copy paper system. 
urea-formaldehyde, melamine-formaldehyde, polyamide, and polyurethane resins [Asano et al. 1983]. Maggio et al. [1978] stated that urea-formaldehyde capsules are more resistant to pressure than those made of gelatin.

\subsection{CCP Production Process}

Apol and Thoburn [1986] described the process of CCP manufacturing. The plant they investigated made paper from pulp and then applied the appropriate coatings to the paper to make CCP. The paper itself is usually produced in a continuous sheet from a pulp slurry to form a wet web of paper as it exits on a screen, such as in a Fourdrinier paper machine. Apol and Thoburn [1986] describe a process in which the $\mathrm{CF}$ and $\mathrm{CB}$ coatings are applied to the wet web. The CF coating can also be applied as the paper exits from the paper machine. As the coating is applied, the paper passes through a dryer and is wound on a roll. The CB coating may be applied in a separate plant area to the paper as it passes through a series of dryers and is rewound on a roll.

The $\mathrm{CF}$ and $\mathrm{CB}$ coatings are prepared in the coater preparation area. The phenolic resins (1- to $10-\mu \mathrm{m}$ or $1-$ to $3-\mu \mathrm{m}$ size range is preferred [Mathiaparanam 1992]) may be prepared by grinding the resins to specific-size particles, or they may be purchased already prepared. The already prepared resin reduces exposure to phenol among workers who handle the coating preparation and is the preferred option for today's technology.

A typical coating composition for the $\mathrm{CF}$ component is shown in Table $2-1$. The $\mathrm{CF}$ is dried in a high-velocity air oven at $93{ }^{\circ} \mathrm{C}$ [Kroschwitz and Howe-Grant 1995]. Miller and Phillips [1972] stated that suitable amounts of the various materials per unit of paper are as follows: chromogenic dyes, 0.03 to $0.075 \mathrm{lb} / \mathrm{ream}$ (one ream is 500 sheets of $25-\times 38$-in. paper totaling $3,300 \mathrm{ft}^{2}$ ), with the preferred amount being $0.05 \mathrm{lb} /$ ream; solvent, 1 to $3 \mathrm{lb} /$ ream; polymer, 0.5 to $3 \mathrm{lb} /$ ream.

$\mathrm{CF}, \mathrm{CB}$, and $\mathrm{CFB}$ coated papers are produced in large rolls weighing up to several tons. These are subsequently cut down by machines to a variety of smaller reel and sheet sizes. This cutting means that the contents of the microcapsules will be ruptured and released. Although many of the sheeting, reeling, and packing operations are automated, some of the paper still needs to be hand-sorted. The workers who hand sort these papers are potentially exposed to the components, particularly the contents of the ruptured capsules that have been cut in previous mechanical operations. Some of these workers sort paper at the rate of $90 \mathrm{~kg} / \mathrm{hr}$ (or more than 2 tons/week [600,000 sheets]) [AEMCP 1985].

\section{Table 2-1. CF coating slurry formulation}

\begin{tabular}{lc}
\hline \multicolumn{1}{c}{ Constituent } & Parts \\
\hline Kaolin clay & 64 \\
$\mathrm{CaC}_{3}$ & 3 \\
Colloidal silica & 6 \\
Hydroxyethyl starch & 3 \\
Styrene-butadiene latex & 12 \\
Novolak resin dispersion & 12 \\
\hline
\end{tabular}




\subsection{Forms Production}

CCP is converted into forms for a variety of applications - for example, business forms, invoices, computer paper, and Telex rolls. This process is normally performed by printers with appropriate forms design using conventional printing inks as well as specialized desensitizing inks. The latter are applied to the $\mathrm{CF}$ surface to prevent the color former from developing into an image on certain areas of the paper [AEMCP 1985].

CCP may be collated into business form sets that are glued along one edge. The glues (called edge-padding, edge-tipping, or "fanapart" glues) are similar to those used for ordinary paper writing pads. Manifold forms using pressure-sensitive CCP are produced using conventional printing press techniques. For some applications, the production of the multipart form by photocopying or laser printer operations is preferred-especially in short-run for production, emergencies, and experimental or individualized forms. The manifold forms are bound with an adhesive containing gum resins such as abietic acid. More recently, Moore Business Forms, Inc., was granted a patent [McIntyre and Greig 1989] for the use of a repositionable adhesive pad on the CF (such as is found on money wrappers). Bodmer and Peters [1984] and Bodmer and Miller [1985, 1986] noted that CF coating components can accumulate on the heated fuser roll of the copier or the laser printer, which becomes tacky and can lead to poor copy quality. A phenolic polymeric film material, diolefinic alkylated or alkenylated cyclic hydrocarbons (cyclic terpene derivatives such as limonene), and/or an oil-soluble metallic salt (primarily zinc) of a phenol-formaldehyde novolak resin can be used to overcome the fuser roll contamination problem, which may or may not result in slower print speeds.

\subsection{Other Forms and Variations of CCP Technology}

Forms sometimes combine CCP with carbon paper to become a "two-write" system [Mead Corporation 1992]. The Branch Safety Council for Offices and Administrations [1988] also reported on another type of CCP that is pressure sensitive and is called "mechanical" paper. The CB sheet is coated with zinc chloride and covered by a thin layer of wax. Pressure created on the top side of the form causes the zinc chloride to break through the wax and adhere to the sheet below that is coated with an absorbing layer of color generators, polyvinyl acetate, and clay. The Mead Corporation was granted a patent that incorporated a microencapsulated, photosensitive material that cured to a stable image when heat-activated in the presence of a developer such as an organic peroxide [Sanders 1984]. The Mead Corporation was also granted a patent on a novel system that uses a self-contained imaging sheet to produce images on plain paper using a photosensitive ${ }^{*}$, photocurable, image-forming agent and a developer material on the surface of the paper support [Feldman et al. 1994].

The NCR Corporation (formerly the National Cash Register Company) was granted a patent [Marinelli 1985] for the addition of an aqueous wax emulsion to the $\mathrm{CB}$ coating to act as a barrier between the reactants in the $\mathrm{CB}$ coating and in the $\mathrm{CF}$ coating in multiple-copy printing operations. The technology prevents precolor formation caused by reactants seeping into the $\mathrm{CF}$ and can withstand on-press CF coating (presumably with desensitizing inks). Formulations included the use of Jonwax ${ }^{\mathrm{TM}} 120$ (an emulsion of polyethylene and paraffin wax), Jonwax 26 (a wax emulsion of polythene wax), and Jonwax 22 (a water-based wax compound).

\footnotetext{
"“Actinic radiation," including the entire electromagnetic spectrum.
} 
The wax emulsion also replaces some of the microcapsules on the substrate. (Jonwax ${ }^{\mathrm{TM}}$ is a registered trademark of S.C. Johnson and Son, Inc., of Racine, Wisconsin.) According to Graves and Tardiff [1999], this process was never commercialized.

\subsection{Desensitizing Inks}

Frequently, information entered on the top form must be unreadable on certain sections of the form or forms beneath. If the areas on the forms beneath are not needed for other data, two types of obscuring methods can be used. The most common is the "masking" blockout, which entails the printing of a solid block of blue ink over the appropriate areas. The second type of blockout method calls for printing a dense pattern of random lines and blotches suggestive of Chinese characters ("Chinese blockout"). Both methods use the same color ink as the carbonless image color. When the blocked-out areas must remain clear to allow data entry on lower plies, the manufacturer must print a special clear "desensitizing" ink on that area. This desensitizing ink deactivates the carbonless imaging system by not allowing the CF side to react with the color former encapsulated on the CB surface [Mead Corporation 1993]. Desensitizing inks may contain a variety of solvents such as white spirits, kerosene, toluene, alcohols, glycols, ketones, and plasticizers such as dibutyl phthalate, etc. [AEMCP 1985]. Desensitizing inks are sold to industrial printers much like other printing inks [Graves and Tardiff 1999].

Chang [1978] described a patented method of desensitizing CCP when the color developer is a combination of acid clay, phenolic novolac resin, and metal salt of an organic carboxylic acid coated with 10 to 35 parts $\mathrm{N}$-vinylpyrrolidone and about 65 to 90 parts of a free-radical, co-polymerizable compound of a photoinitiator having at least one terminal ethylenic group per molecule. The paper is then subjected to ultraviolet radiation.

Some CCP originates from printing shops that may use different manufacturing sources of $\mathrm{CCP}$ in the same manifold. Thus it is extremely difficult to trace the origin of a particular paper. For example, the CF sheet could come from one manufacturer and the remainder of the form from another supplier or manufacturer. In addition, the printer can apply the desensitizing inks to the form [Danish Branch Safety Council for Offices and Administration 1988].

\subsection{Summary of Chemical Components of CCP}

This section lists the known components of CCP classified as to the microcapsule, color developer, $\mathrm{CF}$ coating, etc. The compilation was taken from the scientific literature, patent applications, and manufacturers' submissions.

\section{ADHESIVES FOR BINDING THE VARIOUS COATINGS TO THE PAPER}

casein

dextrin

gum arabic

hydroxymethylcellulose

methyl cellulose

polymer lattices (e.g., butadiene/styrene copolymers or acrylic homopolymers or copolymers) starch or starch derivatives (wheat or corn) styrene-butadiene-latex vinyl acetate

water-soluble polymers (e.g., carboxymethyl cellulose, polyvinyl acetate and polyvinyl alcohol) 


\section{COLOR DEVELOPERS FOR DYE-FORMERS ON CF AND OTHER ASSOCIATED AGENTS}

\section{Active clays (examples)}

acid clay

acid-treated montmorillonite clay

activated clay

alumina

aluminum sulfate and phosphate

attapulgite

bentonite

calcium stearate activated kaolin

halloysite

silica or silica gel

zeolite

zinc chloride and nitrate

\section{Phenolic resins (examples)}

novolaks

para-octylphenol resin

bis-Phenol A as an admixture

para-phenylphenol resin

polyphenylphenol as a trace contaminant

para-tertiary phenol resin

\section{Aromatic carboxylic acids (examples)}

benzoic acid

diphenic acid and metal salt compounds

thereof (zinc, aluminum, and calcium)

naphthoic acid

salicylic acid

substituted salicylic acids

\section{Organic acids (examples)}

gallic acid

maleic acid

malonic acid

succinic acid

\section{Addition product with phenol for color developers on the CF}

olefins (e.g., limonene, alpha-terpinene, divinylbenzene, various isomers of diisopropenylbenzene, terpenes, and 4-vinyl-1-cyclohexene)

\author{
Polyvalent metal salt (magnesium, aluminum, \\ and zinc) of carboxylated terpenephenol \\ resin
}

\author{
Inorganic dispersing agents (examples) \\ organic dispersing agents such as carboxylic \\ acid types (polyacrylic acid), polymaleic \\ acid types (styrene-maleic anhydride \\ copolymer), di-tertiary acetylene glycol, \\ and sulfonic acid types (naphthalene- \\ sulphonic acid salts) used in conjunction \\ with coatings of acid clays on the $\mathrm{CF}$ \\ sodium hexamethaphosphate \\ sodium pyrophosphate \\ sodium silicate \\ sodium tripolyphosphate
}

\section{UV absorbers (examples)}

2-(2-hydroxyphenyl) benzotriazoles used in the active clay formulation

\section{Inorganic pigment on the CF}

chalk (calcium carbonate)

kaolin

talcum

titanium dioxide

zinc oxide

zinc sulfide

zirconium dioxide

\section{Organic pigment on the CF}

melamine/formaldehyde condensates urea/formaldehyde condensates

Defoamer used to augment coating (example) sulfonated castor oil

\section{AGENTS CONNECTED WITH THE COATINGS ON THE CB}

\section{Dyes or color formers (examples)}

acyl auramines

acylleucophenothiazines

alpha- and beta-unsaturated aryl ketones

azaphthalides

basic mono azo dyes

BLASB-10-benzoyl-N,N, $\mathrm{N}^{\prime}, \mathrm{N}^{\prime}$ -

tetraethyl-3,7-diamino-10H-phenoxazine

chromogenic azaphthalide compounds

diaryl phthalides diphenylmethanes

dithio-oxamide

di[bis-(indoyl)ethyleneyl]tetraholophthalides

fluoran derivatives (3-dialkylamino-7-

dialkylamylfluoran)

green lactone

3-(indol-3-yl)-3-(4-substituted

aminophenyl)phthalides

indolyl

bis-(indoyl)ethylenes 


\section{Dyes or color formers (examples-continued)}

indolyl red

leucauramines

leucoauramines

leucobenzoyl methylene blue

3-methyl-2,2-spirobi(benzo-[f]-chromene)

phenoxazine

phthalides led by CVL

phthalide red

phthalide violet

phthalide leuco dyes

phthlans

polysryl carbinols and $8^{\prime}$ methoxy

benzoindolinospiropyrans

rhodamine beta lactams

spiropyrans

substituted 4,7-diazaphthalides

para-toluene sulfonate of Michler's hydrol

triarylmethane

triphenylmethanes (gentian violet and

malachite green)

xanthine structure types

\section{Solvents for solubilizing the color formers in the CB coating (examples)}

alkylated diphenyl

alkylbenzenes

alkyldiphenyls

alkyldiphenylethers

alkylnaphthalenes

aromatic ethers (e.g., benzylphenyl ether)

benzyl butyl phthlate

benzylated ethylbenzene

benzylated xylene and other chlorinated or

hydrogenated condensed aromatic

hydrocarbons, paraffin oils or kerosene

and diisopropylnaphthalene

benzyl benzoate

butyl diphenyl (butyl biphenyl)

sec-butylbiphenyls and di-sec-butyl- biphenyls

chlorinated naphthalenes

cotton seed oil

cyclohexane

diallylalkanes

diarylethanes

dibenzyl toluene

dibenzyl ether

dibutyl phthalate

diethylated, di-propylated, or di-butylated biphenyl, biphenyl oxide, or biphenyl methane

diethyl phthalate

diisopropylnaphthalene

di-n-butyl phthalate

dioctyl adipate

dioctyl phthalate

diphenylalkane

ethyldiphenyl methane

hydocarbon oil (e.g., paraffin, kerosene, or odorless [refined] kerosene)

hydrogenated terphenyls

isopropylbiphenyl

linear alkyl benzenes $\left(\mathrm{C}_{10}\right.$ to $\mathrm{C}_{13}$-LABs $)$

Magnaflux oil

mixtures of solvents (e.g., MIPB and

hydrogenated terphenyl)

monochlorobenzene

mono-ethylated, mono-propylated or mono-

butylated biphenyl, biphenyl oxide, or biphenyl methane

naphthalene or terphenyl (e.g., isopropyl,

isobutyl, sec-or tert-butyl)

partially hydrogenated terphenyls

peanut oil

perchloroethylene

petroleum distillate

polyhalogenated paraffin

(e.g., chloroparaffin)

polyhalogenated diphenyl

(e.g., monochlorodiphenyl or trichlorodiphenyl)

Santosol 100 (consists of ethyl-DPMs, benzyl-

ethyl-DPMs, and dibenzyl-ethyl-DPMs)

Santosol 150 (contains dimethyl-DPMs,

benzyl-dimethyl-DPMs, and

dibenzyl-dimethyl-DPMs)

silicone oil

terphenyl

toluene

tricresylphosphate

trichlorobenzene

trichloroethyl phosphate

tricresylphosphate

1,2,4-trimethyl benzene

2,2,4-trimethyl-1,3-pentanediol diisobutyrate xylene

\section{Capsule material}

alcohols (e.g., partially hydrolyzed polyvinyl alcohol or lignosulfonate)

aliphatic diisocyanates dissolved in diiso-

propylnaphthalene, hydrogenated terphenyl, alkylated biphenyl, or diphenyl-alkanes

(such as chloroparaffin) or a mixture of these solvents and diamines

amines (e.g., ethylenediamine, hexamethyl-

enediamine, or triethylenetetramine) and

alcohols (e.g., partially hydrolyzed

polyvinyl alcohol or lignosulfonate)

cyanoacrylate monomers

gelatin

isocyanates

Japan wax, beeswax, paraffin wax,

candelilla wax, rice wax, carnauba wax or

other synthetic waxes and a solvent such

as n-tridecane

melamine-formaldehyde

multifunctional acid chlorides

multifunctional isocyanate

polyamide and polyurethane resins

polyisocyanates and cross-linking agents

(amines)

solvent such as n-tridecane

urea-formaldehyde

\section{Cross-linking agents in the manufacture of capsules}

diethylenetriamine (DETA)

formaldehyde

glutaraldehyde

hexamethylene diisocyanate

\section{Stilt}

aid on $\mathrm{CB}$ in reducing premature microcapsule breakage (e.g., floc, uncooked arrowroot, wheat starch particles, starch, talc) 


\subsection{Brand Names or Trademarks for CCP}

Brand names or trademarks for CCP were obtained from the following sources: Calnan [1979], CHIP [1988], Levy and Hanoa [1982], Olsen and Mørck [1985], Paper Europe [1993], and Dady [1998]. The brand names or trademarks are listed as follows:

\begin{tabular}{ll} 
A-copy & Korofax \\
Action & Lijnco \\
Baron Self Copy & Mitsubishi \\
Biplura & Moore Clean Print (MCP) \\
Carbonless Copy Paper & Nashua \\
Carr's Treform & Nashua Carbonless Paper \\
CCP & NCR Paper \\
CCP Carbonless & NCR Xero/form \\
Copymate & Novo-script Paper \\
Crosley Transcript & Presstype \\
Double EC Copy & Pressure Sensitive Paper \\
Endopapir & Reacto \\
Eurocalco & Readacopy \\
FUJI & Sarrio Carbonless \\
G-copy & Scotchmark Carbonless \\
Giroset & Paper \\
IDEM & Serlacopy \\
Idem Recycled Sheets & Signal \\
Idem Superior CB60 NTC & SM 70 \\
Intus Monoform & Transfer Receptive Paper \\
Jujo & Transform \\
Kanzaki & Zanders \\
K-copy & Zanders Autocopy \\
Kores Direct Copy & \\
\hline
\end{tabular}




\section{Exposure}

\subsection{Introduction}

W orkers may be exposed to $\mathrm{CCP}$ or its components during handling or manufacturing. This chapter summarizes exposures from $\mathrm{CCP}$ handling reported in the literature (Table 3-1). Little consistency exists among these reports: they vary depending on the chemical composition of the CCP, the method of manufacturing during the study period, and the number of forms handled during the industrial hygiene survey. For workers who handle CCP, the most common exposures are to formaldehyde and kerosene or its components. Formaldehyde is used in some microcapsule manufacturing processes as part of the mixture that forms the shell for the microcapsules; it is also used in the manufacture of other paper products such as plain bond paper. Kerosene is one of the principal solvents used to solubilize the precursor dyes contained in the microcapsules.

\subsection{Exposure Data}

\subsubsection{Published Studies}

Some studies listed in this section are described in another section of this review.

Jujo Paper Company, Ltd. 1979. One of the earliest reports with CCP exposure data came from the Jujo Paper Company, Ltd. [1979]. They reported that the maximum concentration of CCP solvent (unspecified) in a finishing room where 100 tons of $\mathrm{CCP}$ were handled each day was $0.3 \mathrm{mg} / \mathrm{m}^{3}$. The company also reported an average CCP solvent retention of
$180 \mu \mathrm{g}$ on the fingers of women who handle, sort, and count 50,000 to 70,000 sheets each day. Blood samples obtained 15 to $16 \mathrm{hr}$ after work revealed no detectable concentrations of the solvent. Further biochemical tests of the blood and urine, skin tests (types unspecified), examinations, and interviews of 135 exposed workers and 84 comparison workers revealed no differences between the two groups. The company indicated that no skin disorders had been reported by any worker since the CCP mill came into operation. No independent survey of worker complaints was performed.

Molhave and Grunnet 1981. In an addendum to the telephone company report by Menné et al. [1981], Mølhave and Grunnet [1981] reported on a headspace analysis (sampling of the gaseous phase of a sample heated to $50{ }^{\circ} \mathrm{C}$ ) of the CCP in use at the time of the study. They used one paper sample received from the factory where the problem was investigated and one sample from the manufacturer of the paper. The authors reported that more than 42 chemicals degassed from the paper samples, and concentrations were seven times greater in the paper from the facility than in those of the manufacturer's sample. About $90 \%$ of the emission was alkanes or alkenes $\left(\mathrm{C}_{5}-\mathrm{C}_{14}\right)$. Another analysis was performed on the Santosol oil content of both CCP samples. The CCP that (according to the authors) caused the original skin problems contained up to 150 times the amount of Santosol oil contained by the manufacturer's sample of CCP. According to the authors, the Santosol oil consists 
Table 3-1. Exposures from CCP handling

\begin{tabular}{|c|c|c|c|}
\hline Reference and country & $\begin{array}{c}\text { Occupation or } \\
\text { exposure scenario }\end{array}$ & Sample type & $\begin{array}{c}\text { Airborne } \\
\text { concentration }\end{array}$ \\
\hline $\begin{array}{l}\text { Jujo Paper Company, Ltd. } \\
\text { [1979], Japan }\end{array}$ & Paper finishing & CCP solvent (unspecified) & $0.3 \mathrm{mg} / \mathrm{m}^{3}$ \\
\hline $\begin{array}{l}\text { Mølhave and Grunnet } \\
\text { [1981], Denmark }\end{array}$ & $\begin{array}{l}\text { Experimental } \\
\text { laboratory conditions }\end{array}$ & $\begin{array}{l}\text { Alkanes or alkenes }\left(\mathrm{C}_{5}-\mathrm{C}_{14}\right) \\
\text { Santosol }\end{array}$ & Levels not reported \\
\hline $\begin{array}{l}\text { Göthe et al. [1981] and } \\
\text { Norbäck et al. [1983b], } \\
\text { Sweden }\end{array}$ & Printing offices & $\begin{array}{l}\text { Kerosene } \\
\text { MIPB } \\
\text { Diarylethane } \\
\text { Hydrogenated terphenyl and } \\
\text { diisopropylnaphthalene }\end{array}$ & $\begin{array}{l}7.0 \mathrm{mg} / \mathrm{m}^{3} \\
0.2 \mathrm{mg} / \mathrm{m}^{3} \\
0.2 \mathrm{mg} / \mathrm{m}^{3} \\
<0.01 \mathrm{mg} / \mathrm{m}^{3}\end{array}$ \\
\hline & Ordinary offices & $\begin{array}{l}\text { Kerosene } \\
\text { MIPB } \\
\text { Diarylethane } \\
\text { Hydrogenated terphenyl and } \\
\text { diisopropylnaphthalene }\end{array}$ & $\begin{array}{l}0.7 \mathrm{mg} / \mathrm{m}^{3} \\
0.2 \mathrm{mg} / \mathrm{m}^{3} \\
0.02 \mathrm{mg} / \mathrm{m}^{3} \\
<0.01 \mathrm{mg} / \mathrm{m}^{3}\end{array}$ \\
\hline $\begin{array}{l}\text { Gockel et al. [1981], } \\
\text { United States }\end{array}$ & Office workers & Formaldehyde & $<0.51 \mathrm{ppm}$ \\
\hline $\begin{array}{l}\text { Chrostek and Moshell } \\
\text { [1982], United States }\end{array}$ & Telephone workers & $\begin{array}{l}\text { Total dust } \\
\text { Formaldehyde } \\
\text { Glove analyses: } \\
\text { Dibutyl phthalate } \\
\text { Diethyl phthalate } \\
\text { Dioctyl adipate }\end{array}$ & $\begin{array}{l}0.06-0.2 \mathrm{mg} / \mathrm{m}^{3} \\
0.22 \mathrm{mg} / \mathrm{m}^{3^{\dagger}} \\
\text { Detected } \\
\text { Detected } \\
\text { Detected }\end{array}$ \\
\hline $\begin{array}{l}\text { Norbäck [1983b], } \\
\text { Sweden }\end{array}$ & $\begin{array}{l}\text { Experimental } \\
\text { laboratory conditions }\end{array}$ & $\begin{array}{l}\text { Kerosene } \\
\text { MIPB } \\
\text { Formaldehyde }\end{array}$ & $\begin{array}{l}0.35-15.5 \mathrm{mg} / \mathrm{m}^{2} \\
\text { per } \mathrm{hr} \\
0.33-0.54 \mathrm{mg} / \mathrm{m}^{2} \\
\text { per } \mathrm{hr} \\
0.1-0.3 \mathrm{mg} / \mathrm{m}^{3}\end{array}$ \\
\hline $\begin{array}{l}\text { Norbäck and Göthe } \\
\text { [1983], Sweden }\end{array}$ & Offices and print shops & $\begin{array}{l}\text { Total dust } \\
\text { Kerosene } \\
\text { MIBP } \\
\text { Diarylethane } \\
\text { Hydrogenated terphenyls }\end{array}$ & $\begin{array}{l}0.02-0.05 \mathrm{mg} / \mathrm{m}^{3} \\
0.7-0.81 \mathrm{mg} / \mathrm{m}^{3} \\
0.06 \mathrm{mg} / \mathrm{m}^{3} \\
0.03 \mathrm{mg} / \mathrm{m}^{3} \\
<0.01 \mathrm{mg} / \mathrm{m}^{3}\end{array}$ \\
\hline $\begin{array}{c}\text { Winfield [1983], } \\
\text { United States }\end{array}$ & Purchasing office & Formaldehyde & $\mathrm{ND}-0.04 \mathrm{ppm}$ \\
\hline
\end{tabular}


Table 3-1 (Continued). Exposures from CCP handling

\begin{tabular}{|c|c|c|c|}
\hline Reference and country & $\begin{array}{c}\text { Occupation or } \\
\text { exposure scenario }\end{array}$ & Sample type & $\begin{array}{c}\text { Airborne } \\
\text { concentration }\end{array}$ \\
\hline $\begin{array}{l}\text { Hazelton Laboratories } \\
\text { [1985], United States }\end{array}$ & $\begin{array}{l}\text { Experimental } \\
\text { laboratory conditions }\end{array}$ & Formaldehyde & $\begin{array}{l}0.033 \mathrm{ppm} \text { for } \\
\text { marking and } \\
\text { separating } 30 \\
\text { 4-ply forms } / \mathrm{hr} \\
\text { for } 8 \mathrm{hr}\end{array}$ \\
\hline $\begin{array}{l}\text { Olsen and Mørck [1985], } \\
\text { Denmark }\end{array}$ & Office workers & $\begin{array}{l}\text { Total dust } \\
\text { Kerosene } \\
\text { Hydrogenated terphenyls }\end{array}$ & $\begin{array}{l}0.11-0.21 \mathrm{mg} / \mathrm{m}^{3} \\
1.9 \mathrm{mg} / \mathrm{m}^{3} \\
\mathrm{ND}\end{array}$ \\
\hline $\begin{array}{l}\text { Apol and Thoburn } \\
\text { [1986], United States }\end{array}$ & $\mathrm{CCP}$ production & $\begin{array}{l}\text { HMDI } \\
\text { DETA } \\
\text { Phenol } \\
\text { Formaldehyde } \\
\text { Biphenyl } \\
\text { Butyl biphenyl } \\
\text { Petroleum solvents } \\
\text { Total particulate }\end{array}$ & $\begin{array}{l}<0.7-14.0 \mu \mathrm{g} / \mathrm{m}^{3} \\
<0.01-<0.35 \mathrm{ppm} \\
<0.02-0.15 \mathrm{ppm} \\
\mathrm{ND}^{\ddagger} \\
0.003-<0.02 \mathrm{ppm} \\
0.12-0.29 \mathrm{ppm} \\
0.7-12 \mathrm{mg} / \mathrm{m}^{3} \\
2.70 \mathrm{mg} / \mathrm{m}^{3}\end{array}$ \\
\hline $\begin{array}{l}\text { Chovil et al. [1986], } \\
\text { United States }\end{array}$ & University office & Formaldehyde & $0.015-0.022 \mathrm{ppm}$ \\
\hline $\begin{array}{l}\text { Burton and Malkin } \\
\text { [1993], United States }\end{array}$ & Printing shop & $\begin{array}{l}\text { Isopropanol } \\
\text { Isobutanol } \\
\text { 1,1,1-trichloroethane } \\
\text { Toluene } \\
\text { Beryllium, calcium, copper, } \\
\text { iron, magnesium, and zinc }\end{array}$ & $\begin{array}{l}53-132 \mathrm{ppm} \\
0.15-0.91 \mathrm{ppm} \\
0.11-0.23 \mathrm{ppm} \\
1.09-5.03 \mathrm{ppm} \\
0.02-1.05 \mu \mathrm{g} / \mathrm{m}^{3}\end{array}$ \\
\hline $\begin{array}{l}\text { Omland et al. [1993], } \\
\text { Denmark }\end{array}$ & Office workers & $\begin{array}{l}\text { Formaldeyde } \\
\text { Total dust }\end{array}$ & $\begin{array}{l}0.1-0.62 \mathrm{mg} / \mathrm{m}^{3} \\
0.28-0.34 \mathrm{mg} / \mathrm{m}^{3}\end{array}$ \\
\hline $\begin{array}{l}\text { Zimmer and Hadwen } \\
\text { [1993], United States }\end{array}$ & $\begin{array}{l}\text { Federal records storage } \\
\text { center }\end{array}$ & $\begin{array}{l}\text { Acetic acid } \\
\text { Cyclohexene } \\
\text { Formaldehyde }\end{array}$ & $\begin{array}{l}<25 \mathrm{mg} / \mathrm{m}^{3}(\mathrm{REL}) \\
<1,050 \mathrm{mg} / \mathrm{m}^{3} \\
\quad(\mathrm{REL}) \\
0.023-0.034 \mathrm{mg} / \mathrm{m}^{3}\end{array}$ \\
\hline $\begin{array}{l}\text { Thompson [1996], } \\
\text { United States }\end{array}$ & Office workers & $\begin{array}{l}\text { Decane } \\
\text { Undecane } \\
\text { Dodecane } \\
\text { meta-, para-Xylene } \\
\text { ortho-Xylene } \\
\text { Toluene } \\
\text { Ethyl benzene }\end{array}$ & $\begin{array}{l}1.0-1.1 \mathrm{ppb} \\
0.3 \mathrm{ppb} \\
0.6 \mathrm{ppb} \\
0.6-1.2 \mathrm{ppb} \\
0.2-0.4 \mathrm{ppb} \\
0.5-1.3 \mathrm{ppb} \\
0.3-0.5 \mathrm{ppb}\end{array}$ \\
\hline
\end{tabular}

*Abbreviations: DETA=diethylene diamine tetraacetic acid; HMDI=hexamethylene diisocyanate; MIPB=monoisopropyl biphenyl; $\mathrm{ND}=$ none detected; REL=NIOSH recommended exposure limit.

${ }^{\dagger}$ Attributed to cigarette smoking.

${ }^{\ddagger}$ Limits of detection varied from 0.04 to $0.08 \mathrm{ppm}$. 
mainly of hydrogenated terphenyl, which is known to produce eye, skin, and respiratory irritation and possibly sensitization in experimental animals [Haley et al. 1959]. At the telephone company that reported the problem, workers exposed to CCP dust and vapors emitted from the paper experienced marked irritation at air concentrations exceeding $10 \mathrm{mg} / \mathrm{m}^{3}$ (data not given). Mølhave and Grunnet [1981] believe that the terphenyls act as primary irritants, particularly when workers are wearing protective gloves that trap moisture and exposures next to the skin.

Göthe et al. 1981 and Norbäck et al. 1983b. Göthe et al. [1981] and Norbäck et al. [1983b] reported on an investigation of climatic and airborne concentrations of microcapsule solvents found in printing offices and ordinary offices that used the same type of CCP. The authors noted that very few complaints were related to $\mathrm{CCP}$ in the printing offices compared with ordinary offices. Temperature and relative humidity were, on the average, about the same in the two environments. The highest concentrations of microcapsule solvents were observed in the printing offices (Table 3-1). This finding suggests that no simple correlation exists between solvent vapor concentrations and the occurrence of complaints; or it may indicate that skin contact is the important factor.

Gockel et al. 1981. Gockel et al. [1981] reported on formaldehyde released to the air from CCP forms that were suspected of causing eye, skin, and respiratory irritation among office workers. Water extraction of $\mathrm{CB}$ white sheets of CCP yielded 0.18 to $1.89 \mathrm{mg}$ formaldehyde per $8.5-\times 11$-in. top sheet of CCP. The authors felt that water extraction might have enhanced the formaldehyde concentrations, so

\footnotetext{
*This description differs from other descriptions of Santosol components, which do not refer to terphenyls but to diphenylmethanes.
}

they adopted a sampling procedure that collected the formaldehyde released into $15 \mathrm{~L}$ of air (1 L/min for $15 \mathrm{~min}$ ). Formaldehyde concentrations ranged from 33.6 to $858 \mu \mathrm{g} / \mathrm{kg}$ of forms sampled and from 0.02 to $0.96 \mathrm{ppm}$ in the 15-L air samples using 8 different CCP forms. A modification of the procedure ensured adequate air flow past all parts of each form in the sampling apparatus. Standardized testing of four sheets of equivalent area for each type of five different forms resulted in formaldehyde concentrations ranging from 0.45 to $16.8 \mu \mathrm{g} / \mathrm{kg}$, demonstrating a 37 -fold difference in formaldehyde emissions. The authors demonstrated that these air sample analyses using a standardized testing area produced results that varied by a factor of 0.83 to 1.42 compared with sampling of a full form. The authors also provided evidence that the residual formaldehyde is dissipated into the air as a result of handling and storage. Air concentrations of formaldehyde were as high as $0.51 \mathrm{ppm}$ in filing cabinet drawers where the forms had been separated and stored for more than 6 months.

Chrostek and Moshell 1982. See Section 4.2.1 for a description of this study.

Norbäck 1983b. Norbäck [1983b] studied the chemical emissions from entirely unused paper and from paper in which approximately $1 \%$ of the microcapsules had been crushed by standard writing. Most of the CCPs studied were handled by workers who had experienced work-related respiratory irritation symptoms when handling CCP. In light of the observed emissions of formaldehyde from CCP over time [Gockel et al. 1981], the 1- to 2-year-old paper was replaced with fresh CCPs of various types collected from three different printing shops. Most measurements were performed at an ambient temperature of $22{ }^{\circ} \mathrm{C}$ and $20 \%$ to $30 \%$ relative humidity. Several tests were also performed at $27{ }^{\circ} \mathrm{C}$. CCP was cut, weighed, and measured for surface 
area. It was then placed into wash bottles (0.25-L), and air was passed through them at the rate of $0.1 \mathrm{~L} / \mathrm{min}$. Charcoal (for solvent analysis) or Amberlite XAD (coated with 2,4-dinitrophenyl hydrazine for aldehyde analyses) was used to collect the emissions for 30 to $60 \mathrm{~min}$. Solvent concentrations were measured using gas chromatography (GC), and aldehyde analyses were performed with liquid chromatography. The relative solvent emissions calculated were based on measurement times, surface area, and amounts of solvent/aldehyde released. Mann-Whitney's rank sum test was used for testing the statistical significance of paired t-values. Norbäck [1983b] found small but measurable amounts of formaldehyde $\left(0.1\right.$ to $0.3 \mathrm{mg} / \mathrm{m}^{3}$; detection level $=0.3 \mathrm{mg} / \mathrm{kg}$ per hr) in 3 of 4 fresh CCP samples. No glutaraldehyde was detected (detection level=0.1 mg/kg per hr). No aldehyde emissions were detected from any of the papers that were 1 to 2 years old. One week after the microcapsules had been crushed, four of the five solvents studied were still being released in measurable quantities, including monoisopropyl biphenyl (MIPB), kerosene, phenylxylylethane, and diisopropylbiphenylbut not hydrogenated terphenyl. The kerosene emissions ranged from 5 to $60 \mathrm{mg} / \mathrm{m}^{3}$, with the two CCP samples not linked to work-related respiratory tract symptoms yielding the lowest kerosene emissions. On the basis of this observation, the author tested three different groups of kerosene-containing $\mathrm{CCP}$, some of which had observed links with work-related respiratory tract symptoms. He demonstrated in this study that no links existed between mucous membrane symptoms and kerosene emissions. He also showed that there were no statistically demonstrable trends toward a link between work-related respiratory tract symptoms and high kerosene emissions - even where all CCPs associated with respiratory symptoms were combined, and regardless of the solvent content. This difference was attributed to the difference in encapsulation processes (MIPB used "polymer," and hydrogenated terphenyl used gelatin). The author noted that the kerosene concentrations in the wash bottles were 10 to 100 times higher than those measured in the breathing zones of workers involved in intensive manual handling of CCP. The author also concluded that aldehyde emissions from CCP were not likely to explain the irritative mucous membrane symptoms among workers who handle such paper. Table 3-2 demonstrates how writing on CCP (and thereby crushing the microcapsules) affects the solvent emissions from the paper.

Norbäck and Göthe 1983. In a Swedish study, Norbäck and Göthe [1983] collected personal and area samples in Stockholm at 11 offices where large quantities of CCP were handled and at five printing shops where form (manifold) sets of CCP were produced. The measurements were made from January 1980 to November 1981, mainly during the winter half of the year (the period in which problems

Table 3-2. Solvent emissions from CCP with intact microcapules and $1 \%$ crushed microcapsules $\left(\mathrm{mg} / \mathrm{m}^{2}\right.$ per hour)

\begin{tabular}{lcc}
\hline CCP form treatment & Kerosene emissions & MIPB emissions \\
\hline Unused & 0.35 & 0.33 \\
Crushed (fresh writing) & 15.5 & 0.54 \\
Week-old writing & 3.7 & 0.24 \\
\hline
\end{tabular}

Source: Norbäck [1983b]. 
were reported). Workers from 10 of the offices studied had been referred to the clinic of Occupational Medicine at Southern Hospital because of health problems associated with handling CCP. The authors measured ambient temperatures, relative humidities, and ventilation efficiencies. As a measure of the chemical emissions from CCP, airborne concentrations of the solvents from microcapsules were analyzed using activated charcoal tubes. The carbon-disulfide-desorbed solvents were analyzed by GC, and detection limits varied between 0.001 and $0.02 \mathrm{mg} / \mathrm{m}^{3}$.

Airborne concentrations of total dust, dust-bound solvent, solvent in the vapor phase, and formaldehyde were also determined in a laboratory situation using a $34-\mathrm{m}^{3}$ room with an air-exchange rate of $0.8 \mathrm{times} / \mathrm{hr}$. Thirty sheets of each type of paper were handled in a standardized procedure for $60 \mathrm{~min}$. Table 3-3 shows that airborne solvent concentrations are generally low, and they are considerably lower in the office environment than in the printing shop. Area samples were also consistently lower than personal samples, suggesting that manual handling generates airborne solvent. For example, kerosene (which is relatively volatile) had the highest airborne concentrations, whereas the hydrogenated terphenyls (whose volatility is low) produced unmeasurable concentrations. The data indicate that various paper types generated similar concentrations of dust during standardized paper handling in the laboratory.

The airborne formaldehyde concentrations were below the limit of detection $\left(<0.05 \mathrm{mg} / \mathrm{m}^{3}\right)$. This finding does not support formaldehyde as the cause of the health effects. The particle-bound solvents were also consistently below the detection limit $\left(<0.0002 \mathrm{mg} / \mathrm{m}^{3}\right)$, which corresponds to a dust solvent content of less than $1 \%$ by weight. Norbäck and Göthe [1983] concluded that no obvious climatic differences were evident between the two environments, even though health problems occurred in the offices and not in the printing shops. The author observed that these health problems occur in offices with both high and low levels of

Table 3-3. Airborne concentrations of total dust and solvents produced with standardized paper handling in the laboratory $\left(\mathrm{mg} / \mathrm{m}^{3}\right)$

\begin{tabular}{lccccc}
\hline & & \multicolumn{4}{c}{ Solvent } \\
\cline { 3 - 5 } \multicolumn{1}{c}{ Paper type } & Total dust & Kerosene & MIBP & Diarylethane & $\begin{array}{c}\text { Hydrated } \\
\text { terphenyl }\end{array}$ \\
\hline $\begin{array}{l}\text { Paper containing MIBP } \\
+ \text { kerosene }\end{array}$ & 0.05 & 0.81 & 0.06 & $-{ }^{*}$ & - \\
$\begin{array}{l}\text { Paper containing } \\
\text { diarylethane }\end{array}$ & 0.02 & - & - & 0.03 & - \\
$\begin{array}{l}\text { Paper containing } \\
\text { hydrogenated terphenyl } \\
+ \text { kerosene }\end{array}$ & 0.05 & 0.70 & - & - & $<0.01$ \\
$\begin{array}{l}\text { Ordinary paper } \\
\text { Control-without paper }\end{array}$ & 0.02 & - & - & - & - \\
\hline
\end{tabular}

Source: Norbäck and Göthe [1983].

"Dash indicates that no measurement was performed. 
ventilation. The solvent concentrations were relatively higher in printing shops than in offices, but the number of health problems in the printing shops was low. The authors cited a study by Hasegawa et al. [1973] that found a diisopropylnaphthalene concentration of $0.3 \mathrm{mg} / \mathrm{m}^{3}$ in the air at a sorting department in which each worker daily handled 50,000 to $70,000 \mathrm{CCP}$ sheets containing the solvent. They also cited an unpublished report by Dodds [1980] who found hydrated terphenyl concentrations in the ppb range during the production of microcapsules containing color former dissolved in hydrogenated terphenyls. Norbäck and Göthe [1983] conclude that the measured dust concentrations did not contain solvents in sufficient quantity to be associated with primary irritation. This study is unclear as to whether encapsulated CCP solvent attached to airborne fibers is extractable by carbon disulfide and is thus included in measurements of dust-bound solvent. This study did not consider the effect of high local concentrations of solvent on the epidermis when a microcapsule fractures. Also unresolved are the relative skin exposures for workers in offices and printing plants. Although printing plant workers process a far greater tonnage of paper than office workers, its not clear whether printing plant workers have more or even as much skin contact as CCP users in offices.

Olsen and Morck 1985. Olsen and Mørck [1985] extensively studied a brand of CCP that was dominant in the Scandinavian countries at that time. They performed gas chromatography/mass spectrometry (GC/MS) analysis, finger analysis of the residual CCP components on the skin, analysis of keyboard surfaces of computers and typewriters, microbiological analysis of the microcapsules, analysis of the mucous membranes of the nose, electron microscope studies of the skin using tape before and after handling $\mathrm{CCP}$, dust measurements, and headspace analysis of CCP emissions. The authors found that hydrogenated terphenyls are transferred to the skin $(120 \mu \mathrm{g}$ per sorting finger) along with their impurities of bi-, tetra-, and pentaphenyls, but they did not find kerosene in detectable amounts owing to its volatile nature. The ratio of hydrogenated terphenyls to kerosene in the microcapsules was $1: 3$; but after rupture, analysis of the $\mathrm{CF}$ layer revealed that more than half of the kerosene had evaporated. Analysis of exposed workers' mucous membrane secretions failed to reveal any CCP components. Headspace analysis demonstrated that kerosene evaporated from the CCP without mechanical rupture of the microcapsules (value not given). The amount evaporating increased after rupture (the highest concentration found in room air was $1.9 \mathrm{mg} / \mathrm{m}^{3}$ [0.3 ppm]), but hydrogenated terphenyls were not released into the air as vapor. Analysis of keyboards revealed concentrations of hydrogenated terphenyls and transfer of this compound to telephones, table tops, etc. in the office. Measurements of total dust ranged from 0.11 to $0.21 \mathrm{mg} / \mathrm{m}^{3}$, and no chemical components of the CCP were associated with it. No growth of fungi or bacteria resulted from the incubation of microcapsules, but one base paper sample (not CCP) supported the growth of actinomycetes at $50{ }^{\circ} \mathrm{C}$. Electron microscopy did not show transfer of the clay/kaolin components to the hands after $3 \mathrm{hr}$ of handling CCP.

Apol and Thoburn 1986, Chovil et al. 1986, and Burton and Malkin 1993. See Section 4.2.1 for a discussion of these studies.

Omland et al. 1993. See Section 4.2.3.2 for a discussion of this study.

Zimmer and Hadwen 1993. In response to a request from the management of the Federal Records Center in Dayton, Ohio, Zimmer and Hadwen [1993] investigated six worker complaints of an overpowering, irritating odor in the archives area where Federal tax records and $\mathrm{X}$-ray films were stored. Acetic acid was the 
apparent source. Concentrations of acetic acid and cyclohexane were below the NIOSH RELs of 25 and $1,050 \mathrm{mg} / \mathrm{m}^{3}$, respectively. Formaldehyde concentrations were $0.023,0.024$, and exceeding the NIOSH REL of $0.02 \mathrm{mg} / \mathrm{m}^{3}$. The most likely source of the formaldehyde was the $\mathrm{CCP}$ records located throughout the center.

Thompson 1996. Thompson [1996] reported measurements of indoor air quality in an unpublished U.S. study of 75 workers who continuously handled $\mathrm{CCP}$ in the finance and accounting building of a university. This building had a history of indoor air quality problems and medical complaints from workers dating from 1992. The relative humidity, temperature, and mold and fungus counts were within the American Society of Heating, Refrigerating, and Air-Conditioning (ASHRAE) limits of $40 \%$ to $60 \%$ relative humidity, 74 to $78{ }^{\circ} \mathrm{F}$ temperature, and low indoor spore counts (relative to outside counts for mold and fungus) [ASHRAE 1981]. The carbon dioxide concentration was $1,000 \mathrm{ppm}$, which exceeded the
ASHRAE standard [ASHRAE 1989]. Corrective actions to the ventilation system included repair of the heating, ventilating, and air-conditioning system, increased outside fresh air supply, earlier air-handling startup times, and increased air circulation (which decreased carbon dioxide concentrations to 400 to $700 \mathrm{ppm}$ ).

Area air samples were collected in two locations of the CCP building and compared with an air sample from another building that had 60 occupants, no history of medical complaints, and minimal use of CCP. GC/MS standards were prepared from the CCP forms (all three sheets, top sheets alone, and bottom sheets alone) and a sample of SurSol 290 (a solvent carrier for dyes used in the production of the microcapsules). Table 3-4 lists the concentrations of chemicals found in these samples. The sample from the comparison building showed concentrations that were about three orders of magnitude less than those found in the CCP building. Of the chemicals for which

\section{Table 3-4. GC/MS analysis of CCP samples, SurSol 290 solvent, and area air samples (ppb)}

\begin{tabular}{|c|c|c|c|c|c|c|c|}
\hline \multirow[b]{3}{*}{$\begin{array}{l}\text { Chemical } \\
\text { measured }\end{array}$} & \multirow{2}{*}{\multicolumn{3}{|c|}{ CCP samples }} & \multirow[b]{3}{*}{$\begin{array}{c}\text { SurSol } 290 \\
\text { solvent }\end{array}$} & \multicolumn{3}{|c|}{ Area air samples } \\
\hline & & & & & \multicolumn{2}{|c|}{ CCP building } & \multirow[b]{2}{*}{$\begin{array}{c}\text { Comparison } \\
\text { building }\end{array}$} \\
\hline & $\begin{array}{l}\text { Top } \\
\text { sheet }\end{array}$ & $\begin{array}{c}\text { Bottom } \\
\text { sheet }\end{array}$ & $\begin{array}{l}\text { Three } \\
\text { sheets }\end{array}$ & & Sample 1 & Sample 2 & \\
\hline Decane & 13.2 & 0.001 & 7.9 & - & 1.0 & 1.1 & 0 \\
\hline Undecane & 0.02 & $<0.001$ & 12.7 & - & 0.3 & 0.3 & 0.004 \\
\hline Dodecane & 2.6 & $<0.001$ & 4.8 & 0.027 & 0.6 & 0.6 & 0.006 \\
\hline $\begin{array}{l}\text { meta-, para- } \\
\text { Xylene }\end{array}$ & 0.1 & 0 & 0 & 6.2 & 1.2 & 0.6 & 0 \\
\hline ortho-Xylene & 0.0 & 0 & 0 & - & 0.4 & 0.2 & 0 \\
\hline Toluene & 2.9 & 0.3 & 0.1 & - & 1.3 & 0.5 & $<0.001$ \\
\hline Ethyl benzene & 0.4 & 0 & 0 & 8.9 & 0.5 & 0.3 & 0 \\
\hline
\end{tabular}


occupational safety and health standards exist, the concentrations were four to six orders of magnitude lower than the standards.

\subsubsection{NIOSH Docket Submissions}

\subsubsection{Winfield 1983}

Winfield [1983] performed an industrial hygiene survey in a purchasing office at the University of Texas in response to worker complaints of headaches, skin eruptions, upper airways irritation, and other symptoms. The number of workers who reported symptoms was not given, but the report stated that the incidence of symptoms was higher among the 22 employed in the purchasing section than in the 16 employed in the vouchers section. Several former employees reported that their symptoms ceased when they terminated employment. Formaldehyde was measured inside a closed cabinet containing CCP forms, and the level was found to be just above the limit of detection. Other measurements were obtained for hydrocarbons linked to toner solvent from a copy machine and for chlorinated solvents linked with correction fluid, waxes, glues, etc. Interviews were conducted at four other offices where workers handled CCP forms. Workers reported no symptoms in the press office, where forms were handled for printing and gluing. In the personnel office, where forms were handled but not typed on, one worker reported transient skin irritation. Two of four workers in the mail and supply office reported skin irritation. In the central receiving office, two workers complained of odor and headaches when using continuous-roll copy paper; however, the report did not note whether this paper was CCP. Alterations in the air-handling system (which were engineered to exceed the minimum rate for office spaces) did not reduce the reported symptoms. The author stated that the reported symptoms were probably caused by CCP based on the available scientific literature, but she offered no definitive scientific evidence in support of this conclusion.
Recommendations from the available literature were suggested to improve the comfort and health of the workers, but no followup survey was reported.

\subsubsection{Hazelton Laboratories 1985}

A NIOSH docket submission by Hazelton Laboratories [1985] (Final Report, March 11, 1985: A Study to Determine the Potential Emanation of Formaldehyde Vapor from Carbonless Copy Paper) describes an investigation performed for a member of the U.S. CCP industry to determine the potential emanation of formaldehyde vapor from CCP.

The experiments were performed in a glove box to measure the following: (1) the maximum formaldehyde air concentration (collected with impinger and measured using NIOSH Method 125 [NIOSH 1994]) produced by a set number of sheets of CCP and (2) the effects of marking and separating four-ply CCP forms on the emission of formaldehyde. The experiments also evaluated the effects of ventilation on the formaldehyde concentrations from various types of CCP. The formaldehyde concentration in the glove box ranged from 0 to $0.7 \mathrm{ppm}$ for the $\mathrm{CF}$ and the "self-contained black" paper, respectively. Those products containing black ink produced substantially higher formaldehyde concentrations than those containing blue ink. A model was developed from the kinetic experiments to predict air concentrations of formaldehyde attributable to handling CCP in the office environment.

Product test methods. An aluminum pouch containing the papers was placed in the $285-\mathrm{L}$ chamber for testing. Table $3-5$ presents the data for turning 2 or 6 sheets/min using a varying number of total sheets turned. Chamber concentration of formaldehyde increased as 
Table 3-5. Formaldehyde concentration after repeated turning of CCP sheets in a test chamber*

\begin{tabular}{cc}
\hline $\begin{array}{c}\text { Rate of turning and total number } \\
\text { of sheets in chamber }\end{array}$ & $\begin{array}{c}\text { Average formaldehyde concentration } \\
\text { (ppm) }\end{array}$ \\
\hline 2 sheets/min: & \\
& \\
24 & 0.089 \\
48 & 0.165 \\
72 & 0.171 \\
6 sheets/min: & \\
72 & \\
144 & 0.081 \\
216 & 0.102 \\
288 & 0.212 \\
\hline
\end{tabular}

Adapted from Hazelton Laboratories [1985].

"The indicated number of sheets placed in the chamber, turned at the stated rate, and repackaged. Air samples were then collected from the chamber.

the number of exposed sheets increased. Another test (Table 3-6) was performed to determine whether the rate of turning would affect the final concentration of formaldehyde in the test chamber immediately after turning and 60 and 90 min after turning. When measured immediately after turning, concentrations decreased as the turning rate increased. But concentrations varied little when measured 60 and 90 min after the tests. This result indicates that the rate-limiting factor for total formaldehyde released from CCP is the amount of time spent equilibrating with the environment.

The final test method evaluated was an emission rate study. In this study, 120 sheets of paper were placed in the chamber and turned at a rate of 4 sheets/min. Short-interval sampling began with the initiation of the page turning and continued for $90 \mathrm{~min}$ (Table 3-7). The chamber air achieved a constant formaldehyde concentration in less than $30 \mathrm{~min}$. The initial rate of formaldehyde release was $0.098 \mu \mathrm{g} /$ sheet per min. This rate was calculated from the first sample by considering the $0.310-\mu \mathrm{g} / \mathrm{L}$ concentration as the midpoint concentration between $0 \mu \mathrm{g} / \mathrm{L}$ and equilibrium, and by assuming an approximately linear increase in the airborne concentration of formaldehyde over the 15-min sampling period.

Product testing. Three replicate sets of eight types of CCP were tested by placing 60 sheets of CCP in the chamber and turning them at a rate of 4 sheets/min. They remained stacked in the chamber for $15 \mathrm{~min}$ and were then returned to the foil packages for the duration of the air sampling, which was conducted for $20 \mathrm{~min}$ at a rate of approximately $0.5 \mathrm{~L} / \mathrm{min}$. The airborne concentrations of formaldehyde in the test chamber averaged from 0.009 to $0.693 \mathrm{ppm}$ (Table 3-8). Little formaldehyde would be expected from the CF since it contains no microcapsules. All types of the $\mathrm{CB}$ and $\mathrm{CFB}$ with black ink produced higher average formaldehyde concentrations than did the blue ink counterpart. The self-contained samples yielded the highest formaldehyde 
Table 3-6. Formaldehyde concentrations in the test chamber at various points after turning (total of 60 sheets for each condition)

\begin{tabular}{cccc}
\hline & \multicolumn{3}{c}{ Average formaldehyde concentration (ppm) } \\
\cline { 2 - 4 } $\begin{array}{c}\text { Turning rate } \\
\text { (sheets/min) }\end{array}$ & $\begin{array}{c}\text { Immediately } \\
\text { after turning }^{\dagger}\end{array}$ & $\begin{array}{c}\mathbf{6 0} \text { min } \\
\text { after turning }\end{array}$ & $\begin{array}{c}\mathbf{9 0} \text { min } \\
\text { after turning }\end{array}$ \\
\hline 6 & 0.150 & 0.307 & 0.456 \\
5 & 0.184 & 0.318 & - \\
4 & 0.210 & 0.308 & 0.387 \\
3 & 0.316 & 0.318 & 0.386 \\
2 & 0.334 & 0.367 & 0.429 \\
0 & - & 0.260 & 0.427 \\
\hline
\end{tabular}

Adapted from Hazelton Laboratories [1985].

* Sixty sheets were placed in the chamber and turned at the indicated rate.

${ }^{\dagger}$ After turning was completed, the sheets were repackaged in the foil pouch and an air sample was collected.

$\ddagger$ Sixty minutes from the start of the turning, the sheets were repackaged in the foil pouch and an air sample was collected.

${ }^{\S}$ Ninety minutes from the start of the turning, the sheets were repackaged in the foil pouch and an air sample was collected.

Table 3-7. Formaldehyde concentrations in the test chamber during a 90-min period"

\begin{tabular}{lc}
\hline $\begin{array}{c}\text { Sampling interval } \\
\text { (min) }\end{array}$ & $\begin{array}{c}\text { Formaldehyde concentration } \\
(\mathbf{p p m})\end{array}$ \\
\hline $0-15$ & 0.252 \\
$7.5-22.5$ & 0.317 \\
$20.8-30.5$ & 0.413 \\
$24-39.5$ & 0.454 \\
$32-46$ & 0.420 \\
$41-56.5$ & 0.456 \\
$48.5-64$ & 0.406 \\
$60.5-75$ & 0.479 \\
$66-84.5$ & 0.415 \\
$76.5-91$ & 0.441 \\
\hline
\end{tabular}

Adapted from Hazelton Laboratories [1985].

* One hundred twenty sheets were placed in the chamber and turned at 4 sheets $/ \mathrm{min}$. Air sampling began when turning began and continued for 60 min after turning was completed. 
Table 3-8. Formaldehyde concentrations in a test chamber containing eight CCP products*

\begin{tabular}{lc}
\hline Product & $\begin{array}{c}\text { Average formaldehyde concentration } \\
\text { for 3 replicates (ppm) }\end{array}$ \\
\hline CF & 0.009 \\
CFB-blue & 0.108 \\
CFB-black & 0.209 \\
CB-blue & 0.258 \\
CB-black & 0.291 \\
SC'-blue & 0.355 \\
SC-black & 0.693 \\
Four-part form & 0.178 \\
\hline
\end{tabular}

Adapted from Hazelton Laboratories [1985].

${ }^{*}$ Sixty sheets were placed in the chamber, turned at the rate of 4 sheets/min, and left stacked for $15 \mathrm{~min}$ before they were repackaged in aluminum foil pouches. Air samples were then collected.

${ }^{\dagger} \mathrm{SC}=$ self-contained.

${ }^{\ddagger}$ The four-part form consisted of a CB sheet, two CBF sheets, and a CF sheet.

concentrations. The study director stated that the total formaldehyde release for the four-part form could be predicted from the sum of its parts.

Office activities. Experiments were performed to examine the effects of office activities on formaldehyde emissions from CCP. Four-ply CCP forms were manipulated by marking, separating marked forms, and separating unmarked forms.

- Marking forms: Four-ply forms were used to examine the effects of marking on the emission of formaldehyde vapor. Thirty forms (120 sheets) were placed inside the chamber for each test. A template was used to achieve consistent pencil lines. The desired rate of marking was 40 lines/minute, 20 lines/form, repeated four times throughout the 1-hr sampling period. This rate was achieved on the second test; the first test averaged a rate of approximately 28.7 lines/min. The sampling flow rate was approximately $0.5 \mathrm{~L} / \mathrm{min}$. The maximum average formaldehyde concentration for two replicates was $0.402 \mathrm{ppm}$ after $1 \mathrm{hr}$.

- Marking and separating forms: Four-ply forms were used to examine the effects of marking and separating pages on the emission of formaldehyde vapor. Thirty forms (120 sheets) were placed inside the chamber for each test and a template was used to achieve consistent pencil lines. Each form was marked with 20 lines and separated in $1 \mathrm{~min}$. After the 30-min marking and separating period, the forms were left exposed in the chamber the rest of the 1-hr sampling process.

The sampling rate was approximately $0.5 \mathrm{~L} / \mathrm{min}$. The maximum average formaldehyde concentration for 2 replicates was $0.402 \mathrm{ppm}$ after $1 \mathrm{hr}$.

- Separating unmarked forms: Four-ply forms were used to examine the effects of separating unmarked forms on the emission of formaldehyde vapor. Thirty 
forms (120 sheets) were placed inside the chamber for each test. Sheets were separated at the rate of 1 form or 4 sheets/min. After the 30-min separating procedure, the sheets were left exposed in the chamber for the rest of the 1-hr sampling process. The sampling flow rate was approximately $0.5 \mathrm{~L} / \mathrm{min}$. The maximum average formaldehyde concentration for 3 replicates was $0.37 \mathrm{ppm}$ after $1 \mathrm{hr}$.

- Ventilation studies: Four types of paper were used to examine the effect of ventilation on the concentration of formaldehyde in the chamber air. For each test, 120 sheets of paper were placed inside the chamber. Page turning, ventilation, and sampling all began at time zero. Pages were turned at the rate of 4 sheets $/ \mathrm{min}$ for $30 \mathrm{~min}$ and were left exposed in the chamber for the final 30 mins. Ventilation and sampling were continuous for the full hr. Ventilation was simulated by forcing compressed air into the chamber and allowing the air to flow out through a hole in the rear of the chamber. The ventilation rate was approximately 0.5 air change/hr for $\mathrm{CB}-15$ blue, $\mathrm{CB}-15$ black, and self-contained-17 black. This rate was obtained by using a flow rate of 2.6 to $2.9 \mathrm{~L} / \mathrm{min}$. Ventilation for $\mathrm{SC}-14$ black was approximately 1 air change/hr, obtained by using a flow rate of $5.1 \mathrm{~L} / \mathrm{min}$. The sampling flow rate was approximately $0.5 \mathrm{~L} / \mathrm{min}$. The results are shown in Table 3-9.

The release of formaldehyde for the combined marking and separating activity demonstrated a value between the maximum concentrations for either activity measured alone. The maximum average formaldehyde concentration was $0.402 \mathrm{ppm}$ after $1 \mathrm{hr}$ for 2 replicates for marking and separating. Marking the forms (maximum average formaldehyde concentration was
$0.497 \mathrm{ppm}$ after $1 \mathrm{hr}$ for two replicates) had a greater impact on the release of formaldehyde than did separating them (maximum average formaldehyde concentration was $0.37 \mathrm{ppm}$ after $1 \mathrm{hr}$ for 3 replicates). The results permitted the investigator to develop a formula for predicting formaldehyde release in the office environment. Using the rate constants developed (the assumptions and calculations used were not provided), the investigator predicted a formaldehyde concentration of $0.033 \mathrm{ppm}$ for a worker confined to a $1,000 \mathrm{ft}^{3}$ room with no ventilation while marking and separating 30 four-ply forms $/ \mathrm{hr}$ for $8 \mathrm{hr}$. This value is between the NIOSH recommended exposure limit (REL) of $0.016 \mathrm{ppm}$ as an 8-hr time-weighted average (TWA) (with a 15-min ceiling limit of $0.1 \mathrm{ppm}$ ) and the OSHA permissible exposure limit (PEL) of $0.75 \mathrm{ppm}$ as an 8-hr TWA (with a 2-ppm short-term exposure limit [STEL]).

\subsection{Conclusions}

Little consistency has been found in the literature when various investigators elected to perform air sampling analyses to assess potential exposure to CCP and its components as summarized in Table 3-1. The most frequently chosen analyte was formaldehyde. Of the seven studies reporting formaldehyde concentrations (summarized in Table 3-10), nearly all measurements exceeded the NIOSH REL of $0.016 \mathrm{ppm}$ as an 8 -hr TWA with a 15 -min ceiling limit of $0.1 \mathrm{ppm}$ [NIOSH 1981]; however, none exceeded the OSHA PEL of $0.75 \mathrm{ppm}$ as an 8-hr TWA with a short-term exposure limit of 2 ppm [29 CFR 1910.1048]. Short-term exposures to this strong-smelling gas cause eye, nose, and throat irritation in some persons at concentrations of $<1 \mathrm{ppm}$. At 5 to $30 \mathrm{ppm}$, formaldehyde causes cough, chest tightness, unusual heartbeat, and lower airway and chronic pulmonary obstruction [NIOSH 1996, 1998; NRC 1981]. The OSHA formaldehyde standard [29 CFR 1910.1048] 
Table 3-9. Effect of ventilation on formaldehyde concentrations in test chambers containing $\mathrm{CCP}$

\begin{tabular}{ccccc}
\hline & \multicolumn{4}{c}{ Average formaldehyde concentration in test chamber (ppm) } \\
\cline { 2 - 5 } Exposure time (min) & CB-15 blue & CB-15 black & SC-17 black & SC-14 black \\
\hline $0-10$ & 0.050 & 0.080 & 0.166 & 0.065 \\
$5-15$ & 0.049 & 0.089 & 0.216 & 0.072 \\
$10-20$ & 0.071 & 0.099 & 0.214 & 0.072 \\
$15-25$ & 0.060 & 0.089 & 0.219 & 0.074 \\
$20-30$ & 0.055 & 0.093 & 0.227 & 0.068 \\
$25-35$ & 0.039 & 0.064 & 0.173 & 0.023 \\
$30-40$ & 0.028 & 0.042 & 0.113 & 0.010 \\
$40-50$ & 0.007 & 0.032 & 0.053 & 0.001 \\
$50-60$ & 0.0 & 0.010 & 0.059 & 0.004 \\
\hline
\end{tabular}

Adapted from Hazelton Laboratories [1985].

Table 3-10. Summary of formaldehyde concentrations reported in CCP studies"

Reference

Gockel et al. [1981]

Norbäck [1983b]

Hazelton Laboratories [1985]

Apol and Thoburn [1986]

Chovil et al. [1986]

Omland et al. [1993]

Zimmer and Hadwen [1993]

\section{Concentration (ppm) $)^{\dagger}$}

\footnotetext{
"The NIOSH REL is $0.016 \mathrm{ppm}$ as an 8 -hr TWA with a 15 -min ceiling limit of $0.1 \mathrm{ppm}$. The OSHA permissible exposure limit is $0.75 \mathrm{ppm}$ as an 8-hr TWA with a short-term exposure limit of $2 \mathrm{ppm}$.

${ }^{\dagger} 1 \mathrm{ppm}=1.23 \mathrm{mg} / \mathrm{m}^{3}$.

${ }^{\ddagger}$ For marking and separating 30 four-ply forms/hr for $8 \mathrm{hr}$ (range $0.009-0.693$ ).

${ }^{\S}$ Limits of detection varied from 0.04 to $0.08 \mathrm{ppm}$.
} 
is based on a number of adverse health effects ranging from irritation to cancer [57 Fed. Reg. 22290 (1992)]. A full discussion of the health effects of formaldehyde is beyond the scope of this review.

Reported measurements for kerosene and total dust were far below the occupational exposure limits. The NIOSH REL for kerosene is $100 \mathrm{mg} / \mathrm{m}^{3}$ as a $10-\mathrm{hr}$ TWA during a 40-hr workweek [NIOSH 1977]. No NIOSH REL has been established for total dust. OSHA has a PEL of $5 \mathrm{mg} / \mathrm{m}^{3}$ for the respirable fraction of particulates not otherwise regulated [29 CFR 1910.1000(z)(1)]. Kerosene is defined as Fuel Oil No. 1, Range oil (note: a refined petroleum solvent [predominantly $\mathrm{C} 9-\mathrm{C} 16]$ that is typically $25 \%$ normal paraffins, $11 \%$ branched paraffins,
$30 \%$ monocycloparaffins, $12 \%$ dicycloparaffins, $1 \%$ tricycloparaffins, $16 \%$ mononuclear aromatics, and 5\% dinuclar aromatics) [NIOSH 1997]. Santosol, SurSol, and odorless kerosene are similar in chemical composition to kerosene. Symptoms of kerosene exposure include eye, skin, nose, and throat irritation; burning sensation in the chest; headache; nausea; weakness; restlessness; incoordination; confusion, drowsiness; vomiting, diarrhea; dermatitis; and chemical pneumonia (if liquid kerosene is aspirated). Airborne exposures at concentrations cited in the CCP studies are not likely to lead to eye or upper respiratory irritation. Quantitation of skin exposure to kerosene from CCP has not been reported. However, skin contact with CCP containing kerosene or its components could result in skin irritation. 


\section{Health Effects}

\subsection{Introduction}

D. uring the early 1970s, manufacturers, employers, and occupational safety and health organizations received numerous complaints of skin and mucous membrane symptoms related to handling or working in close proximity to CCP [Calnan 1979; Göthe et al. 1981; Parmeggiani 1983]. The association of CCP with cases of occupational contact dermatitis was first investigated by Calnan [1979], who also reviewed reactions to ordinary carbon paper, which CCP has largely replaced. According to Calnan, proven allergic contact dermatitis from carbon paper was a rarity. Four early outbreaks of CCP health effects were described by Calnan [1979] and Göthe et al. [1981] at a scientific symposium in Stockholm in 1981. Although skin-patch tests were negative and therefore did not support allergic contact dermatitis as the mechanism of CCP health effects, five pieces of evidence indicated an occupational origin for the CCP symptoms:

- The reporting of symptoms from several workers in a number of unrelated and unconnected companies

- The receipt of customer complaints by all of the CCP manufacturers

- The similarity of reported symptoms and signs

- The similarity of complaints from different countries

- The absence of reported symptoms before the introduction of $\mathrm{CCP}$
Calnan [1979] concluded that the reactions appeared to be toxic (i.e., irritant) rather than allergic because the affected workers were able to continue working in the same general environment without immediate recurrence of their symptoms and because many of the workers related their symptoms to periods of intensive work handling large amounts of CCP.

Calnan [1979] noted that the CCP manufacturers had reported an absence of skin, oral, ocular, or respiratory tract symptoms among their own workers employed in packing large quantities of CCP. However, subsequent investigations identified health problems in these groups as well. Calnan also pointed out that all CCP complaints were associated with used CCP paper, indicating that the rupture of the microcapsules containing the color formers and solvents may be important - even though only a small proportion of capsules in each sheet of paper are broken. Ultimately, Calnan concluded that the eye, nose, mouth, and throat symptoms were caused not by the color former chemicals but rather by the encapsulated solvents, which would presumably have to evaporate to cause other than dermal symptoms.

In a review of the evidence, Buring and Hennekens [1991] found most of the available studies on CCP health effects to be critically lacking epidemiologically and difficult to interpret. They were able to find no "analytic studies" of CCP health effects for review. However, they concluded that unequivocal evidence was not likely ever to be available, even with great expenditure of effort and resources. 
They recommended instead that consideration be given to "implementing measures to prevent or reduce the frequency" of the reported effects.

Murray [1991] also conducted a review of the potential health effects of CCP exposure at the request of the Commission of the European Communities. He noted an absence of documented cases of skin disorders among workers in the manufacturing industry - despite the fact that workers in this industry would be expected to have much higher exposures than office workers. On the basis of both his review of the literature and his experiences as a consultant for a manufacturer of CCP, Murray concluded that although individual cases of sensitivity to CCP components would continue to be reported, a "negligible" threat is posed to the health of producers and users.

Since 1991, additional studies (including some that qualify as analytical epidemiology) have appeared in the scientific literature. The following review considers not only information published in the scientific literature but also information that was submitted to NIOSH in response to announcements in the Federal Register in 1987 and 1997. More than 14,000 pages of combined submissions were received in response to the 1987 and 1997 Federal Register notices. Most of the submissions were made after the latter notice. No materials were accepted or reviewed if the submitter considered the items to contain proprietary information that could not be made available to the public. Information that contained personal identifiers was blocked out unless the submitter wanted the information to remain public.

The following review of $\mathrm{CCP}$ health effects separately considers the information from human and animal studies.

\subsection{Human Studies}

Human studies of CCP have dealt mostly with exposures in office settings. Three types of human studies of CCP have been conducted: individual case studies or case series, cross-sectional studies, and laboratory studies in humans. The following sections separately review each type of study.

\subsubsection{Published Case Reports and Case Series}

The case report is a detailed profile of a single subject; case series describe the characteristics of a number of patients with a given disease. Case reports and series document unusual features of a disease or a patient's exposure history; they are a type of descriptive epidemiologic assessment. Case reports and series can present a major problem in interpretability because the presence of any risk factor may be simply coincidental. Their usefulness is generally limited by the lack of a comparison group (i.e., persons without such symptoms who had similar opportunity for exposure). The lack of a formal comparison group in these studies can make it difficult to determine whether the observed associations represent more than the normal background rate of disease. Lack of a comparison group is particularly problematic when the cases involve common diseases or symptoms and when the exposure is relatively common (which is clearly the case with these reports for CCP exposures). In the absence of a comparison group, case reports and series can provide the first clues to the identification of new diseases or exposure effects, and they are potentially useful for formulating research questions; however, the evidence usually cannot be used to test hypotheses [Buring and Hennekens 1991]. On the other hand, when characteristic symptoms and clinical signs vary over time in direct correspondence with 
changing work exposures, it may be possible to reliably discern a causal relationship. Furthermore, some of these reports included individual experiments in which subjects were exposed to CCP or its components and objective signs and symptoms were evaluated following these exposures. These studies can provide stronger evidence for causality than ordinary case reports that are based on subjective reports of past experiences.

Table 4-1 lists 39 currently available, published case reports and case series related to $\mathrm{CCP}$, including a number of series assembled in NIOSH Health Hazard Evaluations (investigations conducted under the authority of the Occupational Safety and Health Act of 1970 [29 USC $\left.\left.{ }^{*} 1900\right]\right)$. Nine reports provided information about the experience of a single worker. In the case series, ranging from 2 to 276 workers, symptoms were generally clustered within a defined period and involved a number of employees at a single workplace, often situated in a single room or activity. The observed symptoms varied considerably from site to site, but most included skin problems such as itching, rash, dryness, and eczema as well as mucous membrane irritation, particularly of the eyes, mouth, nose, and throat. Lower respiratory problems were less frequent. Headache was also reported as a problem (to a smaller extent), and fatigue was also mentioned.

The following are summaries of the studies outlined in Table 4-1.

Magnusson 1974. Magnusson [1974] conducted his investigation in Sweden at a workplace where 15 of 18 women working with CCP had reported itching and dryness of the skin, lips, tip of nose, and eyes as well as burning sensations or dryness in the mouth. The

${ }^{*}$ United States Code. See USC in references. symptoms mostly appeared a few weeks after the first exposure to CCP. Seven of the 15 women showing symptoms were skin-patch tested using the paper in question and a standard series. All tests were negative but one, which showed reaction to nickel and cobalt. Symptoms disappeared after introduction of a new type of paper containing a resin to bind the clay material.

Hannuksela 1975. A report by Hannuksela [1975] (unavailable to NIOSH but cited by Jeansson et al. [1983]) found 20 workers among several hundred in a Swedish bank who suspected that eczema on their hands was caused by contact with CCP. None of the 19 workers who were skin-patch tested with a CCP bottom sheet emulsion showed an allergic reaction. One later case was reported as positive, with most of the complaints attributed to physical factors (such as abrasiveness) related to $\mathrm{CCP}$.

Wahlberg 1975. In a personal communication reported by Jeansson et al. [1983], Wahlberg found the CCP-related problems to be relatively evenly distributed between two main types of CCP used in Sweden at the timeclay- and polymer-based papers. He suggested that a finely distributed dust arising from leafing through and tearing the paper was a likely explanation of the symptoms.

Hirvonen et al. 1976. Hirvonen et al. [1976] obtained positive skin-patch test reactions for irritation in 4 of 32 cases associated with CCP from a total of 1,050 cases of occupational dermatitis in Sweden during the period 1973 to 1976. In all four cases, the rash began in areas typical of paper contact - the finger tips of one or both hands and the outer edges of the hand. The eyelids of one worker also revealed a rash. Of the four patients, two reacted only to the top side of the paper but not to the CB or CF portions. Two patients reacted to all of the 
Table 4-1. Published case reports, case series, and health hazard evaluations involving exposure to $\mathrm{CCP}$ or $\mathrm{CCP}$ components

\begin{tabular}{|c|c|c|c|}
\hline Authors & Country & Number of cases & Symptoms ${ }^{*}$ \\
\hline Magnusson 1974 & Sweden & 15 & $\begin{array}{l}\text { Itching and dryness of skin, lips, tip of } \\
\text { nose, eyes; burning or dryness of } \\
\text { mouth }\end{array}$ \\
\hline Hannuksela 1975 & Sweden & 20 & Eczema \\
\hline Wahlberg 1975 & Sweden & $\mathrm{NR}^{\dagger}$ & "Problems" \\
\hline Hirvonen et al. 1976 & Sweden & 32 & Skin irritation \\
\hline Maggio et al. 1978 & Italy & NR & Acne, headaches, nausea \\
\hline Andanson et al. 1979 & France & 27 & $\begin{array}{l}\text { Skin symptoms (pruritus of uncovered } \\
\text { areas on hands, face, forearms, thorax, } \\
\text { and legs); eye symptoms (pruritus, } \\
\text { conjunctival hyperemia with tearing } \\
\text { and photophobia); respiratory system } \\
\text { symptoms (pruritus, burning, } \\
\text { prickling, dysphagia, throat } \\
\text { constriction, rhinorrhea, nasal } \\
\text { obstruction, glottal edema, asthma) }\end{array}$ \\
\hline \multirow[t]{8}{*}{ Calnan 1979, 1981} & United Kingdom & Several & $\begin{array}{l}\text { Itchy hands, swollen eyelids, } \\
\text { headaches }\end{array}$ \\
\hline & & 2 & $\begin{array}{l}\text { Burning face and forehead, fatigue, } \\
\text { thirst, sore throat and tongue, chills, } \\
\text { aching limbs, small itchy blisters on } \\
\text { palms }\end{array}$ \\
\hline & & 4 & $\begin{array}{l}\text { Burning lips and tongue, sore eyes, } \\
\text { dry throat and skin }\end{array}$ \\
\hline & Japan & 1 & $\begin{array}{l}\text { Nausea, sore eyes and throat, skin } \\
\text { irritation }\end{array}$ \\
\hline & & 1 & Dry throat \\
\hline & & 1 & Facial rash \\
\hline & & 1 & Rash on hands \\
\hline & England & 4 & $\begin{array}{l}\text { Dry, burning lips, and tongue; } \\
\text { stinging, running eyes and nose; dry, } \\
\text { cracked skin on hands; facial rash; } \\
\text { chest tightness }\end{array}$ \\
\hline Cronin 1980 & United Kingdom & 4 & Eczema \\
\hline
\end{tabular}




\section{Table 4-1 (Continued). Published case reports, case series, and health hazard evaluations involving exposure to $\mathrm{CCP}$ or $\mathrm{CCP}$ components}

\begin{tabular}{|c|c|c|c|}
\hline Authors & Country & Number of cases & Symptoms ${ }^{*}$ \\
\hline Dodds and Butler 1981 & Belgium & 17 & $\begin{array}{l}\text { Eczema, itching, red spots, itching } \\
\text { eyes }\end{array}$ \\
\hline Marks 1981 & United States & 1 & Dermatitis on face and neck \\
\hline Menné et al. 1981 & Denmark & 38 & $\begin{array}{l}\text { Skin redness, burning, itching; itching } \\
\text { eyes, nose; hoarseness; burning } \\
\text { mouth, red face, headache, dizziness }\end{array}$ \\
\hline $\begin{array}{l}\text { Chrostek and Moshell } \\
1982\end{array}$ & United States & 21 & $\begin{array}{l}\text { Eye and nose itching and burning; dry } \\
\text { throat; headaches; facial itching; and } \\
\text { sinus, skin, and respiratory problems }\end{array}$ \\
\hline Levy and Hanoa, 1982 & Norway & 13 & $\begin{array}{l}\text { Perception of unpleasant odor; itching } \\
\text { eyes, face, and hands; rashes; } \\
\text { headaches }\end{array}$ \\
\hline \multirow[t]{12}{*}{ Roure et al. 1982} & France & 28 & $\begin{array}{l}\text { Pruritis on the hands, face, forearms, } \\
\text { or thorax and legs }\end{array}$ \\
\hline & & 11 & $\begin{array}{l}\text { Burning sensation, nasopharyngeal } \\
\text { tingling, slight dysphagia, } \\
\text { photophobia, eye irritation, and } \\
\text { conjunctival pruritus }\end{array}$ \\
\hline & & 3 & $\begin{array}{l}\text { Dryness of the mouth, burning, and } \\
\text { taste perturbations }\end{array}$ \\
\hline & & 3 & Headache \\
\hline & & 9 & $\begin{array}{l}\text { Erythematous patches on hands and } \\
\text { face }\end{array}$ \\
\hline & & 1 & Urticaria \\
\hline & & 1 & Migratory edema \\
\hline & & 1 & Conjuntivitis with eyelid edema \\
\hline & & 2 & Conjuctival hyperemia with lacrimation \\
\hline & & 4 & Rhinorrhea \\
\hline & & 1 & Glottal stricture \\
\hline & & 1 & Nasal obstruction \\
\hline
\end{tabular}

See footnotes at end of table.

(Continued) 


\section{Table 4-1 (Continued). Published case reports, case series, and health hazard evaluations involving exposure to $\mathrm{CCP}$ or $\mathrm{CCP}$ components}

\begin{tabular}{|c|c|c|c|}
\hline Authors & Country & Number of cases & Symptoms $^{*}$ \\
\hline $\begin{array}{l}\text { Roure et al. } 1982 \\
\text { (continued) }\end{array}$ & & 4 & $\begin{array}{l}\text { Spasmodic cough and asthmatic } \\
\text { breathing }\end{array}$ \\
\hline Certin and Zissu 1983 & France & $46^{\ddagger}$ & $\begin{array}{l}\text { Skin, eye, and respiratory irritation; } \\
\text { headache; arthralgia }\end{array}$ \\
\hline Jeansson et al. 1983, 1984 & Sweden & 148 & $\begin{array}{l}\text { Irritation of the eyes, nose, throat, } \\
\text { arms, face, and scalp; cold symptoms; } \\
\text { hoarseness; sores behind the ears or } \\
\text { in the nose; itching, dryness, redness, } \\
\text { or eczema of the hands; unpleasant } \\
\text { odor or taste; fatigue; headache; } \\
\text { nausea; joint pains; a feeling of } \\
\text { paralysis }\end{array}$ \\
\hline Norbäck et al. 1983a,b & Sweden & 80 & Respiratory tract and eye irritation \\
\hline \multirow[t]{11}{*}{$\begin{array}{l}\text { Marks et al. 1984; } \\
\text { Trautlein et al. } 1984\end{array}$} & United States & 1 & $\begin{array}{l}\text { Pruritus, eye and throat irritation, } \\
\text { hoarseness irregular heartbeat, } \\
\text { headache, nausea, tightness of chest, } \\
\text { shortness of breath, and fatigue; } \\
\text { challenge test with CCP indicated } \\
\text { contact urticaria, changes in } \\
\text { pulmunary function indicative of } \\
\text { upper airway obstruction, and } \\
\text { increased prostaglandin PGF2 alpha } \\
\text { and thromboxane BE }\end{array}$ \\
\hline & & 8 & Throat irritation \\
\hline & & 5 & Skin itching \\
\hline & & 4 & Headache \\
\hline & & 3 & Hoarseness \\
\hline & & 3 & Difficult breathing \\
\hline & & 3 & Chest tightness \\
\hline & & 2 & Rash \\
\hline & & 2 & Burning eyes \\
\hline & & 2 & Chest pain \\
\hline & & 1 & Nausea \\
\hline
\end{tabular}

See footnotes at end of table.

(Continued) 


\section{Table 4-1 (Continued). Published case reports, case series, and health hazard evaluations involving exposure to $\mathrm{CCP}$ or $\mathrm{CCP}$ components}

\begin{tabular}{|c|c|c|c|}
\hline Authors & Country & Number of cases & Symptoms ${ }^{*}$ \\
\hline \multirow[t]{2}{*}{$\begin{array}{l}\text { Marks et al. 1984; } \\
\text { Trautlein et al. } 1984 \\
\text { (continued) }\end{array}$} & & 1 & Weakness \\
\hline & & 1 & Rapid heartbeat \\
\hline $\begin{array}{l}\text { Messite and Baker 1984; } \\
\text { Messite and Fannick } 1980\end{array}$ & United States & 6 & Skin and eye irritation \\
\hline Menné and Hjorth 1985 & Denmark & 3 & Contact dermatitis, eczema on fingers \\
\hline Olsen and Mørck 1985 & Denmark & 1 & Skin irritation \\
\hline Apol and Thoburn 1986 & United States & NR & $\begin{array}{l}\text { Voice change, cough, chest tightness } \\
\text { and soreness, running sinuses, skin } \\
\text { rash }\end{array}$ \\
\hline $\begin{array}{l}\text { Bennett and Chrostek } \\
1986\end{array}$ & United States & NA & $\begin{array}{l}\text { Respiratory problems reported but no } \\
\text { attributed to } \mathrm{CCP} \text {; some mention of } \\
\text { formaldehyde exposure that was } \\
\text { assumed to originate from } \mathrm{CCP}\end{array}$ \\
\hline Chovil et. al. 1986 & United States & 9 & $\begin{array}{l}\text { Eye irritation, sinusitis, dermatitis, } \\
\text { psychological manifestations }\end{array}$ \\
\hline Shehade et al. 1987 & United Kingdom & 1 & Allergic contact dermatitis \\
\hline LaMarte et al. 1988 & United States & 2 & $\begin{array}{l}\text { Hoarseness, wheezing, coughing, } \\
\text { flushing, pruritus, rash, laryngeal } \\
\text { edema, localized angioedema }\end{array}$ \\
\hline Norbäck et al. 1983c; 1988 & Sweden & $\cong 276$ & $\begin{array}{l}\text { Skin and mucous membrane and skin } \\
\text { irritation }\end{array}$ \\
\hline \multirow[t]{3}{*}{ Hammel 1990} & United States & 2 & $\begin{array}{l}\text { Hoarseness, cough, flushing, pruritus, } \\
\text { rash }\end{array}$ \\
\hline & & 1 & Nausea, dizziness \\
\hline & & 1 & Redness and itching on hands \\
\hline $\begin{array}{l}\text { Kanerva et al. 1990a,b; } \\
1993\end{array}$ & Finland & 1 & Allergic contact dermatitis \\
\hline Burton and Malkin 1993 & United States & 1 & Chest tightness, cough \\
\hline & & 1 & Cough, rhinitis, headache, rash \\
\hline
\end{tabular}

See footnotes at end of table.

(Continued) 
Table 4-1 (Continued). Published case reports, case series, and health hazard evaluations involving exposure to CCP or CCP components

\begin{tabular}{llcl}
\hline \multicolumn{1}{c}{ Authors } & Country & Number of cases & Symptoms \\
\hline Sim and Echt 1993 & United States & NA & $\begin{array}{l}\text { Itchy skin and rashes attributed to } \\
\text { fibrous glass } \\
\text { Zimmer and Hadwen 1993 }\end{array}$ \\
$\begin{array}{l}\text { Ziem and McTamney } \\
1997\end{array}$ & United States & 6 & Odor in archives area \\
Smith et al. 1999 & United Kingdom & 2 & Multiple chemical sensitivity disorder \\
\hline
\end{tabular}

Adapted from Buring and Hennekens [1991], with additional references added.

* Symptoms were observed in one or more subjects. Exact numbers are supplied in parentheses if they were reported.

${ }^{\dagger}$ Abbreviations: $\mathrm{NA}=$ not available; $\mathrm{NR}=$ not reported.

${ }^{\ddagger}$ Requests for CCP analysis—not cases. 
surfaces of the papers. Tests on the ingredients of the papers were negative. The authors attribute the reactions to nonspecific irritation of the skin.

Maggio et al. 1978. Maggio et al. [1978] reported an investigation of the chemical composition of CCP in Italy. They identified organic dyes dissolved in mineral oil or PCBs enclosed in the microcapsules made of urea-formaldehyde resins or gelatin. The symptoms reported by those using CCP were skin complaints such as acne and general complaints such as headache, nausea, and uncomfortable olfactory sensations. The authors assumed the symptoms to be related to the PCB exposure.

Andanson et al. 1979. In France, Andanson et al. [1979] described the chemical composition of CCP and the spectrum of symptoms resulting from handling sheets of CCP directly or possibly from contact with vapor. The onset of symptoms (reported by 27 of 35 exposed workers) varied but generally developed a few weeks after first exposure. The authors mentioned symptoms of the skin (pruritus of uncovered areas on the hands, face, forearms, thorax, and legs), eyes (pruritus, conjunctival hyperemia with tearing and photophobia), and respiratory system (pruritus, burning, prickling, dysphagia, throat constriction accompanied by rhinorrhea, nasal obstruction, glottal edema, and one case of true immediate asthma). The authors noted that chemical information from the manufacturers was inadequate to relate the symptoms to the exposure and that office environments involved nonexistent or inadequate ventilation. The authors reported that symptoms disappeared soon after exposure ended. They considered the irritant symptoms definitive but performed no tests to assess the allergic potential. The authors concluded that while some of the cases were relatively severe, they did not consider them "a great historic pathology."
Calnan 1979, 1981. Calnan [1979, 1981$]$ reported on three episodes of complaints from various types of office workers in the United Kingdom who attributed their symptoms to the use of CCP. The first episode occurred in 1965 in a group of nine women who worked with business forms in an enclosed computer room at an insurance company. Within a few weeks of the introduction of CCP, several of the women complained of itchy hands, swollen eyelids, and headaches. Skin-patch testing to the paper and all of its constituents was negative. At the time, the solvent for the ink was chlorobiphenyl (a PCB), which was suspected as the causal agent. When ventilation in the workroom was improved, the episode subsided. Soon afterwards, the PCB use was discontinued by all manufacturers.

A second episode occurred in 1975 and involved two men working intensively over a long, hot weekend checking a large number of forms in a small office. One reported a burning sensation on his face and forehead, fatigue, thirst, sore throat and tongue, chills, and aching limbs. He recovered in a few days without treatment, returned to the office to continue his work, and suffered a recurrence of the same symptoms. The other man was similarly but less severely affected and had small, itchy blisters on the centers of his palms.

The third episode described by Calnan occurred in 1976 in a small office where all four workers complained of similar symptoms whenever they handled large amounts of CCP. They reported a burning sensation of the lips and tongue, sore eyes, dry throat, and some dryness of the skin.

Calnan [1979] also reported on complaints from three users of CCP made in Japan. The complaints included nausea, sore eyes and throat, and skin irritation (see Table 4-1). 
Among all of these reported episodes, no workers changed jobs or were forced to stop work. All skin test investigations were negative, and the CCP came from different manufacturers. Calnan hypothesized that if there was a responsible agent, it was most likely to be the solvent in the microcapsules, which could include kerosene, diarylethanes, alkyl naphthalenes, cyclohexane, and dibutyl phthalate.

Cronin 1980. Cronin [1980] reported that four workers involved in the making of microcapsules for CCP in the United Kingdom were found with eczema of the hand (which had been present in one worker for 4 years) or palms (present in one worker for 10 years). Two Proxel compounds (Imperial Chemical Industries) were used as preservatives for gelatin in a factory making the emulsion for CCP. Both contained the active ingredient 1,2-benzisothiazolin-3-one, and one also contained ethylenediamine. Both the active ingredient and the Proxel provoked positive skin-patch test reactions in all four workers, but the ethylenediamine provoked a response in only two of them [Kanerva et al. 1993]. The author concluded that two of the workers' eczema predated their contact with the agents, and the sensitization was thought to be an aggravating factor in their dermatitis rather than its complete cause. Another dermatitis case was cited in a paper mill worker.

Dodds and Butler 1981. In Belgium in 1975, these investigators described five female workers who handled paper forms and reported skin and eye irritation (specifically eczema, itching, and red spots). An additional 12 workers reported itching of the eyes. The incident coincided with the use of a new desensitizing ink ("D-ink," a coating to disable the color formation process). Before the use of this ink, no symptoms had been reported for 7 years. A hamster cheek-pouch test resulted in transient ischemia that lasted approximately $15 \mathrm{~min}$.
Detailed studies of the new desensitizing formula led to the conclusion that one of its ingredients (1-hydroxyethyl-2-oleylimido-azoline) caused the severe effect. In a second case in Denmark, similar symptoms were reported after workers handled paper that contained the same desensitizing ink. The manufacturer was reported to have immediately terminated production of the formulation.

Marks 1981. Marks [1981] reported the following case of a 21-year-old woman in the United States who had a 1.5-year history of an intermittent eruption of the face and neck. She worked as a clerk in a college registrar's office where CCP forms were used for student registration. Within 24 to $48 \mathrm{hr}$ after using the forms, she developed pruritic, erythematous, and edematous dermatitis. She was skin-patch tested with a standard series of allergens as well as with pieces of paper and the components of the paper backing. She reacted to three of the four colored sheets of CCP. She also tested positive to the color former, identified as paratoluene sulfinate of Michler's hydrol, a component of some CCP. She was further skin-patch tested with paratoluene sulfonic acid (results were negative) and with the Michler's hydrol (4,4'-bis[dimethylamino]benzhydrol) (results were positive). Twelve control subjects tested negative to the paper and coating materials.

Menné et al. 1981. Menné et al. [1981] performed an investigation resulting from 70 complaints at a telephone company in Denmark that employed 2,600 workers who handled up to 900,000 sets of CCP per year (i.e., an average of 1.3 sets per person per day). They first investigated 38 of the complaints and found that 26 workers had skin symptoms only, 9 had skin and mucous membrane symptoms, and 3 had mucous membrane symptoms only. Among the workers with skin symptoms, 22 reported that they started on the hands, and 4 reported that they began on the face. The skin 
symptoms were temporary redness, burning, and itching that occurred after 2 to $3 \mathrm{hr}$ of work; they disappeared overnight or over the weekend. Itching of the eyes or the nose, hoarseness, and burning in the mouth were the other symptoms recorded. Twenty-nine of the 38 received standard skin-patch tests, and 11 were found with one or more reactions. Twenty-five workers were further skin-patch tested with 17 paper substances and with the paper. Eight workers were tested with the paper components plus the paper, but no reactions were observed. Other tests included prick testing, photo-patch testing, open tests on the forehead (dab testing), and short-term patch testing for $20 \mathrm{~min}$. All results were negative. The three skin-prick tests using the paper components were negative. Eight were photo-patch tested, and eight had open-patch tests to assess phototoxicity, but all reactions were negative. Twenty-six were skin-prick tested with two types of CCP; six reacted to one type, and five reacted to the other type with reactions the size of one histamine equivalent. However, authors considered these responses to be nonimmunological. Among the 35 controls, one had a positive reaction to one of the skin-paper prick tests. The controls were also tested with 17 different components of the CCP; all tests were negative. The authors stated that approximately 4,000 separate tests were carried out without reaching any definite conclusions.

Menné et al. [1981] also reported on the case of a worker from a different company who began experiencing redness of the face, headache, and dizzy spells on the day that a new delivery of CCP was made. The worker's symptoms disappeared $2 \mathrm{hr}$ after he returned home. Two months later, the paper was replaced and his symptoms disappeared.

Chrostek and Moshell 1982. Chrostek and Moshell [1982] conducted a walk-through survey and administered nondirected medical interviews with 21 workers at a U.S. telephone company. These service department workers acted on reports of malfunctioning telephone service and requests for new services, which were printed on yellow CCP. Previously, carbon paper had been used with no complaints. The following health complaints were described after the introduction of CCP: eye itching and burning, nose itching and burning, dry throat, headaches, facial itching, and sinus, skin, and respiratory problems. Some of the workers stated that the adverse health problems existed only when handling yellow $\mathrm{CCP}$ - not white CCP. Five air samples were collected for total dust; they ranged from 0.06 to $0.2 \mathrm{mg} / \mathrm{m}^{3}$. The two samples collected for formaldehyde were $0.22 \mathrm{mg} / \mathrm{m}^{3}$. Workers handling the CCP were asked to wear white cotton gloves, which were analyzed. The common contaminant in both the gloves and the CCP was dibutyl phthalate, although other contaminants (diethyl phthalate and dioctyl adipate) were also detected in the gloves. Qualitative analysis of the carbonless paper did not detect formaldehyde. On May 13-14, 1981, a NIOSH dermatologist interviewed and examined 33 workers. Of these, 28 were skin-patch tested with unmarked white and yellow $\mathrm{CCP}$ and a marked yellow CCP. On the basis of the negative skin-patch tests and a lack of skin findings consistent with allergic contact dermatitis, the authors ruled out type IV allergic phenomena as a major problem. However, they allowed that certain individuals might have been allergic to a component of the paper.

Levy and Hanoa 1982. Levy and Hanoa [1982] reported on an isolated epidemic that occurred in northern Norway when a new type of invoice form (30,000 sets) had been introduced by a builder's supply company. During the first week of use, workers complained about an unpleasant odor, rashes, headaches, and itching eyes, face, and hands. Thirteen female workers were examined in June 1979; six had serious symptoms and three exhibited mild 
symptoms. These workers were again examined in November 1979 when some CCP sets were still in circulation but most had been returned to the supplier. The complaints gradually declined until none of the workers exhibited serious symptoms and eight had only mild symptoms. In September 1980, when none of the original CCP remained in use, only one of the workers (who had a previous history of allergy) complained of itching and irritation of the eyes. The solvent MIPB and associated impurities (which had a characteristic odor) were suspected. Formaldehyde was not thought to be of any importance in the incident.

Roure et al. 1982. Roure et al. [1982] described subjective symptoms and objective signs occurring in 22 of 35 workers exposed in a French company during the introduction of CCP. The following frequencies of subjective symptoms were observed: pruritis localized on the hands ( 13 cases), face ( 9 cases), forearms (5 cases), or thorax and legs (1 case); burning sensation, nasopharyngeal tingling, slight dysphagia, photophobia, eye irritation, and conjunctival pruritis (11 cases); dryness of the mouth, burning, and taste perturbations ( 3 cases); and headache (3 cases). All symptoms appeared as early as the start of the workweek, lessened in the evening, and disappeared on the weekends. Objective signs in 18 workers consisted of erythematous patches on the hands and face ( 9 cases), urticaria ( 1 case), migratory edema (1 case), conjunctivitis with edema of the eyelid (1 case), conjunctival hyperemia with lacrimation ( 2 cases), rhinorrhea (4 cases), glottal stricture (1 case), nasal obstruction (1 case), and spasmodic cough and asthmatic breathing (4 cases). An etiologic survey showed evidence of previous allergies in three subjects and enabled a distinction to be made between the risks due to "transfer-contact" and "chemical-contact" copy papers.

Certin and Zissu 1983. Results of analyses requested of the French National Research and Safety Institute were reported by Certin and Zissu [1983] and compared with other published studies. They reported 51 requests for analysis of CCP during the 10 years preceding publication of the results. Reasons stated in 46 of the requests included cutaneous problems (allergies, irritation, pruritis, and chapping) (41), respiratory problems (12), ocular disorders (lacrimation, conjunctivitis) (10), irritation of the nasal mucosa (2), and others including asthenia, anemia, headache, and arthralgias. According to the authors, dermatological and respiratory problems seemed to be linked to the use of these papers and were more likely to be due to irritation than to allergy.

Norbäck et al. 1983a,b,c; 1988. Norbäck et al. [1983a] summarized conclusions from five studies in Sweden. Studies in 80 office workers observed only eye and respiratory tract irritation caused by CCP. Norbäck et al. [1983b] found no correlations between airborne solvent concentrations from CCP and the occurrence of irritative symptoms. Formaldehyde, glutaraldehyde, and the organic solvents in which the color formers are dissolved were studied under standardized conditions. According to the authors, the emission of aldehydes from CCP was too low to cause the irritative symptoms. The highest airborne concentration was that of kerosene, which could not be related to symptoms.

Norbäck et al. [1983c, 1988] searched for the discomfort-inducing factors in 276 paper samples (233 of which were CCP) submitted by workers claiming to have experienced irritative symptoms while handling the papers. Interviews regarding symptoms and handling volume were conducted with subjects who had submitted 190 of the CCP samples. To distinguish between CCP of different makes, GC of paper extracts was performed, sometimes combined with thin-layer chromatography (TLC) of the color formers. Coded paper samples were used to permit blind analyses of the 
papers and blind interviews of the exposed persons. The samples were extracted with carbon disulfide, and the extracts were analyzed by GC or TLC. Most correlations of CCP with discomfort were not statistically significant but were found in one brand of paper that used MIPB as the solvent for the color formers. However, the authors concluded that the discomfort-inducing factor was unlikely to be MIPB because two types of MIPB paper were on the market at the time of this study, but patient complaints identified only one of them. CCPs treated with D-ink were more frequently linked to work-related skin symptoms than those not treated with the ink. This correlation was statistically significant $(P<0.05)$. No such correlation was seen for mucous membrane irritation symptoms. The authors concluded that the causal factor was probably two desensitizing inks available on the Swedish market during the investigation period (from January 1 to October 27, 1980) — but not necessarily to D-inks in general. The suspected ingredient in one of the D-inks was 1-hydroxyethyl-2-oleylimidoazoline - the same ink that had previously been associated with skin and eye irritation among office staff in Belgium [Dodds and Butler 1981].

Jeansson et al. 1983, 1984. See Section 4.2.3.1 for a discussion of this study.

Marks et al. 1984; Trautlein et al. 1984. A 27-year-old woman in the United States had an 8-year history of pruritus, eye and throat irritation, hoarseness, irregular heartbeat, headache, nausea, tightness of the chest, shortness of breath, and fatigue within $30 \mathrm{~min}$ of exposure to CCP [Marks et al. 1984; Trautlein et al. 1984]. For 10 years, she had worked in the same factory, which printed, cut, collated, and packaged CCP. She reported that her symptoms became progressively worse as she processed greater amounts of CCP in her job of removing and stacking forms from a collating machine. When working with regular paper, she was asymptomatic. Her symptoms disappeared on weekends, nights, and after $1 \mathrm{hr}$ of exposure to fresh air. On two occasions, she was challenged in a controlled-blinded fashion with portions of complete forms of the CCP. Both challenges resulted in contact urticaria of the hand that held the paper and changes in pulmonary function characteristic of upper airway obstruction. To determine whether alterations in prostaglandin (PG) metabolism might explain these findings, plasma PGF2 alpha and thromboxane B2 (both capable of causing these symptoms) were measured before and during the second exposure period. Both PGF2 alpha and thromboxane B2 increased substantially. The authors concluded that the cutaneous and respiratory symptoms induced by CCP were probably related to $\mathrm{PG}$ release and caused by a chemical formed from the reaction of the color former with the color developer, since the patient reacted only to the complete forms and not to the single sheets. When the patient was relocated within the factory with no exposure to $\mathrm{CCP}$, she was asymptomatic.

Similar symptoms were found in 9 of 59 workers in a subsequent plant survey. The symptoms reported by the 9 workers included throat irritation (8), skin itching (5), headache (4), hoarseness (3), difficulty breathing (3), chest tightness (3), rash (2), burning eyes (2), chest pain (2), nausea (1), weakness (1), and rapid heartbeat (1). A statistically significant $(P<0.01)$ relationship existed between symptoms and high exposure to CCP (compared with low exposure to $\mathrm{CCP}$ ).

\section{Messite and Baker 1984; Messite and} Fannick 1980. Messite and Baker [1984] summarized a number of NIOSH Health Hazard Evaluations dealing with indoor environmental quality and specifically reported on a previous study involving CCP [Messite and Fannick 1980]. Six complaints of skin and eye irritation among 100 office staff members and faculty at a school were related to heavy CCP 
exposure during marking periods of 1 to 2 days. Analysis of the paper did not identify the sensitizing agents or significant irritants. The problem was alleviated by spreading the task of marking papers over several days and frequent hand-washing during handling of the paper.

Menné and Hjorth 1985. Menné and Hjorth [1985] reported from Denmark that frictional trauma with CCP to the palms and fingertips can provoke dermatitis. Elimination of the exposure led to healing within 2 to 3 weeks. Three case histories of patients with frictional contact dermatitis were examined.

Case 1 involved a 35-year-old male office worker. Each day for 2 years, he had handled 100 to 200 documents written on CCP. He gradually developed a scaling patch of dermatitis on the left hypothenar, second finger, and tip of the right index finger at areas of contact with paper. Standard skin-patch tests and paper- and glue-patch tests were negative.

In Case 2, a 64-year-old female medical secretary spent long hours handling CCP. She had noted pruritic vesicles on the left palm surface of the thumb that was in contact with the paper. Eruptions decreased when she wore gloves. Standard skin-patch tests and patch tests to the carbonless paper were negative.

In Case 3, a 37-year-old male bus driver had a fissured eczema of the fingertips, apparently caused by tearing CCP tickets from the stub. The eczema cleared during holidays and on night shifts when there were fewer passengers. Standard skin-patch tests and patch tests with the ticket paper were negative. The histopathology of this type of dermatitis was characteristic, showing necrosis of prickle cells with intraepidermal vesicles and an absence of spongiosis, which excludes a diagnosis of chemical dermatitis. The authors concluded that in patients with dermatitis of the palm or fingertips, frictional trauma should be considered.

Olsen and Morck 1985. See Section 4.2.3.2 for a discussion of this study.

Apol and Thoburn 1986. Apol and Thoburn [1986] reported on an investigation requested by an authorized representative of the Association of Western Pulp and Paper Workers in the United States. They examined employee exposure to diethylenetriamine (DETA), hexamethylene diisocyanate (HMDI), and other chemicals used during the production of CCP at the Boise Cascade facility in Vancouver, Washington. This facility makes paper from pulp and applies CCP coatings to the paper. Personal breathing zone samples and area samples were collected to determine worker exposures to chemicals used by the coater preparation operators, coating operators, and maintenance personnel. The airborne concentrations were as follows: HMDI $(<0.7$ to $\left.14.0 \mu \mathrm{g} / \mathrm{m}^{3}\right)$, DETA $(<0.01$ to $<0.35$ part per million [ppm]), phenol ( $<0.02$ to $0.15 \mathrm{ppm})$, formaldehyde $(<0.04$ to $<0.08 \mathrm{ppm})$, biphenyl ( 0.003 to $<0.02 \mathrm{ppm})$, butyl biphenyl ( 0.12 to $0.29 \mathrm{ppm})$, petroleum solvents $\left(0.7\right.$ to $12 \mathrm{mg} / \mathrm{m}^{3}$ ), and total particulate (one sample was $2.70 \mathrm{mg} / \mathrm{m}^{3}$ ). All the sample results were less than the regulatory limits for these substances. Symptoms reported as a result of exposure included voice change, cough (sometimes productive), tightness and soreness in the chest, running sinuses, and skin rashes.

Medical interviews with 65 employees suggested that when the process was operating properly, few (number unspecified) health complaints were associated with the coating process. The maintenance workers had symptoms associated with exposure to the coating equipment, with the HMDI equipment reportedly being the worst offender. Four workers reported pulmonary symptoms consistent with exposure to diisocyanates. Breathing 
zone concentrations of biphenyl were below the limit of detection (i.e., $<0.02 \mathrm{ppm}$ ), butylobiphenyl concentrations ranged from 0.12 to $0.29 \mathrm{ppm}$, and HMDI concentrations ranged from 0.7 to $4.5 \mu \mathrm{g} / \mathrm{m}^{3}$ for coater and assistant coater operators. On the basis of the medical questionnaire data obtained during the investigation, the authors concluded that some workers may have had pulmonary problems related to past diisocyanate exposure. This investigation is one of several that document CCP-attributable health effects at a CCP manufacturing facility.

Bennett and Chrostek 1986. At the request of the management of the Defense Industrial Supply Center in Philadelphia, Pennsylvania, NIOSH evaluated possible excess cancer deaths and respiratory problems encountered among workers [Bennett and Chrostek 1986]. Measurements were taken for carbon dioxide, carbon monoxide, temperature, relative humidity, organic vapors, and airborne dust. Samples were taken of insulation, solvent cleaners, and CCP used at the facility. The amount of outside air being introduced into the building was occasionally in the low range - such that headaches and complaints of respiratory and mucous membrane problems could develop, even though concentrations of carbon monoxide and carbon dioxide were within safe limits. In addition, the building was overcrowded. The authors concluded that hazards were posed by inadequate ventilation, high temperatures, and low humidity. The authors recommended improvements in ventilation and the use of impermeable gloves when using solvents. However, they made no statements or recommendations about the use of $\mathrm{CCP}$ - other than the possibility of formaldehyde release.

Chovil et al. 1986. Chovil et al. [1986] reported cases of eye irritation, sinusitis, dermatitis, and psychological manifestations associated with an outbreak of a building-related illness at a U.S. university. As part of a building expansion program in August 1983, the student advisement office was relocated to a renovated area on another floor. Shortly after the move, the nine-member staff began complaining of skin and mucous membrane irritation. The presence of asbestos increased staff concern over their symptoms. Medical histories were taken and clinical examinations were performed. Air flow in the ventilation system was evaluated. Seven staff members reported symptoms that they believed were work related. All claimed that their symptoms occurred when they were in the file storage area or when they handled the files.

Air-flow measurements indicated that any noxious agent originating from the files would tend to stay localized in the filing area instead of being dispersed throughout the work area. An inquiry revealed that the university had changed suppliers of advisement forms composed of CCP in April 1983. The authors suggest that the outbreak was due to low-level environmental pollution, probably originating from the CCP in the forms. Reported symptoms may have been exacerbated by the fear of asbestos. In all but one case, symptoms were mild. The worker who exhibited severe symptoms restricted contact with CCP and had no recurrence. The authors added that informal inquiries revealed at least two workers in other departments who had symptoms of mucous membrane irritation during periods of peak usage of these forms (at the beginning of each semester). A followup 8 months later revealed that the staff members were no longer complaining about symptoms - in spite of the fact that previous recommendations for improving the ventilation and for reducing $\mathrm{CCP}$ handling had not been implemented.

Shehade et al. 1987. In the United Kingdom, Shehade et al. [1987] identified a case of allergic contact dermatitis associated with exposure to $\mathrm{CVL}$ in CCP. Skin-patch tests were 
employed to identify the cause of an irritant vesicular rash on the hands and fingers of a female office worker whose occupation entailed the day-long handling of significant quantities of CCP. The symptoms developed within 2 days of the subject's return to work after 18 months of leave. They resulted in the patient's stopping work after 3 weeks. Initial skin-patch tests to nickel sulfate, cobalt chloride, and fragrance mix gave positive results, but there was no reaction to the CCP. The patient improved during 3 months on sick leave, but the condition recurred severely as soon as she returned to work. Subsequent skin-patch tests to the five color formers supplied by the manufacturer of the CCP showed an allergic reaction to CVL at concentrations of $0.01 \%$ to $5 \%$. The authors concluded that the patient was allergic to CVL and that CCP skin-patch tests with CCP only are not sufficient to detect allergies to color formers. They therefore suggested that the color formers themselves be used to test patients with hand eczema and regular contact with CCP.

LaMarte et al. 1988. Acute systemic reactions to $\mathrm{CCP}$, including laryngeal edema, were reported in two U.S. office workers by LaMarte et al. [1988]. The first case was a 39-year-old woman with a 2-year history of recurring episodes of hoarseness, coughing, flushing, pruritus, and rash appearing within $30 \mathrm{~min}$ of topical exposure to CCP. She was a clerk/typist with frequent exposures to CCP during her working hours. Cutaneous application tests were performed using six chemical ingredients of CCP. Approximately $15 \mathrm{~min}$ after $1 \%$ alkylphenol novolac resin dispersion was rubbed onto her forearm, she was noted to develop hoarseness, wheezing, and angioedema of both arms. A subsequent challenge with the material was followed by hoarseness, wheezing, and angioedema at the challenge site. Video endoscopy of the larynx was interpreted as showing diffuse swelling and marked edema of the true vocal cords. Plasma histamine levels obtained at the onset and peak of symptoms were sixfold higher than the prechallenge level.

The second case described by LaMarte et al. [1988] was a coworker of the patient in the first case. This 45-year-old woman had a 6-month history of hoarseness, coughing, flushing, and localized angioedema subsequent to skin contact with CCP. She was challenged by rubbing $1 \%$ alkylphenol novolac resin onto one arm and was reported to have angioedema of the arm and hoarseness $30 \mathrm{~min}$ after the challenge. The authors concluded that the reaction was mast cell/basophil-mediated, that these cases demonstrate a connection to a specific component of $\mathrm{CCP}$, and that they indicate a potentially life-threatening adverse reaction in susceptible patients.

Hammel 1990. Hammel [1990] reported the results of a NIOSH Health Hazard Evaluation of a U.S. consumer refrigeration manufacturer employing 2,600 workers, including 900 office personnel. CCP was used in all departments, but most users were in the export and purchasing departments. Medical interviews were performed for four workers who felt that their health problems were associated with CCP exposure. Two of four workers had developed recurrent episodes of hoarseness, coughing, flushing, pruritis, and rash, which would occur within $30 \mathrm{~min}$ of handling CCP. The third worker described having nausea and dizziness when handling one type of CCP form but not other types. The fourth worker developed redness and itching on the edges of both hands when handling CCP forms (a dermatitis that resolved during weekends). Symptoms improved in all four workers when they avoided exposure to CCP. Two of the four workers became so sensitized that they could not be in the vicinity of CCP without being hoarse. Medical evaluations confirmed acute systemic reactions to CCP (laryngeal edema and sixfold increases in plasma histamine levels) after 
blinded, provocative, cutaneous challenges with alkylphenol novolac resin, a component of CCP. Subsequently, both workers developed hoarseness as a response to other chemicals such as paint, wall paper adhesives, and colognes. Job rotation to positions with minimal or no contact with CCP effectively alleviated health problems in all four workers.

Kanerva et al. 1990a,b; 1993. Kanerva et al. [1990a,b; 1993] investigated the case of a 43-year-old machinist in Finland whose work involved the manufacture of CCP and who developed occupational dermatitis on the hands. The worker was a healthy man with no previous skin disease. He had been employed by the same paper-making company for 23 years. During the last 4 years, he was exposed to the agents used in the CCP manufacturing system-initially, just on the weekends. After a new microcapsule machine was introduced, the patient was given the responsibility of getting the machine into operation. Because of problems with the new machine, his exposure exceeded what would have been expected in normal use. He had direct contact with the microcapsule dispersion and contracted hand dermatitis within a month of the installation of this new machine. Vesicular eczema developed on both hands but cleared over a 3-month sick leave followed by vacation. Upon returning to work, the worker relapsed.

Skin-prick testing was negative for 20 common allergens and natural rubber latex. On skin-patch testing using a series of standard European allergens and $\mathrm{CCP}$, both $\mathrm{CCP}$ and one of the chemicals used to produce the microcapsules of CCP provoked a strong (3+) allergic reaction. Analysis of the paper showed that it contained enough DETA to induce allergic contact dermatitis. The patient tested negative to ethylenediamine, para-phenylenediamine, hexamethylenetetramine, 4-tolyldiethanolamine, and triethanolamine; but he cross-reacted to triethylenetetramine and diaminodiphenylmethane.

Twenty control subjects were skin-patch tested with the microcapsule dispersion substance, the microcapsule paste, and the paper. They all reacted negatively.

The source of the DETA in this case was its use as a cross-linking agent that was added to a solution of color formers in a suitable organic solvent and then mixed with a polyisocyanate. The authors commented that DETA remained even though the vendor claimed that the process ensures that all of the polyisocyanate has reacted. The authors recommended that workers who handle CCP and develop symptoms of contact dermatitis be skin-patch tested with DETA. This patient was the only one who reacted to DETA among the 20 to 30 subjects tested each year since 1986 at the facility-except for a painter who also tested positive to ethylenediaminetetraacetic acid (EDTA), which was a component of the hardener in an epoxy resin paint.

Burton and Malkin 1993. Burton and Malkin [1993] responded to a management request based on a report that a former worker at the Michigan Printers in Chicago, Illinois, had suffered adverse reactions to CCP and solvents. They conducted an industrial hygiene and medical survey. The facility employed 12 workers in check printing and other offset printing on CCP. Samples of personal breathing zone and area air quality were analyzed for printing solvents and metal particles. Workers were interviewed and work practices were observed. The ventilation units appeared to be operating well and were well maintained. The authors concluded that workers were not overexposed to organic solvents or metals at the time of the survey. Of the 11 workers interviewed, 1 reported chest tightness and cough. The former employee (on which the investigation was based) had reportedly experienced cough, 
rhinitis, headache, and rash when using CCP; however, management reported that the current CCP was a different brand than that used by the former worker. The authors were unable to evaluate the effects of the previously used $\mathrm{CCP}$ and concluded that no symptoms were related to the current use of CCP.

Sim and Echt 1993. In response to a request from the Health Commissioner for Kentucky, Sim and Echt [1993] investigated an outbreak of skin disorders among 10 laboratory workers at the Health Services Building in Frankfort, Kentucky. Workers were concerned about their symptoms, which they felt resulted from contact with CCP forms that accompanied the biological specimens analyzed in the laboratories. Itchy skin and rashes on exposed skin and areas where clothes rub were reported in early May of 1993, soon after the start of fibrous glass insulation installation in the mechanical rooms that housed the air-handling units for the laboratories. Symptoms were reported more often in the early part of the week, were less severe in the latter part of the week, and usually resolved on the weekends. The symptoms tended to recur upon returning to work the following week. Several nonskin symptoms were reported during medical interviews with some workers, including breathing difficulties, headaches, sinus infections, irritated eyes, and a tingling sensation of the nose and lips. Three of the workers reporting skin symptoms did not handle CCP forms. The number of workers with symptoms who handled CCP was not reported. Although a new printing of CCP forms occurred at the beginning of 1993, the manufacturer indicated that no change to the forms had recently occurred. The nature of some of the symptoms was consistent with the irritant dermatitis caused by exposure to insulation, and the onset of symptoms also coordinated well with the timing of this operation. The authors concluded that the most likely cause of the symptoms was irritant dermatitis due to contact with glass fibers.
Zimmer and Hadwen 1993. See Section 3.2.1 for a description of this study.

Ziem and McTamney 1997. In the United States, Ziem and McTamney [1997] published a case series of patients assigned the diagnosis of multiple chemical sensitivity (MCS). MCS is a controversial diagnosis used by some practitioners to refer to illness in persons who typically describe multiple symptoms attributed to numerous and varied environmental chemical exposures in the absence of objective, diagnostic physical findings or laboratory test abnormalities that define an illness. A new name for the condition-idiopathic environmental intolerances - was recommended in 1996 by a workshop organized by the International Programme on Chemical Safety of the World Health Organization [American Academy of Allergy, Asthma, and Immunology 1999; Miller 1997]. Cullen [1987] proposed the most commonly referenced definition of MCS: an acquired disorder characterized by recurrent symptoms that (1) are referable to multiple organ systems, (2) occur in response to demonstrable exposure to many chemically unrelated compounds at doses far below those known to cause harmful effects in the general population, and (3) do not correlate with any single widely accepted test of physiological function. The Interagency Workgroup on Multiple Chemical Sensitivity [1998], in reviewing three categories of proposed theories of causation (immunological, neurological, and psychological), found many variations and theories that were interrelated.

Two of 91 patients attributed their conditions to CCP. For one of these patients, few immunologic changes were demonstrated, and most of the values were within normal limits. The authors believed that immune measures preand post-challenge testing were unlikely to show major changes and were therefore not diagnostic of specific MCS etiologies. They reported that after being away from exposure for 
many months, this patient showed significant clinical improvement. They also mentioned that another investigator had seen chemical sensitivity in about 100 patients with substantial occupational exposure to $\mathrm{CCP}$, but this information was unpublished.

Smith et al. 1999. In the United Kingdom, a 49-year-old male forklift driver at a paper mill producing CCP described a 2-year history of hand dermatitis and was diagnosed as having fissured hyperkeratotic eczema of the thumbs. He responded positively to patch testing with para-phenylenediamine in a standard series; and when tested with a dye series, he reacted to the azo dye Disperse Orange 3. Several azo dyes were used at the mill to produce colored paper; the patient's job entailed transportation of dye containers. Skin contamination was thought to have occurred during the collection of the used dye containers. Work restrictions from handling the dyes led to resolution of the hand dermatitis. The azo dyes were not likely to have been part of the CCP system, but they were used as a background color for the paper; the authors did not explain the use of the dyes.

\subsubsection{NIOSH Docket Submissions}

\subsubsection{Unpublished Case Reports and Case Series Submitted by Individuals}

This subsection describes case reports or case series that were submitted to the NIOSH docket from sources other than CCP manufacturers in response to the 1987 and 1997 Federal Register notices regarding CCP [52 Fed. Reg. 22534 (1987); 62 Fed. Reg. 8023 (1997)]. Twenty-six cases involving health effects attributed to CCP were submitted. The sex of the respondent is mentioned in 14 cases, all of which were female.
Age was mentioned in 11 cases. Mean age was 43, with a range from 32 to 55. Symptoms were reported in 23 cases. Multiple symptoms were attributed to CCP in many cases, with 5 or more symptoms reported in 14 of the 23 cases. The most common symptoms attributed by patients or their doctors to CCP included skin symptoms (irritation, rash), respiratory symptoms (breathing difficulty/shortness of breath, nasal/respiratory irritation, lip sores, frequent colds, hoarseness or loss of voice), eye symptoms (eye irritation, blurred vision, eyes feeling swollen and hurt), and general symptoms (fatigue, dizziness, vertigo, lack of energy, fever, malaise, trouble thinking/focusing, and weakness/pain of muscles in general or specifically of the legs, back, or arms). Some information about laboratory workup was provided in eight cases. Immunologic testing, performed in six cases, was extensive but used tests of unknown utility. Small deviations from laboratory normal ranges were attributed to or said to be compatible with immunotoxicity. Extensive neuropsychiatric testing was reported in seven cases, and abnormal results were attributed to or said to be compatible with neurotoxicity. Sophisticated neuroimaging studies such as magnetic resonance imaging (MRI) scans of the brain and single positron emission computed tomography (SPECT) scans of the brain were reported in three cases. Abnormalities in SPECT scans of unknown importance were often attributed to or said to be compatible with neurotoxicity. Eleven of the subjects were characterized as suffering from MCS or "chemical sensitivity." In four cases, symptoms were attributed to formaldehyde sensitivity. Diagnoses of chronic Epstein-Barr virus infection and chronic fatigue syndrome were each made in one case. One subject reported having been treated with "drops under tongue of formaldehyde and petrochemicals." Another reported having been treated with "antigen." 


\subsubsection{Inquiries about Health Effects Submitted by CCP Manufacturers}

NIOSH also received docket submissions from CCP manufacturers describing inquiries they had received about alleged adverse health effects associated with use of CCP. These inquiries are summarized in this section.

Appleton Papers, Inc. 1987. A letter from Duane Jones at Appleton Papers, Inc. (dated August 18, 1987, and submitted to the NIOSH docket) reported that from 1976 to 1986, Appleton received an average of six inquiries per month (with a range of one to nine per month) regarding skin, headache, nausea, odor, breathing, eyes, nose, mouth, and unspecified symptoms. No seasonal or other patterns were reported in the frequency of symptoms. Table 4-2 summarizes these data. Other details are contained in the NIOSH docket submission.

Moore Business Forms, Inc. 1987. An August 24, 1987, letter to Richard Lemen from Dr. Norman Macaulay of Moore Business Forms, Inc., noted that in the past 5 years (1982 to 1987), Moore had received only 23 inquiries concerning CCP, and only 6 of 7,500 customers had inquired about skin irritation that they thought was associated with CCP. Also, Moore had produced 13 billion $\mathrm{CCP}$ forms during the previous year.

CCP Manufacturers 1998. A letter dated October 6, 1998, was received from Robert G. Tardiff, Ph.D. (representing the CCP manufacturers in the United States) in response to a query from NIOSH. The Institute had asked whether the end users of CCP were reporting to the CCP manufacturers and sellers any health-related symptoms that might be perceived to be associated with CCP in the workplace over the last 10 years (1987-1996). Each of the five U.S. manufacturers contributed data, which were normalized to the amount of paper sold yearly. The letter stated that the figure might be overestimated, based on the following rationale: (1) customers, unsure of which manufacturer's paper was and is being used, might have addressed the same inquiry to several different companies; (2) a customer might inquire at different levels within the manufacturing and distribution chain, with each contact being treated as a separate report; (3) a consumer might

Table 4-2. Summary of health-related inquiries from customers to Appleton Papers, Inc., May 1976 to December 1986

\begin{tabular}{lcc}
\hline \multicolumn{1}{c}{ Item } & Number & \% \\
\hline Focus of inquiry: & 246 & \\
Skin & 46 & 28.3 \\
Headache, nausea & 151 & 5.2 \\
Odor & 33 & 17.4 \\
Breathing & 108 & 3.3 \\
Eyes, nose, throat & 284 & 12.4 \\
Unspecified & 868 & 32.7 \\
Total & & 99.3 \\
\end{tabular}


inquire repeatedly over time to the same company regarding the claim of a single health-related symptom; and (4) inquiries received at one CCP company might not relate to that company's products, since some sample CCP forms submitted were those of manufacturers.

The letter further explained that most of the information they receive is anecdotal and inconsistent in terms of type, quantity, and quality of information, including the circumstances of product use. Most often the inquiry is received indirectly from merchants, printers, brokers, etc. The yearly average of health-based inquiries is stated to include claims from companies alleging health symptoms and may or may not have included the regular inquiries. Furthermore, some inquiries do not state the number of workers affected and are thus treated as a single inquiry. Some of the inquiries result from odors associated with CCP. Also, some inquiries result from news articles and may have no temporal relationship with actual exposure. For the years 1987 to 1996, the yearly average ( \pm standard deviation) for health-based inquiries for all U.S. CCP manufacturers was $113( \pm 4)$ for $960,115( \pm 6,473)$ tons of paper sold - or approximately 1 inquiry per 10,000 tons of CCP sold (equivalent to less than 1 inquiry per 1 billion $8.5-\times 11$-in. sheets). The information was examined for trends by the companies. They found an increasing volume of CCP sold during the period 1987-1992, with a corresponding increasing rate of inquiries followed by an apparent sharp decrease in health inquiries over the last 5 years (1992-1996) (see Figure 4-1). CCP manufacturers have provided no descriptive details (such as conditions of work or volume of CCP used) for the health complaints that led to the reported inquiries.

\subsubsection{Cross-Sectional Studies}

The cross-sectional studies reviewed in this section were conducted to evaluate either the potential health effects of indoor air contaminants in general or those of CCP specifically. Both types of studies are summarized in Table 4-3. In both cases, the information about

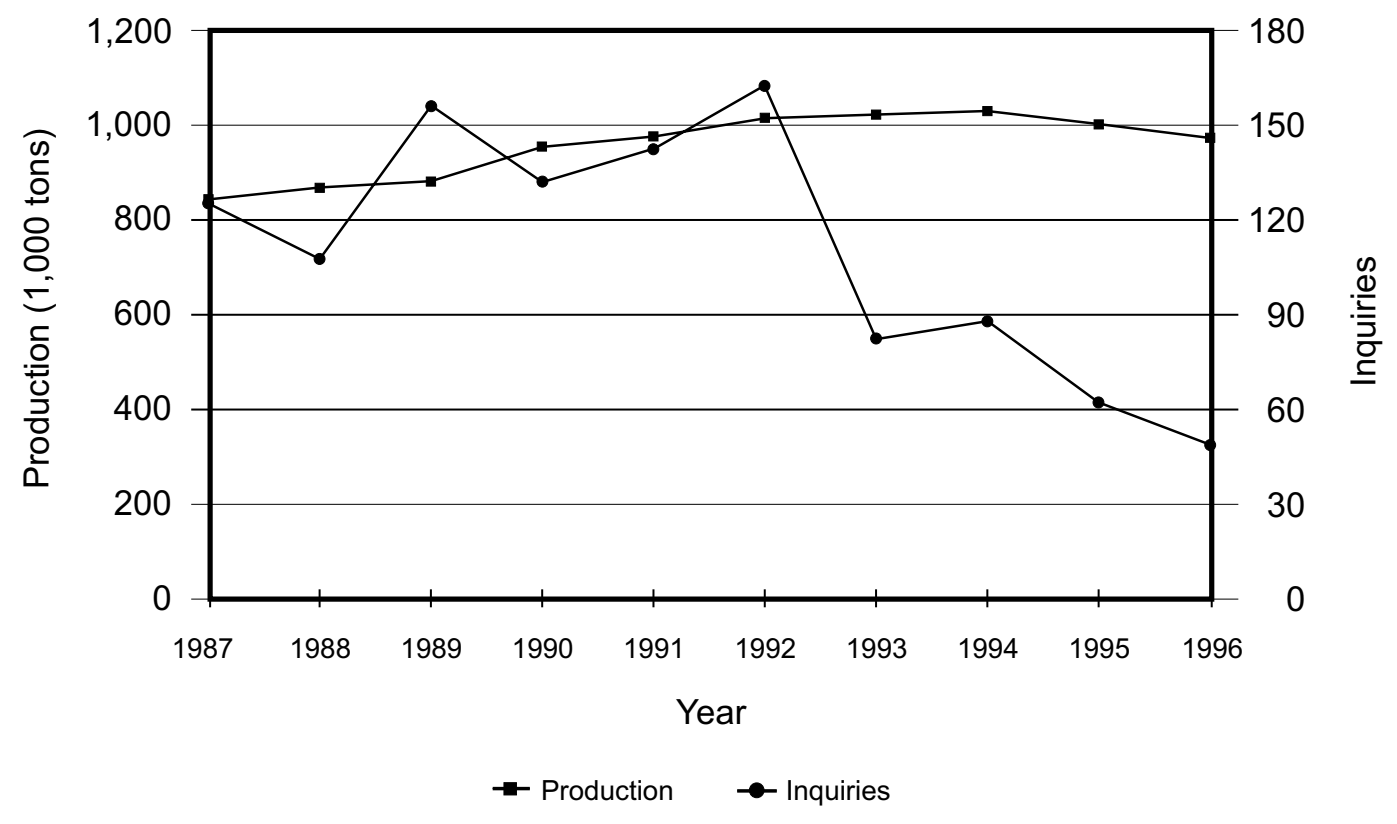

Figure 4-1. Production of CCP and number of inquiries per year for all U.S. manufacturers from 1987 to 1996. (Source: Graves et al. [2000]. Reprinted with permission. Copyright ${ }^{\odot}$ by Academic Press.) 
Table 4-3. Summary of cross-sectional studies that used questionnaires to assess the health effects of indoor air contaminants in general or CCP specifically

\begin{tabular}{|c|c|c|c|c|c|c|}
\hline \multirow[b]{3}{*}{ Study } & \multirow[b]{3}{*}{ Country } & \multirow[b]{3}{*}{ Methods } & \multicolumn{3}{|c|}{ CCP-exposed workers } & \multirow[b]{3}{*}{ Results } \\
\hline & & & \multirow{2}{*}{$\begin{array}{l}\text { Number } \\
\text { responding } \\
\text { to survey }^{*}\end{array}$} & \multicolumn{2}{|c|}{$\begin{array}{c}\text { Workers with } \\
\text { complaints }\end{array}$} & \\
\hline & & & & Number & $\%$ & \\
\hline \multicolumn{7}{|c|}{ Studies of indoor air contaminants: } \\
\hline Skov et al. 1987, 1989 & Denmark & $\begin{array}{l}\text { Questionnaires were sent to } \\
4,369 \text { municipal workers in } \\
\text { different buildings. Ambient } \\
\text { measurements were taken for } \\
\text { a large number of factors. }\end{array}$ & $\begin{array}{l}424 \text { men } \\
1,102 \text { women }\end{array}$ & $\begin{array}{l}110 \\
397\end{array}$ & $\begin{array}{l}26 \\
36\end{array}$ & $\begin{array}{l}\text { Clerks had the highest } \\
\text { frequency of mucosal } \\
\text { irritation; social workers had } \\
\text { the highest frequency of } \\
\text { general symptoms. Other } \\
\text { significant correlations with } \\
\text { mucosal irritation and general } \\
\text { symptoms included sex, job } \\
\text { category, photoprinting, and } \\
\text { VDTs. Older buildings had } \\
\text { lower incidences, but no } \\
\text { relationship was found } \\
\text { between naturally and } \\
\text { mechanically ventilated } \\
\text { buildings. Handling CCP was } \\
\text { related to mucous membrane } \\
\text { symptoms (OR=1.3; } \\
P<0.0001) \text { and general } \\
\text { symptoms (OR=1.6; } \\
P<0.0001) \text {. }\end{array}$ \\
\hline See footnotes at end of table. & & & & & & (Continued) \\
\hline
\end{tabular}


Table 4-3 (Continued). Summary of cross-sectional studies that used questionnaires to assess the health effects of indoor air contaminants in general or CCP specifically

\begin{tabular}{|c|c|c|c|c|c|c|}
\hline \multirow[b]{3}{*}{ Study } & \multirow[b]{3}{*}{ Country } & \multirow[b]{3}{*}{ Methods } & \multicolumn{3}{|c|}{ CCP-exposed workers } & \multirow[b]{3}{*}{ Results } \\
\hline & & & \multirow{2}{*}{$\begin{array}{l}\text { Number } \\
\text { responding } \\
\text { to survey }\end{array}$} & \multicolumn{2}{|c|}{$\begin{array}{l}\text { Workers with } \\
\text { complaints }\end{array}$} & \\
\hline & & & & Number & $\%$ & \\
\hline Zweers et al. 1992 & Netherlands & $\begin{array}{l}\text { Authors surveyed } 10,500 \\
\text { workers in } 61 \text { office } \\
\text { buildings. }\end{array}$ & Unknown & Unknown & Unknown & $\begin{array}{l}\text { The study found statistically } \\
\text { significant associations of } \\
\text { handling CCP with oronasal } \\
\text { symptoms (OR=1.18), } \\
\text { perception of air contaminants } \\
\text { (OR=1.48), air quality } \\
\text { complaints (OR=1.21), and } \\
\text { lighting complaints } \\
(\mathrm{OR}=1.30) \text {. Near-significant } \\
\text { elevations found for eye and } \\
\text { fever symptoms. }\end{array}$ \\
\hline
\end{tabular}


Table 4-3 (Continued). Summary of cross-sectional studies that used questionnaires to assess the health effects of indoor air contaminants in general or CCP specifically

\begin{tabular}{|c|c|c|c|c|c|c|}
\hline \multirow[b]{3}{*}{ Study } & \multirow[b]{3}{*}{ Country } & \multirow[b]{3}{*}{ Methods } & \multicolumn{3}{|c|}{ CCP-exposed workers } & \multirow[b]{3}{*}{ Results } \\
\hline & & & \multirow{2}{*}{$\begin{array}{l}\text { Number } \\
\text { responding } \\
\text { to survey }\end{array}$} & \multicolumn{2}{|c|}{$\begin{array}{l}\text { Workers with } \\
\text { complaints }\end{array}$} & \\
\hline & & & & Number & $\%$ & \\
\hline Mendell 1991 and Fisk et al. 1993 & United States & $\begin{array}{l}\text { Authors surveyed } 880 \text { office } \\
\text { workers in } 12 \text { office } \\
\text { buildings. Building } \\
\text { characteristics were } \\
\text { described, and ambient } \\
\text { measures of air quality were } \\
\text { taken. }\end{array}$ & 142 & 82 & 58 & $\begin{array}{l}\text { Increased prevalence of some } \\
\text { symptoms was associated with } \\
\text { several job and workspace } \\
\text { factors-including the } \\
\text { presence of carpet, the use of } \\
\text { CCP and photocopiers, space- } \\
\text { sharing, and distance from a } \\
\text { window. Statistically } \\
\text { significant associations were } \\
\text { observed between use of CCP } \\
\text { and symptoms such as eye, } \\
\text { nose, or throat }(\mathrm{OR}=1.6) \text { and } \\
\text { chest tightness/difficulty } \\
\text { breathing }(\mathrm{OR}=2.3) \text {. }\end{array}$ \\
\hline
\end{tabular}


Table 4-3 (Continued). Summary of cross-sectional studies that used questionnaires to assess the health effects of indoor air contaminants in general or CCP specifically

\begin{tabular}{|c|c|c|c|c|c|c|}
\hline \multirow[b]{3}{*}{ Study } & \multirow[b]{3}{*}{ Country } & \multirow[b]{3}{*}{ Methods } & \multicolumn{3}{|c|}{ CCP-exposed workers } & \multirow[b]{3}{*}{ Results } \\
\hline & & & \multirow{2}{*}{$\begin{array}{l}\text { Number } \\
\text { responding } \\
\text { to survey }\end{array}$} & \multicolumn{2}{|c|}{$\begin{array}{l}\text { Workers with } \\
\text { complaints }\end{array}$} & \\
\hline & & & & Number & $\%$ & \\
\hline Jaakkola and Jaakkola 1999 & Finland & $\begin{array}{l}\text { Authors conducted a } \\
\text { population-based, cross- } \\
\text { sectional questionnaire } \\
\text { study of workers in } 41 \text { office } \\
\text { buildings working with } \\
\text { CCP, photocopying, and } \\
\text { using VDT's. }\end{array}$ & 910 & Unknown & Unknown & $\begin{array}{l}\text { Statistically significant } \\
\text { associations (ORs) observed } \\
\text { between work with CCP }(34 \% \\
\text { of population) and symptoms } \\
\text { such as eye (OR=1.56), nose } \\
(\mathrm{OR}=1.48) \text {, pharyngeal } \\
(\mathrm{OR}=1.89) \text {, and skin symptoms } \\
(\mathrm{OR}=1.68) \text {; headache } \\
(\mathrm{OR}=1.66) \text {; and lethargy } \\
(\mathrm{OR}=1.38) \text {. The ORs for } \\
\text { chronic respiratory symptoms } \\
\text { and some measures of } \\
\text { respiratory infection (acute } \\
\text { bronchitis and sinusitis) were } \\
\text { significantly elevated } \\
\text { (ORs=1.3-1.8). In contrast, } \\
\text { only the OR for the common } \\
\text { cold was significantly } \\
\text { elevated in those performing } \\
\text { photo-copying, as were the } \\
\text { ORs for otitis and general } \\
\text { symptoms in those using } \\
\text { VDTs. }\end{array}$ \\
\hline
\end{tabular}


Table 4-3 (Continued). Summary of cross-sectional studies that used questionnaires to assess the health effects of indoor air contaminants in general or CCP specifically

\begin{tabular}{|c|c|c|c|c|c|c|}
\hline \multirow[b]{3}{*}{ Study } & \multirow[b]{3}{*}{ Country } & \multirow[b]{3}{*}{ Methods } & \multicolumn{3}{|c|}{ CCP-exposed workers } & \multirow[b]{3}{*}{ Results } \\
\hline & & & \multirow{2}{*}{$\begin{array}{l}\text { Number } \\
\text { responding } \\
\text { to survey }\end{array}$} & \multicolumn{2}{|c|}{$\begin{array}{c}\text { Workers with } \\
\text { complaints }\end{array}$} & \\
\hline & & & & Number & $\%$ & \\
\hline
\end{tabular}

\section{Studies of CCP:}

Fristedt and Pettersson 1980

Sweden

Authors surveyed 3,000 workers and described those with complaints.

Authors surveyed subjects at 5 sites comparing atopics and nonatopics exposed to CCP:
Atopics
Nonatopics

Sweden
180

See footnotes at end of table.
122

39

68
A greater incidence of skin symptoms was reported with clay-based $\mathrm{CF}$ than with phenolic-based CF. A greater incidence of mucous membrane symptoms was reported with phenolic-based $\mathrm{CF}$ than with clay-based $\mathrm{CF}$.

Increased complaints of skin, eye, and mucous membrane irritation were associated with CCP. More frequent itching and dry skin were reported in atopic patients or those with existing skin disease than in nonatopic patients or those lacking prior skin symptoms. 
Table 4-3 (Continued). Summary of cross-sectional studies that used questionnaires to assess

the health effects of indoor air contaminants in general or CCP specifically

\begin{tabular}{|c|c|c|c|c|c|c|}
\hline \multirow[b]{3}{*}{ Study } & \multirow[b]{3}{*}{ Country } & \multirow[b]{3}{*}{ Methods } & \multicolumn{3}{|c|}{ CCP-exposed workers } & \multirow[b]{3}{*}{ Results } \\
\hline & & & \multirow{2}{*}{$\begin{array}{l}\text { Number } \\
\text { responding } \\
\text { to survey }\end{array}$} & \multicolumn{2}{|c|}{$\begin{array}{l}\text { Workers with } \\
\text { complaints }\end{array}$} & \\
\hline & & & & Number & $\%$ & \\
\hline $\begin{array}{l}\text { Öberg } 1980 \text { (cited in Murray } \\
1991^{\dagger} \text { ) }\end{array}$ & Sweden & $\begin{array}{l}\text { Authors surveyed } 205 \\
\text { workers; } 74 \% \text { handled more } \\
\text { than } 10 \mathrm{CCP} \text { forms daily. }\end{array}$ & 205 & 82 & 40 & $\begin{array}{l}\text { Respondents complained of } \\
\text { itching and dryness of the } \\
\text { hands, eyes, and mouth; } \\
4 \text { reported eczema. }\end{array}$ \\
\hline $\begin{array}{l}\text { Sondergard } 1981 \text { (cited by } \\
\text { Murray } 1991 \text { and Olsen and } \\
\text { Mørck } 1985^{\dagger} \text { ) }\end{array}$ & Sweden & $\begin{array}{l}\text { Surveyed offices of an } \\
\text { airline. }\end{array}$ & 93 & 68 & 73 & $\begin{array}{l}\text { Symptoms not described; } \\
\text { dose-response connection } \\
\text { was not statistically } \\
\text { significant because of small } \\
\text { numbers of workers in two } \\
\text { groups. }\end{array}$ \\
\hline Menné et al. 1981 & Denmark & $\begin{array}{l}\text { Authors surveyed those } \\
\text { with CCP exposure at } \\
\text { telephone company by } \\
\text { asking about symptoms } \\
\text { caused by CCP. }\end{array}$ & 1,855 & 208 & 11 & $\begin{array}{l}5.1 \% \text { of men ( } 32 \text { of } 624) \\
\text { and } 14.3 \% \text { of women (176 } \\
\text { of } 1,231) \text { reported skin } \\
\text { symptoms or mucous } \\
\text { membrane irritation. } \\
\text { Symptoms were unrelated to } \\
\text { the type of building in } \\
\text { which subjects worked. A } \\
\text { dose-response relationship } \\
\text { was noted. }\end{array}$ \\
\hline See footnotes at end of table. & & & & & & (Continued) \\
\hline
\end{tabular}


Table 4-3 (Continued). Summary of cross-sectional studies that used questionnaires to assess the health effects of indoor air contaminants in general or CCP specifically

\begin{tabular}{|c|c|c|c|c|c|c|}
\hline \multirow[b]{3}{*}{ Study } & \multirow[b]{3}{*}{ Country } & \multirow[b]{3}{*}{ Methods } & \multicolumn{3}{|c|}{ CCP-exposed workers } & \multirow[b]{3}{*}{ Results } \\
\hline & & & \multirow{2}{*}{$\begin{array}{l}\text { Number } \\
\text { responding } \\
\text { to survey }\end{array}$} & \multicolumn{2}{|c|}{$\begin{array}{l}\text { Workers with } \\
\text { complaints }\end{array}$} & \\
\hline & & & & Number & $\%$ & \\
\hline $\begin{array}{l}\text { Göthe et al. } 1981 \text { and } \\
\text { Norbäck et al. } 1983 b\end{array}$ & Sweden & $\begin{array}{l}\text { Authors described } \\
\text { complaints from handling } \\
\text { CCP, ordinary bond } \\
\text { paper, or carbon paper; } \\
\text { used a comparison group } \\
\text { of } 22 \text {. }\end{array}$ & Unknown & 58 & Unknown & $\begin{array}{l}\text { The prevalence of mucous } \\
\text { membrane symptoms }(P<0.01) \\
\text { was greater with CCP than } \\
\text { with ordinary bond or carbon } \\
\text { paper. }\end{array}$ \\
\hline \multirow[t]{3}{*}{ Kolmodin-Hedman et al. 1981} & Sweden & $\begin{array}{l}\text { Authors surveyed the } \\
\text { following: }\end{array}$ & & & & \multirow{3}{*}{$\begin{array}{l}\text { Laboratory workers handled } \\
>1,000 \text { CCP sheets/day } \\
\text { compared with insurance } \\
\text { workers handling fewer } \\
\text { sheets (unspecified no.) and } \\
\text { office controls who handled } \\
\text { no CCP. Symptom } \\
\text { prevalence: } 92 \%, 32 \% \text {, and } \\
10 \% \text {, respectively. }\end{array}$} \\
\hline & & $\begin{array}{l}\text { Insurance workers } \\
\text { Hospital laboratory }\end{array}$ & 145 & 46 & 32 & \\
\hline & & $\begin{array}{l}\text { workers } \\
\text { Hospital office workers } \\
\text { (controls) }\end{array}$ & 12 & 11 & 92 & \\
\hline Kleinman and Horstman 1982 & United States & $\begin{array}{l}\text { Authors surveyed workers in } \\
61 \text { U. of Washington offices } \\
\text { with heavy CCP use. } \\
\text { Subjects were asked about } \\
\text { symptoms caused by CCP; } \\
\text { respondents had a physical } \\
\text { examination. }\end{array}$ & 265 & 71 & 27 & $\begin{array}{l}\text { Significant dose-response } \\
\text { relationship reported } \\
\text { between CCP use and } \\
\text { health complaints. } \\
\text { Estimated minimum rate of } \\
\text { complaints across different } \\
\text { offices was } 11 \% \text {. }\end{array}$ \\
\hline See footnotes at end of table. & & & & & & (Continued) \\
\hline
\end{tabular}




\begin{tabular}{|c|c|c|c|c|c|c|}
\hline \multirow[b]{3}{*}{ Study } & \multirow[b]{3}{*}{ Country } & \multirow[b]{3}{*}{ Methods } & \multicolumn{3}{|c|}{ CCP-exposed workers } & \multirow[b]{3}{*}{ Results } \\
\hline & & & \multirow{2}{*}{$\begin{array}{l}\text { Number } \\
\text { responding } \\
\text { to survey }\end{array}$} & \multicolumn{2}{|c|}{$\begin{array}{l}\text { Workers with } \\
\text { complaints }\end{array}$} & \\
\hline & & & & Number & $\%$ & \\
\hline Pryor et al. 1983 & $\begin{array}{l}\text { United } \\
\text { States }\end{array}$ & $\begin{array}{l}\text { Authors surveyed } 8 \\
\text { workers in municipal } \\
\text { court office and } 8 \text { age- } \\
\text { and sex-matched controls } \\
\text { in accounting office. }\end{array}$ & 8 & Unknown & Unknown & $\begin{array}{l}\text { Eye, nasal, and throat com- } \\
\text { plaints were higher in CCP- } \\
\text { exposed workers than in con- } \\
\text { trols, but numbers were too } \\
\text { small for meaningful } \\
\text { comparison. }\end{array}$ \\
\hline Olsen and Mørck 1985 & Denmark & $\begin{array}{l}\text { Authors surveyed employees } \\
\text { of } 2 \text { form-printing shops. }\end{array}$ & 129 & 40 & 31 & $\begin{array}{l}31 \% \text { reported skin and mucous } \\
\text { membrane symptoms; } 22.5 \% \\
\text { reported skin symptoms only. }\end{array}$ \\
\hline Omland et al. 1993 & Denmark & $\begin{array}{l}\text { Authors surveyed } 20 \\
\text { government office workers } \\
\text { handling large amounts of } \\
\text { CCP and a comparison } \\
\text { group of } 20 .\end{array}$ & 20 & 10 & 50 & $\begin{array}{l}\text { Increased incidences of pruri- } \\
\text { tus }(P=0.007) \text { and skin irrita- } \\
\text { tion }(P=0.03) \text { were associated } \\
\text { with CCP. A dose-response re- } \\
\text { lationship was established be- } \\
\text { tween pruritus and increased } \\
\text { handling of CCP }(P=0.049) \text {. }\end{array}$ \\
\hline Apol and Thoburn 1986 & United States & $\begin{array}{l}\text { Authors surveyed } 65 \\
\text { employees making CCP. } \\
\text { Ambient evaluation was also } \\
\text { performed. }\end{array}$ & 65 & Unknown & - & $\begin{array}{l}\text { No numbers were presented. } \\
\text { Maintenance workers in the } \\
\text { coater area reported the most } \\
\text { problems; } 4 \text { men reported pul- } \\
\text { monary symptoms consistent } \\
\text { with exposure to } \\
\text { diisocyanates. }\end{array}$ \\
\hline
\end{tabular}

\footnotetext{
* The number of CCP-exposed workers surveyed was not generally known except for those responding to the surveys; therefore, response rates were unknown. †Original reference was not retrievable by NIOSH.
} 
health effects (symptoms) was generally identified by surveys of workers using a questionnaire. A major concern with studies based on questionnaires is the potential for overreporting of symptoms, particularly when the study subjects are already concerned about the exposure being studied.

This concern is greater for the CCP studies than for the indoor air quality studies because the CCP studies were generally conducted at facilities where complaints of symptoms were allegedly related to CCP. The indoor air quality studies were not conducted in facilities where complaints were related to $\mathrm{CCP}$, and thus they are generally considered to provide better information than the CCP cross-sectional studies. The indoor air quality studies and the CCP studies are considered separately below.

\subsubsection{Cross-Sectional Studies of Indoor Air Contaminants}

A number of studies on indoor air quality have associated CCP exposure (and other factors) with workers' symptoms (Table 4-3). Three indoor air quality studies - Knave et al. [1985], Reinikainen et al. [1990], and Thompson [1996] - are not included in this review because they were judged to be largely uninformative with respect to potential health effects associated with CCP exposure. One common limitation of the studies described below is that they generally include only two or at most three categories of CCP exposure and thus provide a very limited assessment of exposure-response.

Skov et al. 1987, 1989. Skov et al. [1987] conducted a cross-sectional survey of office workers and indoor climates in 14 town halls and other affiliated buildings in Copenhagen. Researchers administered a questionnaire to 4,369 workers and measured indoor climate factors in town halls. The return rate for the questionnaire was $80 \%$. Measurements of the many indoor climate factors yielded values considered acceptable or within a typical range for office buildings as previously reported. The analysis showed that the following tasks were significantly correlated with the presence of mucosal and general symptoms: photocopying, working at video display terminals (VDTs), and handling CCP. However, in this univariate analysis the potential exists for confounding between $\mathrm{CCP}$, photocopying, and VDT exposures.

Subsequently, Skov et al. [1989] described the influence of personal characteristics as well as job-related and psychosocial factors on indoor air quality complaints in the same population. Of the 3,507 respondents $(2,347$ women), the CCP-exposed included 1,102 women and 424 men. For the 19 buildings studied, numbers were sufficient for multivariate analyses. The questionnaire provided information about work activity, previous and present diseases, the presence of mucous membrane and general symptoms (headache, fatigue, and malaise), indoor climate, family and housing conditions, exercise habits, smoking, and consumption of alcohol and other beverages. Thirty-six percent (397) of these women reported complaints, as did 26\% (110) of the men. In logistic regression analyses, sex, type of job, and the following job activities were significantly related to mucous membrane symptoms: handling CCP $(P<0.0001)$, handling carbon papers $(P<0.0001)$, photocopying $(P<0.0001)$, working at VDTs $(P<0.0001)$, dissatisfaction with one's superiors $(P<0.0001)$, and work overload $(P<0.0001)$. Crude prevalence rates showed a dose-response between frequency of CCP exposure and mucous membrane symptoms:

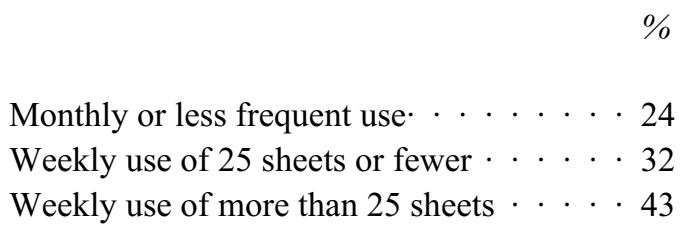


With multiple logistic regression analysis, handling CCP weekly or daily had a significant effect on mucosal irritation (odds ratio $[\mathrm{OR}]=1.3$, $95 \%$ confidence interval $[\mathrm{CI}]=1.1-1.6$ ), and handling $\mathrm{CCP}$ was the only exposure with a significant effect on general symptoms (see above; $\mathrm{OR}=1.6,95 \% \mathrm{CI}=1.1-1.7)$. Also the authors commented that these office workers handled relatively small quantities of CCP.

Zweers et al. 1992. Zweers et al. [1992] conducted a cross-sectional epidemiologic study of indoor air quality and health effects in the Netherlands. Approximately 10,500 workers in 61 office buildings were studied. CCP usage, which was not the primary focus of the study, was ascertained in a questionnaire and analyzed as a dichotomous variable - handling "more than zero CCP per day" versus handling "zero." No usage prevalence was reported. Multivariate logistic regression models adjusted for personal variables, type of air-handling system, and various job and workspace variables. Controlling for some variables in the multivariate models (e.g., allergic or respiratory symptoms) may have underestimated actual CCP effects, as these factors may themselves have resulted from CCP exposures. Despite these limitations, the authors found associations of CCP handling with oronasal symptoms $(\mathrm{OR}=1.18,95 \% \mathrm{CI}=1.00-1.39)$, perception of air contaminants $(\mathrm{OR}=1.48,95 \%$ $\mathrm{CI}=1.15-1.89)$, air quality complaints $(\mathrm{OR}=1.21$, 95\% CI $=1.05-1.40)$, and lighting complaints $(\mathrm{OR}=1.30,95 \% \mathrm{CI}=1.12-1.51)$.

Mendell 1991 and Fiske et al. 1993. Mendell [1991] and Fiske et al. [1993] conducted a cross-sectional epidemiologic study in Northern California among 880 office workers in 12 office buildings. A strength of this study, unlike previous studies, was that the study facilities were selected without regard to worker complaints. Work-related symptoms used in the analyses were defined as those that "occurred often or always in the last year and improved when away from work." The questionnaire response rate was $85 \%$. A number of factors (including CCP) were associated with the prevalence of work-related symptoms after adjustment in a logistic regression model for personal, psychosocial, job, workspace, and building factors (Table 4-4). The OR was not increased for a set of control symptoms included to detect overreporting associated with risk factors of possible concern (such as air-conditioning or CCP). In multivariate analyses adjusted for other workplace exposures, the authors reported that the use of $\mathrm{CCP}$ for more than $1 \mathrm{hr} /$ day was associated with increased ORs for the following: eye, nose, and throat symptoms (OR=1.6, 95\% $\mathrm{CI}=1.0-2.6)$; chest tightness or difficult breathing $(\mathrm{OR}=2.3,95 \% \mathrm{CI}=1.1-4.9)$; and fatigue or sleepiness $(\mathrm{OR}=2.1,95 \% \mathrm{CI}=1.3-3.5)$.

Omland et al. 1993. See Section 4.2.3.2 for a discussion of this study.

Jaakkola and Jaakkola 1999. Jaakkola and Jaakkola [1999] conducted a cross-sectional epidemiologic study of office workers in 41 randomly selected buildings in Helsinki in 1991. They used a questionnaire to investigate associations of health effects with work involving CCP, photocopying, and VDT use. The populations studied had not been selected on the basis of prior complaints or concerns about CCP. The response rate to the questionnaire was $81 \%$, representing a study population of 2,678 (1,119 men and 1,559 women). Of these workers, 910 were exposed to CCP. The outcomes studied included the work-related symptoms often associated with sick building syndrome as well as chronic respiratory symptoms and respiratory infections. Multivariate analyses controlled for building ventilation type in addition to a number of demographic, psychosocial, and other environmental factors. Blinding to the specific study hypotheses reduced the likelihood of information bias in reporting exposure. Known confounders 
Table 4-4. Job or workspace factors associated with the prevalence of work-related symptoms after adjustment ${ }^{*}$ for other personal, psychological, job, workspace, and building factors in northern California office workers, June-September 1990

\begin{tabular}{|c|c|c|c|c|c|c|c|c|c|c|c|c|c|c|}
\hline \multirow{3}{*}{$\begin{array}{c}\text { Job or } \\
\text { workspace factor }\end{array}$} & \multicolumn{14}{|c|}{ Work-related symptoms } \\
\hline & \multicolumn{2}{|c|}{$\begin{array}{c}\text { Eye, nose, or } \\
\text { throat } \\
\text { symptoms }\end{array}$} & \multicolumn{2}{|c|}{$\begin{array}{l}\text { Chest tightness or } \\
\text { difficult breathing }\end{array}$} & \multicolumn{2}{|c|}{ Chills or fevers } & \multicolumn{2}{|c|}{$\begin{array}{l}\text { Fatigue or } \\
\text { sleepiness }\end{array}$} & \multicolumn{2}{|c|}{ Headache } & \multicolumn{2}{|c|}{$\begin{array}{c}\text { Dry or } \\
\text { itchy skin }\end{array}$} & \multicolumn{2}{|c|}{$\begin{array}{l}\text { Non-indoor- } \\
\text { air-related } \\
\text { symptoms }\end{array}$} \\
\hline & $\mathbf{O R}^{\dagger}$ & $95 \% \mathrm{CI}$ & OR & $95 \% \mathrm{CI}$ & OR & $95 \% \mathrm{CI}$ & OR & $95 \% \mathrm{CI}$ & OR & $95 \% \mathrm{CI}$ & OR & $95 \% \mathrm{CI}$ & OR & $95 \% \mathrm{CI}$ \\
\hline Managerial job & 1.2 & $0.7-2.2$ & 0.8 & $0.2-3.2$ & 1.7 & $0.2-1.3$ & 0.8 & $0.4-1.6$ & 0.6 & $0.2-1.4$ & 1.2 & $0.4-3.8$ & 1.2 & $0.5-2.9$ \\
\hline Case worker job & 1.2 & $0.6-2.5$ & 0.8 & $0.2-3.0$ & 1.0 & $0.1-7.5$ & 1.2 & $0.6-2.4$ & 0.6 & $0.3-1.5$ & 2.2 & $0.7-7.3$ & 1.7 & $0.7-4.3$ \\
\hline Technical job & 1.9 & $0.9-4.0$ & 0.5 & $0.1-3.1$ & 3.1 & $0.4-2.3$ & 0.5 & $0.2-1.1$ & 1.3 & $0.5-3.2$ & 2.5 & $0.8-8.2$ & 1.6 & $0.6-4.6$ \\
\hline Clerical job & 1.3 & $0.8-2.1$ & 1.3 & $0.4-3.8$ & 2.9 & $0.5-1.7$ & 0.9 & $0.5-1.5$ & 1.2 & $0.6-2.4$ & 1.5 & $0.6-3.9$ & 1.7 & $0.8-3.5$ \\
\hline CCP use more than & & & & & & & & & & & & & & \\
\hline $1 \mathrm{hr} / \mathrm{day}$ & $1.6^{\dagger}$ & $1.0-2.6$ & 2.3 & $1.1-4.9$ & 1.7 & $0.7-4.6$ & 2.1 & $1.3-3.5$ & 1.4 & $0.8-2.4$ & 0.9 & $0.5-1.9$ & 1.4 & $0.8-2.4$ \\
\hline $\begin{array}{l}\text { Photocopier use } \\
\text { more than } 1 \mathrm{hr} \text { /day }\end{array}$ & 1.6 & $0.8-3.1$ & 1.7 & $0.6-4.7$ & 0.4 & $0.1-2.1$ & 1.4 & $0.7-2.8$ & 1.5 & $0.7-3.1$ & 3.1 & $1.4-6.9$ & 1.4 & $0.6-2.9$ \\
\hline $\begin{array}{l}\text { Space-sharing with } \\
2 \text { or more workers }\end{array}$ & 1.3 & $0.9-1.9$ & 2.0 & $1.0-3.9$ & 1.3 & 01.21 & 1.6 & $1.1-2.3$ & 1.8 & $1.2-2.7$ & 1.6 & $0.9-2.8$ & 1.4 & $0.9-2.2$ \\
\hline $\begin{array}{l}\text { New paint within } \\
15 \mathrm{ft} \text { of workstation }\end{array}$ & 0.6 & $0.3-1.1$ & 0.5 & $0.2-1.6$ & 0.9 & $0.2-3.5$ & 0.4 & $0.2-0.8$ & 0.7 & $0.4-1.4$ & 0.5 & $0.2-1.2$ & 1.0 & $0.5-2.0$ \\
\hline $\begin{array}{l}\text { New walls within } \\
15 \mathrm{ft} \text { of workstation }\end{array}$ & 1.4 & $0.8-2.4$ & 1.9 & $0.7-5.0$ & 2.2 & $0.7-7.0$ & 1.3 & $0.7-2.3$ & 1.8 & $0.9-3.4$ & 1.5 & $0.7-3.4$ & 0.8 & $0.4-1.7$ \\
\hline
\end{tabular}


Table 4-4 (Continued). Job or workspace factors associated with the prevalence of work-related symptoms after adjustment ${ }^{*}$ for other personal, psychological, job, workspace, and building factors in northern California office workers, June-September 1990

\begin{tabular}{|c|c|c|c|c|c|c|c|c|c|c|c|c|c|c|}
\hline \multirow{3}{*}{$\begin{array}{c}\text { Job or } \\
\text { workspace factor }\end{array}$} & \multicolumn{14}{|c|}{ Work-related symptoms } \\
\hline & \multicolumn{2}{|c|}{$\begin{array}{c}\text { Eye, nose, or } \\
\text { throat } \\
\text { symptoms }\end{array}$} & \multicolumn{2}{|c|}{$\begin{array}{l}\text { Chest tightness or } \\
\text { difficult breathing }\end{array}$} & \multicolumn{2}{|c|}{ Chills or fevers } & \multicolumn{2}{|c|}{$\begin{array}{l}\text { Fatigue or } \\
\text { sleepiness }\end{array}$} & \multicolumn{2}{|c|}{ Headache } & \multicolumn{2}{|c|}{$\begin{array}{c}\text { Dry or } \\
\text { itchy skin }\end{array}$} & \multicolumn{2}{|c|}{$\begin{array}{l}\text { Non-indoor- } \\
\text { air-related } \\
\text { symptoms }\end{array}$} \\
\hline & OR & $95 \% \mathrm{CI}$ & OR & $95 \% \mathrm{CI}$ & OR & $95 \% \mathrm{CI}$ & OR & $95 \% \mathrm{CI}$ & OR & $95 \% \mathrm{CI}$ & OR & $95 \% \mathrm{CI}$ & OR & $95 \% \mathrm{CI}$ \\
\hline $\begin{array}{l}\text { New carpet within } \\
15 \mathrm{ft} \text { of workstation }\end{array}$ & 3.0 & $1.0-8.8$ & 14.2 & $3.2-63$ & 1.2 & $0.1-15$ & 1.4 & $0.4-4.4$ & 2.6 & $0.8-9.2$ & 0.5 & $0.0-6.0$ & 2.8 & $0.8-9.5$ \\
\hline $\begin{array}{l}\text { Carpet-any in } \\
\text { study space }\end{array}$ & 1.7 & $1.1-2.6$ & 2.5 & $1.0-6.2$ & 1.4 & $0.5-3.7$ & 1.1 & $0.7-1.7$ & 2.0 & $1.1-3.4$ & 0.9 & $0.5-1.8$ & 1.1 & $0.6-1.9$ \\
\hline $\begin{array}{l}\text { Cloth partitions- } \\
\text { any in study space }\end{array}$ & 0.5 & $0.3-0.8$ & 0.2 & $0.1-6.2$ & 0.5 & $0.1-1.6$ & 0.5 & $0.1-1.6$ & 0.6 & $0.4-1.1$ & 0.5 & $0.2-1.0$ & 1.2 & $0.7-2.0$ \\
\hline $\begin{array}{l}\text { No windows within } \\
15 \mathrm{ft} \text { of workstation }\end{array}$ & 1.6 & $1.1-2.3$ & 1.6 & $0.8-3.2$ & 2.4 & $1.1-5.6$ & 1.5 & $1.0-2.5$ & 2.1 & $1.3-3.3$ & 1.6 & $0.9-2.7$ & 1.3 & $0.8-2.1$ \\
\hline $\begin{array}{l}\text { Inability to see out } \\
\text { of window from } \\
\text { workstation }\end{array}$ & 0.8 & $0.5-1.3$ & 0.8 & $0.3-1.7$ & 0.4 & $0.2-1.2$ & 1.6 & $1.0-2.5$ & 1.0 & $0.6-1.7$ & 1.1 & $0.6-2.1$ & 1.0 & $0.6-1.7$ \\
\hline
\end{tabular}

Source: Mendell [1991].

"ORs and 95\% CIs were adjusted in a logistic regression model.

'Abbreviations: $\mathrm{OR}=$ odds ratio; $\mathrm{CI}=$ confidence interval. 
(including personal characteristics, smoking, socioeconomic status, and psychological and social factors at work) were controlled in the analysis. CCP use was analyzed as "any" versus "none."

Statistically significant associations were observed between work with CCP (involving $34 \%$ of the population) and most of the outcomes studied - including weekly work-related eye, nose, pharyngeal, and skin symptoms, headache, and lethargy $(\mathrm{ORs}=1.56,1.48,1.83$, $1.68,1.66$, and 1.38, respectively); chronic respiratory symptoms including wheeze, cough, mucus, and chronic bronchitis (ORs=1.29, 1.43, 1.41 , and 1.79 , respectively); and respiratory infections including sinusitis and acute bronchitis $(\mathrm{ORs}=1.46$ and 1.54, respectively).

In contrast, only one of the 20 or so outcomes assessed (the common cold) was significantly elevated among workers with light or heavy photocopying work, and two symptom categories (otitis and general symptoms) were elevated for light or heavy VDT users. Additional analyses focused only on VDT and photocopier users; they identified several additional outcomes related specifically to these activities.

This study provides strong support for the CCP health effects hypothesis. The numerous relationships found between health outcomes and CCP use (but not between health outcomes and photocopying or VDT work) make overreporting due to health concerns in the randomly selected buildings an unlikely explanation for these findings.

\subsubsection{Cross-Sectional Studies of CCP Exposures}

Sixteen cross-sectional studies using questionnaires to assess health problems in relation to CCP exposure were conducted in Sweden, Denmark, and the United States (see Table 4-3). These studies attempted to describe and estimate the prevalences of various symptoms, primarily mucous membrane and skin irritation associated with the handling or manufacturing of CCP. A few of these studies had strong cross-sectional designs with appropriate unexposed comparison groups, ascertainment of symptoms independent of workers' opinions on their association with $\mathrm{CCP}$ use, and multivariate analysis allowing determination of the association with CCP exposures independent of other factors. In surveys with data on self-reported and unconfirmed symptoms that respondents subjectively attributed to $\mathrm{CCP}$ handling, concern about the use of CCP might (through hypervigilance or enhanced recall) upwardly bias estimates of symptom prevalence.

Fristedt and Pettersson 1980. Fristedt and Pettersson [1980] conducted a questionnaire survey of 180 persons ( $88 \%$ were women) in Sweden. Of these 180 study subjects, 135 had been identified in a previous survey ${ }^{\dagger}$ of the Swedish Association of Municipal Technology (SKTF) union as having reported symptoms related to CCP exposure. An additional 45 cases were identified from interview referrals (i.e., workers who had not previously disclosed symptoms but were mentioned in interviews with other workers). The average duration of CCP exposure was 5 years (maximum of 18 years), with $87 \%$ handling paper for more than $50 \%$ of their working time.

By correlating the time and use patterns, $68 \%$ (122 workers) were thought to have symptoms related to work with $\mathrm{CCP}$, including some workers in printing operations. Fifty-three percent of this group with symptoms reported mucous membrane symptoms (primarily of the nose and eyes), and $47 \%$ reported skin symptoms

\footnotetext{
${ }^{\dagger}$ In this previous survey, only $243(8 \%)$ of the 3,000 persons surveyed responded to the questionnaire, which raises serious concerns about the representativeness of the respondents.
} 
(see Table 4-5). The skin disorders consisted mainly of dryness that occurred first on the hands and later on the face. The latter is localized around the eyes and sometimes combined with irritation of the eyes (assumed to be caused by touching the face with the hands). According to the authors, the most striking disorders occurred among the 67 who had a history of similar complaints or "a tendency to allergy." Of the 180 interviewees, 22 complained of an unpleasant smell that could not be linked to a specific CCP. One interviewee lost the sense of smell and taste, and two stated that they no longer had feeling in their tongues.

The authors stated that in the original survey of 3,000 workers, $30 \%$ to $50 \%$ of the employees at some workplaces had complained; but at others, no one had complained in spite of massive handling of CCP. Workers who handled clay-based papers reported skin disorders more frequently than those who handled polymer-based (phenolic) papers (71\% [29/41]

\section{Table 4-5. Types and locations of skin and mucous membrane symptoms in a Swedish questionnaire study}

\begin{tabular}{|c|c|c|}
\hline $\begin{array}{c}\text { Type and } \\
\text { location of symptom }\end{array}$ & $\begin{array}{l}\text { Number of workers } \\
\text { reporting symptoms }\end{array}$ & $\begin{array}{l}\text { \% workers linking } \\
\text { symptoms with CCP }\end{array}$ \\
\hline \multicolumn{3}{|l|}{ Type of skin symptom } \\
\hline Dryness & 39 & 36 \\
\hline Itchng & 16 & 94 \\
\hline Dryness and itching & 26 & 62 \\
\hline Redness and rash & 20 & 55 \\
\hline Eczema & 7 & 14 \\
\hline Total & 108 & - \\
\hline \multicolumn{3}{|l|}{ Location of symptom: } \\
\hline Hands & 66 & 53 \\
\hline Arms & 11 & 64 \\
\hline Face & 29 & 69 \\
\hline Other & 12 & 67 \\
\hline Total & 118 & - \\
\hline \multicolumn{3}{|c|}{ Type of mucous memrane symptom: } \\
\hline Dryness & 18 & 50 \\
\hline Irritation & 78 & 58 \\
\hline Dryness and irritation & 18 & 6 \\
\hline Allergy & 6 & 17 \\
\hline Total & 120 & - \\
\hline \multicolumn{3}{|l|}{ Location of symptom: } \\
\hline Eyes & 57 & 54 \\
\hline Nose & 86 & 63 \\
\hline Mouth & 23 & 57 \\
\hline Throat & 29 & 66 \\
\hline Total & 195 & - \\
\hline
\end{tabular}

Source: Fristedt and Pettersson [1980]. 
compared with 52\% [36/69]). But those who worked with polymer-based (phenolic) papers reported mucous membrane disorders more often (81\% [56/69] compared with 68\% [28/41]). Solvents used in the clay paper consisted of hydrogenated terphenyls plus kerosene, and those in the polymer paper consisted of phenylxylylethane plus diisopropylnaphthalene [Norbäck et al. 1988]. Other numbers of symptoms were too small to discern patterns. Of the 35 workers who were skin-patch tested with $\mathrm{CCP}$, none had positive reactions. Environmental factors such as high temperature, low humidity, and dust were thought to be contributing. The authors concluded that it was difficult to decide which symptoms could definitely be correlated with CCP. The prevalence of complaints was $4 \%$ of the 3,000 workers who came in contact with CCP; but if slight complaints of doubtful origin were ignored, the prevalence was $2.4 \%$. Symptoms were more severe in those predisposed to allergy, but no allergy to CCP components was demonstrated. Also, the authors remarked that most of the workers interviewed had reported ill health symptoms only after the newspaper publicity had appeared.

Andersson et al. 1980. This Swedish study used a questionnaire to address CCP effects among 158 workers at an insurance office who had reported symptoms of the skin (irritation and itching of hands, forearms, and face), eyes (itching and burning), and mucous membranes (dryness of mouth and throat, nasal stuffiness, and catarrh). To obtain comparative data, the same kind of questionnaire was distributed to four other office places (183 persons). The authors examined the type of paper in question as well as other environmental factors. The prevalence of symptoms increased when subjects were exposed to $\mathrm{CCP}$ or to wall-to-wall carpeting. This increase was observed in both atopic and nonatopic patients.
Öberg 1980. As cited in Murray [1991], Öberg conducted a questionnaire study of 205 people; $74 \%$ handled more than $10 \mathrm{CCP}$ forms per day. Forty percent of the study population reported symptoms, including itching and dryness of the hands, eyes, and mouth. Four cases of eczema were found. The author reports a dose-response relationship, but Murray suggests that information was inadequate to verify this result.

Sondergard 1981. Sondergard [1981], as cited by Murray [1991] and Olsen and Mørck [1985], conducted a questionnaire study of workers at two locations of Scandinavian Airlines Systems. The frequency of symptoms reported was $73 \%$ (68 of 93 workers studied), and the symptom frequency increased with the amount of CCP handled daily (see Table 4-6). The author noted that the dose-response connection was not statistically significant because of the small number of workers in Groups 2 and 4 (numbers were not reported by the reviewers).

Menné et al. 1981. Menné et al. [1981] administered a questionnaire survey to workers at the Danish telephone company; the authors also performed a clinical evaluation of the cases (see Section 4.2.1). Approximately $77 \%$ of the workers responded to the questionnaire. Of these, some were eliminated because they did not handle CCP. Of the remaining 1,855 respondents, 208 (11\%) indicated that they had experienced skin and/or mucous membrane irritation. Analysis revealed that the symptoms were not related to the type of building in which the subjects worked. According to the authors, the number of CCP contacts per day appeared to be clearly related to the frequency of symptoms:

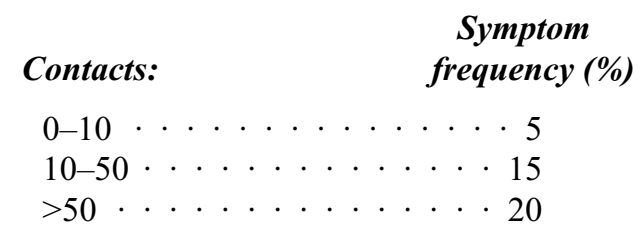


Table 4-6. Dose-response relationship of CCP handling frequency with symptoms reported by respondents

\begin{tabular}{ccc}
\hline Group & $\begin{array}{c}\text { Number of CCP sheets } \\
\text { handled per day }\end{array}$ & $\begin{array}{c}\text { \% Respondents } \\
\text { with symptoms }\end{array}$ \\
\hline 1 & $<100$ & 57.6 \\
2 & $100-250$ & 66.7 \\
3 & $250-1,000$ & 93.5 \\
4 & $>1,000$ & 100 \\
\hline
\end{tabular}

Source: Sondergard [1981] as cited by Murray [1991] and Olsen and Mørck [1985].

The authors suggested that mass psychosis was an unlikely explanation for their findings since an exposure-response relationship was identified - not the all or nothing response expected with mass psychosis. The authors also suggested that mass psychosis was inconsistent with the fact that no relationship existed between the age of the workers and the number of complaints: they would expect younger workers to have the weakest ties to the company and thus to be more likely to report symptoms. In rejecting mass psychosis as an explanation for their findings, the authors suggested that some component of the paper was responsible for the observed symptoms.

Göthe et al. 1981 and Norbäck et al. 1983b. Göthe et al. [1981] and Norbäck et al. [1983b] presented findings about the frequency of respiratory symptoms in three groups of Swedish patients:

- Group A: 19 patients referred to the Clinic of Occupational Medicine at South Hospital

- Group B: 38 patients at the Karolinska Clinic of Occupational Dermatology

- Group C: a random sample of 22 patients with no CCP exposure
The patients in Groups A and B were referred during the period January 1976 to October 1980 because of health problems associated with occupational handling of CCP. However, because the authors did not describe the population from which the patients were referred, population prevalence rates could not be calculated. Among patients with health complaints from handling $\mathrm{CCP}$, roughly half reported irritative symptoms involving the eyes or upper respiratory tract, and 11\% (Group A) to $28 \%$ (Group B) experienced nasal catarrh or congestion. In the unexposed group (Group C), 14\% experienced ocular or upper respiratory irritation, and there were no cases of nasal catarrh or congestion. The difference in incidence between the exposed groups (A and B) and the unexposed group (C) was statistically significant $(P<0.01)$ for eye and upper respiratory irritation. The elevated incidence of nasal catarrh or congestion was statistically significant $(P<0.01)$ in Group B but not in Group A relative to the unexposed Group C. Symptoms such as headache, fatigue, nausea, and a metallic taste in the mouth occurred at a low rate ( $1 \%$ to $9 \%$ ), with no statistically demonstrable correlation with the type of exposure or the volume of CCP handled. The results in Table 4-7 contrast patients in a high-exposure group ( $\geq 150$ sheets per day) with those in a low-exposure group 
Table 4-7. Frequency of respiratory tract symptoms by type of paper and exposure level*

\begin{tabular}{|c|c|c|c|c|c|c|}
\hline \multirow[b]{3}{*}{ Type of paper } & \multicolumn{3}{|c|}{ Workers exposed to $<150$ sheets per day } & \multicolumn{3}{|c|}{ Workers exposed to $\geq 150$ sheets per day } \\
\hline & \multirow{2}{*}{$\begin{array}{c}\text { Total } \\
\text { number } \\
\text { in group }\end{array}$} & \multicolumn{2}{|c|}{$\begin{array}{c}\text { Workers reporting } \\
\text { symptoms }\end{array}$} & \multirow{2}{*}{$\begin{array}{c}\text { Total } \\
\text { number } \\
\text { in group }\end{array}$} & \multicolumn{2}{|c|}{$\begin{array}{c}\text { Workers reporting } \\
\text { symptoms }\end{array}$} \\
\hline & & Number & $\%$ Total & & Number & $\%$ Total \\
\hline \multicolumn{7}{|l|}{ Paper containing } \\
\hline MIPB & 6 & 3 & 50 & 5 & 5 & 100 \\
\hline Other CCP & 21 & 4 & 19 & 26 & 13 & 50 \\
\hline \multicolumn{7}{|l|}{$\begin{array}{l}\text { Ordinary paper } \\
\text { and carbon }\end{array}$} \\
\hline paper & 7 & 0 & 0 & 15 & 3 & 20 \\
\hline
\end{tabular}

Source: Göthe et al. [1981] and Norbäck et al. [1983b].

${ }^{*}$ Note: These values vary slightly in the earlier publication.

( $<150$ sheets per day). Patients were excluded if they had irritation of the respiratory tract that was not specifically related to work with paper. The data show that throughout, the frequency of complaints was higher in the high-exposure groups than in the corresponding low-exposure groups for all types of paper, including ordinary paper. These data also demonstrated a higher prevalence of work-related respiratory symptoms in patients seen at the clinic and exposed to CCP containing MIPB - a solvent used in the microcapsules. This prevalence rate was $100 \%$ in the high-exposure group.

Norbäck et al. [1983b] also investigated whether the dose-response associations might be due to an increased proportion of sensitive workers among those who handle large amounts of paper. They determined whether patients with atopy or nonspecific hyperreactivity of the respiratory tract were concentrated among these highly exposed individuals. Atopy was assumed to be present if the patient had a history of asthma or hay fever or a tendency to develop eczema.
Nonspecific hyperreactivity was assumed to be present if the patient had reported experiencing respiratory tract irritation when exposed to nonspecific irritants such as perfume, cigarette smoke, and vehicle exhaust in the everyday environment. Fewer sensitive patients $(P<0.05)$ were identified among those who handled large volumes of paper than among those who handled small volumes of paper, indicating that confounding by atopy could not explain the observed exposure-response relationships.

These authors also investigated the role of D-inks, which were present in about $20 \%$ of the CCP. A significant increase $(P=0.00009)$ occurred in the prevalence of work-related pruritus combined with erythema in those working with CCP treated with D-ink versus those not working with these inks (39\% versus $0 \%$ ).

Analysis of other contributing factors in this population revealed that work involving photocopies or the presence of wall-to-wall carpeting was not significantly correlated with skin or mucous membrane symptoms. The authors concluded that a significant dose-response 
relationship could be shown only between exposure to $\mathrm{CCP}$ and mucous membrane irritation of the upper respiratory tract. The authors stated that the same phenomenon occurs with ordinary paper and carbon paper but that $\mathrm{CCP}$ can produce symptoms when lower volumes of paper are handled.

Kolmodin-Hedman et al. 1981. At a clinic for occupational medicine in Uppsala, Sweden, Kolmodin-Hedman et al. [1981] conducted an inquiry among those employed by an insurance office (total of 145 workers) and a hospital laboratory (12 workers). A comparison group of 20 was composed of hospital office staff who did not handle CCP. The investigation was triggered by six cases in an insurance office; the main symptoms were irritation of the upper respiratory tract. The prevalence of symptoms was greatest in the hospital laboratory $(92 \%)$, where about 1,000 forms were handled per day by each of the five receptionists and seven computer operators. The insurance office workers worked with fewer forms (number not given) than the laboratory workers; they reported a $32 \%$ prevalence. The comparison group reported a $10 \%$ prevalence of symptoms. Of those in the insurance group who complained of symptoms (46), 17 were diagnosed as atopic and 6 with underlying allergic or eczematous conditions. Of the remaining 23, one had symptoms connected with handling "wet copies," and another had a complaint that was clearly linked to the use of a certain type of stamp pad. The remaining 21 had skin and/or mucous membrane complaints: 13 stated that they had the most trouble at work, and 8 stated that their symptoms were independent of where they were. None of the six types of CCP forms used were known to contain D-inks, and three contained hydrogenated terphenyls, diethylethane, and diisopropylnaphthalenes. Two contained unknown solvents. Among the workers who handled only clay-based paper at the insurance office, the frequency of mucous membrane symptoms was approximately equal to that of the comparison group. The skin (hands and face) and eye symptoms were considered likely to be related to CCP exposure, since their frequency $(21 \%$ among insurance workers versus $67 \%$ in laboratory workers) was much higher than that of the comparison group $(5 \%)$.

Kleinman and Horstman 1982. In the United States, persistent health complaints attributed to the use of CCP by office workers on the campus of the University of Washington led to a preliminary study by Kleinman and Horstman [1982]. The goals were (1) to estimate the extent of the problem in a population of known CCP users, (2) to describe the health problems that the users attributed to $\mathrm{CCP}$, and (3) to make a preliminary determination of the chemical constituents of the paper. An unknown number of office workers were asked to complete a health questionnaire and to attach to it copies of the forms they used. Among the 265 subjects respondng to the survey, 71 (27\%) reported complaints. Across different offices, the minimum estimate was 10.7 health complainants per 100 users, similar to that found by investigators in the United Kingdom and Denmark [Calnan 1979; Menné et al. 1981], but this estimate was lower than that reported by other investigators and by anecdotal material. Of the 108 respondents who answered "yes" (n=71) or "don't know" $(n=37)$ to the question relating symptoms to $\mathrm{CCP}, 53$ participated in a medical exam. The positive findings are tabulated in Table 4-8. Kleinman and Horstman [1982] also reported a significant relationship $\left(\mathrm{X}_{1}^{2}=0.0002\right)$ between the amount of CCP used daily and worker reports of health effects they attributed to CCP: $41.3 \%$ of the heavy users of CCP (those who handled 51 or more forms/day) responded "yes" to the question relating health effects with CCP, compared with $29.9 \%$ of moderate users (11 to 50 forms/day) and $18.8 \%$ of minimal users (1 to 10 forms/day). The authors hypothesized that concurrent factors such as poor 


\section{Table 4-8. Positive findings from physician interviews} of 53 respondents to a health questionnaire

\begin{tabular}{lc}
\hline \multicolumn{1}{c}{ Finding } & \% total \\
\hline Red, swollen, scaly hands & 41.5 \\
Stuffed nose & 39.6 \\
Sneezing & 37.5 \\
Headaches & 35.8 \\
Running nose & 30.2 \\
Infected, itching, red conjunctiva & 29.6 \\
Red, swollen eyelids & 20.4 \\
Red face & 17.0 \\
Shortness of breath & 15.1 \\
Coughing & 13.2 \\
Red, crusted skin & 7.5 \\
Wheezing & 7.5 \\
Red arms & 5.7 \\
\hline
\end{tabular}

Adapted from Kleinman and Horstman [1982].

ventilation, high temperature, and/or low humidity might play a role in the clinical expression of CCP effects.

Pryor et al. 1983. In response to a request for a NIOSH Health Hazard Evaluation, Pryor et al. [1983] investigated complaints of respiratory, eye, and skin irritation and one case of thrombocytopenia at a Colorado municipal court house. A questionnaire was administered to eight employees who worked in an area with intensive storage and use of CCP forms and also to eight others who worked in an area with little CCP contact. The CCP storage was immediately next to 2- and 4-inch pipes carrying hot water during the winter for heating the building; these pipes were believed to be causing increased emissions from the CCP. Heating CCP paper samples in the NIOSH laboratory produced formaldehyde and also substituted biphenyls and terphenyls typical of CCP. However, air samples taken in the office at various times during the months of December and March identified only formaldehyde.
CCP-exposed workers during the month of April had somewhat higher prevalences of eye, nasal, and throat complaints (ranging from $25 \%$ to $75 \%$ ) than non-CCP-exposed workers, whose symptoms ranged from $0 \%$ to $50 \%$. However, small numbers precluded a statistical test.

Olsen and Morck 1985. Olsen and Mørck [1985] administered a questionnaire and physical exams to the 129 workers at two Danish form-printing shops. The authors confirmed complaints that the CCP-exposed parts of the skin exhibited "heavy erythema, combined with irritative itching, vesicles, and wounds together with more chronic changes with lichenification, furrows, and chaps." The frequency of symptoms increased significantly $(P<0.01)$ with the volume of CCP handling (see Table 4-9).

Omland et al. 1993. Omland et al. [1993] investigated the extent to which handling large amounts of CCP caused skin and mucous 
Table 4-9. Dose-response relationship between CCP handling and mucous membrane and skin symptoms in two form-printing shops

\begin{tabular}{|c|c|c|c|c|c|}
\hline \multirow[b]{3}{*}{$\begin{array}{l}\text { CCP handling } \\
\text { frequency } \\
\text { (sheets per day) }\end{array}$} & \multirow[b]{3}{*}{$\begin{array}{c}\text { Total } \\
\text { number } \\
\text { of workers }\end{array}$} & \multicolumn{4}{|c|}{ Workers with symptoms } \\
\hline & & \multicolumn{2}{|c|}{$\begin{array}{c}\text { Skin and mucous } \\
\text { membrane symptoms }\end{array}$} & \multicolumn{2}{|c|}{ Skin symptoms } \\
\hline & & Number & $\%$ & Number & $\%$ \\
\hline $0-5$ & 26 & 0 & 0 & 0 & 0 \\
\hline $6-20$ & 26 & 0 & 0 & 0 & 0 \\
\hline $21-75$ & 28 & 9 & 32.1 & 5 & 17.9 \\
\hline $76-250$ & 25 & 14 & 56.0 & 10 & 40.0 \\
\hline $251-2000$ & 24 & 17 & 70.8 & 14 & 58 \\
\hline Total & 129 & 40 & 31.0 & 29 & 22.5 \\
\hline
\end{tabular}

Source: Olsen and Mørck [1985].

membrane symptoms in a cross-sectional study of 20 Danish government workers who were highly exposed to CCP and a comparison group of 20 workers who were generally not exposed. These groups were matched for sex, age, location of workplace, known skin diseases, history of childhood asthma, known allergy to nickel, asthmatic conditions, chronic bronchitis, eye diseases, nettle rash, and use of tanning facilities. Double-blind dermatological exams included observations and histories, skin-prick tests for allergens, scratch tests for CCP and its components versus ordinary paper, objective measures of dermal erythema after occluded testing, and skin-patch tests. Temperature, humidity, formaldehyde, and total dust were measured. Two groups of workers were exposed to CCP. Over a period of 4 weeks, the first group of 5 sent out 120,000 identical forms printed on CCP that had been stored in the work area. Their work consisted of tearing off forms from a continuous paper web and stuffing the forms into envelopes (about 1,200 per day per worker). The second exposure group of 15 workers processed the 42,000 returned forms over a 2-week period, checking and entering information into computers (about 280 per day per worker). The comparison group was selected from $122 \mathrm{em}$ ployees who worked in the same large office building and had returned completed questionnaires about symptoms and exposure to CCP. These questionnaires were administered weekly during the exposure periods. They included questions about CCP exposure, work with computers and photocopying, and subjective symptoms of skin and respiratory irritation. Temperature was $23.5^{\circ} \mathrm{C}$ and humidity was about $40 \%$ in both offices. These were reported along with six formaldehyde measurements, (including both area and personal samples) ranging from 0.1 to $0.62 \mathrm{mg} / \mathrm{m}^{3}$. Total dust measurements were $0.34 \mathrm{mg} / \mathrm{m}^{3}$ in the study office and $0.28 \mathrm{mg} / \mathrm{m}^{3}$ in the comparison group office. Table 4-10 shows the incidence of symptoms during both exposure periods among the exposed workers and their matched comparison workers. A significantly greater incidence of skin irritation $(P=0.03)$ and pruritus $(P=0.007)$ occurred in the exposed group during the first exposure period. However, no differences occurred in the incidence of 
Table 4-10. Incidence of symptoms in exposed workers and their matched comparison workers during two exposure periods

Symptoms (\%)

\begin{tabular}{|c|c|c|c|c|c|c|c|c|c|c|c|c|}
\hline $\begin{array}{l}\text { Exposure period } \\
\text { and type of } \\
\text { worker }\end{array}$ & $\begin{array}{l}\text { Number } \\
\text { of } \\
\text { responses }\end{array}$ & $\begin{array}{c}\text { Eye } \\
\text { irritation }\end{array}$ & Red eyes & $\begin{array}{c}\text { Skin } \\
\text { irritation }\end{array}$ & $\begin{array}{c}\text { Facial } \\
\text { erythema }\end{array}$ & $\begin{array}{c}\text { Erythema } \\
\text { of the hands }\end{array}$ & Pruritus & Rash & $\begin{array}{c}\text { Nasal } \\
\text { congestion }\end{array}$ & $\begin{array}{l}\text { Runny } \\
\text { nose }\end{array}$ & Nosebleed & Cough \\
\hline \multicolumn{13}{|l|}{ Exposure period $1:^{\dagger}$} \\
\hline $\begin{array}{l}\text { Comparison } \\
\text { worker }\end{array}$ & 18 & 33.3 & 22.2 & 16.7 & 11.1 & 0 & 22.2 & 11.1 & 11.1 & 5.6 & 0 & 11.1 \\
\hline Exposed worker & 5 & 60.0 & 20.0 & 80.0 & 0 & 20.0 & 100.0 & 0 & 60.0 & 0 & 20.0 & 60.0 \\
\hline \multicolumn{13}{|l|}{ Exposure period 2: } \\
\hline $\begin{array}{l}\text { Comparison } \\
\text { worker }\end{array}$ & 16 & 25.0 & 25.0 & 25.0 & 6.3 & 6.3 & 18.8 & 12.5 & 6.3 & 18.8 & 0 & 12.5 \\
\hline Exposed worker & 15 & 20.0 & 20.0 & 13.3 & 20.0 & 13.3 & 33.3 & 6.7 & 20.0 & 20.0 & 6.7 & 20.0 \\
\hline
\end{tabular}

Source: Omland et al. [1993]

"Some comparison workers were unable to respond because they were absent from work.

Workers were exposed to 1,200 fresh forms per day during period 1 .

Workers were exposed to 280 forms (with broken microcapsules) per day during period 2. 
symptoms reported by the exposed and comparison workers during the second exposure period, which involved processing forms that were several months old. Exposed workers reported large decreases in most symptoms during the second period, when they handled the completed forms with broken microcapsules (280/day) rather than the fresh forms (1,200 per day) during the first period. These symptom decreases during the second period included a sixfold decrease in skin irritation and threefold decreases in eye irritation, pruritus, nasal congestion, nosebleed, and cough. However, increases occurred in facial erythema, rash, and runny nose.

Figure 4-2 shows the relationship between pruritus and increasing CCP exposure. Four of the 18 comparison workers $(22.2 \%)$ during the first exposure period and 3 of the 16 comparison workers $(18.8 \%)$ during the second exposure period reported pruritus. Ten of the 20 workers $(50 \%)$ exposed to $\mathrm{CCP}$ experienced pruritus: 4 of 10 employees ( $40 \%$ ) who worked daily with 101 to 750 form sets, and 6 of 10 employees $(60 \%)$ who worked with $>750$ form sets reported pruritus. These results show a statistically significant increase in the prevalence of pruritus with increasing exposure to $\mathrm{CCP}$, regardless of whether the responses were used from the first exposure period $(P=0.049)$ or the second exposure period $(P=0.03)$. Clinical examination revealed no significant differences between atopic workers in the exposed and comparison groups. The duration of pruritus after histamine provocation was also the same in both groups. Erythema index measurements showed large variations, and no significant differences existed between the reactions of workers in the exposed and the comparison groups to contact with paper, CCP, the contents of the microcapsules, or a damping solution from CCP. Scratch tests with CCP were negative, and skin patch tests with nickel yielded four reactions in the exposed group and one reaction in the comparison group. Although these differences were not statistically

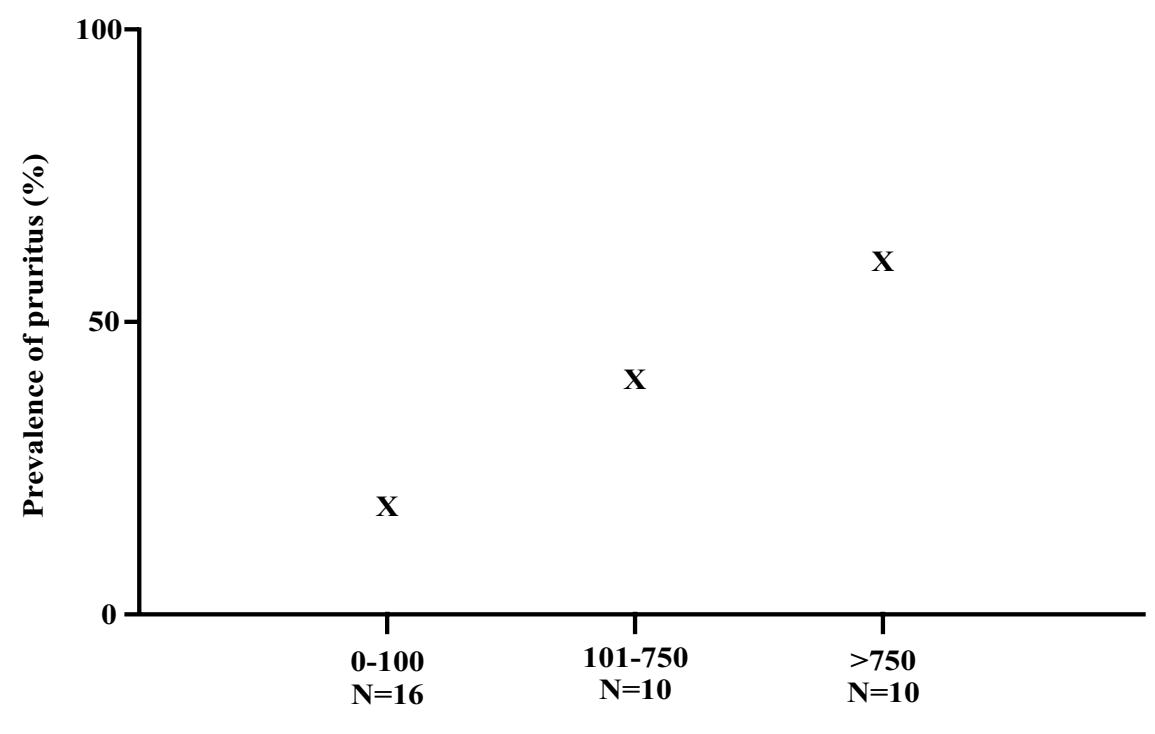

Sheets handled

Figure 4-2. Prevalence of pruritus among CCP handlers by sheets of CCP handled during the exposure period. 
significant, the authors noted that the higher number of nickel reactions in the exposed group may indicate a higher prevalence of atopic workers in that group and thus a potential bias in the study. No increased skin dryness or desiccation was noted in the exposed or comparison groups. Possible shortcomings of this otherwise well-designed study are that (1) the matched comparison workers were not matched for the amount of ordinary paper they handled, and (2) the matching does not appear to have been considered in the analysis of the data. Thus the study results may be potentially confounded by the matching factors and by ordinary paper exposure. On the other hand, the strength of the association $(P<0.007)$ and the evidence of an exposure-response relationship $(P=0.049)$ support an association of some types of CCP with pruritus.

Apol and Thoborn 1986. See Section 4.2.1 for a discussion of this study.

\subsubsection{Laboratory Studies in Humans}

This section reviews studies that used some form of experimental testing in humans (such as patch or prick tests) under controlled laboratory conditions to assess the potential health effects of exposure to CCP or its components. These studies are distinct from the laboratory studies performed in some of the case studies and cross-sectional studies reviewed earlier in this chapter (see Sections 4.2.1 and 4.2.3), which generally involved a few cases from a specific company and did not employ a rigorous experimental design. In addition to the peer-reviewed literature, this section examines unpublished experimental studies that were usually sponsored by the U.S. manufacturers of CCP and were submitted to the NIOSH docket.

The experimental nature of laboratory studies offers advantages over the observational studies described in earlier sections. These studies do not have the potential for confounding or recall bias that the observational studies had. However, laboratory studies also have limitations that undermine their usefulness for judging the causal relationship between $\mathrm{CCP}$ exposure and health effects. First, these studies are largely limited to the inclusion of healthy volunteers. A consequence of this approach is that persons with a history of allergy or irritation reaction might be less likely to volunteer than those with no symptoms, thus creating selection bias. Second, it is unclear whether the exposures in laboratory studies are representative of those actually experienced by workers in the field. Third, most of the laboratory studies did not include ordinary paper as a control. Thus it is not possible to determine whether the effects observed in some studies result from chemical components of CCP or from the paper itself.

\subsubsection{Peer-Reviewed Literature Studies}

Table 4-11 summarizes the three experimental studies in humans that have appeared in the peer-reviewed literature. These studies are discussed below.

Nilzen 1975. At the request of a CCP manufacturer, Nilzen [1975] of Sweden conducted provocative tests (including patch, prick, eye, and nose irritation tests with water extracts) and vapor inhalation studies with crushed CCP and ordinary bond paper. The patch tests in eight subjects were negative, but prick tests resulted in an unspecified number of weak and medium-strong reactions to both CCP and ordinary bond paper. Two subjects were tested by inhalation of vapors from CCP or bond paper, and both resulted in irritation; however, the $\mathrm{CCP}$ caused a greater reaction. The author concluded that (1) certain persons with a history of allergy or irritative reactions may react to $\mathrm{CCP}$ as well as to ordinary bond paper and a variety of other materials and (2) despite evidence of 
Table 4-11. Experimental laboratory investigations of allergic and irritative reactions in humans exposed to $\mathrm{CCP}$

\begin{tabular}{|c|c|c|c|c|c|c|}
\hline Authors & Country & Number tested & Agents & Type of test & $\begin{array}{c}\text { Comparison } \\
\text { workers }\end{array}$ & Results \\
\hline Nilzen 1975 & Sweden & $16^{*}$ & $\begin{array}{l}\mathrm{CCP} \text {, nose and eye } \\
\text { administration of } \\
\text { extracts }\end{array}$ & $\begin{array}{l}\text { Patch and prick } \\
\text { tests, eye and nose } \\
\text { irritation, inhala- } \\
\text { tion of vapors from } \\
\text { pulverized paper }\end{array}$ & $\begin{array}{l}8 \text { matched } \\
\text { comparison } \\
\text { workers }\end{array}$ & $\begin{array}{l}\text { No positive patch tests; some weak } \\
\text { and moderate reactions to prick test } \\
\text { with CCP and ordinary paper; two } \\
\text { subjects had irritation reactions to } \\
\text { vapors from CCP and ordinary } \\
\text { bond paper. }\end{array}$ \\
\hline $\begin{array}{l}\text { Jeansson et al. } \\
1983,1984\end{array}$ & Sweden & 148 & $\begin{array}{l}\mathrm{CCP} \text {, non-CCP } \\
\text { paper components, } \\
\text { specific chemicals } \\
\text { in CCP }\end{array}$ & $\begin{array}{l}\text { Patch and scratch } \\
\text { tests and other } \\
\text { examinations }\end{array}$ & None & $\begin{array}{l}\text { Positive reactions to } 2 \text { types of } \\
\text { carbon paper. Slight irritation from } \\
50 \% \text { kerosene (1/59), } 50 \% \\
\text { isoparaffins (1/59). Slight redness } \\
\text { from } 100 \% \text { alkylated benzene (1/1), } \\
\text { but no reaction with a } 50 \% \\
\text { concentration ( } 0 / 54) \text {. Primary } \\
\text { irritation from } 2 \text { D-inks ( } 1 \text { at } 5 \% \\
\text { concentration [19/44] and 1at } 1 \% \\
\text { [26/44]). CCP-exposed patients had } \\
\text { a longer duration of itch in tests } \\
\text { assessing skin response to } \\
\text { histamine. Two probable allergic } \\
\text { reactions to synthetic resin } \\
\text { components ( } 1 \text { to melamine } \\
\text { formaldehyde and } 1 \text { to resorcin). No } \\
\text { specific reactions to subjects' } \\
\text { exposures to their own CCP. }\end{array}$ \\
\hline See footnotes at $\mathrm{e}$ & able. & & & & & (Continued) \\
\hline
\end{tabular}


Table 4-11 (Continued). Laboratory investigations of allergic and irritative reactions in humans exposed to CCP

\begin{tabular}{|c|c|c|c|c|c|c|}
\hline Authors & Country & Number tested & Agents & Type of test & $\begin{array}{l}\text { Comparison } \\
\text { group }\end{array}$ & Results \\
\hline $\begin{array}{l}\text { Morgan and } \\
\text { Camp } 1986\end{array}$ & $\begin{array}{l}\text { United } \\
\text { States }\end{array}$ & 28 & $\begin{array}{l}\text { Vapors from CCP } \\
\text { and bond paper }\end{array}$ & Nasal impedance & None & $\begin{array}{l}\text { In clerical workers, nasal } \\
\text { impedance increased } 34 \% \\
(P<0.025) \text { after exposure to CCP } \\
\text { vapors and } 8 \% \text { after exposure to } \\
\text { plain paper }(P>0.01) \text {. In atopic } \\
\text { workers, nasal impedance increased } \\
\text { significantly after exposure to both } \\
\text { CCP vapors ( } 30 \% \text { to } 40 \%) \text { and } \\
\text { plain paper. }\end{array}$ \\
\hline
\end{tabular}

*Eight test subjects and 8 comparison workers. 
CCP reactions, nonreacting persons (those without a history of allergy or irritative reactions) can handle CCP without risk.

Jeansson et al. 1983, 1984. During patient followup visits, the authors investigated patients who had complaints related to any type of paper and who had been referred to an occupational dermatitis clinic in Sweden from January 1974 to December 1980. Their complaints included irritation of the eyes, nose, throat, arms, face, and scalp; cold symptoms; hoarseness; sores; itching, dryness, redness, or eczema of the hands; unpleasant odor or taste; fatigue; headache; nausea; joint pains; and a feeling of paralysis.

Jeansson et al. [1983] appraised the chemical contents of the papers by skin tests (patch and scratch) and by other examinations of 148 patients. No controls were included in this study. Three of the original 151 complainants were lost to followup. The focus of the study was to find the triggering chemical factor by (1) examining the chemical content and the toxicological effects of the paper, (2) examining the distribution of patients according to the suspected cause of problems, and (3) investigating the relative prevalence of contact allergies. The complaints involved multiple brands of CCP. Manufacturers submitted lists of the composition of 13 brands of CCP on the Swedish market along with samples of the chemicals from the production process. The authors applied a series of patch tests using a standard panel of 30 known antigens as well as samples of paper (CCP, data paper, carbon paper, and photocopying paper) and CCP components. The tests were performed on 134 patients (those with CCP-related complaints) using the CCP with which they worked. Of these patients, about 50 were also tested with approximately 60 chemicals from the paper production process. The authors tested the following $\mathrm{CCP}$ components: those in the $\mathrm{CB}$ and $\mathrm{CF}$ surfaces in both wet and dry preparations, saline extracts of CCP, 62 chemical components (representing about $95 \%$ of the components on the Swedish market), 7 desensitizing chemicals, and 3 adhesive products.

Specific antibodies (IgE, RAST) against dust and molds were identified in 4 of 35 cases, none of whom were among the patients with CCP complaints. The authors noted that this number was not an overrepresentation for a group such as this. The only positive reactions that occurred from any of the test materials other than the standard ones were from two types of carbon paper (not CCP). Slight irritation occurred when testing 50\% kerosene (1 of 59 ) and 50\% isoparaffins (1 of 59). Slight redness ( 1 of 1 ) occurred with $100 \%$ alkylated benzene, but no reaction occurred at repeat testing with a $50 \%$ concentration in 54 test subjects. Two of five D-inks produced primary irritation at 5\% concentration: the first ink resulted in a slight redness in $43 \%$ of patients (19 of 44); and at 1\% concentration, the second caused slight redness in $59 \%$ of those tested (26 of 44). "Itch" tests assessing skin response to a nonantigenic stimulus (histamine) were performed. Responses were measured as the duration of the sensation of itch and the size of the reddened area after administration of 3 concentrations of histamine below the epidermis. Twenty patients having CCP-related complaints were compared with 17 patients having previous complaints about non-CCP paper. The CCP patients suffered a significantly longer duration of itch $(0.05>P>0.01$ [Göthe et al. 1981]) than the matched comparisons; however, the area of redness did not differ between the two groups. The authors commented that the longer-lasting itch correlated with the higher prevalence of mucous membrane irritation on exposure to CCP (65\% versus $50 \%$ ).

Among the patients examined with possible CCP-related symptoms, no allergic or single irritant mechanism was found to explain how the handling of $\mathrm{CCP}$ directly resulted in 
medical problems. On the basis of the available assays of irritant or allergenic potency, the authors were unable to conclude that a specific chemical was common to CCP complaints. Two patients had probable allergic reactions to components in the synthetic resins (one to melamine formaldehyde and one to resorcin), but those reacting to resins or solvents did not react in patch tests to their own CCP. Other contributing factors were mentioned, such as the handling of paper generally (i.e., carbon paper, plain paper, CCP, etc.) and atopy. The authors asserted that there were no differences by $\mathrm{CCP}$ brand; however, because of the design of the study (only symptomatic workers were included) differences in prevalence or incidence of symptoms across CCP brands could not be assessed. The authors concluded (based on the absence of a causal agent) that CCP was not the leading suspect responsible for symptoms in most of the patients exposed to CCP.

Morgan and Camp 1986. Morgan and Camp [1986] conducted an experiment in the United States under controlled laboratory conditions to quantify upper respiratory congestion in clerical workers reporting prior sensitivity when exposed to CCP. Seventy percent of the subjects reported having symptoms associated with CCP use. These symptoms included dryness, light-headedness, headache, dry mouth, burning sinuses, dizziness, sore throat, tickle in throat, sneezing, irritation, itching nose, congestion in throat, and flushed face. The symptoms reportedly increased with increased use of CCP and tended to dissipate rapidly when the worker was removed from the exposure. The authors used an objective measure of nasal congestion - measurement of the nasal contribution to the work of breathing (nasal impedence) by posterior rhinomanometry. The subjects were 28 clerical workers who reported handling 1 to $200 \mathrm{CCP}$ forms per day, with an average of 90 forms per day. These workers were subjected in random, single-blind fashion to controlled exposures of vapors from two sets of three-page, blue-dye CCP forms and to vapors from plain bond paper. Any particles released by the paper were removed by a $0.3-\mu \mathrm{m}$ particle filter. Total hydrocarbon concentration during $\mathrm{CCP}$ exposure averaged 1 ppm. Nasal impedance increased 34\% after exposure to CCP forms $(P<0.025)$ and $8 \%$ after exposure to plain paper $(P>0.10)$. However, frequency of symptoms did not differ between exposure to $\mathrm{CCP}$ and plain paper, and they were not correlated with the nasal measurements. The authors concluded that quantitation of nasal congestion by this technique may be a sensitive measure of short-term reaction to inhalation of irritants. In subjects with a history of allergy, changes in nasal function were reported after exposure to both paper types, but only the change after CCP exposure was statistically significant (paired t-test, $P<0.05)$. In these patients, nasal aerodynamic response to $\mathrm{CCP}$ vapor was significant even with low concentrations of hydrocarbon exposure, and objective changes were measured in the absence of consistent subjective complaints.

\subsubsection{NIOSH Docket Submissions}

RIPT Studies. NIOSH reviewed all of the industry-sponsored laboratory studies in humans submitted to its docket as a result of the Federal Register notices in 1987 and 1997. Most of these studies were RIPT studies, which are summarized in Table 4-12. The RIPT is a test method designed to evaluate the potential of a material to induce and elicit type IV skin sensitization reactions (allergic contact dermatitis) in humans [ASTM 1999]. In general, these tests were performed by administering multiple potentially sensitizing doses of study material as occlusive patch tests over a several-week period. After 2 to 3 weeks, subjects were challenged with an additional diagnostic patch test and evaluated for responses consistent with allergic contact dermatitis. 
Table 4-12. Analysis of repeated insult patch test (RIPT) studies submitted by industry clients in response to 1987 and 1997 Federal Register notices on CCP and its components

\begin{tabular}{|c|c|c|c|c|c|c|c|c|}
\hline \multirow[b]{2}{*}{$\begin{array}{l}\text { Study } \\
\text { year }\end{array}$} & \multirow[b]{2}{*}{$\begin{array}{c}\text { Report } \\
\text { number* }\end{array}$} & \multirow[b]{2}{*}{ Laboratory } & \multirow[b]{2}{*}{ Test material } & \multirow[b]{2}{*}{$\begin{array}{l}\text { Response } \\
\text { rate }^{\dagger}\end{array}$} & \multicolumn{2}{|c|}{ Irritancy } & \multirow[b]{2}{*}{$\begin{array}{l}\text { Classifi- } \\
\text { cation as } \\
\text { irritant } \\
(\mathrm{Y} / \mathrm{N})^{\S, \mathbb{I}}\end{array}$} & \multirow[b]{2}{*}{ Current use of material } \\
\hline & & & & & Score ${ }^{*}$ & $\begin{array}{c}\text { No. of } \\
\text { subjects } \\
\text { with } \\
\text { score }\end{array}$ & & \\
\hline 1955 & E-107 & $\begin{array}{l}\text { Hill Top } \\
\text { Research, Inc. }\end{array}$ & $\begin{array}{l}\text { "Internal phase" diluted } 50 \% \text { w/oil, CB, } \\
\mathrm{CF} \text {, carbon, and base paper }\end{array}$ & ND & ND & - & $\mathrm{N}$ & $\begin{array}{l}\text { Solution of CCP component; } \\
\text { end-user not exposed; } \\
\text { discontinued }^{\star} \text { after } 1971\end{array}$ \\
\hline 1972 & SH-72-4 & $\begin{array}{l}\text { Shelanski Holding } \\
\text { Co. }\end{array}$ & $\begin{array}{l}\text { Monsanto Co. Lot QA-I-SHC No. } \\
\text { M-77 (100\% Santosol } 100 \text { solvent only) }\end{array}$ & $1 / 50$ & ND & - & $\mathrm{N}^{+}$ & $\begin{array}{l}\text { Component of CCP; } \\
\text { end-user would not be exposed }\end{array}$ \\
\hline \multirow[t]{13}{*}{1977} & $77-512-70$ & $\begin{array}{l}\text { Hill Top } \\
\text { Research, Inc. }\end{array}$ & $\begin{array}{l}\text { A. Paper, CF surface colored by } \\
\text { transfer from ruptured CB surface }\end{array}$ & $0 / 71$ & NR & - & $\mathrm{N}$ & $\begin{array}{l}\text { Test materials discontinued in } \\
\text { late } 1970 \text { s }\end{array}$ \\
\hline & & & B. Paper, CF surface not colored & $0 / 71$ & NR & - & $\mathrm{N}$ & \\
\hline & & & C. Blue liquid & $5 / 71$ & & & $\mathrm{Y}^{+}$ & \\
\hline & & & & & 1 & 3 & & \\
\hline & & & & & 2 & 1 & & \\
\hline & & & & & 5 & 1 & & \\
\hline & & & D. Dark liquid & $3 / 71$ & & & $\mathrm{~N}$ & \\
\hline & & & & & 1 & 1 & & \\
\hline & & & & & 2 & 2 & & \\
\hline & & & E. Brown granules & $7 / 71^{\#}$ & & & $\mathrm{Y}$ & \\
\hline & & & & & 1 & 1 & & \\
\hline & & & & & 2 & 2 & & \\
\hline & & & & & 6 & 4 & & \\
\hline
\end{tabular}


Table 4-12 (Continued). Analysis of repeated insult patch test (RIPT) studies submitted by industry clients in response to 1987 and 1997 Federal Register notices on CCP and its components

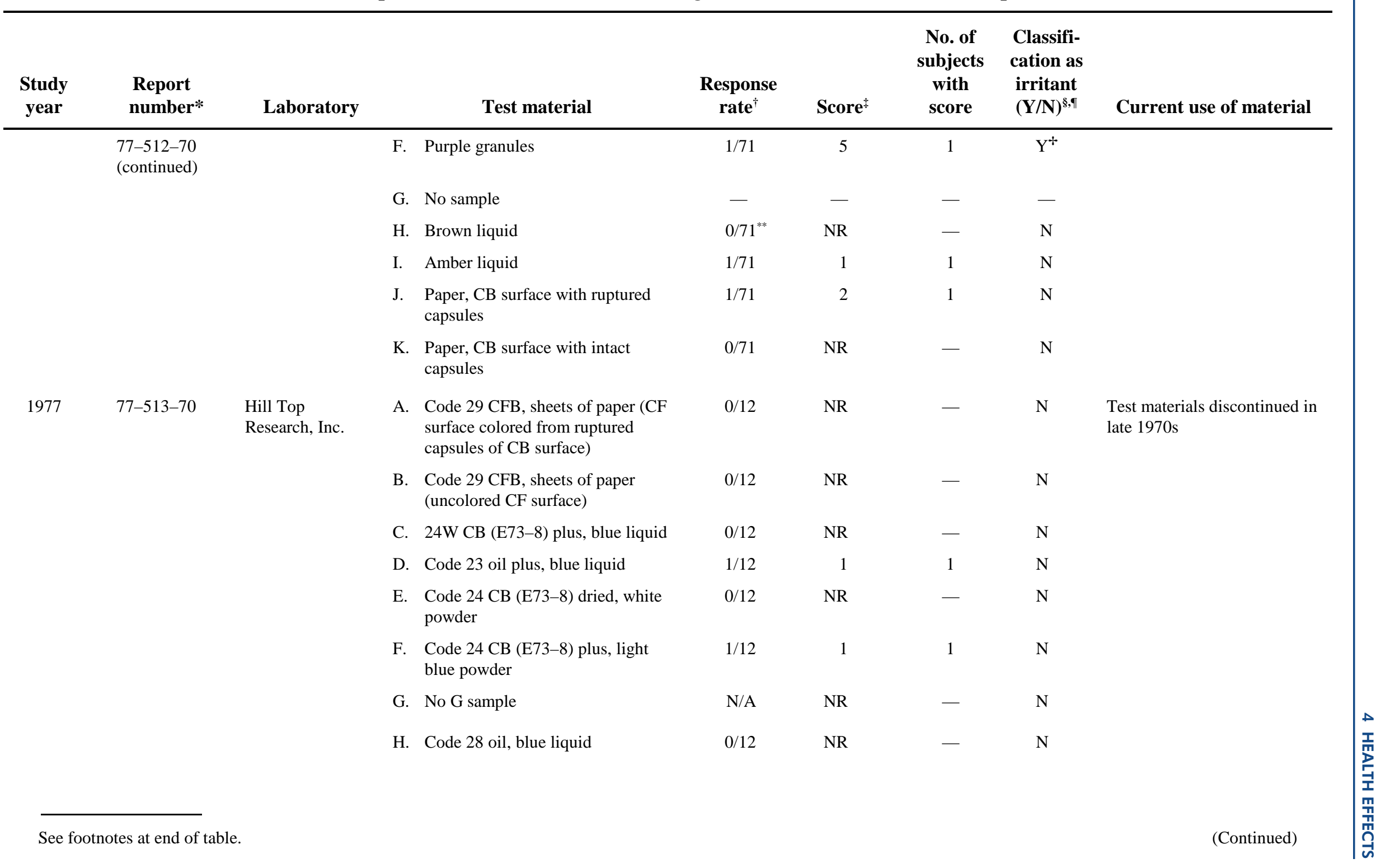


Table 4-12 (Continued). Analysis of repeated insult patch test (RIPT) studies submitted by industry clients in response to 1987 and 1997 Federal Register notices on CCP and its components

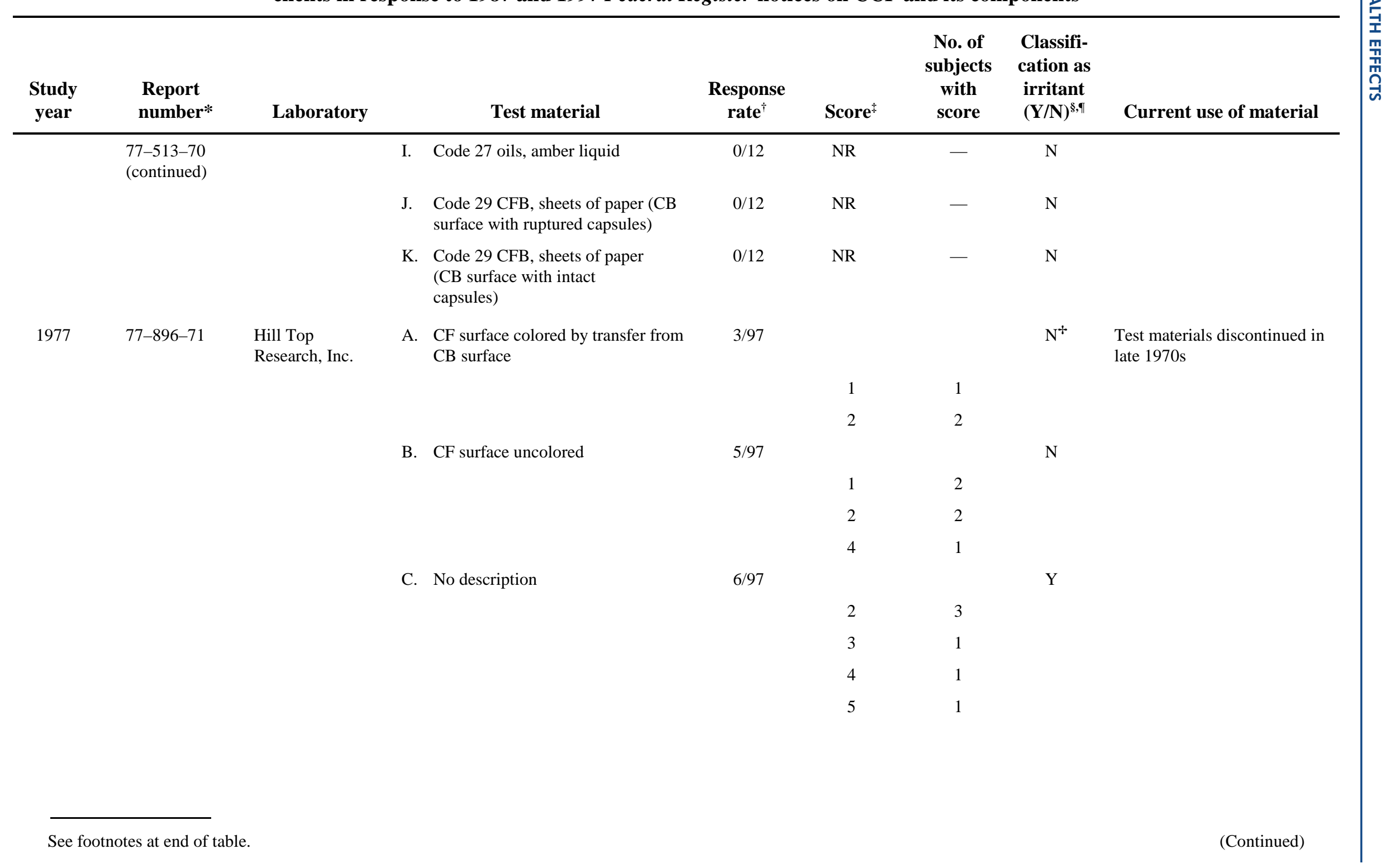


Table 4-12 (Continued). Analysis of repeated insult patch test (RIPT) studies submitted by industry clients in response to 1987 and 1997 Federal Register notices on CCP and its components

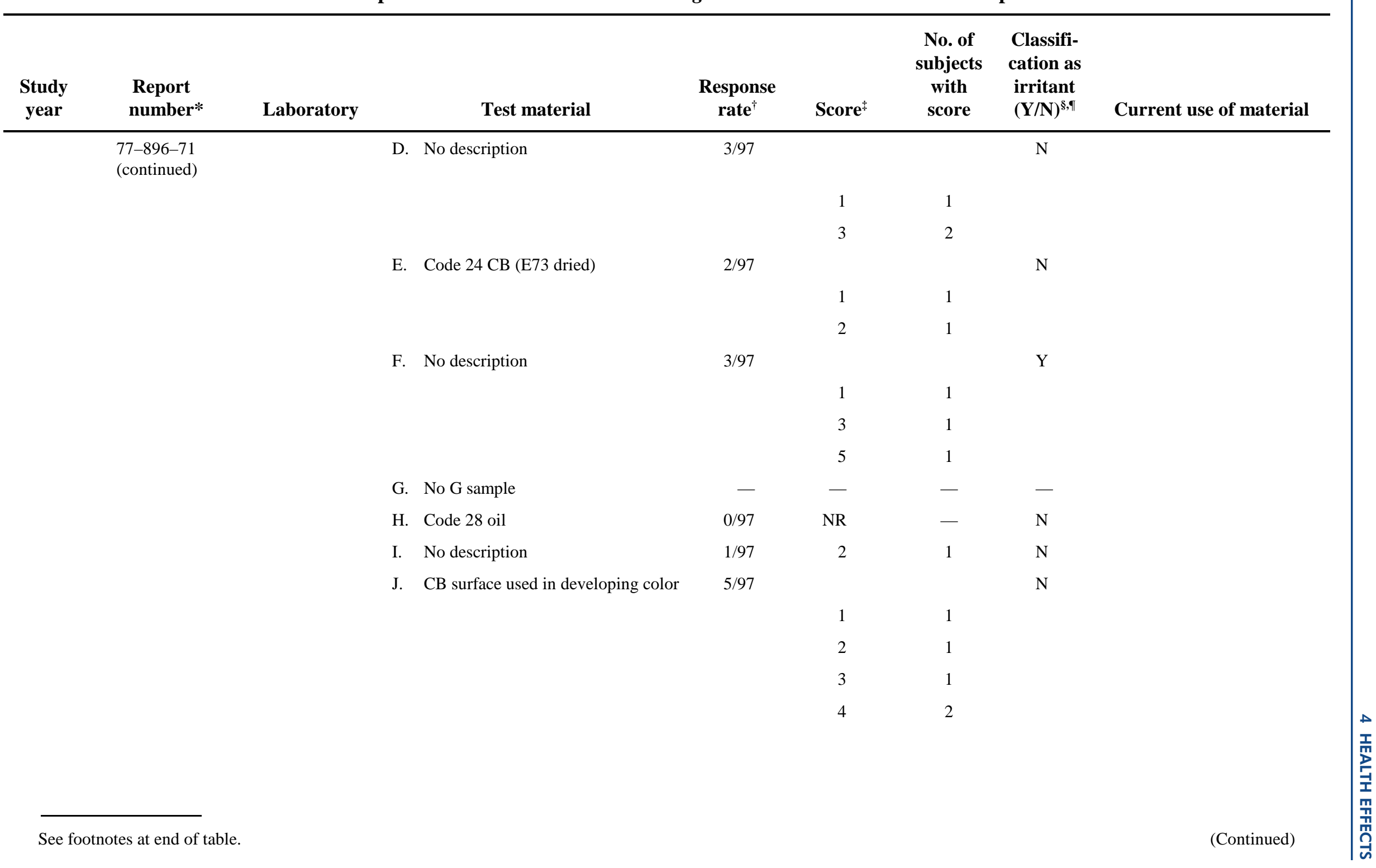


Table 4-12 (Continued). Analysis of repeated insult patch test (RIPT) studies submitted by industry clients in response to 1987 and 1997 Federal Register notices on CCP and its components

\begin{tabular}{|c|c|c|c|c|c|c|c|c|}
\hline $\begin{array}{l}\text { Study } \\
\text { year }\end{array}$ & $\begin{array}{l}\text { Report } \\
\text { number* }\end{array}$ & Laboratory & Test material & $\begin{array}{l}\text { Response } \\
\text { rate }^{\dagger}\end{array}$ & Score ${ }^{*}$ & $\begin{array}{l}\text { No. of } \\
\text { subjects } \\
\text { with } \\
\text { score }\end{array}$ & $\begin{array}{l}\text { Classifi- } \\
\text { cation as } \\
\text { irritant } \\
(\mathbf{Y} / \mathbf{N})^{\S, \mathbb{I}}\end{array}$ & Current use of material \\
\hline & $\begin{array}{l}\text { 77-896-71 } \\
\text { (continued) }\end{array}$ & & K. CB surface with intact capsules & $3 / 97$ & & & $\mathrm{Y}$ & \\
\hline & & & & & 2 & 1 & & \\
\hline & & & & & 4 & 1 & & \\
\hline & & & & & 5 & 1 & & \\
\hline \multirow[t]{5}{*}{1977} & 77-926-71 & $\begin{array}{l}\text { Hill Top } \\
\text { Research, Inc. }\end{array}$ & A. Not identified & $1 / 163$ & 1 & 1 & $\mathrm{~N}$ & $\begin{array}{l}\text { Test materials discontinued in } \\
\text { late 1970s }\end{array}$ \\
\hline & & & J. Not identified & $2 / 163$ & 1 & 2 & $\mathrm{~N}$ & \\
\hline & & & K. Not identified & $4 / 163$ & & & $\mathrm{~N}$ & \\
\hline & & & & & 1 & 3 & & \\
\hline & & & & & 4 & 1 & & \\
\hline \multirow[t]{8}{*}{1978} & $78-557-71$ & $\begin{array}{l}\text { Hill Top } \\
\text { Research, Inc. }\end{array}$ & A. Blue print internal phase, liquid & $85 / 211$ & & & $\mathrm{~N}$ & $\begin{array}{l}\text { Solution of CCP component; } \\
\text { end-user not exposed; test } \\
\text { materials discontinued in } \\
\text { mid-1980s }\end{array}$ \\
\hline & & & & & 1 & 61 & & \\
\hline & & & & & 2 & 15 & & \\
\hline & & & & & 3 & 3 & & \\
\hline & & & & & 4 & 6 & & \\
\hline & & & B. Blue print emulsion, lavender liquid & $0 / 211$ & NR & - & $\mathrm{N}$ & \\
\hline & & & C. Blue transfer paper, off-white paper & $2 / 211$ & 1 & 2 & $\mathrm{~N}$ & \\
\hline & & & D. Black print internal phase, liquid & $0 / 211$ & NR & - & $\mathrm{N}$ & \\
\hline
\end{tabular}


Table 4-12 (Continued). Analysis of repeated insult patch test (RIPT) studies submitted by industry clients in response to 1987 and 1997 Federal Register notices on CCP and its components

\begin{tabular}{|c|c|c|c|c|c|c|c|c|}
\hline $\begin{array}{l}\text { Study } \\
\text { year }\end{array}$ & $\begin{array}{l}\text { Report } \\
\text { number* }\end{array}$ & Laboratory & Test material & $\begin{array}{c}\text { Response } \\
\text { rate }^{\dagger}\end{array}$ & Score $^{*}$ & $\begin{array}{c}\text { No. of } \\
\text { subjects } \\
\text { with } \\
\text { score }\end{array}$ & $\begin{array}{c}\text { Classifi- } \\
\text { cation as } \\
\text { irritant } \\
(\mathbf{Y} / \mathrm{N})^{\S, \mathbb{I}}\end{array}$ & Current use of material \\
\hline & $\begin{array}{l}78-557-71 \\
\text { (continued) }\end{array}$ & & $\begin{array}{l}\text { E. Black print capsule slurry, lavender } \\
\text { liquid }\end{array}$ & $0 / 211$ & NR & - & $\mathrm{N}$ & \\
\hline & & & $\begin{array}{l}\text { F. Black transfer paper, off-white } \\
\text { paper }\end{array}$ & $2 / 211$ & 1 & 2 & $\mathrm{~N}$ & \\
\hline & & & G. Internal phase black print, liquid & $1 / 211$ & 1 & 1 & $\mathrm{~N}$ & \\
\hline & & & $\begin{array}{l}\text { H. Black print self-contained capsules, } \\
\text { lavender liquid }\end{array}$ & $1 / 211$ & 2 & 1 & $\mathrm{~N}$ & \\
\hline & & & $\begin{array}{l}\text { I. Self-contained black, off-white } \\
\text { paper }\end{array}$ & $5 / 211$ & 1 & 5 & $\mathrm{~N}$ & \\
\hline \multirow[t]{4}{*}{1978} & $78-578-70$ & $\begin{array}{l}\text { Hill Top } \\
\text { Research, Inc. }\end{array}$ & $\begin{array}{l}\text { A. CF surface colored by transfer from } \\
\text { CB surface }\end{array}$ & $1 / 152$ & 2 & 1 & $\mathrm{~N}$ & $\begin{array}{l}\text { Test materials discontinued in } \\
\text { mid-1980s }\end{array}$ \\
\hline & & & B. CF surface uncolored ${ }^{\dagger \dagger}$ & $1 / 152$ & 1 & 1 & $\mathrm{~N}$ & \\
\hline & & & J. CB surface used in developing color & $0 / 152$ & NR & - & $\mathrm{N}$ & \\
\hline & & & K. CB surface with intact capsules & $0 / 152$ & NR & - & $\mathrm{N}$ & \\
\hline \multirow[t]{2}{*}{1979} & 79-512B-70 & $\begin{array}{l}\text { Hill Top } \\
\text { Research, Inc. }\end{array}$ & $\begin{array}{l}\text { A. Imaged CF colored ruptured } \\
\text { capsules of } \mathrm{CB} \text { surface }\end{array}$ & $1 / 2$ & ND & - & $\mathrm{N}^{+}$ & Not known \\
\hline & & & B. Unimaged CF surface & $0 / 2$ & ND & - & $\mathrm{N}$ & \\
\hline \multirow[t]{2}{*}{1979} & 79-0002-73 & $\begin{array}{l}\text { Hill Top } \\
\text { Research, Inc. }\end{array}$ & A. CFB CF surface colored & $1 / 166$ & 2 & 1 & $\mathrm{~N}$ & $\begin{array}{l}\text { Test materials discontinued in } \\
\text { mid-1980s }\end{array}$ \\
\hline & & & B. CF surface uncolored & $1 / 166$ & 2 & 2 & $\mathrm{~N}$ & \\
\hline See fo & tes at end of ta & & & & & & & (Continued) \\
\hline
\end{tabular}


Table 4-12 (Continued). Analysis of repeated insult patch test (RIPT) studies submitted by industry clients in response to 1987 and 1997 Federal Register notices on CCP and its components

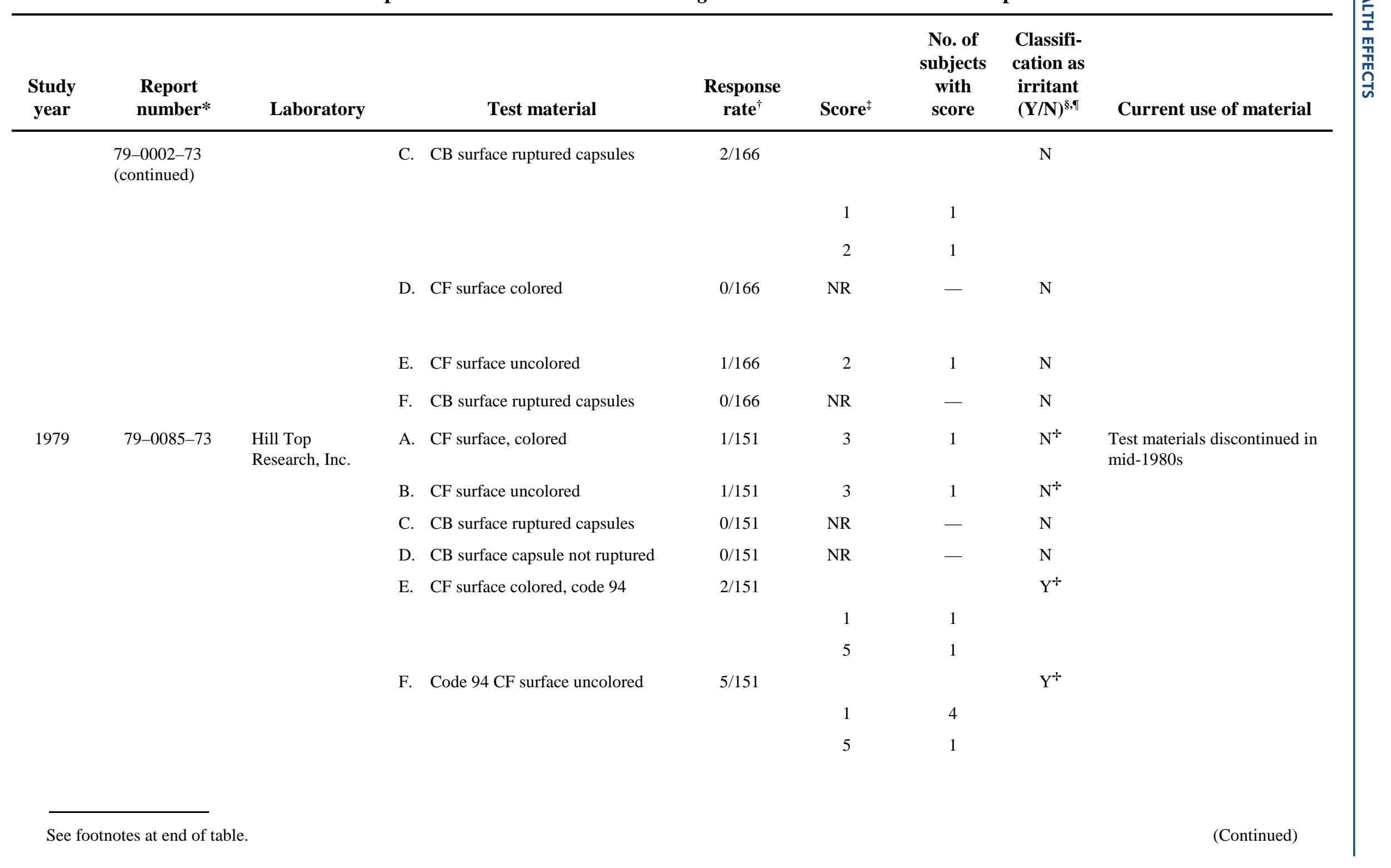


Table 4-12 (Continued). Analysis of repeated insult patch test (RIPT) studies submitted by industry clients in response to 1987 and 1997 Federal Register notices on CCP and its components

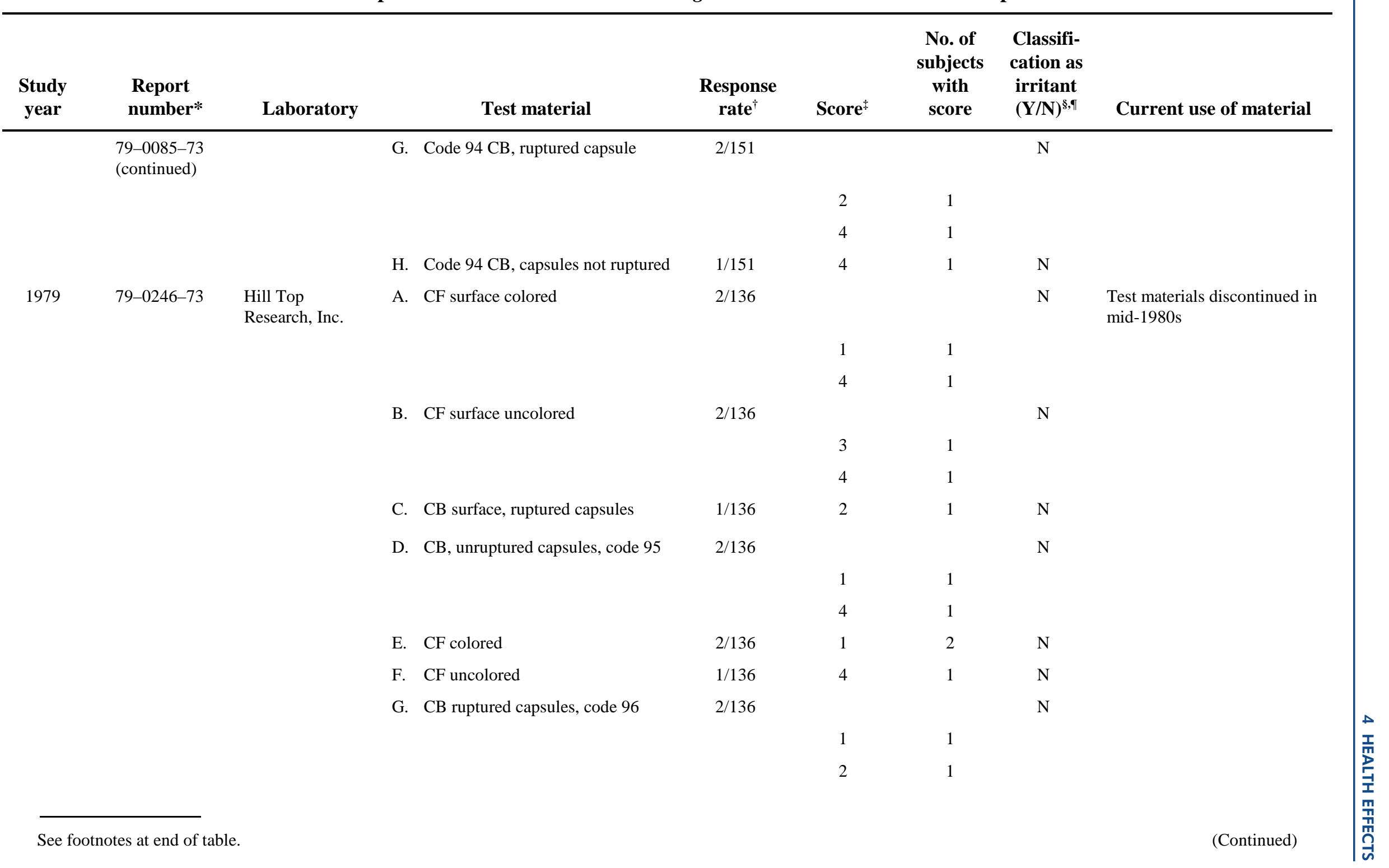


Table 4-12 (Continued). Analysis of repeated insult patch test (RIPT) studies submitted by industry clients in response to 1987 and 1997 Federal Register notices on CCP and its components

\begin{tabular}{|c|c|c|c|c|c|c|c|c|c|}
\hline $\begin{array}{l}\text { Study } \\
\text { year }\end{array}$ & $\begin{array}{l}\text { Report } \\
\text { number* }\end{array}$ & Laboratory & & Test material & $\begin{array}{l}\text { Response } \\
\text { rate }^{\dagger}\end{array}$ & Score ${ }^{*}$ & $\begin{array}{c}\text { No. of } \\
\text { subjects } \\
\text { with } \\
\text { score }\end{array}$ & $\begin{array}{l}\text { Classifi- } \\
\text { cation as } \\
\text { irritant } \\
(\mathrm{Y} / \mathrm{N})^{\S, \mathbb{I}}\end{array}$ & Current use of material \\
\hline & $\begin{array}{l}79-0246-73 \\
\text { (continued) }\end{array}$ & & H. & $\mathrm{CB}$, unruptured capsules, code 96 & $0 / 136$ & NR & - & $\mathrm{N}$ & \\
\hline \multirow[t]{15}{*}{1979} & 79-0801-73 & $\begin{array}{l}\text { Hill Top } \\
\text { Research, Inc. }\end{array}$ & A. & $\begin{array}{l}\text { Yellow paper CB surface } \\
\text { unruptured capsules }\end{array}$ & $7 / 122$ & & & $\mathrm{~N}$ & $\begin{array}{l}\text { Test materials discontinued in } \\
\text { mid-1980s }\end{array}$ \\
\hline & & & & & & 1 & 3 & & \\
\hline & & & & & & 2 & 3 & & \\
\hline & & & & & & 4 & 1 & & \\
\hline & & & & $\begin{array}{l}\text { Yellow paper CF surface imaged by } \\
\text { ruptured capsules }\end{array}$ & $2 / 122$ & & & $\mathrm{~N}$ & \\
\hline & & & & & & 1 & 1 & & \\
\hline & & & & & & 2 & 1 & & \\
\hline & & & C. & Yellow paper uncolored CF surface & $1 / 122$ & 1 & 1 & $\mathrm{~N}$ & \\
\hline & & & & $\begin{array}{l}\text { Yellow paper CB surface ruptured } \\
\text { capsules }\end{array}$ & $5 / 122$ & & & $\mathrm{~N}$ & \\
\hline & & & & & & 1 & 1 & & \\
\hline & & & & & & 2 & 4 & & \\
\hline & & & & $\begin{array}{l}\text { White paper self-contained surface } \\
\text { of paper imaged }\end{array}$ & $2 / 122$ & 2 & 2 & $\mathrm{~N}$ & \\
\hline & & & F. & $\begin{array}{l}\text { White paper self-contained surface } \\
\text { of paper unimaged }\end{array}$ & $3 / 122$ & & & $\mathrm{~N}$ & \\
\hline & & & & & & 1 & 2 & & \\
\hline & & & & & & 2 & 1 & & \\
\hline
\end{tabular}


Table 4-12 (Continued). Analysis of repeated insult patch test (RIPT) studies submitted by industry clients in response to 1987 and 1997 Federal Register notices on CCP and its components

\begin{tabular}{|c|c|c|c|c|c|c|c|c|}
\hline $\begin{array}{l}\text { Study } \\
\text { year }\end{array}$ & $\begin{array}{l}\text { Report } \\
\text { number* }\end{array}$ & Laboratory & Test material & $\begin{array}{l}\text { Response } \\
\text { rate }^{\dagger}\end{array}$ & Score $^{*}$ & $\begin{array}{c}\text { No. of } \\
\text { subjects } \\
\text { with } \\
\text { score }\end{array}$ & $\begin{array}{c}\text { Classifi- } \\
\text { cation as } \\
\text { irritant } \\
(\mathrm{Y} / \mathrm{N})^{\S, \mathbb{I}}\end{array}$ & Current use of material \\
\hline \multirow[t]{10}{*}{1980} & 80-0079-73 & $\begin{array}{l}\text { Hill Top } \\
\text { Research, Inc. }\end{array}$ & $\begin{array}{l}\text { A. } 118 \mathrm{CF} \text { surface uncolored } \\
\text { (unimaged) }\end{array}$ & $0 / 99$ & NR & - & $\mathrm{N}$ & Test materials never marketed \\
\hline & & & B. 118 CF surface colored (imaged) & $1 / 99$ & 1 & 1 & $\mathrm{~N}$ & \\
\hline & & & C. $121 \mathrm{CB}$ surface unruptured capsules & $0 / 99$ & NR & - & $\mathrm{N}$ & \\
\hline & & & $\begin{array}{l}\text { D. } 121 \mathrm{CF} \text { surface uncolored } \\
\text { (unimaged) }\end{array}$ & $0 / 99$ & NR & - & $\mathrm{N}$ & \\
\hline & & & E. $121 \mathrm{CB}$ surface ruptured capsules & $0 / 99$ & NR & - & $\mathrm{N}$ & \\
\hline & & & $\begin{array}{l}\text { F. } 121 \mathrm{CB} \text { surface colored } \\
\text { (imaged) }\end{array}$ & $0 / 99$ & NR & - & $\mathrm{N}$ & \\
\hline & & & $\begin{array}{l}\text { G. } 122 \mathrm{CB} \text { surface unruptured } \\
\text { capsules }\end{array}$ & $0 / 99$ & NR & - & $\mathrm{N}$ & \\
\hline & & & $\begin{array}{l}\text { H. } 122 \mathrm{CF} \text { surface uncolored } \\
\text { (unimaged) }\end{array}$ & $0 / 99$ & NR & - & $\mathrm{N}$ & \\
\hline & & & $\begin{array}{l}\text { I. } 122 \mathrm{CB} \text { surface ruptured } \\
\text { capsules }\end{array}$ & $0 / 99$ & NR & - & $\mathrm{N}$ & \\
\hline & & & $\begin{array}{l}\text { J. } 122 \text { CF surface colored } \\
\text { (imaged) }\end{array}$ & $0 / 99$ & NR & - & $\mathrm{N}$ & \\
\hline \multirow[t]{2}{*}{1981} & $81-0138-73(2)$ & $\begin{array}{l}\text { Hill Top } \\
\text { Research, Inc. }\end{array}$ & B. T-3012PP-White paper & $0 / 207$ & $\S \S$ & $\S \S$ & $\mathrm{N}$ & Discontinued in mid-1980s \\
\hline & & & C. T-3013PP_Pink paper & $0 / 207$ & IIII & IIII & $\mathrm{N}$ & \\
\hline \multirow[t]{2}{*}{1983} & $83-0305-70$ & $\begin{array}{l}\text { Hill Top } \\
\text { Research, Inc. }\end{array}$ & $\begin{array}{l}\text { C1. Pink paper, CB surface with } \\
\text { unruptured capsules }\end{array}$ & $0 / 93$ & NR & - & $\mathrm{N}$ & $\begin{array}{l}\text { Not repeatable results; test } \\
\text { materials discontinued in } \\
\text { mid-1980s }\end{array}$ \\
\hline & & & C2. Pink paper, $\mathrm{CF}$ uncolored surface & $0 / 93$ & NR & - & $\mathrm{N}$ & \\
\hline
\end{tabular}


Table 4-12 (Continued). Analysis of repeated insult patch test (RIPT) studies submitted by industry clients in response to 1987 and 1997 Federal Register notices on CCP and its components

\begin{tabular}{|c|c|c|c|c|c|c|c|c|}
\hline $\begin{array}{l}\text { Study } \\
\text { year }\end{array}$ & $\begin{array}{l}\text { Report } \\
\text { number* }\end{array}$ & Laboratory & Test material & $\begin{array}{c}\text { Response } \\
\text { rate }^{\dagger}\end{array}$ & Score ${ }^{*}$ & $\begin{array}{c}\text { No. of } \\
\text { subjects } \\
\text { with } \\
\text { score }\end{array}$ & $\begin{array}{c}\text { Classifi- } \\
\text { cation as } \\
\text { irritant } \\
(\mathbf{Y} / \mathrm{N})^{\S, \mathbb{I}}\end{array}$ & Current use of material \\
\hline & $\begin{array}{l}83-0305-70 \\
\text { (continued) }\end{array}$ & & C3. Pink paper, CB ruptured capsules & $0 / 93$ & NR & - & $\mathrm{N}$ & \\
\hline & & & $\begin{array}{l}\text { C4. Blue and imaged pink paper CF } \\
\text { (blue) surface with color transferred } \\
\text { from ruptured capsules }\end{array}$ & $0 / 93$ & NR & - & $\mathrm{N}$ & \\
\hline & & & $\begin{array}{l}\text { D1. White paper, CB surface with } \\
\text { unruptured capsules }\end{array}$ & $0 / 93$ & NR & - & $\mathrm{N}$ & \\
\hline & & & D2. White paper, CF uncolored surface & $1 / 93$ & 1 & 1 & $\mathrm{~N}$ & \\
\hline & & & $\begin{array}{l}\text { D3. White paper, ruptured capsules, CB } \\
\text { surface }\end{array}$ & $0 / 93$ & NR & - & $\mathrm{N}$ & \\
\hline & & & $\begin{array}{l}\text { D4. Blue and imaged white paper CF } \\
\text { (blue) surface with color transferred } \\
\text { from ruptured capsules }\end{array}$ & $0 / 93$ & NR & - & $\mathrm{N}$ & \\
\hline 1983 & $83-3592 \mathrm{H}$ & Biosearch & Moore Business forms, MCP 2010 & $0 / 200$ & NR & - & $\mathrm{N}$ & $\begin{array}{l}\text { Test material discontinued in } \\
\text { early } 1980 \text { s }\end{array}$ \\
\hline 1983 & $83-0771-70$ & $\begin{array}{l}\text { Hill Top } \\
\text { Research, Inc. }\end{array}$ & $\begin{array}{l}\text { "Sample A" - no other information } \\
\text { given }\end{array}$ & $1 / 14$ & ND & - & $\mathrm{Y}$ & $\begin{array}{l}\text { Solution of CCP formulation; } \\
\text { end-users not exposed }\end{array}$ \\
\hline \multirow[t]{5}{*}{1986} & 3683 & $\begin{array}{l}\text { Inveresk Research } \\
\text { International }\end{array}$ & $\begin{array}{l}\text { A. Resin CF based on Durez resin } \\
32131\end{array}$ & $24 / 27^{\star \star}$ & & & $\mathrm{N}$ & $\begin{array}{l}\text { Test material never used in } \\
\text { United States }\end{array}$ \\
\hline & & & & & 1 & 7 & & \\
\hline & & & & & 2 & 10 & & \\
\hline & & & & & 3 & 6 & & \\
\hline & & & & & 4 & 1 & & \\
\hline See $f$ & tes at end of $\mathrm{t}$ & & & & & & & (Continued) \\
\hline
\end{tabular}


Table 4-12 (Continued). Analysis of repeated insult patch test (RIPT) studies submitted by industry clients in response to 1987 and 1997 Federal Register notices on CCP and its components

\begin{tabular}{|c|c|c|c|c|c|c|c|c|}
\hline $\begin{array}{l}\text { Study } \\
\text { year }\end{array}$ & $\begin{array}{l}\text { Report } \\
\text { number* }\end{array}$ & Laboratory & Test material & $\begin{array}{c}\text { Response } \\
\text { rate }^{\dagger}\end{array}$ & Score & $\begin{array}{c}\text { No. of } \\
\text { subjects } \\
\text { with } \\
\text { score }\end{array}$ & $\begin{array}{c}\text { Classifi- } \\
\text { cation as } \\
\text { irritant } \\
(\mathbf{Y} / \mathbf{N})^{\S, \mathbb{I}}\end{array}$ & Current use of material \\
\hline & $\begin{array}{l}3683 \\
\text { (continued) }\end{array}$ & & $\begin{array}{l}\text { B. CF control, standard production } \\
\text { paper, } S / \text { K/Dow } 675 \text { formulation }\end{array}$ & $27 / 27^{++}$ & & & $\mathrm{N}$ & \\
\hline & & & & & 1 & 10 & & \\
\hline & & & & & 2 & 9 & & \\
\hline & & & & & 3 & 5 & & \\
\hline & & & & & 4 & 3 & & \\
\hline & & & $\begin{array}{l}\text { C. CB, E20 formulation } \\
\text { in 1:2 HB } \\
\text { 40/alkylbenzenes in } \\
\text { Gel-CMC } \\
\text { microcapsules }\end{array}$ & $25 / 27^{* *}$ & & & $\mathrm{Y}$ & \\
\hline & & & & & 1 & 11 & & \\
\hline & & & & & 2 & 8 & & \\
\hline & & & & & 3 & 4 & & \\
\hline & & & & & 4 & 1 & & \\
\hline & & & & & 5 & 1 & & \\
\hline & & & $\begin{array}{l}\text { D. } \mathrm{CB}, \mathrm{SF} 2 \text { formulation in } 100 \% \\
\text { alkylbenzenes in Gel-CMC } \\
\text { microcapsules }\end{array}$ & $25 / 27^{\# \#}$ & & & $\mathrm{~N}$ & \\
\hline & & & & & 1 & 10 & & \\
\hline & & & & & 2 & 7 & & \\
\hline & & & & & 3 & 6 & & \\
\hline & & & & & 4 & 2 & & \\
\hline
\end{tabular}


Table 4-12 (Continued). Analysis of repeated insult patch test (RIPT) studies submitted by industry clients in response to 1987 and 1997 Federal Register notices on CCP and its components

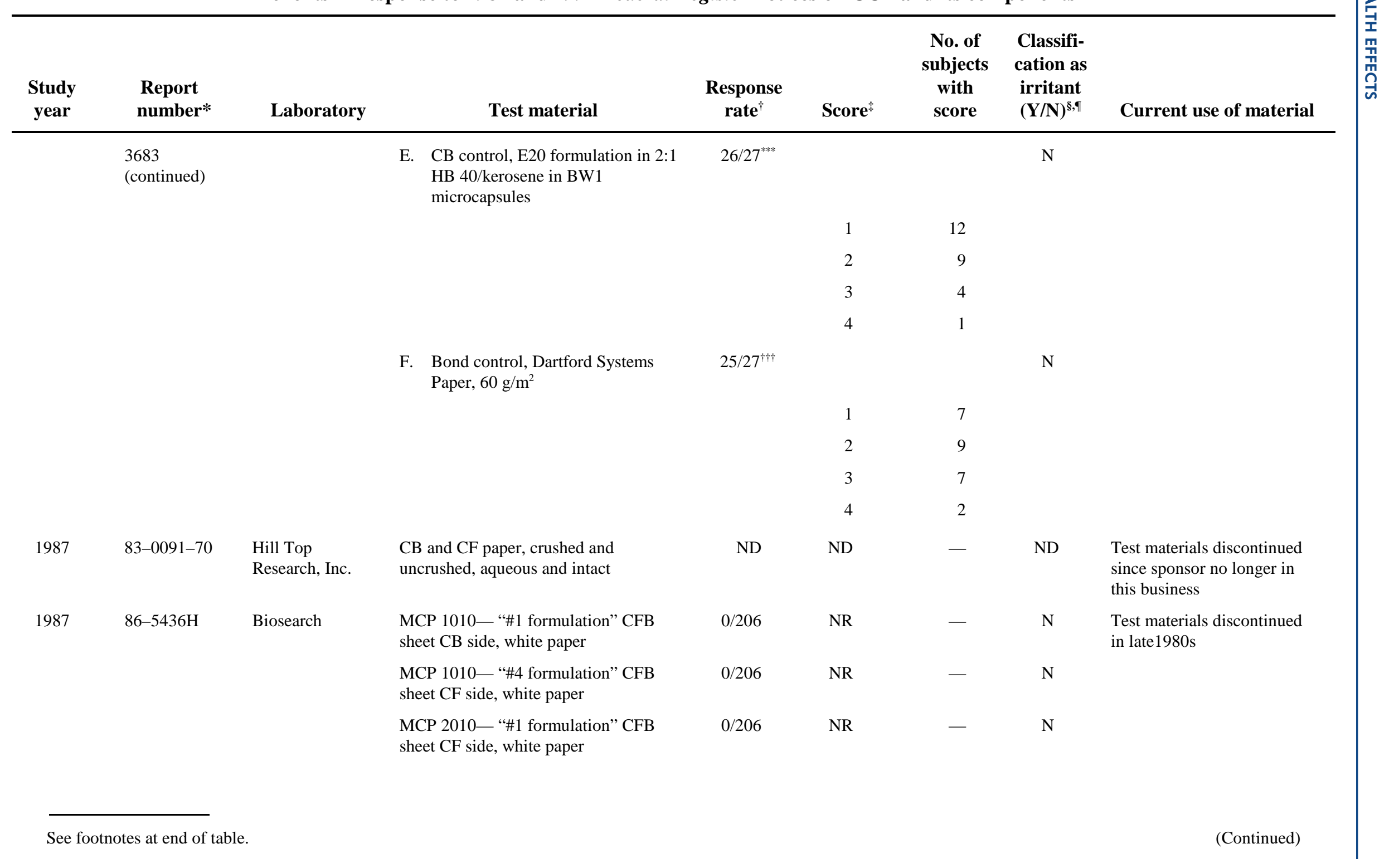


Table 4-12 (Continued). Analysis of repeated insult patch test (RIPT) studies submitted by industry clients in response to 1987 and 1997 Federal Register notices on CCP and its components

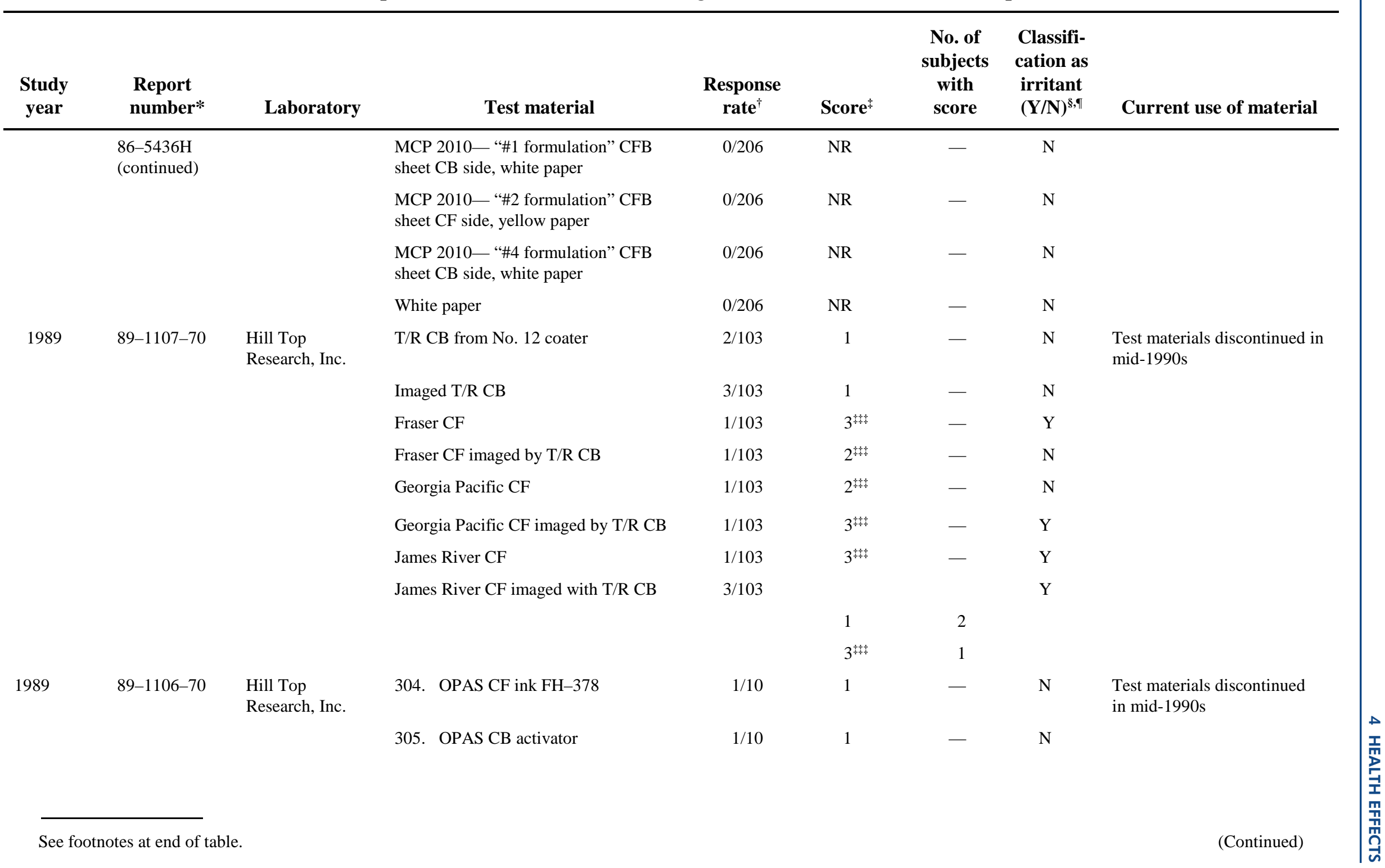


Table 4-12 (Continued). Analysis of repeated insult patch test (RIPT) studies submitted by industry clients in response to 1987 and 1997 Federal Register notices on CCP and its components

\begin{tabular}{|c|c|c|c|c|c|c|c|c|}
\hline $\begin{array}{l}\text { Study } \\
\text { year }\end{array}$ & $\begin{array}{l}\text { Report } \\
\text { number* }\end{array}$ & Laboratory & Test material & $\begin{array}{c}\text { Response } \\
\text { rate }^{\dagger}\end{array}$ & Score $^{\ddagger}$ & $\begin{array}{c}\text { No. of } \\
\text { subjects } \\
\text { with } \\
\text { score }\end{array}$ & $\begin{array}{l}\text { Classifi- } \\
\text { cation as } \\
\text { irritant } \\
(\mathrm{Y} / \mathrm{N})^{\S, \mathbb{I}}\end{array}$ & Current use of material \\
\hline \multirow[t]{8}{*}{1989} & 89-1105-70 & $\begin{array}{l}\text { Hill Top } \\
\text { Research, Inc. }\end{array}$ & 308a. CB of CFB & $2 / 105$ & 1 & - & $\mathrm{N}$ & $\begin{array}{l}\text { Test materials discontinued } \\
\text { in mid-1990s }\end{array}$ \\
\hline & & & 308b. Imaged CF of CFB & $4 / 105$ & 1 & - & $\mathrm{N}$ & \\
\hline & & & 308c. CF of CFB & $3 / 105$ & 1 & - & $\mathrm{N}$ & \\
\hline & & & $\begin{array}{l}\text { 308d. CB of CFB after imaging } \\
\text { w/CF }\end{array}$ & $1 / 105$ & 1 & - & $\mathrm{N}$ & \\
\hline & & & 309a. CB of CFB & $4 / 105$ & 1 & - & $\mathrm{N}$ & \\
\hline & & & 309b. Imaged CF of CFB & $5 / 105$ & 1 & - & $\mathrm{N}$ & \\
\hline & & & 309c. CF of CFB & $3 / 105$ & 1 & - & $\mathrm{N}$ & \\
\hline & & & $\begin{array}{l}\text { 309d. CB of CFB after imaging } \\
\text { w/CF }\end{array}$ & $3 / 105$ & 1 & - & $\mathrm{N}$ & \\
\hline \multirow[t]{5}{*}{1989} & $89-6733 \mathrm{H}$ & Biosearch & 151. Unimaged CB & $0 / 99$ & 0 & - & $\mathrm{N}$ & Test materials in use \\
\hline & & & 152. Imaged CB & $0 / 99$ & 0 & - & $\mathrm{N}$ & \\
\hline & & & 153. Unimaged CF & $1 / 99$ & $+t^{\S \S}$ & - & $\mathrm{N}$ & \\
\hline & & & 154. Imaged CF & $0 / 99$ & 0 & - & $\mathrm{N}$ & \\
\hline & & & 157. Unimaged CB & $0 / 99$ & 0 & - & $\mathrm{N}$ & \\
\hline \multirow[t]{4}{*}{1989} & 89-1359-70 & $\begin{array}{l}\text { Hill Top } \\
\text { Research, Inc. }\end{array}$ & 161. Unimaged CB & $0 / 109$ & 0 & - & $\mathrm{N}$ & Test materials in use \\
\hline & & & 162. Imaged CB & $0 / 109$ & 0 & - & $\mathrm{N}$ & \\
\hline & & & 163. Unimaged CF & $0 / 109$ & 0 & - & $\mathrm{N}$ & \\
\hline & & & 166. Imaged CF & $0 / 109$ & 0 & - & $\mathrm{N}$ & \\
\hline
\end{tabular}


Table 4-12 (Continued). Analysis of repeated insult patch test (RIPT) studies submitted by industry clients in response to 1987 and 1997 Federal Register notices on CCP and its components

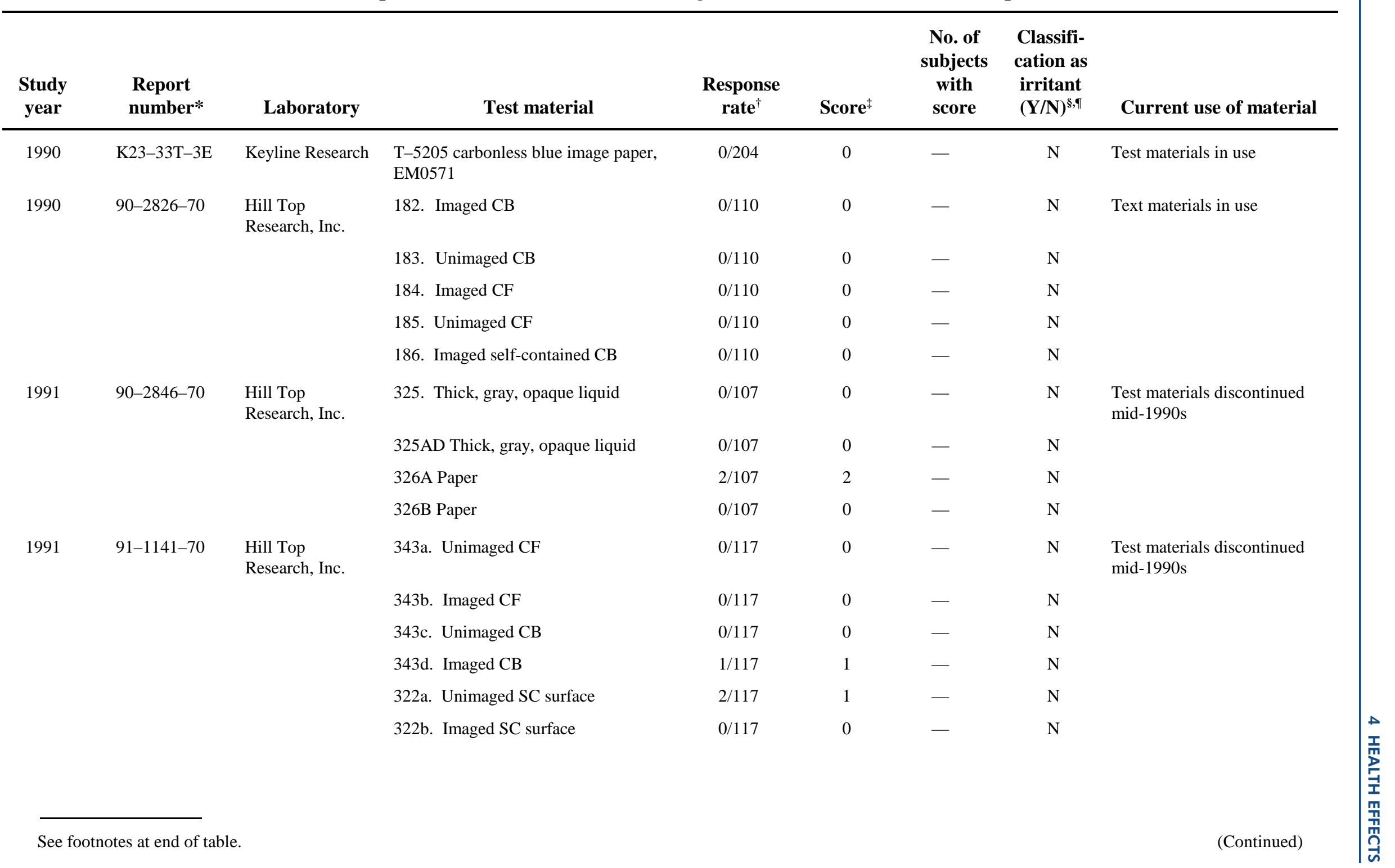




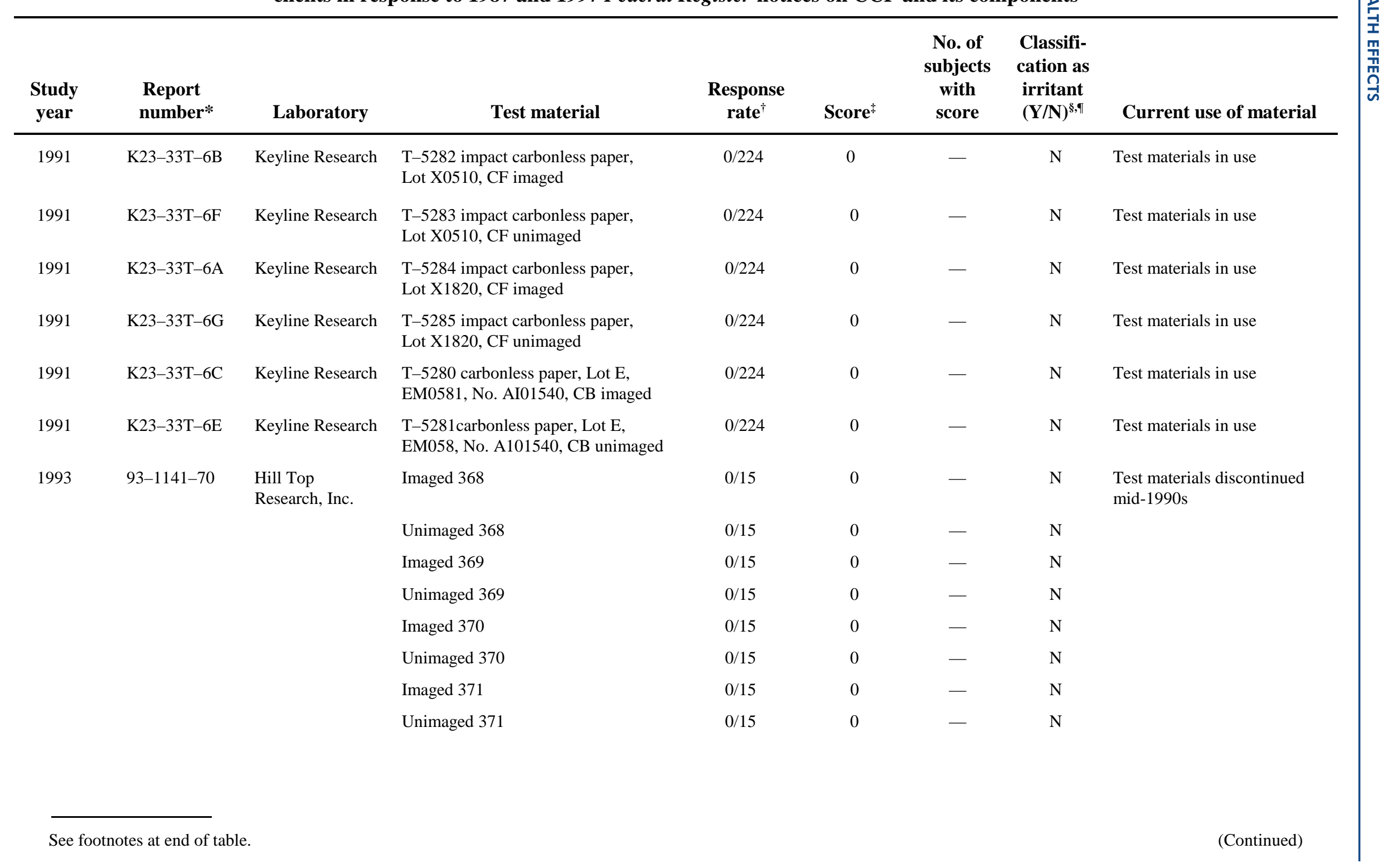


Table 4-12 (Continued). Analysis of repeated insult patch test (RIPT) studies submitted by industry clients in response to 1987 and 1997 Federal Register notices on CCP and its components

\begin{tabular}{|c|c|c|c|c|c|c|c|c|}
\hline $\begin{array}{l}\text { Study } \\
\text { year }\end{array}$ & $\begin{array}{l}\text { Report } \\
\text { number* }\end{array}$ & Laboratory & Test material & $\begin{array}{c}\text { Response } \\
\text { rate }^{\dagger}\end{array}$ & Score & $\begin{array}{c}\text { No. of } \\
\text { subjects } \\
\text { with } \\
\text { score }\end{array}$ & $\begin{array}{l}\text { Classifi- } \\
\text { cation as } \\
\text { irritant } \\
(\mathrm{Y} / \mathrm{N})^{\S, \pi}\end{array}$ & Current use of material \\
\hline \multirow[t]{8}{*}{1993} & $93-1034-70$ & $\begin{array}{l}\text { Hill Top } \\
\text { Research, Inc. }\end{array}$ & Imaged 368 & $0 / 107$ & 0 & - & $\mathrm{N}$ & $\begin{array}{l}\text { Test materials discontinued } \\
\text { mid-1990s }\end{array}$ \\
\hline & & & Unimaged 368 & $0 / 107$ & 0 & - & $\mathrm{N}$ & \\
\hline & & & Imaged 369 & 0/107 & 0 & - & $\mathrm{N}$ & \\
\hline & & & Unimaged 369 & $0 / 107$ & 0 & - & $\mathrm{N}$ & \\
\hline & & & Imaged 370 & 0/107 & 0 & - & $\mathrm{N}$ & \\
\hline & & & Unimaged 370 & $0 / 107$ & 0 & - & $\mathrm{N}$ & \\
\hline & & & Imaged 371 & 0/107 & 0 & - & $\mathrm{N}$ & \\
\hline & & & Unimaged 371 & $0 / 107$ & 0 & - & $\mathrm{N}$ & \\
\hline \multirow[t]{8}{*}{1994} & $93-1206-70$ & $\begin{array}{l}\text { Hill Top } \\
\text { Research, Inc. }\end{array}$ & Imaged 368 & $0 / 94$ & 0 & - & $\mathrm{N}$ & $\begin{array}{l}\text { Test materials discontinued } \\
\text { mid-1990s }\end{array}$ \\
\hline & & & Unimaged 368 & $0 / 94$ & 0 & - & $\mathrm{N}$ & \\
\hline & & & Imaged 369 & $1 / 94$ & 1 & - & $\mathrm{N}$ & \\
\hline & & & Unimaged 369 & $0 / 94$ & 0 & - & $\mathrm{N}$ & \\
\hline & & & Imaged 370 & $0 / 94$ & 0 & - & $\mathrm{N}$ & \\
\hline & & & Unimaged 370 & $0 / 94$ & 0 & - & $\mathrm{N}$ & \\
\hline & & & Imaged 371 & $1 / 94$ & 1 & - & $\mathrm{N}$ & \\
\hline & & & Unimaged 371 & $0 / 94$ & 0 & - & $\mathrm{N}$ & \\
\hline
\end{tabular}


Table 4-12 (Continued). Analysis of repeated insult patch test (RIPT) studies submitted by industry clients in response to 1987 and 1997 Federal Register notices on CCP and its components

\begin{tabular}{|c|c|c|c|c|c|c|c|c|}
\hline $\begin{array}{l}\text { Study } \\
\text { year }\end{array}$ & $\begin{array}{l}\text { Report } \\
\text { number* }\end{array}$ & Laboratory & Test material & $\begin{array}{l}\text { Response } \\
\text { rate }^{\dagger}\end{array}$ & Score ${ }^{\ddagger}$ & $\begin{array}{c}\text { No. of } \\
\text { subjects } \\
\text { with } \\
\text { score }\end{array}$ & $\begin{array}{c}\text { Classifi- } \\
\text { cation as } \\
\text { irritant } \\
(\mathbf{Y} / \mathbf{N})^{\S, \mathbb{I}}\end{array}$ & Current use of material \\
\hline \multirow[t]{10}{*}{1995} & $95-1631-70$ & $\begin{array}{l}\text { Hill Top } \\
\text { Research, Inc. }\end{array}$ & 396a. Unimaged CB & $3 / 110$ & 1 & - & $\mathrm{N}$ & $\begin{array}{l}\text { Test materials discontinued } \\
\text { mid-1990s }\end{array}$ \\
\hline & & & 396b. Imaged CIF & $5 / 110$ & 1 & - & $\mathrm{N}$ & \\
\hline & & & 396c. Unimaged CF & $2 / 110$ & 1 & - & $\mathrm{N}$ & \\
\hline & & & 396d. Imaged CB & $2 / 110$ & 1 & - & $\mathrm{N}$ & \\
\hline & & & 407a. Unimaged CB & $4 / 110$ & 1 & - & $\mathrm{N}$ & \\
\hline & & & 407b. Imaged CF & $2 / 110$ & 1 & - & $\mathrm{N}$ & \\
\hline & & & 407c. Unimaged CF & $2 / 110$ & 1 & - & $\mathrm{N}$ & \\
\hline & & & 407d. Imaged CB & $4 / 110$ & 1 & - & $\mathrm{N}$ & \\
\hline & & & 402a. Unimaged self-contained & $5 / 110$ & 1 & - & $\mathrm{N}$ & \\
\hline & & & 402b. Imaged self-contained & & 1 & - & $\mathrm{N}$ & \\
\hline \multirow[t]{7}{*}{1996} & $95-1632-70$ & $\begin{array}{l}\text { Hill Top } \\
\text { Research, Inc. }\end{array}$ & 419a. Unimaged CB & $0 / 118$ & 0 & - & $\mathrm{N}$ & Test materials in use \\
\hline & & & 419b. Imaged CF & $2 / 118$ & 1 & - & $\mathrm{N}$ & \\
\hline & & & 422aq. Liquid & $0 / 118$ & 0 & - & $\mathrm{N}$ & \\
\hline & & & 424a. Unimaged CB & $0 / 118$ & 0 & - & $\mathrm{N}$ & \\
\hline & & & 424b. Imaged CF & $0 / 118$ & 0 & - & $\mathrm{N}$ & \\
\hline & & & 424c. Unimaged CF & $0 / 118$ & 0 & - & $\mathrm{N}$ & \\
\hline & & & 424d. Imaged CB & $0 / 118$ & 0 & - & $\mathrm{N}$ & \\
\hline
\end{tabular}


Table 4-12 (Continued). Analysis of repeated insult patch test (RIPT) studies submitted by industry clients in response to 1987 and 1997 Federal Register notices on CCP and its components

\begin{tabular}{|c|c|c|c|c|c|c|c|c|}
\hline $\begin{array}{l}\text { Study } \\
\text { year }\end{array}$ & $\begin{array}{l}\text { Report } \\
\text { number* }\end{array}$ & Laboratory & Test material & $\begin{array}{c}\text { Response } \\
\text { rate }^{\dagger}\end{array}$ & Score & $\begin{array}{c}\text { No. of } \\
\text { subjects } \\
\text { with } \\
\text { score }\end{array}$ & $\begin{array}{l}\text { Classifi- } \\
\text { cation as } \\
\text { irritant } \\
(\mathbf{Y} / \mathbf{N})^{\S, \pi}\end{array}$ & Current use of material \\
\hline \multirow[t]{11}{*}{1998} & 98-101080-76 & $\begin{array}{l}\text { Hill Top } \\
\text { Research, Inc. }\end{array}$ & 215. CF unimaged & $8 / 100$ & & & $\mathrm{~N}$ & Test materials in use \\
\hline & & & & & + & 7 & & \\
\hline & & & & & 1 & 1 & & \\
\hline & & & 215. Back of $\mathrm{CF}$ & $11 / 100$ & & & $\mathrm{~N}$ & \\
\hline & & & & & + & 9 & & \\
\hline & & & & & 1 & 1 & & \\
\hline & & & 217. CB side & $2 / 100$ & 2 & $1^{\mathbb{I U T I}}$ & $\mathrm{N}$ & \\
\hline & & & 220. Non CB side & $8 / 100$ & & & $\mathrm{~N}$ & \\
\hline & & & & & + & 2 & & \\
\hline & & & & & + & 7 & & \\
\hline & & & & & 1 & 1 & & \\
\hline \multirow[t]{8}{*}{1999} & 99-101981-70 & $\begin{array}{l}\text { Hill Top } \\
\text { Research, Inc. }\end{array}$ & 215. CF side unimaged & $5 / 115$ & + & - & $\mathrm{N}$ & Test materials in use \\
\hline & & & 215. CF side imaged & $16 / 115$ & + & - & $\mathrm{N}$ & \\
\hline & & & 215. Backside of CF & $6 / 115$ & + & - & $\mathrm{N}$ & \\
\hline & & & 217. CB side unimaged & $8 / 115$ & + & - & $\mathrm{N}$ & \\
\hline & & & 217. CB side imaged & $1 / 115$ & + & - & $\mathrm{N}$ & \\
\hline & & & 220. Non-CB side & $1 / 115$ & + & - & $\mathrm{N}$ & \\
\hline & & & 226. CB side imaged & $3 / 115$ & + & - & $\mathrm{N}$ & \\
\hline & & & 227. CF side imaged & $3 / 115$ & + & - & $\mathrm{N}$ & \\
\hline
\end{tabular}


Adapted from Graves and Tardiff [1999] supplemental submission of peer review comments.

*The report numbers refer to submissions to the NIOSH docket; they are not listed in the references. Except in Report 86-5436H, no test results for control materials are included in this table.

$\dagger$ Number of responders/total number of persons who completed the study.

Footnotes continued on next page.

$\ddagger$ Highest recorded grade of skin reaction per study participant for a particular test material (based on multiple applications). Before 1980, Hill Top Research, Inc. employed a scoring scale that ranged from

0 to 7 (a score of 5 or greater=primary skin irritant; less than $5=$ nonirritating). Since 1980, Hill Top has used a scoring scale that ranges from 0 to 5 (a score of 3 or greater=primary skin irritant; less than $3=$ nonirritating).

Inveresk Research International used a scoring system of 0 to 8, with a score of 5 or greater indicating irritancy. This laboratory scoring system is more analogous to the Hill Top pre-1980

system, even though it is a post-1980 study.

§Abbreviations: $\mathrm{CB}=$ coated back; $\mathrm{CF}=$ coated front; $\mathrm{CFB}=$ coated front and back; $\mathrm{N}=$ no; $\mathrm{NA}=$ not applicable; $\mathrm{ND}=$ no data provided; $\mathrm{NR}=$ no reaction; $\mathrm{Y}=\mathrm{yes}$.

II $\mathrm{Y}$ and $\mathrm{N}$ were determined by NIOSH according to the scoring system listed in footnote

$\star$ Discontinued means that (1) the ingredient is no longer used to make CCP, or (2) the formulation as constituted is no longer used to make CCP, or (3) the CCP product is no longer sold in the United States. + The study director described skin reactions as sensitization.

\#Responders to sample E (grade 2 and grade 6 reactions) were dropped from the study (77-512-70).

**A responder to sample $\mathrm{H}$ (grade 1 reaction) was dropped $(77-512-70 \mathrm{H})$

$\dagger \dagger$ Responder to sample B (grade 1 reaction) was dropped (78-578-70).

$\S \S$ Two reactors with grade 2 reactions and one reactor with grade 3 reaction to T3012PP dropped out of the study [81-0318-73(2)] and are not included in the denominators.

पा[One grade 3 reactor to T3013PP was dropped from the study [81-0138-73(2)].

$\star \star$ Two dropped out with a score of $1 ; 1$ dropped out with a score of 2 .

++ One dropped out with a score of $1 ; 2$ dropped out with a score of 2 .

Three dropped out with a score of $1 ; 1$ dropped out with a score of 3

\#\#One dropped out with a score of $1 ; 1$ dropped out with a score of 3 .

****Three dropped out with a score of $1 ; 1$ dropped out with a score of 2 .

$\dagger+\dagger$ Two dropped out with a score of $1 ; 2$ dropped out with a score of 2 .

$+f+$ These results reflect the same person who expressed elevated scores throughout this study, regardless of the material tested. In addition, the scoring responses conflict with the study methodology since the responses increased, rather than decreased, across primary, secondary, and tertiary application sites. Therefore, the results for this person are suspect.

$\S \S$ As designated by performing laboratory, “+” denotes "slight, confluent or patchy erythema." This symbol indicates a score between 0 and 1 on a scale of 0 to 7 (see footnote $\ddagger$ ) and is not used universally.

IIIITT analytical laboratory that conducted this study concluded that this irritancy score was likely to be a recording error because of deviations from the study protocol. 
One of the difficulties in interpreting the RIPT studies is that although there is a standard procedure for evaluating changes consistent with allergic contact dermatitis, no guidelines exist for determining what constitutes a significant irritant response in humans [Gupta 1999]. OSHA [29 CFR ${ }^{\$} 1910.1200$, Appendix A] and the Consumer Product Safety Commission (CPSC) [16 CFR Part 1500.41] have guidelines for animal testing but not for human testing. Report 81-0138-73(2) from Hill Top Research, Inc., (Table 4-12) defines categories of responses for interpreting the findings in their test reports [Graves and Tardiff 1999]. The test report states the following:

If Category I responses (defined as negative or insignificant findings or significant findings unrelated to the test material) are projected to 98 percent or more of the total population, then the results are not significant for dermatotoxic potential. This means that two percent or less of the population could possibly have some type of mild reaction.

A mild significance is one where no Category III reactions (no vesicular, bullous, or spreading) exist and Category I (negative) reactions exist in 95 percent or more of total population. This means, that at most five percent of the population could have some type of mild, non-vesicular, non-bullous, non-spreading response.

A strong significance for dermatotoxic potential exists if there are any Category III responses (vesicular, bullous, strong spreading reactions) or if enough Category II responses (significant responses excluding vesicular, bullous, and spreading reactions) exist to decrease Category I to 85 percent or less of total population. This means that if any one person (approximately 1/200 or one-half percent of the test subjects) would have vesicular, bullous, or spreading reaction or 15 percent or more would have some type of significant reaction, then the test would be defined as having

${ }^{\ddagger}$ Code of Federal Regulations. See CFR in references. strong statistical significance for dermatotoxic potential. Eighty-five (85) percent of the population could have non-significant or negative reactions and the test would still be considered strongly significant.

This definition, which henceforth will be referred to as the "Hilltop Guidelines," combines information about the likelihood of the response with information about the severity of the response to determine whether the overall response is significant. With this definition a test would be declared negative or insignificant even if mild reactions occurred in a small proportion $(\leq 2 \%)$ of the test population. Moreover, as the ASTM standard argues, from a population experiencing 1.5 allergic reactions per 100 users, a sample of 200 could easily yield no cases just by chance [ASTM 1999].

Most of the RIPT reports submitted to NIOSH were judged to be negative by the investigators using criteria similar to those described above. However, in 8 of 217 test material combinations shown in Table 4-12, study directors indicated that skin sensitization occurred among human subjects. A few of the RIPT reports submitted in response to the 1987 Federal Register notice document responses to CCP or its components that were consistent with the induction of allergic contact dermatitis under the intensive exposures of the experimental protocols. These RIPT reports include Hill Top Research, Inc., Report 77-512-70, 77-896-71, 79-512-70, and 79-0085-73; and Shelanski Holding Company Report SH-72-4 (Table 4-12). Note, however, that reactions occurred in response to types of CCP that manufacturers claim are no longer in use. Cases of allergic contact dermatitis were not observed in any of the studies submitted in response to the 1997 Federal Register notice.

Two of the RIPT reports (e.g., Hill Top Research, Inc., Reports 98-101981-76 and 99-101981-70) suggest that some CCP test materials have a minor potential for skin 
irritation. Test results for these materials did not meet the testing laboratories' criteria for primary skin irritants, but they provided evidence of an irritant response. Because most studies did not include comparison groups exposed to plain paper, it is unclear whether this potential for skin irritation would have been much different from that of paper alone.

Tests Under Simulated Conditions of Use. Three industry-sponsored tests evaluating the irritation potential of CCP under simulated conditions of office use were submitted to the NIOSH docket in response to the 1987 and 1997 Federal Register notices.

Hill Top Research, Inc., conducted a double-blind placebo study in which subjects were provided with scissors and asked on 4 consecutive days to cut up samples of paper for $60 \mathrm{~min}$ under controlled temperature and humidity (Hilltop Research, Inc., Report 83-0965-70). Three types of CCP and a control ("white") paper were tested in random order by two groups of 10 and 9 subjects. After the 19 study subjects were exposed to one of the CCP samples (sample B), 10 (53\%) reported irritation of the eyes, nose, or skin. When exposed to the second and third of the remaining CCP samples, 3 subjects $(16 \%)$ and 2 subjects $(10 \%)$, respectively, reported irritation symptoms. One subject (5\%) reported irritation following exposure to the control paper. The authors concluded that their results demonstrated an unequal distribution of irritation symptoms among the samples tested and that the number of symptoms reported was particularly high with exposure to one of the CCP samples. The eyes were the most sensitive indicator, and some symptoms persisted for $24 \mathrm{hr}$. The authors recommended that studies of this type allow greater separation in time between samples to prevent carryover effects from preceding samples.
Hill Top Research, Inc., (Report 83-0123-70) conducted another double-blind study in which 20 subjects were recruited to handle a stack of 120 sheets of test paper. Every $30 \mathrm{sec}$, the subjects ran their hands over each side of another piece of paper until all the pieces had been handled at the end of $1 \mathrm{hr}$. The testing was done in a single room, with four different types of paper being handled each day. Subjects were examined for signs of irritation and were questioned regarding symptoms before exposure and $30 \mathrm{~min}, 60 \mathrm{~min}$, and $24 \mathrm{hr}$ after exposure. One subject dropped out. No irritation responses were reported or observed for the eyes, forearms, or face with any of the test papers. Seven subjects reported respiratory symptoms, but four of them demonstrated these effects with all four samples. These latter symptoms appear to have resulted from preexisting cold symptoms rather than from exposure to the paper samples. The results of this study are difficult to interpret in light of the coexisting cold symptoms and pretest symptoms present even for the control exposure.

In 1998, Moore Business Forms, Inc., reported on tests for scoring irritation or sensitization as a result of challenge with Moore Clean Print ${ }^{\circledR}$ $\mathrm{CB}, \mathrm{CF}$, and CFB. This test was performed by Biosearch in 1983 (Table 4-12). The volunteers included 200 men and women aged 16 to 68 . Of the 200 subjects, 33 had allergies to typical materials. Subjects were instructed to rub a sheet of the test paper (CFB) on their hands and wrists using a hand-washing motion. The procedure was performed over a 4-week period using 8 sheets of paper per day for 5 days per week. The subjects were examined weekly and were instructed to report any unusual interim occurrences. After day 20 of treatment, the subjects rested for 2 weeks and again performed the same procedure with 8 sheets of CCP. They were examined immediately after the challenge and 4 and $24 \mathrm{hr}$ later. The commercial laboratory that performed the test reported that none of the 200 subjects had any 
signs of irritation or sensitization following any of the 20 initial or challenge exposures.

\subsubsection{Summary}

In summary, the results of these laboratory studies in humans suggest that under some conditions of exposure to CCP or its components, workers may experience irritation of the upper respiratory tract or skin, and/or they may develop allergic contact dermatitis. It must be emphasized that most of these studies were negative, and the reactions observed in the positive studies were extremely rare. Furthermore, cases of allergic contact dermatitis were reported only in the earlier RIPT studies, which tested CCP types that are no longer in use; the more recent RIPT studies have detected only minor signs of skin irritation. If the Hill Top Research, Inc., guidelines are applied, then the mild irritation responses identified in some of the industry-sponsored RIPT studies would be considered Category I responses, which are defined as negative or insignificant findings, or significant findings unrelated to the test material. However, these same results do suggest that $2 \%$ or less of the population could have some type of mild reaction to CCP. Whether these mild irritation reactions would have been observed with ordinary bond paper is unclear, since these studies did not include bond paper as a control.

\subsection{Animal Studies}

\subsubsection{Published Studies}

Hasegawa et al. 1982a. Hasegawa et al. [1982a] reported that diisopropylnaphthalenes (Kureha Micro Capsule Oil [KMC-A]) and 1-phenyl-1-xylyl-ethanes (SAS) are two classes of solvents that are used in the manufacture of CCP. They were introduced in Japan as replacements for PCBs in 1971. KMC is used by the Federal Republic of Germany and by Japan at a rate of 10,000 tons per year
[Sturaro et al. 1994]. Large amounts of both materials were found in the body fat and subcutaneous fat of male JCL-SD rats $2 \mathrm{hr}$ after a single oral dose of $0.1 \mathrm{mg} / \mathrm{kg}$. The amounts increased with time until $24 \mathrm{hr}$ after the dose. In the liver, the amounts were nearly the same as those in the fat after $2 \mathrm{hr}$, but they rapidly disappeared thereafter. The concentrations in blood were similar to those of the heart, kidneys, and brain. Although the ratio of isomers in the KMC-A did not change, those of the SAS 296 differed by a ratio of $3: 1$ for 1-phenyl-1-metaxylyl to 1-phenyl-1-orthoxylylethane, respectively. This result was attributed to differences in hepatic metabolic rates. No accumulation was found in the organs, and little accumulation was found in the fat after daily administration for 1 month.

Hasegawa et al. 1982b. Hasegawa et al. [1982b] administered $0.1 \mathrm{~g} / \mathrm{kg}$ body weight of KMC-A and SAS 296 to JCL-SD rats every day for 1 month. Biochemical examination revealed (1) a slight decrease in body weight and a small increase in liver weight $(0.3 \%$ to $0.6 \%)$ compared with the controls; (2) disturbance of lipid metabolism in the liver (statistically significant decreases in triglycerides, glycolipids, and phospholipids) and serum (statistically significant free fatty acid twofold to threefold increases, total and free cholesterol decreases); and (3) disturbance of glucose metabolism in the liver (statistically significant decrease in glycogen and increase in pyruvate) from administration of both substances. A significant increase in alkaline phosphatase activity in the serum occurred in the case of SAS 296 administration.

Löfroth 1982. Löfroth [1982] examined a number of office materials for their potential mutagenic activity and found that none of the CCPs contained detectable amounts of mutagenic components. However, the author commented that some impurities in triaryl methanes 
(used as color formers) have been reported to be mutagenic [Bonin et al. 1981].

Certin and Zissu 1983. Certin and Zissu [1983] performed cutaneous irritation tests in rabbits. They compared extracts of 12 CCPs with 5 highly irritant reference oils, acetone (CB), or ethyl acetate or acetone (CF) extracts $(4 \mathrm{hr}$ of soxlet extraction of $50 \mathrm{~g}$, or acetone extraction of $1 \mathrm{~kg} \mathrm{CB}$ sheets in an ultrasonic tank for $1 \mathrm{hr}$ ). The CCP extracts were moderately or severely irritating using the Draize method (Table 4-13). Chemical analysis using GC/MS analysis identified the "oils" listed in Table 4-13.

Thirteen papers contained a phenolic resin in the $\mathrm{CF}$ layer and traces of free phenols, bisphenol A, and phenylphenol. For all of the CF analyses, compounds similar to abietic acid were found. Certin and Zissu [1983] reported that 8 of the 12 extracts were moderately irritating (irritation index from 2.7 to 4.7 ), and the remaining 4 extracts were severely irritating (irritation index from 5.6 to 7.3). Histopathology results from animals exposed to moderately irritating products exhibited epidermal acanthoses alternating with superficial epidermal necrosis, which led to thin, scaly crust that was sometimes continuous over the entire extent of the lesion. The severely irritating products caused more pronounced morphological findings. These were characterized by necrosis of the epidermis and superficial dermis, with inflammatory exocytosis and homogeneous degeneration of the connective tissue of the mid-dermis. The authors concluded that it was probably the oily constituents of the papers that produced the observed irritation of the skin and mucosa of office workers. However, they also noted that the animal test results are probably more grave than those experienced by humans, since human exposures were limited to several hundred micrograms on the fingers at the end of a day of handling. The authors

Table 4-13. Frequency of occurrence and animal irritation category for chemicals identified in 12 French CCPs

\begin{tabular}{|c|c|c|}
\hline Chemical & $\begin{array}{l}\text { Number of times identified } \\
\text { by GC/MS analysis }\end{array}$ & Irritation category \\
\hline Hydrogenated terphenyls & 16 & Severe \\
\hline Diisopropylnaphthalenes & 11 & Severe \\
\hline Phenylxylylethanes ${ }^{*}$ & 10 & Moderate to severe \\
\hline Alkylbenzenes & 6 & Severe \\
\hline Methybutyl naphthalenes & 1 & Not tested \\
\hline Benzylxylenes & 1 & Not tested \\
\hline Chlorinated paraffins & 1 & Not tested \\
\hline Chlorinated biphenyls & $1^{\dagger}$ & Not tested \\
\hline Dibutylphthalate & 1 & Not tested \\
\hline Kerosene & $¥$ & Severe \\
\hline
\end{tabular}

Source: Certin and Zissu [1983].

${ }^{*}$ This constituent was noted to have a very pungent odor.

${ }^{\dagger} 1972$.

${ }^{\ddagger}$ Not enumerated. 
remarked that nasal or ocular irritation is probably explained by contact with soiled fingers. They did not think that it was likely that the oils produced respiratory irritation because of the low volatility of their constituents; however, they did not discuss paper fibers as a potential vehicle for the irritants.

Cameron et al. 1986. Cameron et al. [1986] studied the percutaneous absorption of triarylmethane and phenoxazine-type color former components of CCPs. The percutaneous absorption of carbon-14-labeled color former components of CCP was investigated in the rat as a model for assessing possible absorption of these components by human users of such papers. Formulations of a proprietary color former/solvent mixture were applied to the shaved backs of hooded rats. The mixture contained carbon-14-labeled 6-(dimethyl-amino) -3,3-bis(4-(dimethyl-amino) phenyl)-1(3H)isobenzofuranone (CVL), a triarylamine color

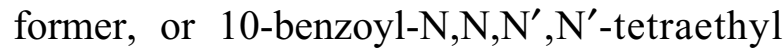
-3,7-diamino-10H-phenoxazine (BLASB), a phenoxazine color former. Some of the rats had been surgically prepared with bile duct and urinary bladder cannulae. Urine and bile samples were collected hourly for $24 \mathrm{hr}$ and assayed for carbon-14 activity. The animals were then sacrificed, and carbon-14 activity was measured in the skin, skin dressing, and body. Selected animals were sacrificed 2, 6, 24, or $96 \mathrm{hr}$ after application, and carbon-14 activity in the excreta, skin and dressings, and body was determined. Microhistoautoradiography was performed on the skins of some animals. Nearly all the CVL- or BLASB-derived carbon-14 activity was retained in or on the skin. Only $2.6 \%$ to $3.4 \%$ of the CVL and $1.0 \%$ to $2.1 \%$ of the BLASB doses were absorbed. During the 12 to $24 \mathrm{hr}$ after application, $0.02 \%$ of the CVL and $0.11 \%$ of the BLASB doses were eliminated in the urine and bile. The authors conclude that CVL and BLASB are slowly absorbed into the systemic circulation following topical application to rat skin. The authors concluded that these results (if extrapolated to humans) suggest that percutaneous absorption of these compounds should not be significant during normal handling of CCP.

Wolkoff et al. 1988. Wolkoff et al. [1988] reported airway-irritating effects in mice exposed to CCP using sensory irritation techniques [Alarie 1973]. Four mice were exposed for $10 \mathrm{~min}$ to emissions from CCP and emissions from crushed and compressed virgin copy papers. One CCP suspected of causing complaints decreased the respiratory rate significantly more than did a second CCP used without adverse effects. This result suggests irritation. Because the $\mathrm{CB}$ layer of the first CCP produced only negligible irritation, the authors concluded that neither the solvent nor the color formers caused the irritation. The authors suggested that the irritation was due to one or more of the following: the evolution of formaldehyde or other unidentified irritants in the paper, the evolution of irritant solvents from the paper and their transfer to the hands of the users, and the transfer of irritant particulate matter from the paper to the hands. The authors concluded that it would be beneficial to minimize the free formaldehyde content of the paper, eliminate volatile irritants from the $\mathrm{CCP}$, and minimize the transfer of irritant particulates or solvents to the skin.

Anderson 1992. Anderson [1992] used standard method ASTM E 981 [ASTM 1984] an adaptation of the Alarie [1973] method (which evaluates respiratory irritation) in mice to assess the offgassing of CCP and determine its effects on sensory irritation (upper airway) and pulmonary irritation (deep lung). Using groups of mice, the author concluded CCP to be a demonstrable irritant for both upper and lower airways, causing a greater than $50 \%$ change in respiratory rate. The type or composition of the CCP was not given except that it was 
commercially purchased. No other details were provided.

\subsubsection{NIOSH Docket Submissions}

Most information submitted to the NIOSH docket concerned animal testing of $\mathrm{CCP}$ or its components in extensive, widely accepted toxicology test procedures. The coded submissions did not allow specific identification of chemicals or formulations. Each of the approximately 1,500 animal studies submitted to the docket was reviewed independently by a NIOSH toxicologist. Most materials had been tested in a series of protocols such as inhalation $\mathrm{LC}_{50}$, cutaneous and/or oral $\mathrm{LD}_{50}$, skin and/or eye irritation, and skin sensitization. Some materials had been tested for mutagenesis, reproductive toxicity, or upper airway irritation. Not all materials were tested using every protocol. Most test results were negative; but positive results that were reported during the NIOSH review summarized as follows:

- The Mead Corporation sent summaries of eight reports to the NIOSH 1987 docket. The material tested was code 151 (chemical identification code), and all tests were negative except for a 1980 study of acute dermal toxicity in rabbits that estimated the acute dermal $\mathrm{LD}_{50}$ to be greater than $2 \mathrm{~g} / \mathrm{kg}$ body weight. However, slight to well-defined erythema was noted in all animals on days 1,3, and 7; it continued in most of the animals through day 14 .

- Hazelton Laboratories in Madison, Wisconsin, and Vienna, Virginia, submitted a series of 22 reports to the NIOSH 1987 docket. Irritation was produced by some of the samples, but sensitization did not occur. Inhalation experiments were negative, but exposure concentrations were very low in most cases.
- Biosearch evaluated CCP constituents from Moore Business Forms, Inc., and submitted the results to the NIOSH 1987 docket for acute oral toxicity, primary eye irritation, primary skin irritation, and 5-day repeated dermal irritation. All products tested were considered nontoxic, with $\mathrm{LD}_{50} \mathrm{~s}$ greater than $5 \mathrm{~g} / \mathrm{kg}$. None of the materials were classified by the Food and Drug Administration's regulatory definition as primary eye irritants, primary skin irritants, or dermal sensitizers. Several of the materials acted as mild or moderate skin and eye irritants.

- A series of toxicological test reports on a variety of $\mathrm{CCP}$ constituents were submitted to the NIOSH docket and reviewed. These test reports (Documents 002 through 148) were originally prepared for the Monsanto Company in St. Louis, Missouri. The tests had been conducted between 1956 and 1980. Test material ranged from "white paper" to "yellow liquid" or "white powder." The toxicological tests included acute oral and dermal toxicity and dermal and eye irritation. They also included a few 90-day feeding studies, mutagenesis assays, and inhalation studies as well as two aquatic studies with trout fry and midge larvae. Most substances were nontoxic or exhibited mild toxicity. Some caused mild or moderate irritation to the skin or eyes. However, in most cases, the low scores on the dermal or ocular irritation assays resulted in their classification as nonirritants. A few of the tests $(2 / 69$ primary irritation assays and 3/69 primary eye irritation assays) were graded as positive. From the other tests, NIOSH could infer that the product would cause mild irritation in humans. However, it must be recognized that such testing of pure compounds may produce more exaggerated results than testing the 
final CCP product, since less of the toxic component is available to consumers in the finished product. In the brief comments noted below, substances identified as mild irritants were not classified as primary irritants, even though some irritation occurred in more than one animal. Many of the compounds caused diarrhea. These observations are probably not relevant to humans - especially when animals were gavaged with a large volume of a slurry of white paper. Also of questionable relevance was the liver damage caused by compound 043 . This effect occurred when animals were exposed to $10,000 \mathrm{ppm}$ for 90 days.

- In a NIOSH docket submission numbered Document 050-EMI, a crystalline white powder was suspected to be relatively toxic. Peer reviewers from the industry noted that at full strength, this substance was corrosive to the skin, severely irritating to the eyes, and acutely toxic by oral ingestion [Graves and Tardiff 1999]. However, comments from the same peer reviewers noted that this component was never used in CCP production or offered for sale commercially. When the component was tested as part of a trial CCP, the paper was negative for acute and dermal toxicity and eye and skin irritation.

- Also of concern were a few studies in which compounds (033, 034, 036, 038-TR-33 to TR-38) were tested by inhalation or dermal application. Although these compounds did not produce any deaths or pathological findings, exposures resulted in modified behavior. Animals became hyperactive, salivated, became ataxic, and lost their righting reflex. NIOSH concluded that low exposures to these compounds could produce comparable effects in humans. Peer reviewers from the industry noted that these tests involved pure compounds, and that tests of the finished CCP products containing these compounds were negative [Graves and Tardiff 1999]. The chemical or component identification was unknown to NIOSH because of trade secret claims by the industry. Thus connecting the test results from pure compounds to finished products was not possible. None of the mutagenicity studies were positive, but not all substances were tested for mutagenicity.

- Another NIOSH docket submission from Monsanto is a series of 44 toxicity reports conducted by various testing laboratories on papers and dyes that were tested during the years 1978 to 1986. Each report consists of one to six toxicity tests that include oral and dermal toxicity, skin and eye irritation assessment, mutagenicity testing, and skin sensitization testing in animals.

Santosol 150 dye solution was tested more than any other product. Tests included a 90-day feeding study, developmental toxicity testing, and a series of studies in fish and midges. Unlike the other products tested in the Monsanto series, an $\mathrm{LD}_{50}$ and a maximum tolerated dose were determined for Santosol 150. In general, this dye solution exhibited low toxicity.

None of the products tested in the Monsanto series (including Santosol 150) were mutagenic, but not all products were tested for mutagenicity. None of the products were skin sensitizers in animals or humans, but not all products were tested for skin sensitization. Most compounds were not acutely toxic by the oral or dermal route. This conclusion was based on the fact that they were not lethal at $5 \mathrm{~g} / \mathrm{kg}$ (oral route) or $2 \mathrm{~g} / \mathrm{kg}$ 
(dermal route). However, many of the products induced modified behavior (including lethargy, ataxia, and even paralysis) from which the animals recovered. At necropsy, some animals exhibited mottled kidneys or livers. Diarrhea was a common symptom. For example, rat $\mathrm{s}$ gavaged with a slurry of white paper exhibited white diarrhea for 1 to 2 days. The relevance of such exposures and effects is questionable.

One product (96 Solvent CB Paper Internal Phase) was tested for developmental toxicity; it produced fetal malformations at a concentration that was toxic to the mother.

None of the products were corrosive, and very few were classified as primary irritants. However, some of the products caused mild eye irritation and transitory erythema and edema of the skin.

Several paper products were tested for formaldehyde content, which ranged from 0.014 to $<0.001 \mu \mathrm{g} / \mathrm{g}$ in the products tested. Levels of detection for the methods were not noted. Overall, the materials tested exhibited low or negligible toxicity. Some could act as mild irritants.

- The Mead Corporation submitted toxicology tests performed between March 3, 1987, and July 18, 1996. Tardiff [1997] reviewed the complete testing program of the Mead Corporation's evaluation of $\mathrm{CCP}$ and of the ingredients used to manufacture Mead's CCP. (These same materials were also submitted to and reviewed by NIOSH.) The Tardiff review encompasses 191 substances consisting of individual chemicals, mixtures used in the production of CCP, and various batches of CCP. The individual chemicals and mixtures included various inks, dyes, powders, coatings, adhesives, and other materials. Their identities were not known because of trade secret considerations by the company. Ingredients were selected for testing to supplement information provided by the suppliers of the raw materials and to test chemicals considered for formulations that were sufficiently reactive to have the potential for producing synergistic reactions with other ingredients of CCP. The following is a list of assays that were selectively performed (based on scientific judgment) with the test substances:

-Eye irritation test in the rabbit

- Primary skin irritation test in the guinea pig

- Skin sensitization test in the guinea pig

-Acute oral toxicity test in the rat

-Acute dermal toxicity test in the rabbit

-Acute inhalation toxicity test in the rat

- Genotoxicity tests (Ames mutagenicity assay and chromosomal aberration test)

The toxicity studies summarized in Tardiff [1997] were evaluated using data interpretation methods and guidelines accepted by the CPSC. Since that commission does not require the genotoxicity testing mentioned above, Tardiff [1997] used conventional professional practice found acceptable by the U.S. Environmental Protection Agency and supported by the National Academy of Sciences. To confirm the quality of the toxicologic tests summarized in the report, each study was verified as having been conducted in accordance with the 
testing requirements of the CPSC or the Organization for Economic Cooperation and Development. Each of the protocols included stipulations for adhering to good laboratory practices.

The following results were reported. Oral toxicity in rats was tested with 84 chemicals and mixtures. Each possessed an $\mathrm{LD}_{50}$ of $>5 \mathrm{~g} / \mathrm{kg}$. According to CPSC criteria, these materials are negative and unlikely to pose an acute hazard to humans by ingestion. Ocular irritation tests in rabbits were conducted with 83 chemicals or mixtures; 55 produced no ocular irritation. According to Tardiff [1997], the 28 materials that tested positive consisted of powders, liquids, and pastes. They produced a range of treatment-related effects, including iridal and/or corneal involvement and slight to moderate conjunctival irritation (which cleared within 24 to $72 \mathrm{hr}$ of the test material administration). According to the author, these substances are unlikely to lead to positive results in humans exposed to CCP because the test results indicated only mild and transitory effects with liquids, and end users would not be exposed to the liquids.

Primary skin irritation tests in the guinea pigs were conducted with 86 chemicals or mixtures. Each produced a skin irritation score of less than 5. Tardiff [1997] states that based on CPSC criteria and the primary irritation scoring data, these materials are negative and are unlikely to cause primary skin irritation in humans exposed to CCP. Acute dermal toxicity tests in rabbits were conducted with 18 chemicals or mixtures. Each possessed an $\mathrm{LD}_{50}>2 \mathrm{~g} / \mathrm{kg}$. On the basis of CPSC criteria, these materials are negative for acute dermal toxicity. Skin sensitization tests in guinea pigs were performed with 95 chemicals or mix- tures. Eighty-seven were negative. Of the eight positive tests, treatment-related results ranged from very faint to faint erythema reactions that cleared within 24 $\mathrm{hr}$ of the test material administration. Six materials were tested as liquids — which does not represent normal usage of CCP. Therefore, Tardiff [1997] concludes that these reactions would not occur in humans. The other two positive substances were tested as powders. Because the exposure is expected to be limited to "minute" quantities produced as CCP is cut, shredded, or torn, the doses encountered were considered insufficient by the authors to cause sensitization.

Acute inhalation toxicity testing in rats was conducted with 44 chemical substances or mixtures. Forty-three were negative according to CPSC criteria. The only positive result came from a liquid mixture with an $\mathrm{LC}_{50}$ between 2 and $200 \mathrm{mg} / \mathrm{L}$. Treatment-related effects included failure to gain expected body weight, respiratory distress, increased secretory responses, other changes in hair coat, and death. Since exposure conditions with normal use of CCP would not be in liquid form, Graves and Tardiff [1999] concluded that the test material was unlikely to be an acute hazard to humans by inhalation.

All 22 chemicals or mixtures tested for genotoxicity were negative for point mutations and did not increase chromosomal aberrations. These toxicity tests demonstrate that the tested CCP constituents are not mutagenic.

\subsubsection{Summary}

After examining the toxicological animal studies submitted to the NIOSH docket, NIOSH concludes that with a few exceptions, CCP constituents are not acutely toxic by the oral, dermal, or inhalation route. A number of $\mathrm{CCP}$ 
constituents were shown to be mild irritants to the skin and eyes of experimental animals. One study [Anderson 1992] stated that CCP from an unspecified source acted as both a sensory and pulmonary irritant in mice.

In summary, more than 300 substances and various combinations of materials were included in the animal studies. Of 238 tested for skin irritation, 8 were positive. In addition, some materials caused mild, transient irritation $(25.2 \% ; 60 / 238)$ but did not satisfy FDA's regulatory definition of an irritant. In 129 dermal lethality tests, mild skin irritation was noted $(17.8 \%$; 23/129); however, the regulatory definition is not based on this type of test. No pattern was observed to identify the CCP component responsible for the mild skin irritation reported in humans. A total of 271 substances were tested in the allergic contact dermatitis animal model, and 13 were positive. This result suggests that CCP infrequently causes allergic contact dermatitis in animals. Whether materials with positive toxicological outcomes were actually marketed is unclear; but the general rationale for toxicity testing is to prevent the marketing of materials that may harm users.

Most of the toxicological data submitted to the NIOSH docket were coded by the manufacturers for proprietary reasons. Thus it was not possible to identify replicate tests or the nature of the test materials or their means of preparation (dry, aqueous, neet, etc.). However, the animal toxicology results indicate only mild and transitory effects with liquids, and end users would not be exposed to the liquids. 


\section{Summary and Conclusions}

$\mathrm{O}$ verall, the toxicologic, epidemiologic, and experimental studies reviewed in this document indicate that exposure to CCP has been associated with the following adverse health effects: irritation of the skin and mucous membranes of the eyes and upper respiratory tract, allergic contact dermatitis (rarely), and some systemic reactions (rarely). The evidence regarding each of these possible health effects is summarized in this Chapter.

\subsection{Irritation of the Skin, Eyes, and Upper Respiratory Tract}

Evidence in the scientific literature indicates an association between exposure to some types of CCP and symptoms consistent with irritation of the skin, eyes, and upper respiratory tract. The primary evidence for an association comes from human studies. Irritative symptoms of the skin, eyes, and upper respiratory tract have been observed in numerous case reports and case series. Associations between irritative symptoms of the skin, eyes, and upper respiratory tract and CCP exposure have also been generally observed in cross-sectional epidemiologic studies of CCP-exposed workers.

A potential source of bias in the epidemiologic studies is overreporting of symptoms by workers who are already aware of a possible association between CCP exposure and irritative symptoms of the skin, eyes, and upper respiratory tract. This form of bias is often referred to as "recall bias" and is well recognized to be an important factor in epidemiologic studies in which symptoms or exposures are identified by questionnaires administered to the study subjects. The potential for recall bias may have been exacerbated by the use of leading questions such as "Do you think the paper makes you itch?” (e.g., Menné et al. [1981]).

A positive exposure-response relationship was observed between increasing CCP exposure and the prevalence of irritative symptoms of the skin, eyes, and upper respiratory tract in all of the studies that examined this issue; but the strength and statistical significance of the exposure-response relationship varied dramatically from report to report. The studies that examined an exposure-response are summarized in Table 5-1. Less potential exists for subjective report biases to influence a dose-response relationship than for such biases to influence an overall relationship with CCP. For subjective report biases to be important, study subjects with high CCP exposures would need to report symptoms more often than those with moderate or low CCP exposures. Though such a scenario is possible, it is less likely than for people with any CCP exposure to report symptoms more often than people with no exposure.

Selection bias is also a major concern in the cross-sectional studies that had low participation rates, such as the study by Fristedt and Pettersson [1980]. It is possible that in these studies, subjects with symptoms would have been more likely to return the questionnaires than were subjects without symptoms.

Potential biases in the epidemiologic studies could also have led to an underestimation of 


\section{Table 5-1. Summary of studies that examined exposure-response relationships between $\mathrm{CCP}$ handling and irritative symptoms of the skin, eyes, or upper respiratory tract}

\begin{tabular}{|c|c|c|c|}
\hline Study & $\begin{array}{l}\text { Number } \\
\text { of cases }\end{array}$ & $\begin{array}{l}\text { Frequency of handling } \\
\text { (sheets/time period) }\end{array}$ & $\begin{array}{c}\text { Reported irritative } \\
\text { symptom prevalence } \\
(\%)\end{array}$ \\
\hline \multirow[t]{3}{*}{ Kolmodin-Hedman et al. 1981} & 20 & 0 & 10 \\
\hline & 145 & $\mathrm{NR}^{\dagger}$ & 32 \\
\hline & 12 & $1,000 /$ day & 92 \\
\hline \multirow[t]{3}{*}{ Menné et al. 1981} & NR & $0-10 /$ day & 5 \\
\hline & - & $10-50 /$ day & 15 \\
\hline & - & $>50 /$ day & $>20$ \\
\hline \multirow[t]{4}{*}{ Sondergard 1981} & NR & $<100 /$ day & 57.6 \\
\hline & - & $100-150 /$ day & 66.7 \\
\hline & - & $250-1,000 /$ day & 93.5 \\
\hline & - & $>1,000 /$ day & 100 \\
\hline \multirow[t]{3}{*}{ Kleinman and Horstman 1982} & 13 & $1-10 /$ day & 18.8 \\
\hline & 23 & $11-50 /$ day & 29.9 \\
\hline & 31 & $>50 /$ day & 41.3 \\
\hline \multirow[t]{2}{*}{ Norbäck et al. 1983b } & NR & $\mathrm{CCP}<150 /$ day & 26 \\
\hline & - & $\mathrm{CCP} \geq 150 /$ day & 58 \\
\hline \multirow[t]{2}{*}{ Messite and Baker 1984} & NR & Low exposure & 0 \\
\hline & - & Heavy exposure & 30 \\
\hline \multirow[t]{5}{*}{ Olson and Mørck 1985} & 26 & $0-5 /$ day & 0 \\
\hline & 26 & $6-20 /$ day & 0 \\
\hline & 28 & $21-75 /$ day & 32 \\
\hline & 25 & $76-250 /$ day & 56 \\
\hline & 24 & $251-2,000 /$ day & 71 \\
\hline \multirow[t]{3}{*}{ Skov et al. 1989} & 1,648 & Monthly or less & 24 \\
\hline & 1,290 & $<25 /$ week or day & 32 \\
\hline & 183 & $>25 /$ week or day & 43 \\
\hline \multirow[t]{3}{*}{ Omland et al. 1993} & $34^{\ddagger}$ & $0 /$ day & 20 \\
\hline & 10 & 100-750/day & 40 \\
\hline & 10 & $>750 /$ day & 60 \\
\hline
\end{tabular}

*Cases are individuals with irritation of the eyes, nose, upper respiratory tract, or skin. $\dagger \mathrm{NR}=$ not reported.

$\$$ Based on repeated measure in group of 18 . 
the health effects associated with CCP. In these cross-sectional studies, workers who reacted to CCP might have left the workforce and thus would not have been included. In addition, since many of the researchers did not classify their subjects by exposure level, the overall effect could have been diluted by the mix of workers with high and low potential for CCP exposure.

The strongest evidence for an association between symptoms and CCP exposure comes from the studies of indoor air quality [Skov et al. 1989; Mendell 1991; Zweers 1992; Jaakola and Jaakola 1999]. These studies report a positive (and in several cases a statistically significant) association between CCP exposure and symptoms of skin, eye, and upper respiratory tract irritation (Table 5-2). These are the least susceptible to recall bias because they were not conducted in workplaces where concerns about CCP or other indoor pollutants played a role in their selection for study. Also, none of the indoor air studies were designed primarily to address the CCP question; hence investigator bias is also less likely. These studies used the most rigorous epidemiologic study designs, and the investigators were able to control for a number of potentially confounding exposures when examining the association between symptoms and CCP exposure.

Determining whether associations observed in epidemiologic studies are causal is frequently difficult given the observational nature of these studies and the possible influence of confounders and other sources of bias. Such is certainly the case with the epidemiologic CCP literature. Hill [1977] has developed useful criteria for evaluating causality using all of the available data. Epidemiologists have widely adopted these criteria for evaluating the evidence of causality in the epidemiologic literature. The criteria include (1) the strength of the association, (2) the consistency of the association,

Table 5-2. Elevated ORs for CCP exposure

and irritation of the skin, eyes, nose, or respiratory system reported in the indoor air cross-sectional studies

\begin{tabular}{llll}
\hline \multicolumn{1}{c}{ Authors } & \multicolumn{1}{c}{ Health effect } & OR* & 95\% CI \\
\hline Skov et al. 1989 & Mucosal irritation & 1.3 & $1.1-1.6$ \\
Zweers et al. 1992 & Oronasal symptoms & 1.18 & $1.0-1.39$ \\
& Eye symptoms & 1.13 & $0.96-1.33$ \\
Mendell 1991, & Eye, nose or throat symptoms & 1.6 & $1.0-2.6$ \\
Fisk et al. 1993 & Chest tightness/ & & $1.1-4.9$ \\
& difficulty breathing & 2.3 & $1.17-2.08$ \\
Jaakkola and Jaakkola 1999 & Eye symptoms & 1.56 & $1.19-1.88$ \\
& Nasal symptoms & 1.49 & $1.27-2.62$ \\
& Pharyngeal symptoms & 1.89 & $1.19-2.39$ \\
& Skin symptoms & 1.68 & $1.31-2.45$ \\
& Chronic bronchitis & 1.79 & $1.14-1.78$ \\
\hline
\end{tabular}

*Abbreviations: $\mathrm{CI}=$ confidence interval; $\mathrm{OR}=$ odds ratio. 
(3) specificity, (4) relationship in time (temporality), (5) biological gradient, (6) biological plausibility, (7) coherence, (8) experimental evidence, and (9) reasoning by analogy. The following sections describe these criteria and use them to evaluate the reported associations between CCP exposure and irritation of the skin, eyes, nose, and upper respiratory tract.

\subsubsection{Strength of the Association}

Associations that are large in magnitude are considered more likely to be causal, since they are less likely to be explained by confounding or other forms of bias.

In the cross-sectional studies, weak to moderate associations were observed between $\mathrm{CCP}$ exposure and irritation of the skin, eyes, and upper respiratory tract. The odds ratios (ORs) reported in the cross-sectional studies summarized in Table 5-2 were approximately between 1.1 (e.g., Zweers [1992]) and 2.3 (e.g., Mendell [1991]). The strength of association for rate (or odds) ratios that are 1.2 to 1.5 and 1.5 to 3.0 has been interpreted as being weak and moderate, respectively (see Monson [1980], p. 94). It should be recognized that the size of the odds ratios are limited by the relatively high background rates of the symptoms studied. Many of the other cross-sectional studies (i.e., non-indoor air studies) did not include an unexposed population, and thus it is difficult to judge the strength of association in these studies. It is noteworthy that the prevalence of symptoms among workers with extremely high $\mathrm{CCP}$ exposures (i.e., $\geq 1,000$ sheets/day) was between $92 \%$ and $100 \%$ in two of the non-indoor air cross-sectional studies (Table 5-1), which suggests a strong association among highly exposed workers.

\subsubsection{Consistency}

Consistency refers to the repeated observation of similar findings in numerous study settings. The case studies and case series reports are consistent insofar as they report similar symptoms involving the skin and mucosal membranes of the eyes and upper respiratory tract. However, this apparent consistency might be partly a reporting bias that occurs because investigators have read previous case reports and are more likely to report findings that are similar to those previous reports. Perhaps more convincing is the fact that the cross-sectional epidemiologic studies were generally consistent (see Table 4-3) in associating skin, eye, and upper respiratory symptoms with exposure to CCP. Associations of CCP with other symptoms such as headache and fatigue have not been consistently observed in these studies. Overall, the epidemiologic studies are judged to be relatively consistent in reporting irritative symptoms of the skin, eyes, and upper respiratory tract.

\subsubsection{Specificity}

Specificity requires that an exposure be associated with a single specific effect. Furthermore, if a disease has no other major risk factors (e.g., asbestos and mesothelioma), the association is often very credible and the studies are the least susceptible to recall bias.

The irritative symptoms of the eyes, skin, and upper respiratory tract reported in CCP studies are common effects with many risk factors. Ocular and upper respiratory tract irritative symptoms in particular can be triggered by many exposures encountered in the indoor environment and are quite prevalent in many office buildings. Thus the irritative symptoms of the eyes, skin, and upper respiratory tract that have been associated with $\mathrm{CCP}$ exposure are not specific to CCP. On the other hand, the studies have been relatively consistent in reporting an association between CCP exposure and irritative symptoms of the eyes, skin, and upper respiratory tract. These symptoms commonly occur together with exposures 
to an irritant and thus should probably be viewed as a single effect and consistent with the specificity criterion.

\subsubsection{Relationship in Time (Temporality)}

Temporality requires that the exposure precede the disease and that the effects follow a course in time that is physiologically plausible in relation to the exposure.

In the epidemiologic studies, it can be reasonably assumed that the CCP exposures preceded the observed symptoms or signs. Furthermore, several of the case reports describe symptoms or signs of disease that subsided or disappeared after the subject left work or after the CCP exposure was removed. Thus these human studies meet the temporality criterion for the irritative symptoms of the eyes, skin, and upper respiratory tract associated with CCP exposure.

\subsubsection{Biological Gradient}

Biological gradient refers to evidence for a dose-response (or exposure-response) relationship. A dose-response relationship is viewed by most epidemiologists to be strong evidence for causality. A dose-response relationship is less likely to be explained by reporting bias or confounding than is an overall measure of association (i.e., a yes/no exposure). However, it is possible that such a dose-response relationship could be produced by confounding.

A positive dose-response relationship between the frequency of handling $\mathrm{CCP}$ and the prevalence of irritative symptoms of the eyes, skin, and upper respiratory tract was reported in the nine studies that examined this relationship (Table 5-1). Recall bias might explain these relationships in some studies. However, it is unlikely to explain the relationships observed in the study by Skov et al. [1989], which was one of the indoor air quality studies that was not conducted at a building with previous complaints related to $\mathrm{CCP}$.

Overall, these studies demonstrate a biological gradient by providing consistent evidence for an exposure-response relationship for irritative symptoms of the eyes, skin, and upper respiratory tract associated with exposure to CCP.

\subsubsection{Biological Plausibility}

Biological plausibility exists when an association is consistent with what is known about the biology of the disease. The biological plausibility of the symptoms associated with $\mathrm{CCP}$ exposure is supported by the presence of several well-known irritants in some formulations of CCP (e.g., formaldehyde, isocyanates, phthalates, acrylates, glutaraldehyde, amines, and kerosene). For example, in seven studies of CCP and formaldehyde, nearly all exposure measurements exceeded the NIOSH REL (but not the OSHA PEL) for formaldehyde [Chrostek and Moshell 1982; Gockel et al. 1981; Hazelton Laboratories 1985; Apol and Thoburn 1986; Chovil et al. 1986; Omland et al. 1993; Zimmer and Hadwen 1993]. The biological plausibility of the irritative effects is further supported by the similar effects observed in animal studies. Irritation of the skin or respiratory tract has been demonstrated in several studies of animals exposed to CCP or its components (e.g., see Certin and Zissu [1983]; Wolkoff et al. [1988]; Anderson [1992]). Irritation of the skin was reported in a number of the industry-sponsored toxicologic studies reported to the NIOSH docket, although these reactions did not indicate primary skin irritation according to the regulatory criteria established by FDA. In addition, the positive reactions observed in these studies were generally due to exposures to $\mathrm{CCP}$ components in liquid form. Users of CCP are not exposed to these substances in liquid form, and 
it is therefore unlikely that they would experience such high levels of exposure.

Understanding the mechanism by which an exposure causes a health effect adds credence to a causal association. The mechanisms involved in the irritative symptoms of the eyes, skin, and upper respiratory tract associated with CCP exposure have not been established. In fact, it is unclear which of the CCP components might be responsible for these symptoms, although (as mentioned above) chemicals in some types of CCP are known irritants. Few studies have included ordinary bond paper as a control for mechanical abrasion from handling paper or for exposure to chemicals (such as formaldehyde) that are contained in ordinary paper. However, in the few studies that compared CCP with ordinary bond, the irritative effects were clearly greater for CCP (i.e., Nilzen [1975], Norbäck et al. [1983b], Morgan and Camp [1988], and Koenig [1988]).

An understanding of the mechanism should not be required for inferring causality. As Hill [1977] suggested, "What is biologically plausible depends upon the biological knowledge of the day." In numerous examples, causal associations have been identified well before the underlying biological mechanisms were understood (e.g., smoking and lung cancer).

Overall, reasonably supportive evidence exists for the biological plausibility of the association between CCP exposure and the irritative symptoms of the eyes, skin, and upper respiratory tract observed in the epidemiologic studies.

\subsubsection{Coherence}

Coherence requires that the observed association not conflict with what is known about the natural history and biology of the disease. The distinction between this criterion and biological plausibility is a fine one. An example given by Hill [1977] is that the association between lung cancer and smoking is coherent with the temporal rise that has taken place in both variables over the last century.

The reports in the literature of an association between exposure to CCP and irritative symptoms of the eyes, skin, and upper respiratory tract are not in conflict with current knowlege of the biology of these health effects. One apparently contradictory fact is that health-related inquiries to CCP manufacturers have reportedly decreased from 1987 to 1996 , dropping from approximately 130 to 50 inquiries per year [letter to the NIOSH docket from Robert Tardiff, October 6, 1998]. This decrease has occurred despite increases in the production of CCP from approximately 85,000 to 100,000 tons/year over the same period. However, increases in production would not necessarily lead to increased exposures in offices and other situations where CCP is used. Thus it is unclear whether the number of people exposed and the level of exposure have dropped or increased during this period. Changes in the formulation of CCP during this period could also explain the decrease in complaints. Therefore, the coherence criterion contributes little to determining causality for the irritative symptoms of the eyes, skin, and upper respiratory tract associated with $\mathrm{CCP}$ exposure.

\subsubsection{Experimental Evidence}

Experiments can provide the strongest evidence for causality, but such information is rarely available for toxic effects in workers. In the case of CCP, a few experimental studies in humans have demonstrated irritative symptoms and signs with exposure to some types or components of CCP.

Nilzen [1975] reported weak to moderate signs of skin irritation among atopic persons exposed to $\mathrm{CCP}$ with skin-prick testing, but the same reactions were observed with exposure to 
ordinary bond paper. Nilzen [1975] also reported symptoms consistent with nasal irritation in subjects exposed to vapors from $\mathrm{CCP}$ or bond paper, but the CCP caused a stronger reaction. Another study measuring the effects of CCP on nasal passages reported signs consistent with nasal irritation and congestion [Morgan and Camp 1986; Koenig 1988]. In an industry-sponsored study, a high percentage of subjects $(40 \%)$ demonstrated irritation of the eyes, skin, or nose when they used scissors to cut one particular type of CCP (Hill Top Research, Inc., Report 83-0965-70), but not when they cut bond paper. Signs of dermal irritation (e.g. Hill Top Research, Inc., Report 79-0085-73) were observed in some of the RIPT studies that were submitted to the 1987 docket. However, the use of the products tested in these studies has generally been discontinued. Only very mild signs of skin irritation were observed among subjects in the more recent RIPT studies that tested $\mathrm{CCP}$ materials in current use and that were submitted to the NIOSH docket in 1997. Generally less than $2 \%$ of subjects demonstrated very mild skin irritation in these studies, but higher percentages (e.g., $>10 \%$ ) were reported for some of the materials tested in two of the more recent studies submitted to the docket (Hill Top Research, Inc., 1998 and 1999). However, these two studies were not considered by the investigators to be positive for irritation.

These experimental studies are not subject to the potential recall bias of the epidemiologic studies, since they used objective tests. Also, it is very unlikely that the positive findings in some of these studies could be explained by other forms of biases or chance. The inconsistency between the findings in these studies may be explained by differences in the types of $\mathrm{CCP}$ tested or other differences in study design. It is unclear how relevant these experimental models are, since the exposure from patch testing is quite different from exposures among workers who use $\mathrm{CCP}$ in offices and elsewhere. These studies also have the potential for a negative selection bias, since they generally involved healthy volunteers and could thus have excluded sensitive persons.

\subsubsection{Reasoning by Analogy}

Reasoning by analogy refers to making an analogy with the known health effects for a similar exposure. For example, the fact that a drug has characteristics similar to Thalidomide (a known teratogen) provides support for a causal relationship between this drug and birth defects. No useful analogies exist for CCP; thus this criterion is not useful for judging causality in this case.

\subsubsection{Summary}

In summary, the Hill criteria for consistency, specificity, temporality, biological gradient (dose-response), biological plausibility, and experimental evidence support a casual association between CCP exposure and irritative symptoms of the skin, eyes, and upper respiratory tract. Because the associations observed in the epidemiologic studies were generally weak to moderate, the evidence does not fully satisfy the criterion for the strength of association. Although not all of the criteria are fully met, Hill [1977] points out that none of the criteria can provide absolute proof of a cause-and-effect relationship, and none should be used as an absolute requirement for proof of a cause-and-effect relationship. Furthermore, not all of these criteria are equally important. The dose-response relationship observed and the experimental evidence reported for some CCP exposures and irritative symptoms of the eyes, skin, and upper respiratory tract provide the strongest evidence for a causal association.

\subsection{Allergic Contact Dermatitis}

Several authors have reported cases of allergic contact dermatitis that appear to have been associated with CCP or its components [Marks 1981; Kannerva et al. 1990a,b, 1993; Shehade 
1987]. Development of sensitization to CCP or its components was also reported in a few persons in several industry-sponsored RIPT studies (Report 77-512-70 and Supplemental Report 79-512b-70, Report 77-896-71, and Report 79-0085-73, all from Hill Top Research, Inc.; and Project SH-72-4, dated April 18, 1972, performed by the Shelanski Holding Company, Conshohocken, Pennsylvania, for Monsanto Co., St. Louis, Missouri). In 8 of 217 test materials shown in Table 4-12, study investigators indicated that skin sensitization occurred in some human subjects. However, these studies were mostly judged to be negative for irritation by the investigators. Thus in a small proportion of the population, CCP or its components appear capable of inducing cell-mediated (type IV) immune response and allergic contact dermatitis, particularly under the intensive exposures associated with RIPT protocols. Cases of allergic contact dermatitis were reported only in RIPT studies from the 1970s that were submitted to the 1987 NIOSH docket; no cases were reported in the studies submitted to the 1997 docket. This fact indicates that the CCP component(s) responsible for the allergic contact dermatitis observed in the early studies may have been removed from the more recent formulations of CCP.

\subsection{Systemic Reactions}

Three patients with systemic reactions clinically suggestive of mast cell and/or basophil degranulation after cutaneous challenge with $\mathrm{CCP}$ or its components have been reported in two published case reports [Marks et al.1984; LaMarte 1988]. One patient challenged by CCP handling became symptomatic approximately 15 to $20 \mathrm{~min}$ after exposure and experienced swelling of the exposed hand, hives on the neck, changes in both the inspiratory and expiratory limbs of the flow-volume loop (suggesting upper airways obstruction), and elevated circulating levels of several arachidonic acid metabolites. Skin-prick testing with $\mathrm{CCP}$ dust was reported to be negative [Marks et al. 1984]. One patient who was challenged by rubbing $1 \%$ alkylphenol novolac resin dispersion onto the forearm became symptomatic approximately $15 \mathrm{~min}$ after exposure and developed hoarseness, wheezing, and angioedema of both arms. A subsequent challenge with this material was followed by hoarseness, wheezing, and angioedema at the challenge site. Video endoscopy of the larynx was interpreted as showing diffuse swelling and marked edema of the true vocal cords. Plasma histamine levels obtained at the onset and peak of symptoms were sixfold higher than the prechallenge level [LaMarte 1988]. Finally, one patient who was challenged by rubbing $1 \%$ alkylphenol novolac resin onto one arm was reported to have angioedema of the arm and hoarseness 30 min after challenge [LaMarte 1988].

These reports suggest that some CCPs or their components can induce reactions clinically compatible with those caused by mast cell and/or basophil mediator release. Immunologic sensitization was not adequately evaluated in these studies, and thus it is unclear whether an immunologic mechanism underlies these reactions. However, no additional reports were located in the peer-reviewed literature over the last 12 years. Thus, even if the reported reactions were referable to CCP exposure, systemic reactions of this type appear to be exceedingly rare. Furthermore, the relevance of these reports to current CCP exposures is uncertain.

\subsection{Conclusions}

On the basis of a NIOSH review of the scientific literature and information submitted in response to its 1987 and 1997 Federal Register notices, NIOSH concludes the following:

- The weight of the evidence supports the conclusion that exposure to certain types of CCP or its components has, under 
some conditions, resulted in symptoms of irritation of the skin and of the mucosal membranes of the eyes and upper respiratory tract.

This conclusion is based primarily on interpretation of the evidence from the epidemiologic studies. Although the magnitude of the effects observed in these studies was only weak to moderate, these studies were reasonably consistent in reporting an association and evidence of an exposure-response relationship between CCP exposure and irritative symptoms of the eyes, skin, and upper respiratory tract. The plausibility of the epidemiologic evidence is supported by the presence of known irritants in some types of CCP, toxicologic studies that demonstrate mild irritation in laboratory animals exposed to $\mathrm{CCP}$, and the evidence for respiratory and skin irritation in some of the experimental laboratory studies in humans. Some of the epidemiologic studies may have been biased, particularly by overreporting from study subjects who were already concerned about the potential effects of CCP exposure (i.e., recall bias). However, it is unlikely that recall bias could explain the associations observed between CCP exposure and irritative symptoms of the eyes, skin, and upper respiratory tract in the indoor air quality studies, since these studies were not conducted in an atmosphere of concern regarding the health effects of CCP.

- Exposure to CCP or its components may rarely cause allergic contact dermatitis.

This conclusion is based on published case reports of allergic contact sensitization and results reported in several industry-sponsored RIPT studies. Cases of allergic contact dermatitis were reported only in RIPT studies from the 1970s that were submitted to the $1987 \mathrm{NIOSH}$ docket; no cases were reported in the studies submitted to the 1997 docket. This fact may indicate that the CCP component responsible for the allergic contact dermatitis observed in the early studies was removed from the more recent formulations of CCP.

- Systemic reactions have occurred in a few persons exposed to CCP.

This conclusion is based on the finding that three such cases have been reported in the peer-reviewed medical literature. No cases have been reported in the last 7 years, and thus there is no evidence that current exposures to CCP present a risk for this health outcome.

- Data are insufficient to evaluate claims of other adverse health effects (such as neurologic effects and reports of MCS) that have been suggested in some of the clinical reports submitted to the NIOSH docket.

In conclusion, although the weight of the evidence indicates that exposure to CCP in the past has resulted in adverse health effects, it is uncertain whether current formulations of CCP represent a significant risk to exposed workers. Only a few cases of systemic reactions and allergic contact dermatitis have been reported in the United States or in Europe, which suggests that the risk of these serious outcomes is extremely low given the large number of people who have been exposed to CCP over a period of many years. Recently conducted experimental studies in humans (RIPT studies) suggest that the potential for skin irritation from exposure to current formulations of CCP is nonexistent, or at most slight. However, it is unclear how well these experimental studies simulate the exposures and 
potential responses of CCP users - particularly heavy users. Data from industry reporting systems suggest no widespread problem and in fact indicate a decrease in health-related complaints in recent years despite an increase in CCP production. However, these passive reporting systems are unlikely to capture all or even most cases of CCP-related health effects, and changes in publicity about CCP may have caused fluctuations in the reporting of cases. Since the 1980s, no epidemiologic studies have been conducted to determine irritative symptoms among U.S. Workers exposed to CCP [Mendell et al. 1991]. A positive epidemiologic study was conducted in Finland in 1991 [Jaakkola and Jaakkola 1999]. However, the relevance of these findings for U.S. workers may be limited because of differences between the CCP products used in Europe and the United States. Thus information is lacking about the prevalence of irritation of the eyes, skin, and upper respiratory tract among workers currently handling CCP in the United States. 


\section{Recommendations}

\subsection{Historical Recommendations in the Scientific Literature}

T he earliest recommendations for eliminating or reducing symptoms associated with CCP exposures originated in Sweden from the National Swedish Board of Occupational Safety and Health [1976]. These recommendations and those that were echoed or expanded by various authors [Andanson et al. 1979; Messite and Fannick 1980; Harris 1983; Messite and Baker 1984], the Danish Branch Safety Council for Offices and Administration [1988], the Cornell University Chemical Hazard Information Program [CHIP 1988], Wattendorf [1988], and Öko-Test Magazin [1990] are enumerated below (not prioritized):

- Ensure adequate environmental conditions (including ventilation, temperature, and humidity control) in office, paper storage, and filing areas.

- Avoid ingesting CCP chemicals by minimizing hand-to-mouth contact.

- Do not rub eyes when handling CCP.

- If symptoms occur, select a CCP with a different composition.

- Substitute a mechanical-type paper (e.g., carbon paper) for a chemical-type paper (i.e., CCP).

- Limit contact with CCP by spreading CCP-related work over a longer period or by reducing the amount used and/or stored in the workspace.

- Employ proper housecleaning and good hand-hygiene procedures (including, occasionally, the use of protective gloves and/or hand creams).

- Inform workers about the symptoms that have been noted by workers who handle CCP.

- If you are a CCP manufacturer or importer, give exact data about the substances used and provide quality certificates for auxiliary substances, additives, and intermediate products used for each lot of CCP.

The Danish Branch Safety Council for Offices and Administration [1988] also recommended use of the following checklist to evaluate complaints received when working with $\mathrm{CCP}$ :

- Why do you think that the discomforts can be traced to CCP work?

- How many persons suffer discomfort in connection with work using this kind of paper?

- Who suffers from the discomforts?

- Have there been complaints in connection with work with CCP? 
- Has the paper quality been recently changed or has a new delivery of CCP been made?

- Have any of the following discomforts developed:

- Irritation of mouth, eyes, nose, or throat

- Skin problems of the face, hands, or arms

-Headache, vertigo, or exhaustion

- How long have the person(s) affected suffered from the symptoms?

- Do the symptoms disappear during weekends and/or vacations?

- Do the symptoms develop especially in certain departments or at some special function?

- How much CCP is handled, separately or in total?

- Does the consumption of CCP vary during the course of a month?

- Is there any connection between the amounts of CCP and the complaints?

- How long have you worked with the CCP that you believe to be the cause of your symptoms?

- Have similar symptoms occurred among fellow workers who do not work with $\mathrm{CCP}$ ?

- Is the indoor climate (temperature, relative humidity, quality of the air, etc.) satisfactory?
- What is the extent of cleaning?

- Who produces the CCP?

- Who prints the CCP?

- Have the symptoms following work with $\mathrm{CCP}$ been reported?

\subsection{NIOSH Recommendations}

NIOSH recognizes that it may occasionally be necessary to limit CCP exposure in certain workers through administrative controls (such as job rotation). But in most cases, implementing normal precautions and recommendations for maintaining acceptable indoor air quality should be adequate to reduce or eliminate symptoms. Good industrial hygiene and work practices are likely to prevent symptoms from potent irritants (such as formaldehyde) that may be emitted from CCP. These include adequate ventilation, humidity, and temperature controls; proper housekeeping; minimal hand-to-mouth and hand-to-eye contact; and periodic cleansing of hands.

In addition, NIOSH recommends the following:

- CCP manufacturers and their suppliers are encouraged to follow best practices, such as the Product Stewardship Code of Management Practices [American Chemistry Council 2000]; they should also consider enhancing their product guidance to reflect that published studies indicate that irritative symptoms appear to increase with increasing exposure to CCP.

- CCP manufacturers and their suppliers should also consider how human test procedures (e.g., RIPT) can be modified 
by the use of standardized protocols that include proper controls (e.g., bond paper), tests that mimic high-use situations, and meaningful criteria for scoring and interpreting these tests to assess safety from skin contact (e.g., ASTM D 6355-98) [ASTM 1999]. Current best practices in the field of product testing may not be sensitive enough to identify mild skin irritants.

- As part of ongoing surveillance, CCP manufacturers and their suppliers may want to evaluate the frequency and severity of irritation in workers using CCP. 


\section{References}

AEMCP [1985]. A review of the report Carbonless copying paper and health problems by the Scandinavisk Biomedicinsk Institut. Paris: Association of European Manufacturers of Carbonless Papers.

Alarie Y [1973]. Sensory irritation by airborne chemicals. CRC Crit Rev Toxicol 2:299-363.

American Chemistry Council [2000]. Product Stewardship Code of Management Practices. [http://www.cmahq.com/rc.nsf/unid/rchy-4ejtat].

American Academy of Allergy, Asthma, and Immunology [1999]. Position statement. Idiopathic environmental intolerances. J Allergy Clin Immunol 103:36-40.

Andanson J, Raulot-Lapointe H, Moulanier M [1979]. Carbonless copy paper intolerance problems: irritation or allergy? Arch Mal Prof 41:168-169.

Anderson RC [1992]. Use of ASTM E 981 to estimate irritant potency of room air and offgasing of commercial products. In: The International Conference: Quality of the Indoor Environment, April 28-30, Athens, Greece, pp. 369-377.

Andersson K, Bornberger S, Andersson I [1980]. Study by means of inquiries concerning some problems when working within certain office environments - results of enquiry investigation conducted in the early summer of 1980. Örebro, Sweden: Department of Occupational Medicine, Örebro Regional Hospital.
Cited by Buring and Hennekens 1991; and Jeansson et al. 1983.

Apol A, Thoburn TW [1986]. Hazard evaluation and technical assistance report: Boise Cascade, Vancouver, WA. Cincinnati, OH: U.S. Department of Health and Human Services, Public Health Service, Centers for Disease Control, National Institute for Occupational Safety and Health, NIOSH Report No. HETA 85-462-1748.

Asano M, Hasegawa K, Akahori H, Tsujimoto M [1983]. Dyestuff containing microscopic capsule dispersion for record materials. U.S. Patent No. 4,384,871.

ASHRAE [1981]. Ventilation for acceptable indoor air quality. Atlanta, GA: American Society of Heating, Refrigerating, and Air-Conditioning Engineers, Inc., Standards Committee 1981-1982, ASHRAE Standard 62-1981.

ASHRAE [1989]. Thermal environmental conditions for human occupancy. Atlanta, GA: American Society of Heating, Refrigerating, and Air-Conditioning Engineers, Inc., Standards Committee 1989-1990, ASHRAE Standard 55-1989.

ASTM [1999]. Standard test method for human repeat insult patch testing of medical gloves. In: Annual book of ASTM standards. West Conshohocken, PA: American Society for Testing and Materials, ASTM Designation D 6355-98. 
Bedekovic D, Fletcher IT [1986]. Ringsubstituted 4-azaphthalides. U.S. Patent No. $4,675,407$.

Bennett D, Chrostek W [1986]. Hazard evaluation and technical assistance report: Defense Industrial Supply Center, Philadelphia, PA. Cincinnati, OH: U.S. Department of Health and Human Services, Public Health Service, Centers for Disease Control, National Institute for Occupational Safety and Health, NIOSH Report No. HETA 84-534-1721.

Bodmer JR, Miller RE [1985]. Record member. U.S. Patent No. 4,540,998.

Bodmer JR, Miller RE [1986]. Record member. U.S. Patent No. 4,610,727.

Bodmer JR, Peters JH [1984]. Pressuresensitive recording sheet. U.S. Patent No. $4,470,058$.

Bonin AM, Farquharson JB, Baker RSU [1981]. Mutagenicity of arylmethane dyes in salmonella. Mutat Res 89:21-34.

Brissette Y, Paquette M [1987]. Health effects related to the use of carbon paper and carbonless copy paper. Québec, Canada: Commission de la Santé et de la Sécurité du Travail, Document No. 5512t.

Buring JE, Hennekens CH [1991]. Carbonless copy paper: a review of published epidemiologic studies. J Occup Med 33(4):486-495.

Burton NC, Malkin R [1993]. Hazard evaluation and technical assistance report: Michigan Printers, Chicago, IL. Cincinnati, OH: U.S. Department of Health and Human Services, Public Health Service, Centers for Disease Control and Prevention, National Institute for Occupational Safety and Health, NIOSH Report No. HETA 93-0366-2370, NTIS No. PB94-163-128.
Calnan CD [1979]. Carbon and carbonless copy paper. Acta Derm Venereol Suppl (Stockh) 59(85):27-32.

Calnan CD [1981]. Unsolved problems in occupational dermatology. $\mathrm{Br} \quad \mathrm{J}$ Derm 105(Suppl 21):3-6.

Cameron BD, Dunshire JP, Draffan GH, Bruce JC [1986]. The percutaneous absorption of triarylmethane and phenoxazine type colour former components of carbonless copy papers. Ann Occup Hyg 30(1):115-122.

Certin J-F, Zissu D [1983]. Experimental and analytical approach to problems posed by carbonless copy paper. Arch Mal Prof 44(4):263-268.

CFR. Code of Federal regulations. Washington, DC: U.S. Government Printing Office, Office of the Federal Register.

Chang JCH [1978]. Method of desensitizing carbonless paper. U.S. Patent No. 4,195,103.

Chang YC, Lamar RS [1988]. Color developing composition for carbonless paper copying system. U.S. Patent No. 4,755,501.

CHIP [1988]. Carbonless copy paper. New York: Cornell University Chemical Hazard Information Program. MSDS Companion Sheet No. 10.

Chovil AC, Feigley CE, Crosscope E [1986]. An occupational illness in a university setting. Am Ind Hyg Assoc J 47(10):A-644, A-646.

Chrostek W, Moshell A [1982]. Hazard evaluation and technical assistance report: General Telephone Company, York, PA. Cincinnati, OH: U.S. Department of Health and Human Services, Public Health Service, Centers for Disease Control, National Institute 
for Occupational Safety and Health, NIOSH Report No. HETA 81-275-1122.

Cronin E [1980]. 'No carbon required' (NCR) paper. In: Contact Dermatitis. London: Churchill Livingstone, pp. 853-854.

Cullen MR [1987]. The worker with multiple chemical sensitivities: an overview. Occup Med: State Art Rev 2(4):655-661.

Dady JM [1998]. Memorandum of January 22, 1998 (accompanying a submission to the NIOSH Docket Office including tests performed by Imation Enterprises Corporation and $3 \mathrm{M}$ ), from J.M. Dady, Imation Entrprises Corp, Oakdale, MN, to Richard Niemeier, Education and Information Division, National Institute for Occupational Safety and Health, Centers for Disease Control and Prevention, Public Health Service, U.S. Department of Health and Human Services.

Danish Branch Safety Council for Offices and Administration (Branchesikkerhedsradet for Kontor og Administration) [1988]. Work with self-copying paper. Copenhagen, Denmark: Arbejdsmiljofondet.

Dodds WJ[1980]. Unpublished report. Cited by Norbäck and Göthe 1983.

Dodds WJ, Butler PEB [1981]. Carbonless copy paper [letter to the editor]. Contact Dermatitis 7:218-219.

52 Fed. Reg. 22534 [1987]. National Institute for Occupational Safety and Health: Request for comments and secondary data on the toxicity of carbonless copy paper.

57 Fed. Reg. 22290 [1992]. Occupational Safety and Health Administration: occupational exposure to formaldehyde.
62 Fed. Reg. 8023 [1997]. National Institute for Occupational Safety and Health: Request for comments on the toxicity of carbonless copy paper.

Feldman L, Gobran DA, Inskeep CL [1994]. Self-contained imaging sheet useful for reproducing images on plain paper and method therefor. U.S. Patent No. 5,283,152.

Fetters RA [1997]. Significant events in the evolution of the carbonless paper industry. Seminar presented at the National Institute for Occupational Safety and Health, Cincinnati, $\mathrm{OH}$. NIOSH CCP docket.

Finch CA [1990]. Ullman's encyclopedia of industrial chemistry. Vol. A16, 5th ed. New York: VCH Publishers, p. 575.

Fisk WF, Mendell MJ, Daisey JM, Faulkner D, Hodgson AT, Nematollahi M, Macher JM [1993]. Phase 1 of the California Health Building study: a summary. Indoor Air 3:246-254.

Fristedt B, Pettersson E [1980]. Self-copying paper: investigation of employees in the county of Malmö who have reported symptoms. Malmö, Sweden: Industrial Medicine Department.

Gockel DL, Horstman SW, Scott CM [1981]. Formaldehyde emissions from carbonless copy paper forms. Am Ind Hyg Assoc J 42(6):474-476.

Göthe C-J, Jeansson I, Lidblom A, Norbäck D [1981]. Carbonless copy papers and health effects. Opusc Med 66:1-16.

Graves CG, Tardiff, RG [1999]. Peer review of draft NIOSH Hazard Review: Carbonless Copy Paper (dated February 18, 1999). Prepared on behalf of the Carbonless Copy Paper Companies of the United States. 98 pages plus appendices. Unpublished material submitted to the NIOSH docket. 
Graves CG, Matanoski GM, Tardiff RG [2000]. Carbonless copy paper and workplace safety: a review. Regul Toxicol Pharmacol 32:99-117.

Green BK [1955]. Pressure sensitive record material. U.S. Patent No. 2,712,507.

Gupta K [1999]. Telephone conversation on October 27, 1999, between K. Gupta, U.S. Consumer Product Safety Commission, and R.W. Niemeier, Education and Information Division, National Institute for Occupational Safety and Health, Centers for Disease Control and Prevention, Public Health Service, U.S. Department of Health and Human Services.

Haley TJ, Detrick LE, Komesu N, Williams P, Upham HC, Baurmash L [1959]. Toxicologic studies on polyphenyl compounds used as atomic reactor moderator-coolants. Toxicol Appl Pharmacol 1:515-523.

Hammel, RR [1990]. Close-out letter of May 10, 1990 (NIOSH Health Evaluation and Technical Assistance [HETA] 89-157), from Richard R. Hammel, Medical Officer, Division of Surveillance, Hazard Evaluations, and Field Studies, National Institute for Occupational Safety and Health to Cindy Baldwin, C.I.H., Director of Occupational Health, Amana Refrigeration, Inc., Amana, IO.

Hannuksela M [1975]. Personal communication with M. Hannuksela, South Karelia Central Hospital, Loppeenartanta, Finland. Cited by Jeansson et al. [1983].

Harris MG, ed. [1983]. Carbonless copy paper-adverse health effects. Ontario Disease Surveillance Report. Vol. 4, No. 31. Toronto, Ontario, Canada: Disease Control and Epidemiology Service, Public Health Branch, Ministry of Health.

Hasegawa H, Sato M, Tsuruta H [1973]. Environment and health investigation in carbonless paper manufacturing. Tokyo, Japan: National Institute of Industrial Health, Ministry of Health. Cited by Norbäck and Gothe [1983].

Hasegawa H, Sato M, Tsuruta H [1982a]. A toxicological study of di-isopropylnaphthalenes (KMC) and 1-phenyl-1-xylyl-ethanes (SAS). I. Distribution and disappearance of KMC and SAS in rats. Ind Health 20(3):237-246.

Hasegawa H, Sato M, Tsuruta H [1982b]. Toxicological studies on di-isopropylnaphthalenes (KMC) and 1-phenyl-1-xylylethanes (SAS). II. Biochemical examination of rats administered KMC and SAS. Ind Health 20(4):283-296.

Hazelton Laboratories [1985]. Final report, March 11, 1985: a study to determine the potential emanation of formaldehyde vapor from carbonless copy paper. A NIOSH docket submision.

Hill AB [1977]. A short textbook of medical statistics. London: Hodder and Stoughton, pp. 285-297.

Hirvonen M-L, Estlander T, Ojanen S [1976]. Paperi ja iho (Paper and the skin). Työ Terveys Turvallisuus 12:42-43.

Interagency Workgroup on Multiple Chemical Sensitivity [1998]. A report on multiple chemical sensitivity (MCS). U.S. Department of Health and Human Services, Public Health Service, Centers for Disease Control and Prevention, Agency for Toxic Substances and Disease Registry. Draft.

Jaakkola MS, Jaakkola JJK [1999]. Office equipment and supplies: a modern occupational health concern? Am J Epidemiol 150(11):1223-1228.

Jeansson I, Löfström A, Lidblom A [1983]. Study of complaints relating to carbonless copy paper. Arbete och halsa 2:1-76. 
Jeansson I, Löfström A, Lidblom A [1984]. Complaints relating to the handling of carbonless copy paper in Sweden. Am Ind Hyg Assoc J 45(11):B24, B26-27.

Jujo Paper Company, Ltd. [1979]. Safety of our carbonless paper. Tokyo, Japan: Jujo Paper Company, Ltd.

Kanerva L, Estlander T, Jolanki R [1990a]. Occupational allergic contact dermatitis due to diethylenetriamine (DETA) from carbonless copy paper and from an epoxy compound. Contact Dermatitis 23(4):272-273.

Kanerva L, Jolanki R, Estlander T [1990b]. Occupational allergic contact dermatitis due to diethylenetriamine (DETA) from an epoxy compound and from carbonless copy paper. Clin Exp Allergy 20(Suppl 1):43.

Kanerva L, Estlander T, Jolanki R, HenriksEckerman M-L [1993]. Occupational allergic contact dermatitis caused by diethylenetriamine in carbonless copy paper. Contact Dermatitis 29:147-151.

Kleinman GD, Horstman SW [1982]. Health complaints attributed to the use of carbonless copy paper (a preliminary report). Am Ind Hyg Assoc J 43(6):432-435.

Knave BG, Wibom RI, Voss M, Hedström LD, Berqvist UOV. [1985]. Work with video display terminals among office employees. Part I. Subjective symptoms and discomfort. Scand J Work Environ Health 11(6):457-466.

Koenig JQ [1988]. Indoor and outdoor pollutants and the upper respiratory tract. J Allergy Clin Immunol 81(No. 5 Part 2):1055-1058.

Kolmodin-Hedman B, Malmgren B, Rand G, Norbeck D [1981]. Group study of individuals who handle carbonless copy paper. Läkartidningen 78(36):3041-3044.
Kroschwitz JI, Howe-Grant M, eds. [1979]. Diphenyls and terphenyls. In: Kirk-Othmer encyclopedia of chemical technology. Vol. 7, 3rd ed. New York: John Wiley and Sons, p. 790 .

Kroschwitz JI, Howe-Grant M, eds. [1995]. Microencapsulation. In: Kirk-Othmer encyclopedia of chemical technology. Vol. 16, 4th ed. New York: John Wiley and Sons, pp. 628-651.

LaMarte FP, Merchant JA, Casale TB [1988]. Acute systemic reactions to carbonless copy paper associated with histamine release. JAMA 260(2):242-243.

Levy F, Hanoa R [1982]. Health problems in connection with carbonless paper. Tidsskr Nor Laegeforen 7(102):442-444.

Löfroth S [1982]. Mutagenic and potentially carcinogenic substances in the office material environment. Research report.

Maggio M, Benvenuti F, D’Emilio M [1978]. A hypothesis of risk deriving from use of carbonless copy paper. Ann Ist Super Sanità 14(3):491-494.

Magnusson B [1974]. Irritation of the skin and mucous membranes by NCR paper. Contact Dermatitis Newsletter 15:450.

Marinelli N [1985]. Carbonless paper coating formulation. U.S. Patent No. 4,533,567.

Marks JG [1981]. Allergic contact dermatitis from carbonless copy. JAMA 245(22):2331-2332.

Marks JG, Trautlein JJ, Zwillich CW, Demers LM [1984]. Contact urticaria and airway obstruction from carbonless copy paper. JAMA 252(8):1038-1040. 
Mathiaparanam P [1992]. Di[bis(indolyl)ethylenyl]tetrahalophthalide record materials. U.S. Patent No. 5,157,012.

McIntyre T, Greig W [1989]. Paper products with receptive coating for repositionable adhesive and methods of making the products. U.S. Patent No. 4,882,211.

Mead Corporation [1992]. Mead carbonless tech notes. 6th ed. Chilicothe, OH: Mead Fine Paper Division, Field Services Department.

Mead Corporation [1993]. Section IIIcarbonless papers. In: Paper knowledge. Rev. ed., pp.195-218.

Mead Corporation [1997]. NIOSH docket submission: Memorandum of July 7, 1997 (Response of the fine paper division of the Mead Corporation to NIOSH's request for comments on the toxicity of carbonless copy paper) from Russell E. Kross, Vice President, Human and Environmental Protection, to Paul A. Schulte, Director, Education and Information Division, National Institute for Occupational Safety and Health, Centers for Disease Control and Prevention, Public Health Service, U.S. Department of Health and Human Services.

Mendell MJ [1991]. Risk factors for work-related symptoms in Northern California office workers [Dissertation]. Berkeley, CA: University of California, Department of Biomedical and Environmental Health Sciences, School of Public Health. Ann Arbor, MI: UMI Dissertation Services.

Menné T, Hjorth N [1985]. Frictional contact dermatitis. Am J Ind Med 8(4/5):401-402.

Menné T, Asnaes G, Hjorth N [1981]. Skin and mucous membrane problems from "no carbon required" paper. Contact Dermatitis 7(2):72-76.
Messite J, Baker DB [1984]. Occupational health problems in offices - a mixed bag. In: Cohen BGF, ed. Human aspects in office automation. Elsevier Series in Office Automation. Amsterdam, Holland: Elsevier Science Publishers, pp. 7-14.

Messite J, Fannick N [1980]. Hazard evaluation and technical assistance report: Fieldson School, Bronx, NY. Cincinnati, OH: U.S. Department of Health and Human Services, Public Health Service, Centers for Disease Control, National Institute for Occupational Safety and Health, NIOSH Report No. HETA 80-69.

Miller CS [1997]. Toxicant-induced loss of tolerance-an emerging theory of disease? Environ Health Perspect 105(Supp1 2):445-453.

Miller RE, Phillips PS Jr. [1972]. Pressuresensitive record material. U.S. Patent No. $3,672,935$.

Mølhave L, Grunnet K [1981]. Addendum: headspace analysis of gases and vapors emitted by carbonless paper. Contact Dermatitis 7(2):76.

Monson R [1980]. Occupational epidemiology. Boca Raton, FL: CRC Press, Inc.

Morgan MS, Camp JE [1986]. Upper respiratory irritation from controlled exposure to vapor from carbonless copy forms. J Occup Med 28(6):415-419.

Murray R [1991]. Health aspects of carbonless copy paper. Contact Dermatitis 24(5):321-333.

National Swedish Board of Occupational Safety and Health [1976]. Carbonless paper-advice and instructions. Announcement No. 1976:2.

Nilzen A [1975]. Rapport over undersoking av allergiska yttringar av vissa sjalvkopierande papper. Stockholm, Sweden: Department of 
Allergy, Karolinska Hospital. Cited by Göthe et al. 1981.

NIOSH [1977]. Criteria for a recommended standard: occupational exposure to refined petroleum solvents. Cincinnati, OH: U.S. Department of Health, Education, and Welfare, Health Services and Mental Health Administration, National Institute for Occupational Safety and Health, DHEW (NIOSH) Publication No. 77-192, NTIS No. PB-85-178-267.

NIOSH [1981]. Current intelligence bulletin 34: formaldehyde; evidence of carcinogenicity. Cincinnati, OH: U.S. Department of Health and Human Services, Public Health Service, Centers for Disease Control and Prevention, National Institute for Occupational Safety and Health, DHHS (NIOSH) Publication No. 81-111, NTIS No. PB-83-101-766.

NIOSH [1994]. Method 125. In: NIOSH manual of analytical methods. 4th ed. Cincinnati, OH: U.S. Department of Health and Human Services, Public Health Service, Centers for Disease Control and Prevention, National Institute for Occupational Safety and Health, DHHS (NIOSH) Publication No. 94-113.

NIOSH [1996]. Formaldehyde: IDLH Documentation. [http://www.cdc.gov/niosh/idlh/50000. html]. Date accessed: November 2000. Washington, DC: U.S. Department of Health and Human Services, Public Health Service, Centers for Disease Control and Prevention, National Institute for Occupational Safety and Health.

NIOSH [1997]. Pocket guide to chemical hazards. Cincinnati, OH: U.S. Department of Health and Human Services, Public Health Service, Centers for Disease Control and Prevention, National Institute for Occupational Safety and Health, DHHS (NIOSH) Publication No. 97-140.
NIOSH [1998]. NIOSH Hazard Control 26: Controlling formaldehyde exposures during embalming. Cincinnati, OH: U.S. Department of Health and Human Services, Public Health Service, Centers for Disease Control and Prevention, National Institute for Occupational Safety and Health, DHHS (NIOSH) Publication number 98-149.

Norbäck D [1983a]. V. Color-formers in carbonless copy paper. Arbete och halsa 3:63-76.

Norbäck D [1983b]. IV. Chemical emissions from carbonless copy paper: laboratory tests under controlled experimental conditions. Arbete och halsa 37:51-62.

Norbäck D, Göthe C-J [1983]. Carbonless copy paper, air pollutants, and indoor climate. Arbete och halsa 37:37-50.

Norbäck D, Göthe C-J, Wieslander G, eds. [1983a]. General summary. In: Carbonless copying paper-occupational, medicinal, and hygienic aspects. Arbete och halsa 37:75-79.

Norbäck D, Wieslander G, Göthe C-J [1983b]. I. Carbonless copying paper and complaints in conjunction with office work. In: Carbonless copying paper-occupational, medicinal, and hygienic aspects. Arbete och halsa 37:6-24.

Norbäck D, Wieslander G, Göthe C-J [1983c]. II. Discomfort-inducing factors in carbonless copying paper. In: Carbonless copying paperoccupational, medicinal, and hygienic aspects. Arbete och halsa. 37:25-35.

Norbäck D, Wieslander G, Göthe C-J [1988]. A search for discomfort-inducing factors in carbonless copying paper. Am Ind Hyg Assoc J 49(3):117-120.

North Carolina Medical Journal [1982]. Problems with carbonless copy paper (editorial). NC Med J 43(8):596. 
NRC (National Research Council) [1981]. Health effects of formaldehyde. In: Formaldehyde and other aldehydes. Washington, DC: National Academy Press.

Öberg T [1980]. Self-copying paper: research concerning complaints from secretaries. Jönköping, Sweden: Jönköping District Council. Cited by Murray 1991.

Öko-Test Magazin [1990]. Highly irritating forms. Öko-Test-Magazin, February, p.78.

Olsen O, Mørck HI [1985]. Carbonless copying paper and health problems. Copenhagen, Denmark: Scandinavisk Biomedicinsk Institut.

Omland O, Andersen PH, Brandt JHM, Thestrup-Pedersen K [1993]. A study of skin and mucous membrane irritation and the incidence of allergy among office personnel exposed to carbonless copy paper. Ugeskr Laeger 155(17):1261-1265.

Paper Europe [1993]. Carbonless looks for better times. Paper Europe 5(2):17-18.

Parmeggiani L [1983]. Carbonless copy paper. In: Encyclopedia of occupational health and safety. Geneva, Switzerland: International Labour Office, p. 549.

Pedersen [1998]. Memorandum of July 27, 1998, from D. Pedersen to the National Institute for Occupational Safety and Health, Centers for Disease Control and Prevention, Public Health Service, U.S. Department of Health and Human Services.

Pryor P, Thoburn TW, Koons RK [1983]. Hazard evaluation and technical assistance report: Municipal Court Section, City of Englewood, Englewood, CO. Cincinnati, OH: U.S. Department of Health and Human Services, Public Health Service, Centers for Disease Control and Prevention, National Institute for
Occupational Safety and Health, NIOSH Report No. HETA 83-313-1534.

Reinikainen LM, Jaakkola JJK, Helenius T, Seppanen O [1990]. The effect of air humidification on symptoms and environmental complaints in office workers: A six period cross-over study. Indoor Air 2:775-780.

Roure MC, Perrusset F, Loriot J, Petiet G, Raix A, Proteau J [1982]. Several cases of cutaneous toxicity during use of carbonless copy paper. Arch Mal Prof 44(1):50-51.

Sandberg RW [1955]. Pressure sensitive manifold sheet. U.S. Patent No. 2,711,375.

Sanders FW [1984]. Imaging system with microcapsules containing photohardenable on photosoftenable composition. U.S. Patent No. $4,483,912$.

Shehade SA, Beck MH, Chalmers RJG [1987]. Allergic contact dermatitis to crystal violet in carbonless copy paper. Contact Dermatitis 17(5):310-311. (Published erratum appears in Contact Dermatitis [1988] 18(4):256.)

Sim M, Echt A [1993]. Hazard evaluation and technical assistance report: Department of Health Services, Frankfort, KY. Cincinnati, OH: U.S. Department of Health and Human Services, Public Health Service, Centers for Disease Control and Prevention, National Institute for Occupational Safety and Health, NIOSH Report No. HETA 93-0974-2353, NTIS No. PB-94-140-183.

Skov P, Valbjørn O, Danish Indoor Climate Study Group [1987]. The "sick" building syndrome in the office environment: the Danish town hall study. Environ Int 13(4/5):339-349.

Skov P, Valbjørn O, Pedersen BV [1989]. Influence of personal characteristics, job-related factors and psychosocial factors on the sick 
building syndrome. Scand J Work Environ Health 15(4):286-295.

Sliwka W [1975]. Microencapsulation. Angew Chem Int Ed Engl 14(8):539-550.

Smith HR, Wakeline SH, Rrycroft, RJ. [1999] Azo dyes as allergens in carbonless copy paper manufacturing. Contact Dermatitis 40(4):214-215.

Sondergard S [1981]. Self-copying paper. Internal SAS report. Cited by Murray [1991] and Olsen and Mørck [1985].

Sturaro A, Parvoli G, Rella R, Bardati S, Doretti L [1994]. Food contamination by diisopropylnaphthalenes from cardboard packages. Int J Food Sci Tech 29(5):593-603.

Takahashi S, Tsukahara H [1992]. Donor sheet for pressure-sensitive image recording. U.S. Patent No. 5,112,797.

Tardiff RG [1997]. Detailed evaluation of toxicity data of Mead's carbonless copy paper and of ingredients used to manufacture Mead's carbonless copy paper. NIOSH docket submission.

Tardiff RG [1998]. Multiple chemical sensitivity: a brief perspective on its plausibility as a human disease. Bethesda, MD: The Sapphire Group, Inc. (NIOSH docket submission).

Thompson KN [1996]. A study of the health effects of carbonless copy paper on occupational workers [Master's thesis]. Gainesville, FL: University of Florida, Environmental Engineering Sciences.

Torii T, Senoo [1981]. Colour developer coating colours for carbonless copying papers. U.K. Patent Application No. GB 2,050,407 for Mitsubishi Paper Mills, Tokyo, Japan.
Trautlein JJ, Marks JG, Zwillich CS, Demers LM [1984]. Contact urticaria syndrome from carbonless copy paper. 40th Annual Congress of the American College of Allergists, San Francisco, CA, April 7-11. [Abstract]. Ann Allergy 52(No. 3, Part 2):238.

USC. United States Code. Washington, DC: U.S. Government Printing Office.

Wahlberg [1975]. Självkopierande papperpallergi? Allergia 19(7/8):2-4. Cited by Jeansson et al. 1983.

Wattendorf [1988]. Dangerous working materials in the office. Humane ProduktionHumane Arbeitsplätze 10(2):10-14.

Winfield M [1983]. Industrial hygiene report: University of Texas, Central Receiving and Delivery Building. Submitted to D. Decker, Safety Engineer, University of Texas Safety Office, Austin, Texas, Nov. 16, 1983. A NIOSH docket submission.

Winfield M [1983]. Industrial hygiene report: University of Texas, Central Receiving and Delivery Building. Submitted to D. Decker, Safety Engineer, University of Texas Safety Office, Austin, Texas, Nov. 16, 1983. A NIOSH docket submission.

Wolkoff P, Hansen L, Nielsen GD [1988]. Airway-irritating effect of carbonless copy paper examined by the sensory irritation test in mice. Environ Int 14(1):43-48.

Ziem G, McTamney J [1997]. Profile of patients with chemical injury and sensitivity. Environ Health Perspect 105(Suppl 2):417-436.

Zimmer AT, Hadwen G [1993]. Hazard evaluation and technical assistance report: Federal Records Center, Dayton, $\mathrm{OH}$. Cincinnati, OH: U.S. Department of Health and Human Services, Public Health Service, 
Centers for Disease Control and Prevention, National Institute for Occupational Safety and Health, NIOSH Report No. HETA 92-287-2294.
Zweers T, Preller L, Brunekreef B, and Boleij JSM. [1992]. Health and indoor climate complaints of 7043 office workers in 61 buildings in the Netherlands. Indoor Air 2:127-136. 


\section{Other Publications Examined}

Ahland R. Numerous causes of office disease. Paper preprint. Stockholm, Sweden.

Arndt R [1984]. Stress, indoor air-pollution top complaints of office workers. Occupational Health and Safety Letter, September, p. 22.

American Academy of Allergy and Immunology, Executive Committee [1986]. Position statements: clinical ecology. J Allergy Clin Immunol 78(2):269-271.

American Academy of Allergy, Asthma, and Immunology, Board of Directors [1999]. Position statement: idiopathic environmental intolerances. J Allergy Clin Immunol 103(No.1, Part 1):36-40.

American College of Occupational Medicine, Toxicology Committee [1990]. What is environmental medicine? (editorial). J Occup Med 32(11):1130-1132.

American College of Physicians [1989]. Clinical ecology. Ann Intern Med 111(2):168-178.

American Medical Association, Council on Scientific Affairs [1992]. Clinical ecology. JAMA 268(24):3465-3467.

Brunea RW, Raby JM [1991]. Security for images formed by impact-based systems. U.S. Patent No. 5,033,773.

Bruze M, Freguri S, Zimerson E [1985]. Contact allergy to phenol-formaldehyde resins. Contact Dermatitis 12(2):81-86.
California Medical Association, Scientific Board Task Force on Clinical Ecology [1986]. Clinical ecology - a critical appraisal. West J Med 144:239-245.

Callender TJ, Morrow L, Kodanallur S, Duhon D, Ristovv M [1993]. Three-dimensional brain metabolic imaging in patients with toxic encephalopathy. Env Research 60:295-319.

Callender TJ, Duhon D, Ristovv M [1994]. Olfactory intolerance and dynamic neurophysiological abnormalities in patients with toxic encephalopathy. Adv Bioscien 93:611-619.

Carlson RM, Carlson RE, Kopperman H, Caple R [1975]. Facile incorporation of chlorine into aromatic systems during aqueous chlorination processes. Environ Sci Technol 9(7):674-675.

Conoley G [1982]. Living may be hazardous to your health. American Way, February.

d'Arrigo V. Research on the content of PCB in chemical carbonless copying papers. pp. 220-222.

Dyer J, Warren K, Merlin S, Metcalfe DO, Kaliner M [1982]. Measurement of plasma histamine: description of an improved method and normal values. J Aller Clin Immunol $70(2): 82-87$.

Earhart HW, Rugen DF [1981]. Sec-ylbiphenyl composition and process for preparing the same. U.S. Patent No. 4,287,074. 
Einkauf MA, Klock MM, Le NT [1992]. Method for adaptively providing near phong grade shading for patterns in a graphics display system. U.S. Patent No. 5,163,126.

Ervin E Jr. [1987]. Heated mats for melting snow and ice from outdoor surfaces. U.S. Patent No. 4,646,818.

Fiedler N, Kipen H [1997]. Chemical sensitivity: the scientific literature. Environ Health Perspect 105(Suppl 2):409-415.

Fristedt B [1983]. The "paper-sick" officejust as dangerous as an industrial chemical plant. Arbetsmiljo 6:24-25.

Goodwin DW, Guze SB [1996]. Somatization disorder (hysteria). In: Psychiatric diagnosis. 5th ed. New York: Oxford University Press, pp. 105-126.

Göthe CJ [1982]. Self-copying paper-a health problem? Lakartidningen 79:336-338.

Harrison J, Pickering CAC, Faragher EB, Austwick PKC, Little SA, and Lawton L [1992]. An investigation of the relationship between micorbial and particulate indoor air pollution and sick building syndrome. Respir Med 86:225-235.

Hazardous Substances Data Base (HSDB). Washington, D.C.: U.S. Department of Health and Human Services, Public Health Service, National Institutes of Health, National Library of Medicine.

International Society of Regulatory Toxicology and Pharmacology [1993]. Report of the ISRTP board. Regul Toxicol Pharmacol 18(1):79.

Ishige S, Usami T, Kamikawa $\mathrm{H}$, Tanaka $\mathrm{T}$ [1989]. Black color heat-sensitive diazo microcapsule recording material with benzoylacetic amide coupler. U.S. Patent No. $4,842,979$.

Jaakkola JJK, Miettinen P [1995]. Type of ventilation system in office building and sick building syndrome. Am J Epidemiol 141(8):755-765.

Kehrl HR [1997]. Laboratory testing of the patient with multiple chemical sensitivity. Environ Health Perspect 105(Suppl 2):443-444.

Knop A, Pilato LA [1985]. Phenolic resinschemistry, applications and performance, future directions. New York: Springer Verlag, p. 103.

Konopinski VJ [1983]. Formaldehyde in office and commercial environments. Am Ind Hyg Assoc J 44(3):205-208.

Konopinski VJ [1985]. Seasonal formaldehyde concentrations in an office building. Am Ind Hyg Assoc J 46(2):65-68.

Krake AM, Kawamoto MM [1993]. Hazard evaluation and technical assistance report: University of Minnesota, Duluth, MN. Cincinnati, OH: U.S. Department of Health and Human Services, Public Health Service, Centers for Disease Control and Prevention, National Institute for Occupational Safety and Health, NIOSH Report No. HETA 93-0190.

Lachapelle J-M [1987]. The concept of industrial airborne irritant or allergic contact dermatitis. In: Maibach HI, ed. Occupational and industrial dermatology. 2nd ed. Chicago, IL: Year Book Medical Publishers, Inc., pp. 179-189.

Levi L [1984]. Stress in industry: causes, effects, and prevention. Occupational safety and 
health series, No. 51. Geneva Switzerland: International Labour Office.

Levy [1980]. Health problems during handling of carbonless copy paper. Summary of lecture at the 29th Conference of Nordic Dermatologists in Norway, November 3-5, Publication No. 1980 N 13, p. 84. (Helseplager ved bruk av selvkopierended papir. Resume av foredrag vid 29e Nordiske Yrkeshygieniske Note I Norge, 3-5 Nov, YIH, Publidasjon 1980 N 13, s. 84.)

Marsh GM [1997]. Carbonless copy paper: an updated review of published epidemiological studies (submitted to NIOSH Docket Office; Marsh is an independent consultant for The Mead Corporation, Fine Paper Division).

Meggs WJ [1997]. Hypothesis for induction and propagation of chemical sensitivity based on biopsy studies. Environ Health Perspect 105(Suppl 2):473-478.

Mendell MJ [1993]. Non-specific symptoms in office workers: a review and summary of the epidemiologic literature. Indoor Air 3:227-236.

Mendell MJ, Fisk WJ, Deddens JA, Seavey WG, Smith AH, Smith DF, Hodgson AT, Daisey JM, Goldman LR [1996]. Elevated symptom prevalence associated with ventilation type in office buildings. Epidemiology 7(6)583-589.

Menzies R, Tamblyn R, Farant J-P, Hanley J, Nunes F, Tamblyn R [1993]. The effect of varying levels of outdoor air supply on the symptoms of sick building syndrome. New Engl J Med 328(12):821-827.

Metz GD, McCrary C, O’Connor JG, Proehl DS, Saccocio EJ, Dowler J [1989]. Developer sheet useful in providing transparencies or re- productions having a controlled gloss finish. U.S. Patent No. 4,859,561.

Miller RE, Brown RW [1987]. Pressure sensitive record material. U.S. Patent No. 4,675,706.

Moramarco SS [1983]. Does your office make you sick? Am Health, Jan/Feb, pp. 79-85.

National Injury Information Clearinghouse [1998]. Printout of reported incidents file on carbonless complaints.

New Jersey Department of Health [1989]. Hazardous substance fact sheet: diethylenetriamine. Trenton, NJ: New Jersey Department of Health.

Norbäck D, Torgén M [1989]. A longitudinal study relating carpeting with sick building syndrome. Environ International 15:129-135.

Piechota CL [1985]. Psychological stress - the unrecognized health hazard (guest editorial). Am Ind Hyg Assoc J .

Ross GH [1997]. Clinical characteristics of chemical sensitivity: an illustrative case history of asthma and MCS. Environ Health Perspect 105(Suppl 2):437-441.

Schmidt CJ, Tebbett IR, Couch MW [1998]. Carbonless copy paper: a review of its chemical components. Gainesville, FL: University of Florida, Department of Environmental Engineering Sciences; University of Florida College of Pharmacy, Department of Medicinal Chemistry. Unpublished.

Shama S [1989]. Skin and systemic reactions from carbonless copy paper. Occup Environ Med Report 3(1):1-2.

Smith JG, McCall RB, Chan PK [1977]. Formation of polychlorinated aromatic compounds 
during aqueous chlorination. Environ Pollution 14:289-296.

Soine L [1995]. Sick building syndrome and gender bias: imperiling women's health. Soc Work Health Care 20(3):51-65.

Stellman J, Henifin MS [1984]. Office work can be dangerous to your health. New York: Pantheon Books.

Stenberg B, Eriksson N, Mild KH, Höög J, Sandström M, Sundell J, Wall S [1993]. The office illness project in Northern Sweden-an interdisciplinary study of the sick building syndrome (SBS). Proceedings of Indoor Air 1:393-398.

Stovall T [1980]. Victims of the 20th century. Dallas Morning News Scene Magazine, November, pp. 1-5.

Sturaro A, Parvoli G, Rella R, Doretti L [1994]. Gas chromatographic - mass spectrometric, high-performance liquid chromatographicUV and gas chromatographic - fourier transform IR responses to an industrial mixture of diisopropylnaphthalenes. J Chromatogr A 688(1/2):211-219.

Sturaro A, Parvoli G, Rella R, Doretti L [1995]. Hydrogenated terphenyl contaminants in recycled paper. Chemosphere 30(4):687-694.
Sylvain DC, Malkin R [1996]. Hazard evaluation and technical assistance report: Jordan Hospital, Plymouth, MA. Cincinnati, OH: U.S. Department of Health and Human Services, Public Health Service, Centers for Disease Control and Prevention, National Institute for Occupational Safety and Health, NIOSH Report No. HETA 95-0362-2587.

Thrasher JD, Madison R, Broughton A, Gard Z [1989]. Building-related illness and antibodies to albumin conjugates of formaldehyde, toluene diisocyanate, and trimelletic anhydride. Am J Ind Med 15:187-195.

Treon JF, Cleveland FP, Cappel JW, Atchley RW [1956]. The toxicity of the vapors of Aroclor $1242^{\circledR}$ and Aroclor $1254^{\circledR}$. Am Ind Hyg Assoc Qtrly 17(2):204-213.

Van Der Leun JC, de Kreek EJ, Deenstra-van Leeuwen M, van Weelden H [1966]. Photosensitivity owing to thiourea [letter to the editor]. Arch Dermatol 113:1611.

WHO (World Health Organization) [1997]. Report of multiple chemical sensitivities (MCS) workshop: International Programme on Chemical Safety (IPCS)/German Workshop on Multiple Chemical Sensitivities, Berlin, Germany. Int Arch Occup Environ Health 69:224-226. 


\section{N/Oesth}

Delivering on the Nation's promise: Safety and health at work for all people through research and prevention

To receive NIOSH documents or more information about occupational safety and health topics, contact NIOSH at

1-800-35-NIO SH (1-800-356-4674)

Fax: (513) 533-8573

Email: pubstaft@cdc.gov

or visit the NIOSH W eb site at www.cdc.gov/niosh

DHHS (NIOSH) Publication N o. 2001-107 